\title{
Summaries of FY 1994 Geosciences Research
}

December 1994

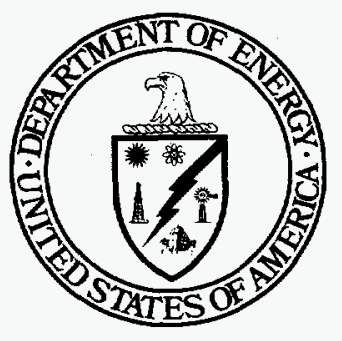

U.S. Department of Energy

Office of Energy Research Office of Basic Energy Sciences Division of Engineering and Geosciences Washington, DC 20585 


\section{DISCLAIMER}

This report was prepared as an account of work sponsored by an agency of the United States Government. Neither the United States Government nor any agency thereof, nor any of their employees, make any warranty, express or implied, or assumes any legal liability or responsibility for the accuracy, completeness, or usefulness of any information, apparatus, product, or process disclosed, or represents that its use would not infringe privately owned rights. Reference herein to any specific commercial product, process, or service by trade name, trademark, manufacturer, or otherwise does not necessarily constitute or imply its endorsement, recommendation, or favoring by the United States Government or any agency thereof. The views and opinions of authors expressed herein do not necessarily state or reflect those of the United States Government or any agency thereof. 


\section{DISCLAIMER}

Portions of this document may be illegible in electronic image products. Images are produced from the best available original document. 


\section{CONTENTS}

FOREWORD xiii

THE GEOSCIENCES RESEARCH PROGRAM IN THE OFFICE OF BASIC ENERGY SCIENCES xiv

PART I. ON-SITE .1

ARGONNE NATIONAL LABORATORY 3

Geochemistry

A. Mineral-Fluid Interactions: Experimental Determination of Atomic-

Scale Processes Using Synchrotron Radiation. 3

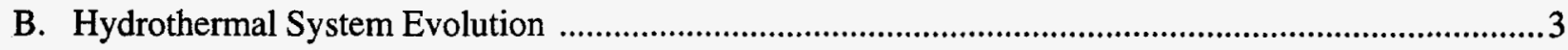

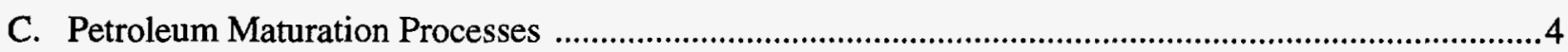

BROOKHAVEN NATIONAL LABORATORY

Geochemistry

A. Geochemistry of Organic Sulfur in Marine Sediments 5

B. Role of Sulfur in the Formation and Diagenesis of Macromolecular Matter in Sediments

LAWRENCE BERKELEY NATIONAL LABORATORY 7

Geophysics and Earth Dynamics

A. Effects of Heterogeneity on the Mechanical Properties of Rock ........................................................ 7

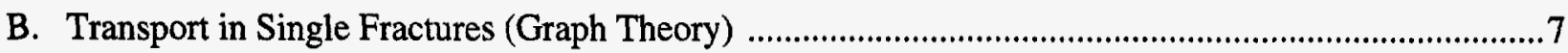

C. High-Resolution Imaging of Electrical Conductivity Using Low-

Frequency Electromagnetic Fields

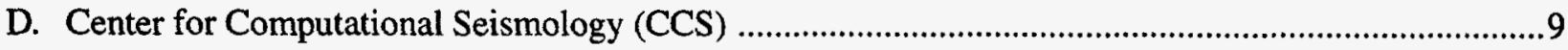

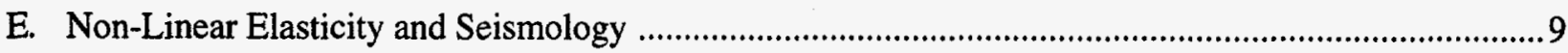

F. Energy Partitioning of Seismic Waves in Fractured Rock ........................................................... 10

G. Coupled Thermal-Hydraulic-Mechanical Processes in Petroleum Reservoirs

H. Controls on Pull-Apart Basin Evolution: Integrated Geological, Geophysical and Modeling Studies

Geochemistry

A. Thermodynamics of High Temperature Brines 12

B. Integrated Isotopic Studies of Geochemical Processes 13 


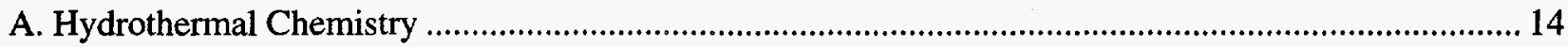

B. Pre-Drilling San Andreas Fault Zone Characterization: Isotopic and Chemical Composition of Fault Zone Fluids ............................................................... 14

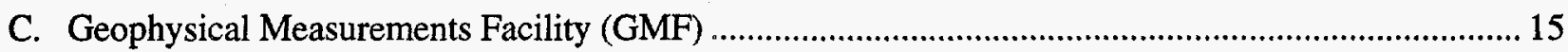

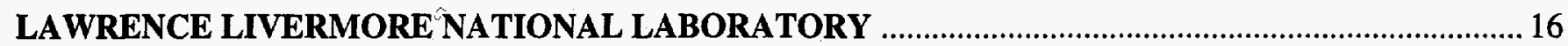

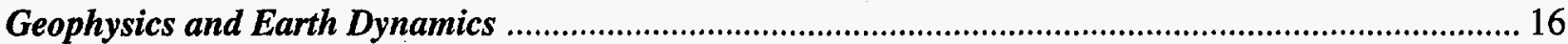

A. Modification of Fracture Transport Properties of Rocks by

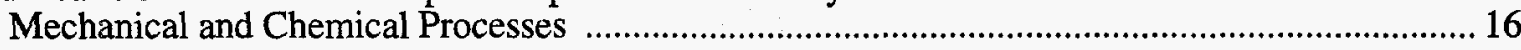

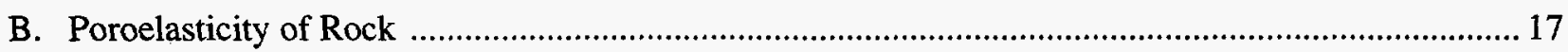

C. The Role of Carbon and Temperature in Determining Electrical

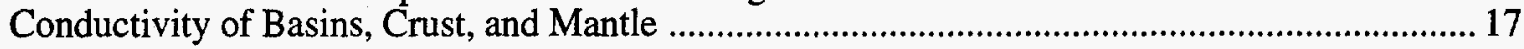

D. Oxygen and Cation Diffusion in Oxide Materials ........................................................................ 18

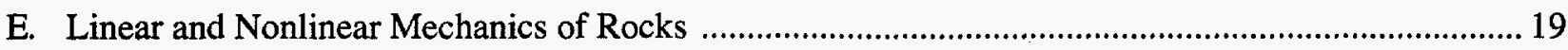

F. Basic Research on Nonlinear Elastic Phenomena in Rock ..........................................................20

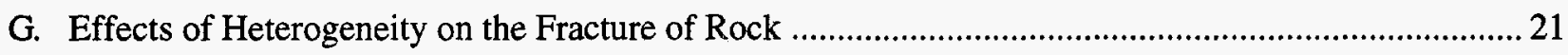

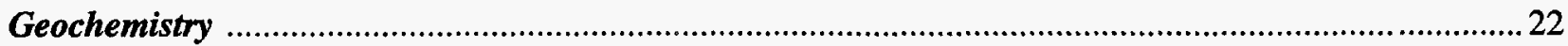

A. Thermodynamic and Transport Properties of Aqueous

Geochemical Systems

B. Experimental Determination of Mineralogical Controls on U-Th-Pb

Redistribution: Implications for Crust/Mantle Differentiation ..................................................23

C. Compositional Kinetic Modeling of Oil and Gas Formation ........................................................... 24

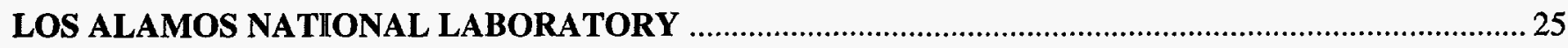

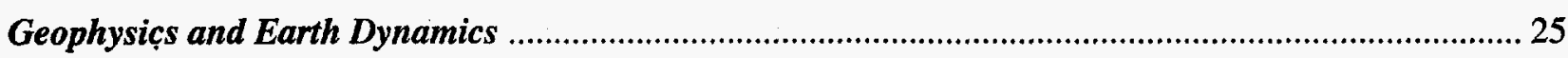

A. Imaging of Reservoirs and Fracture Systems Using Microearthquakes

Induced by Hydraulic Injections

B. The Role of Carbon and Temperature in Determining Electrical

Conductivity of Basins, Crust, and Mantle ......................................................................... 26

C. Basic Research on Nonlinear Elastic Phenomena in Rock .........................................................27

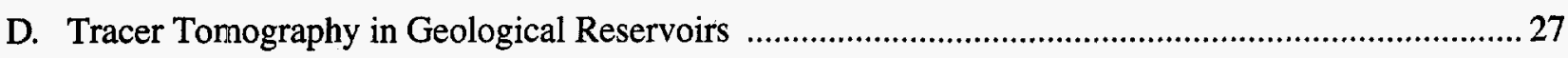

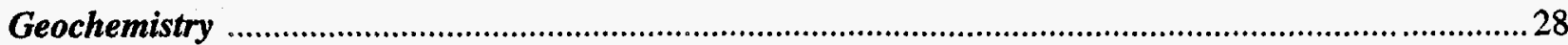

A. ${ }^{230} \mathrm{Th}-{ }^{238} \mathrm{U}$ Disequilibrium in Geologic Systems Using Solid

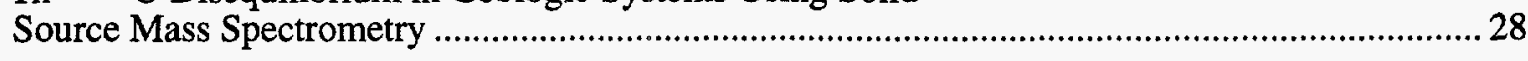

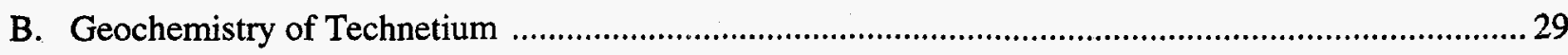

C. Dating Young Surfaces Using Cosmogenic $\mathrm{He}$ and $\mathrm{Ne}$................................................................ 30

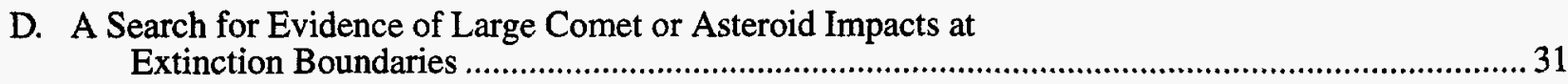

E. Direct Speciation of Metal Ions by Optical Spectroscopies ........................................................... 31 
Solar-Terrestrial Interactions

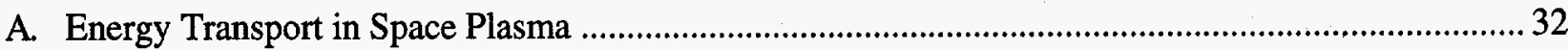

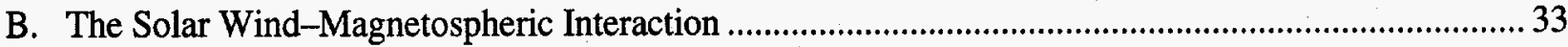

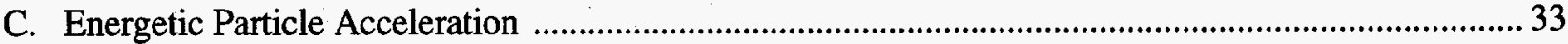

D. Radiation from Space and Astrophysical Plasmas .............................................................................. 34

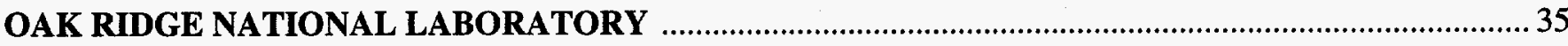

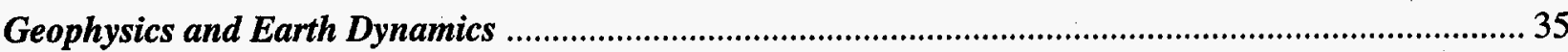

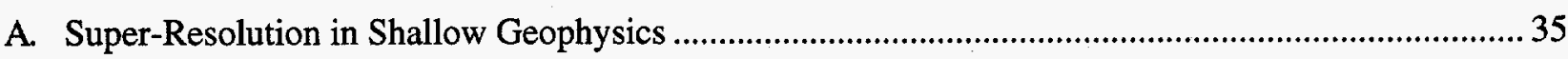

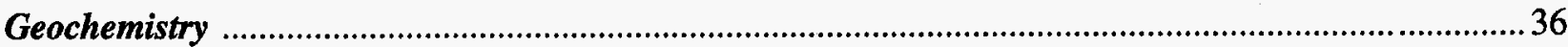

A. Geochemistry of Crustal Processes To High Temperature and Pressure ............................................ 36

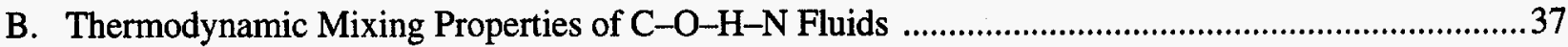

C. Fundamental Research in the Geochemistry of Geothermal Systems ................................................ 38

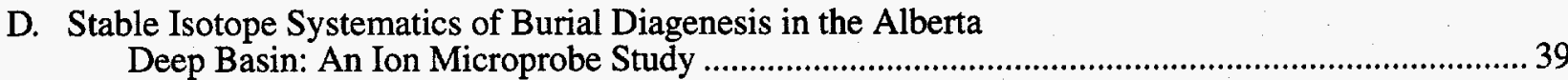

E. Experimental Studies of Fundamental Stable Isotope Exchange Reactions .....................................40

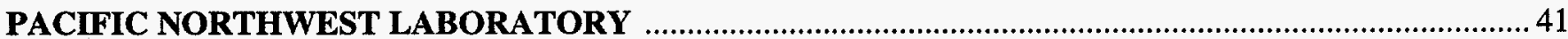

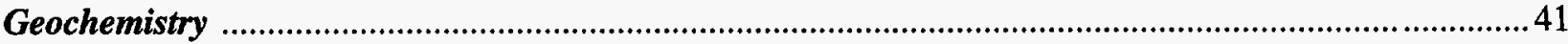

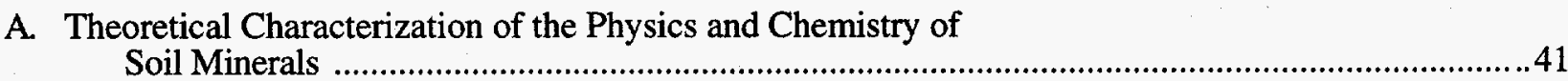

B. Surface Structure and Chemistry of Carbonate Minerals ...............................................................43

Energy Resource Recognition, Evaluation, and Utilization ..............................................................4 43

A. Geosciences Data Integration/Virtual Environments ...................................................................43

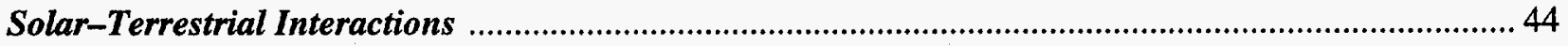

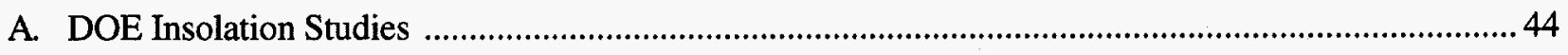

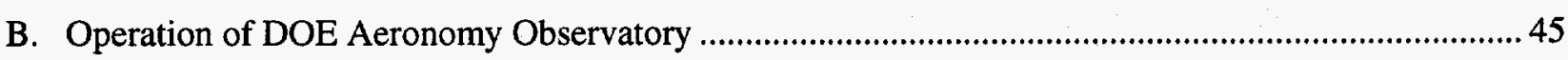

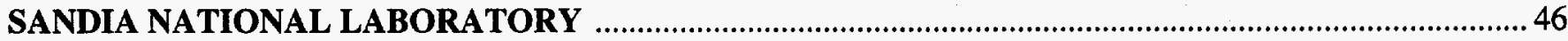

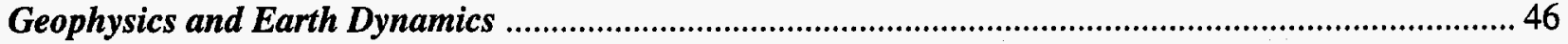

A. 3-D Electromagnetic Data Inversion …...................................................................................... 46

B. Micromechanics of Failure in Brittle Geomaterials ......................................................................... 46

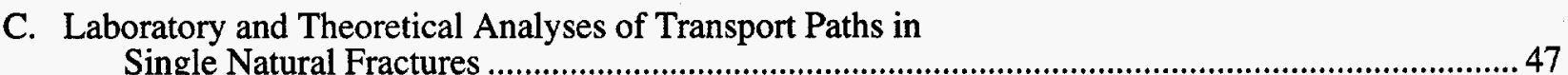

D. Shear Strain Localization and Fracture Evolution in Rocks .........................................................48 
Geochemistry

A. Effects of Microscopic Reactions and Buoyancy on Macroscopic

Transport in Geologic Media: a Lattice Gas Study of Retardation and Dispersion...

B. Mineral Hydrolysis Kinetics .49

C. Cation Diffusion Rates in Selected Silicate Minerals

D. Isotopic and Mineralogical Indicators of Infiltration and Vertical

Fluid Movement in Unsaturated Zones of Semiarid Terrain

Energy Resource Recognition, Evaluation and Utilization . 52

A. Geoscience Research Drilling Office (GRDO)

B. Development of a Smart, High-Temperature Fluid-Sampling Tool

UNIVERSITY OF ALASKA

A Study of Magnetic Reconnection Processes and Plasma Processes

in the Magnetosphere and the Solar Corona 57

Katmai Scientific Drilling Project.....

AMERICAN GEOLOGICAL INSTITUTE 60

U.S.-Russian Geoscience Student Exchange Program .60

AMERICAN MUSEUM OF NATURAL HISTORY 61

The Role of Carbon and Temperature in Determining Electrical

Conductivity of Basins, Crust, and Mantle

ARIZONA STATE UNIVERSITY

A Microanalytical (SIMS) Study of the Trace Element and Isotopic

Geochemistry of Diagenetic Silicates

BROWN UNIVERSITY

Grain Boundary Transport and Related Processes in Natural Fine-

Grained Aggregates

\section{CALIFORNIA INSTITUTE OF TECHNOLOGY}

The Southern Sierra Nevada Continental Dynamics Project-

Caltech Activities

Infrared Spectroscopy and Hydrogen Isotope Geochemistry of

Hydrous Silicate Glasses

Isotope Tracer Studies of Diffusion in Silicates and of Geological

Transport Process in Aqueous Systems Using Actinide Elements 
Experimental Measurement of Thermal Conductivity in Silicate Liquids

Advective-Diffusive/Dispersive Transport of Chemically Reacting

Species in Hydrothermal Systems

UNIVERSITY OF CALIFORNIA AT DAVIS

A New Method for Determining Excess Gibbs Energies in Binary

Metal-Carbonate Solid Solutions

Energetics of Melts from Thermal Diffusion Studies

UNIVERSITY OF CALIFORNIA AT LOS ANGELES .74

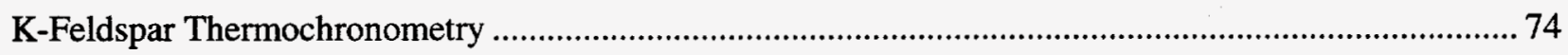

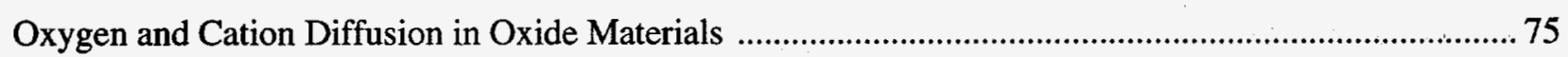

UNIVERSITY OF CALIFORNIA AT SANTA BARBARA

Physical Modeling of Sedimentary Basins, Magma Mechanics, and

Molecular Dynamics of Geological Solutions

CARNEGIE INSTITUTION OF WASHINGTON

Water-Rock Interaction in the Earth's Upper Mantle: Application of

Combined Stable Isotope and Infrared Spectroscopic Analytical Techniques

THE UNIVERSITY OF CHICAGO

Synchrotron X-ray Microprobe and Microspectroscopy:

Technical Development for Advanced Photon Source Research and

Low Temperature Geochemistry Applications

UNIVERSITY OF COLORADO

Crystal Chemistry of Hydroxyl and Water in Silicate Minerals

Seismic Absorption and Modulus Measurements in Porous Rocks Under

Fluid and Gas Flow Physical and Chemical Effects: A Laboratory Study

\section{COLORADO SCHOOL OF MINES}

Computational Methods for Improving the Resolution of Subsurface

Seismic Images

U.S. DEPARTMENT OF ENERGY CORE AND SAMPLE REPOSITORY

U.S. Department of Energy, Core and Sample Repository

COLUMBIA UNIVERSITY

Energetics of Silicate Melts from Thermal Diffusion Studies 
Hydrogeologic Processes: Building and Testing Atomistic- to Basin-Scale Models-Support of a Chapman Conference

UNIVERSITY OF DELAWARE

Development of an Experimental Database and Theories for Prediction of

Thermodynamic Properties of Aqueous Electrolytes and Nonelectrolytes

of Geochemical Significance at Supercritical Temperatures and Pressures

UNIVERSITY OF SOUTH FLORIDA 87

Clay Mineral Diagenesis in the Montery Formation, California

INDIANA UNIVERSITY

Mechano-chemical Self-Organization and Nonlinear Dynamics in

Sedimentary Basins

THE JOHNS HOPKINS UNIVERSITY

HRTEM/AEM and SEM Study of Fluid-Rock Interactions:

Interaction of Copper-, Silver-, Selenium-, Chromium-, and

Cadmium-Bearing Solutions with Geological Materials at Near

Surface Conditions, with an Emphasis on Phyllosilicates

LEHIGH UNIVERSITY

Surface and Solution-Interface Geochemistry of Lead Sulfide and

Lead Selenide Minerals

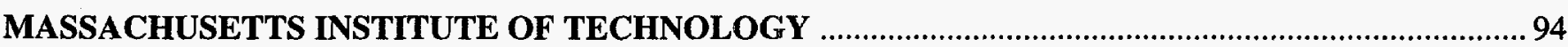

In-Situ Permeability Determination Using Borehole and Seismic Logging Data ..................................99

Electroseismic Characterization of Lithology and Fluid Type in the

Shallow Subsurface 96

A High-Precision MT Study of the Mid and Lower Crustal San Andreas Fault Zone ............................99

UNIVERSITY OF MIAMI

Testing the Correlation Between Sequence Stratigraphy, Seismic Reflectors and Diagenetic Changes in Carbonates: Evaluation of Fluid Flow During Early and Late Diagenesis

UNIVERSITY OF MICHIGAN

Applications of ICP Magnetic Sector Multicollector Mass Spectrometry to Basic Energy Research 
Physical Modeling of Sedimentary Basins, Magma Mechanics, and

Molecular Dynamics of Geological Solutions

\section{NATIONAL ACADEMY OF SCIENCES/}

NATIONAL RESEARCH COUNCIL

Board on Earth Sciences and Resources, Committee on Seismology,

U.S. Geodynamics Committee, Committee on Geodesy, Geophysics Study

Study of High Performance Computing in Seismology

UNIVERSITY OF NEW MEXICO 104

Impact Deposits at the Manson Impact Structure: Diagenesis and Post-Impact Thermal History 104

SANTA FE INSTITUTE 105

Complex Systems in the Earth Sciences: Predictability, Mitigation and Reduction of Natural Hazards 105

THE CITY COLLEGE OF THE CITY UNIVERSITY OF NEW YORK 106

Stochastic Transport in Heterogeneous Flows and Media 106

STATE UNIVERSITY OF NEW YORK AT STONY BROOK 107

Three-Dimensional Imaging of Drill Core Samples using Synchrotron Computed Microtomography 107

Micromechanics of Failure in Brittle Geomaterials . 108

High Precision Radiometric Dating of Sedimentary Materials 109

NORTHWESTERN UNIVERSITY 110

Shear Strain Localization and Fracture Evolution in Rocks 110

UNIVERSITY OF NOTRE DAME 111

Energy Partitioning of Seismic Waves in Fractured Rocks .

THE OHIO STATE UNIVERSITY

Investigation of Ultrasonic Wave Interactions With Fluid-Saturated Porous Rocks

A Study of Hydrocarbon Migration Events: Development and Application of New Methods for Constraining the Time of Migration and an Assessment of Rock-Fluid Interactions 
Multi-station Magnetotellurics

PENNSYLVANIA STATE UNIVERSITY

Cretaceous Shallow Drilling in the U.S. Western Interior: Core Research

PRINCETON UNIVERSITY

Thermodynamics of Minerals Stable Near the Earth's Surface

The Effects of Natural and Radiation Induced Defects on Noble Gas Transport in Silicates: A Study of Argon Using Laser, X-Ray, and Electron Microprobes

PURDUE UNIVERSITY

Rupturing and Ground Deformation During the 28 June 1992 Landers, California, Earthquake

RENSSELAER POLYTECHNIC INSTITUTE

Transport Phenomena in Fluid-Bearing Rocks

RICE UNIVERSITY

Transition Metal Catalysis in the Generation of Petroleum and Natural Gas

UNIVERSITY OF SOUTHERN CALIFORNIA

The Seismology of Geothermal Regimes

Cation Chemisorption at Oxide Surfaces and Oxide-Water Interfaces:

$\mathrm{X}$-Ray Spectroscopic Studies and Modeling

Porous Reservoir Rocks with Fluids: Acoustic and Reservoir

Transport Properties

Experimental Investigation of Kinetics and Rheology During Diagenesis

Models of Natural Fracture Connectivity: Implications for

Reservoir Permeability

Induced Seismicity

Scientific Drilling into the San Andreas Fault Zone and Site Characterization Research and Coordination Efforts

TEXAS A\&M UNIVERSITY

Mechanical Properties and Modeling of Seal-Forming Lithologies 
Energy Flux and Hydrogeology of Thermal Anomalies in the Gulf of Mexico Sedimentary Basin-South Texas Example

The Role of Mud Rocks in Burial Diagenesis .................................................................................136

Organization and Hosting of First North American Rock Mechanics Symposium ................................137

UNIVERSITY OF TULSA .138

Stability of Natural Gas in the Deep Subsurface 138

U.S. GEOLOGICAL SURVEY

Causes of the Abnormally High Fluid Pressure in the Uinta Basin, Utah 139

UNIVERSITY OF UTAH 140

High Resolution Imaging of Electrical Conductivity using Low Frequency Electromagnetic Fields

UNIVERSITY OF UTAH RESEARCH INSTITUTE

Tensor, Controlled-Source Audiomagnetotelluric Survey over the Sulphur Springs Thermal Area, Valles Caldera; Structural Implications and Tensor CSAMT Methodology

Assessing the Role of Active and Ancient Geothermal Processes in Oil-Reservoir Evolution in the Basin and Range Province

VIRGINIA POLYTECHNIC INSTITUTE AND STATE UNIVERSITY 144

PVTX Properties of Fluid Systems: $\mathrm{H}_{2} \mathrm{O}-\mathrm{CO}_{2}-\mathrm{NaCl}$ 144

Zircons and Fluids: An Experimental Investigation with Applications for Radioactive Waste Storage

WASHINGTON STATE UNIVERSITY

Origin of Flood-Basalt Volcanism on the Columbia Plateau: an Integrated Approach Using Geology, Geophysics, and Petrology

WASHINGTON UNIVERSITY 148

Development of an Experimental Database and Theories For Prediction of Thermodynamic Properties of Aqueous Electrolytes and Nonelectrolytes of Geochemical Significance at Supercritical Temperatures and Pressures

Two and Three-Dimensional Magnetotelluric Inversion 
HRTEM Investigations of Interactions Between Minerals, Fluids, and

Lithobiontic Communities During Natural Weathering

Microanalysis of Stable Isotope Ratios in Geothermal Systems:

Long Valley and Skye

Poroelasticity of Rock

Testing the Correlation Between Seismic Stratigraphy, Diagenesis and Physical

Rock Properties: Evaluation of Fluid Flow During Early and Late Diagenesis

WOODS HOLE OCEANOGRAPHIC INSTITUTION

Geochemical Incorporation of Sulfur into Organic Matter: Role of

Sulfur in the Formation and Diagenesis of Macromolecular

Organic Matter in Sediments

Organic Geochemistry of Outer Continental Margins and Deep Water Sediments 156

Robust, Controlled Leverage Magnetotelluric Data Analysis

YALE UNIVERSITY

Reactive Fluid Flow and Applications to Diagenesis, Mineral Deposits, and Crustal Rocks 


\section{FOREWORD}

The Department of Energy supports research in the geosciences in order to provide a sound foundation of fundamental knowledge in those areas of the geosciences that are germane to the Department of Energy's many missions. The Division of Engineering and Geosciences, part of the Office of Basic Energy Sciences of the Office of Energy Research, supports the Geosciences Research Program. The participants in this program include Department of Energy laboratories, academic institutions, and other governmental agencies. These activities are formalized by a contract or grant between the Department of Energy and the organization performing the work, providing funds for salaries, equipment, research materials, and overhead.

The summaries in this document, prepared by the investigators, describe the scope of the individual programs. The Geosciences Research Program includes research in geophysics, geochemistry, resource evaluation, solarterrestrial interactions, and their subdivisions including earth dynamics, properties of earth materials, rock mechanics, underground imaging, rock-fluid interactions, continental scientific drilling, geochemical transport, solar/atmospheric physics, and modeling, with emphasis on the interdisciplinary areas. All such research is related either directly or indirectly to the Department of Energy's long-range technological needs. 


\section{THE GEOSCIENCES RESEARCH PROGRAM IN THE OFFICE OF BASIC ENERGY SCIENCES}

The Geosciences Research Program is directed by the Department of Energy's (DOE's) Office of Energy Research (OER) through its Office of Basic Energy Sciences (OBES). Activities in the Geosciences Research Program are directed toward the long-term fundamental knowledge base necessary to provide for energy technologies of the future.

Future energy technologies and their individual roles in satisfying the nation's energy needs are uncertain in their particulars. It is clear, however, that these future energy technologies will involve consumption of energy and mineral resources and generation of technological wastes. The earth is a source for these energy and mineral resources and is also the host for wastes generated by technological enterprise. Viable energy technologies for the future must contribute to a national energy enterprise that is efficient, economical, and environmentally sound.

The Geosciences Research Program emphasizes research leading to fundamental knowledge of the processes that transport, modify, concentrate, and emplace (1) the energy and mineral resources of the earth and (2) the energy byproducts of man. The Geosciences Research Program is divided into five broad categories:

- Geophysics and Earth Dynamics.

- Geochemistry.

- Energy Resource Recognition, Evaluation, and Utilization.

- Hydrogeology and Exogeochemistry.

- Solar-Terrestrial Interactions.

The following outline of current research in these categories is intended to be illustrative and evolves with time and progress in these fields. Individual research projects supported by this program at DOE laboratories, national laboratories, academic institutions, research centers, and other federal agencies typically have components in more than one of the categories or subcategories listed. Also, it is common for research activities to involve a high level of collaboration between investigators and different institutions.

\section{GEOPHYSICS AND EARTH DYNAMICS}

A. Large-Scale Earth Dynamics. Research on the physics of lithospheric dynamics such as plate motion, mountain building, basin development, and regional scale uplift/subsidence and its concomitant effects.

B. Evolution of Geologic Structures. Research on the physical controls and physical effects of the dynamic evolution of geologic structures (e.g., folds, faults, basins, volcanoes) on a local or regional scale.

C. Properties of Earth Materials. Research on physical properties of rocks and minerals determined in the laboratory or in the field (in situ), by direct or indirect techniques, and applicable on the spatial and temporal scales of geologic processes.

D. Rock Mechanics, Fracture, and Fluid Flow. Research on the response of rock and rock units to induced stress and the role of fluid flow as a cause and/or effect.

E. Underground Imaging. Research to characterize the layering, mineralogy, lithology, geometry, fracture 
density, porosity, fluid content, and composition of the lithosphere using geophysical methods.

\section{GEOCHEMISTRY}

A. Thermochemical Properties of Geologic Materials. Research on the thermodynamic and chemical properties of geologic materials and their kinetic/dynamic interactions.

B. Rock-Fluid Interactions. Research on the chemical and mechanical consequences of rock-fluid interactions and the mass and energy transport controls of such interactions.

C. Organic Geochemistry. Research on naturally occurring carbonaceous and biologically derived substances of geologic and energy importance.

D. Geochemical Transport. Research (both experimental and theoretical) on the geochemical separation, transport, and concentration of materials in the earth's crust induced by the spatial and temporal dynamics of lithospheric processes leading to a predictive capability.

\section{ENERGY RESOURCE RECOGNITION, EVALUATION, AND UTILIZATION}

A. Resource Definition and Utilization. Research to develop new and advanced bases for the physicochemical dynamics needed for improved energy and energy-related resource exploration, definition, and use.

B. Reservoir Dynamics and Modeling. Research on the physiochemical dynamics of geothermal and hydrocarbon reservoirs in their natural and perturbed (by production, injection, or reinjection) states.

C. Properties and Dynamics of Magma. Research on the origin, migration, emplacement, and crystallization of natural silicate liquids and their heat energy.

D. Continental Scientific Drilling. Research on the scientific objectives of the OBES Geosciences Resẹarch Program using advanced technologies in shallow, intermediate, and deep drilling for earth observation facilities. Scientific research and advanced drilling technologies development are coordinated by an Interagency Coordinating Group (DOE, the U.S. Geological Survey, and the National Science Foundation) under the aegis of the Interagency Accord on Continental Scientific Drilling.

\section{HYDROGEOLOGY AND EXOGEOCHEMISTRY}

A. Fluid Transport Dynamics and Modeling. Research on the chemical transport and energy/mechanical consequences of fluid interactions and transport, leading to a predictive capability.

B. Thermochemical Properties of Energy Materials. Research on the thermodynamic and chemical properties of materials and their kinetic/dynamic interactions in fluid-rock systems.

C. Perturbations of Fluid Flow. Research on the physicochemical dynamics and chemical transport of fluid-rock systems in response to mechanical and energy perturbations, leading to a predictive capability,

5. SOLAR-TERRESTRIAL INTERACTIONS 
A. Magnetospheric Physics. Research on the fundamental interactions of the solar wind with the terrestrial magnetic field and the earth's magnetosphere as a model magnetohydrodynamic generator and associated plasma physics research.

B. Upper Atmosphere Chemistry and Physics. Research on thermal, compositional, and electrical phenomena in the upper atmosphere and the interactions induced by solar radiation.

C. Solar Radiation and Solar Physics. Research on the structure and dynamics of the sun and the characteristic interactions of solar radiation with the earth, including the effects of solar radiation on the climate. 
PART I ON-SITE 
CONTRACTOR:

CONTRACT:

CATEGORY:

PERSON IN CHARGE:
ARGONNE NATIONAL LABORATORY

Argonne, Illinois 60439

W-31-109-Eng-38

Geochemistry

N. C. Sturchio

\section{A. Mineral-Fluid Interactions: Experimental Determination of Atomic-Scale Processes Using Synchrotron Radiation (Ronald P. Chiarello [708-252-9327; Fax 708-252-9373; E-mail chiarello@cmt.anl.gov] and Neil C.Sturchio)}

Objectives: The objective of this program is to advance the basic understanding of rock-fluid interactions through experimental studies of atomic-scale processes at mineral-fluid interfaces. This is crucial to establishing the relation between atomic-scale processes and macroscopic geochemical transport in large-scale natural systems.

Project Description: The principal approach is to observe single-crystal mineral surfaces in situ during chemically controlled reactions with fluids in a flowthrough reaction cell, using $x$-ray scattering and $x$-ray absorption spectroscopy techniques with high-brilliance synchrotron radiation. Experiments are being performed on common rock-forming minerals under conditions representative of near-surface environments. Types of reactions being investigated include dissolution-precipitation, adsorption, and oxidation.
Results: Progress during the past year included successful demonstrations of the ability to perform in situ x-ray reflectivity, diffraction, and standing-wave studies of reacting mineral surfaces in chemically controlled conditions. During the past year, experiments were conducted to observe changes in the surface structure of the (104) calcite cleavage plane as a function of $\mathrm{pH}$ and time. $\mathrm{X}$-ray reflectivity and diffraction techniques were used to determine the growth rate and crystallographic characteristics of otavite precipitated heterogenously onto calcite. The $x$ ray standing-wave technique was used to determine the lattice locations of $\mathrm{Mn}$ in calcite and $\mathrm{Pb}$ sorbed onto the calcite surface from aqueous solution (in collaboration with M. J. Bedzyk and Y. L. Qian, of Argonne National Laboratory and Northwestern University).

\section{B . Hydrothermal System Evolution (Neil C. Sturchio [708-252-3986; Fax 708-252-9373; E-mail sturchio@cmt.anl.gov], Greg B.Arehart, and Ben D.Holt)}

Objectives: The objective of this program is to achieve a better understanding of rock-water interactions and geochemical transport in shallow portions of the Earth's crust.

Project Description: Active hydrothermal systems are being examined to determine the sources of fluids and solutes, the mechanisms and rates of geochemical transport processes, and the relation of hydrothermal systems to larger-scale tectonomagmatic and climatic processes, through field-based studies that include detailed chemical and isotopic analyses. Emphasis is given to applications of actinide ( $U$ and Th) decay-series disequilibria and stable isotopes $(H$, B, C, N, O, S, and Sr) to understand hydrothermal processes. Chemical equilibrium and mass transfer calculations are used to interpret phase equilibria and element redistribution. Such work is of basic importance to a wide variety of energy-related concerns involving mass transport in rock-water systems. This program will end in the current fiscal year. 
Results: Progress during the past year included studies of: (1) fumarole gases in the crater of Galeras Volcano, Colombia, and the relation of their compositional changes to seismic and eruptive activity; (2) thermal waters along the Gulf of Suez (Egypt);
(3) isotopic compositions of fluid inclusions from hydrothermal ore deposits. In addition, techniques were developed for chemical and isotopic analysis of dissolved gases in groundwaters.

\section{Petroleum Maturation Processes (Allen J. Bakel 1708-252-9825; Fax 708-252-6476; E-mail bakel@cmt.anl.gov] and GregB.Arehart)}

Objectives: The objective of this program is to contribute to a better understanding of the origin and history of petroleum in sedimentary basins. Fundamental questions addressed by this work include: the relation between oil composition and source rock type; the nature of chemical changes that occur within organic matter during diagenesis and catagenesis; the effects of maturation, migration, and biodegradation on oil composition; and the validity of oil-source rock and oil-oil correlations. The results of this work have significant applications in hydrocarbon resource exploration and production.
Project Description: The principal approach employed in this research is gas chromatography/ isotope ratio mass spectrometry for compound-specific analysis of carbon isotope ratios in complex organic mixtures. Suites of well-characterized petroleum samples, obtained from collaborating scientists, have been used for this research. This program will end in the current fiscal year.

Results: Analyses of nitrogen isotope ratios in crude oils from the Monterey Basin were performed. Significant variations in nitrogen isotope ratios were found to be correlated with primary depositional features and unaffected by post-depositional processes (e.g., biodegradation, maturation, and migration). 
CONTRACTOR:

CONTRACT:

CATEGORY:

PERSON IN CHARGE:
BROOKHAVEN NATIONAL LABORATORY

Associated Universities, Inc.

Upton, Long Island, New York 11973
DE-AC02-76CH00016

Geochemistry

A. Vairavamurthy and B. Manowitz

\section{A. Geochemistry of Organic Sulfur in Marine Sediments (A. Vairavamurthy [516-282-5337; Fax 516-282-5526] and B. Manowitz [516-282-2458; Fax 516-282-5526])}

Objectives: The broad objectives are to understand the geochemical mechanisms of sulfur incorporation into sedimentary organic matter, to study the changes in the abundance and forms of sulfur during early diagenesis in various organic-rich sedimentary environments, and to examine the influence of sulfur incorporation in the preservation of sedimentary organic matter.

Program Description: Sulfur is believed to be involved in preserving organic matter in sediments, in converting this organic matter to petroleum and in controlling the timing of petroleum generation from a source rock. The fundamental geochemical issue in this matter is the mechanism of sulfur incorporation into sedimentary organic matter. Although there is compelling evidence to indicate that reactions of reduced inorganic sulfur species with organic molecules occur during the early stages of diagenesis and under very mild conditions, the molecular mechanisms are still not well understood. Previously, hydrogen sulfide has been considered to be the primary sulfur reactant for organic sulfur formation in sediments. Recently, evidence is emerging that $\mathrm{H}_{2} \mathrm{~S}$ oxidation products, especially polysulfides, are also important. The roles of elemental sulfur, sulfite and thiosulfate in the formation of organic sulfur are still not clear. This project, which is aimed at understanding the formation and transformation of sedimentary organic sulfur during early diagenesis, has four major components: (1) studies of sulfur speciation in sediments, (2) mechanistic studies of organic sulfur formation, (3) mechanistic studies of sulfide oxidation to understand the formation of different oxidation intermediates, and (4) analytical methods development. An important goal of this project is to use synchrotronradiation-based $\mathrm{x}$-ray absorption near-edge-structure (XANES) spectroscopy for characterization and determination of sulfur species, in addition to other state-of-the-art techniques.

Results: We have continued to study sulfur composition of sediment core samples from several organic-rich locations with XANES spectroscopy, which clearly establish sulfonates as a novel class of sulfur compounds constituting about $20-40 \%$ of the total organic sulfur in near-surface sediments. The accumulation of oxidized sulfonate sulfur in reducing marine sediments was not known previously; hence, a new perspective in sulfur geochemistry is established. The origins of sulfonates in sediments are not clear, although biological and geochemical mechanisms are possible. Further work is in progress to understand whether $\mathrm{H}_{2} \mathrm{~S}$ oxidation intermediates, especially sulfite and thiosulfate, are involved in their formation, and to elucidate the structures of the organic moieties associated with these compounds in sediments.

Measurements with high-performance liquid chromatography and XANES spectroscopy have been used to examine whether di- and polysulfide linkages play an important role in the formation of humic polymers in anaerobic marine sediments from a salt marsh. Two low-molecular-weight thiols, 3-mercatopropionic acid and methane thiol bound to the 
humic substances, were studied after separating them with a disulfide cleaving reagent, tributyl phosphine. According to previous studies, these thiols can be easily degraded by sedimentary bacteria. However, both thiols were present as components of the humic substances throughout the sediment column, down to the $22-\mathrm{cm}$ depth sampled. These results suggest that incorporation into humic polymers provides a mechanism for preventing mineralization of labile organic matter. In the near term, similar studies will be conducted on sedimentary humic substances from several other organic-rich locations, including the Peru margin, and the Black Sea.

\section{B. Role of Sulfur in the Formation and Diagenesis of Macromolecular Matter in Sediments (B. Manowitz [516-282-2458; Fax 516-282-5526] and A. Vairavamurthy [516-282- 5337; Fax 516-282-5526])}

Objectives: This work couples a Brookhaven National Laboratory program on early incorporation of sulfur into sediments with a Woods Hole program on the role of sulfur in the formation and diagenesis of macromolecular matter. The objective of the work is to quantitatively speciate sulfur compounds by $x$-ray absorption spectroscopy in sediments and in the products of diagenesis.

Project Description: The $x$-ray absorption spectra are taken in beam line $\mathrm{X}-19 \mathrm{~A}$ at the National Synchrotron Light Source. The samples are scanned in the neighborhood of the absorption edge with a relative energy bandwidth of $2 \times 10^{-4}$. At low concentrations the spectra are measured by measurement of the elemental fluorescence. For analysis of the XANES regions of the spectra, comparisons are made with spectra taken from model compounds of that element. The model compounds for a particular element would cover the range of oxidation states as well as the types of binding and symmetries displayed by that element. This technique is used to establish the presence of several different types of compounds of an element quantitatively by computer simulation.

A series of sediment and pore water samples were obtained off the coast of Peru and in Long Island salt marshes. An additional series of samples were obtained from the Black Sea and a third series obtained from the Monterey formation in California. Sulfur K-edge X-ray absorption measurements were performed at the X-19A beam line for a large number of samples and an analysis was provided for the sulfur species present.
Results: Results from the Peruvian sample indicate that sulfur incorporation into organic matter takes primarily within the upper few meters of sediment, but sulfur "in-growth" continues at greater depths. The major initial products are organic sulfides, with subordinate amounts of thiophenes. Sulfonic acids also comprise a significant portion of the organically bound sulfur in the shallowest sediments.

Analysis of chemically defined organic matter subfractions isolated from a surficial $(<1 \mathrm{~m})$ sample revealed no consistent relationship between molecular size and the proportion of sulfide bridges. In contrast, a strong correlation between these two parameters was observed for the Monterey Formation sample, implying that the degree of sulfur cross-linking may, in part, control molecular size and/or solubility.

The relative proportion of kerogen-derived thiophenic pyrolysis products increases significantly over the $100-\mathrm{m}$ depth interval and in the deepest samples approaches those of the Monterey sample. The distribution of thiophenic pyrolysis products in the deepest Peru sample also closely resembles that of the Monterey kerogen, suggesting the presence of similar sulfur-bound (lipid) building blocks. Subtle differences include a higher proportion of products held to derive from steroid carbon skeletons in the Peru kerogens and a more significant contribution of products originating from isoprenoid carbon skeletons in the Monterey sample. The close similarity in organic sulfur composition for these samples lends support for the premise that the Peru margin is a modern analog of the Monterey Formation.

Fuller descriptions of results are given in the BNL and Woods Hole summaries. 
CONTRACTOR:

CONTRACT:

CATEGORY:
LAWRENCE BERKELEY NATIONAL LABORATORY

University of California

Berkeley, California

DE-AC03-76F00098

Geophysics and Earth Dynamics

PERSON IN CHARGE: S. M. Benson

\begin{abstract}
A. Effects of Heterogeneity on the Mechanical Properties of Rock (L. R. Myer [510-4566456; Fax 510-486-5686; E-mail myer@lbl.gov],N.G.W.Cook, and K. T. Nihei)
\end{abstract}

Objectives: This work is aimed at developing a new fundamental understanding of the effects of heterogeneity in rock microstructure on the characteristics of deformation and failure in rocks and on the relationship between the static and dynamic effective moduli.

Project Description: This project uses numeri cal simulation and experimental analysis to investigate the influence of grain-scale and larger-scale heterogeneity on the deformation and strength of rocks. The details of the microscale failure processes which lead to ultimate macroscopic failure are being examined using a Wood's metal casting technique and SEM analysis. These experiments, which are being conducted on rocks of similar composition but with different microstructures, will freeze the microcrack geometry during various stages of loading. Analysis of the SEM photomicrographs will provide important information on the effects of heterogeneity on stable and unstable microcrack growth and microcrack localization. Numerical studies using a boundary element code and a Lagrangian discontinuous deformation analysis code are also being conducted in parallel with the experiments to quantify the effects of stochastic variations in grain strength, size and packing geometry on the nucleation and coalescence of microcracks.

Results: Numerical studies with the boundary element code have revealed that realistic microcrack localization can be obtained only when individual grains are allowed to fracture along the direction perpendicular to the maximum local extensile stress. Modeling grain failure by assigning the failed grain a lower (isotropic) modulus results in unrealistic localization across the diameter of a rock sample subjected to axial compression. Numerical simulations of a random packing of cylindrical grains with uniformly distributed radii have revealed that variability in grain size results in a lower peak strength, more strain softening, and a more distributed pattern of fractures.

\title{
B . Transport in Single Fractures (Graph Theory) (L. R. Myer 1510-456-6456; Fax 510-486- 5686; E-mail myer@lbl.gov],N.G.W.Cook, and G.Yang)
}

Objectives: This research will provide a level of understanding of multiple-phase flow in fractures sufficient to develop algorithms that can be used to analyze and quantitatively predict transport in fractures in the field.
Project Description: The mathematics of graph theory is used to characterize the topology of the fracture void space and calculate flow through it. The focus of the work is on single fractures. The general approach is to create a network which captures the 
important topological characteristics of the flow paths in a single fracture. Graph theory techniques are then used to develop highly efficient algorithms for solving network flow problems.

Results: First-year studies focused on the hierarchy of flow paths and the calculation of total flux through the network. Three networks were generated in which the conductivities of the network elements were statistically distributed. A uniform distribution was assumed for two cases, and a skewed distribution for the third. Spatial correlation was included for one case with uniformly distributed conductivities. The priority first search algorithm was employed to find the most conductive path. The spanning tree was formed around the most conductive paths. Having identified a hierarchy of conductive paths, loop equations based on Kirchhoff's Laws were solved using the Hardy-Cross method to find the flux carried by each connected path. In this way, it was possible to determine the percentage of total flux carried by each path and the effect of the statistical properties of the network on flux through it. Results for the uniform and skewed distributions without spatial correlation were similar. However, when conductivities were spatially correlated, a significantly higher percentage of the total flux was carried by a few connected, highly conductive paths.

\section{High-Resolution Imaging of Electrical Conductivity Using Low-Frequency Electromagnetic Fields (K.H. Lee [510-486-7468; Fax 510-486-5686; E-mail kiha@csem.lbl.gov],H.F.Morrison, and A.Becker)}

Objectives: The objective is to develop numerical and field techniques for high-resolution imaging of electrical conductivity using magnetotelluric (MT) and controlled-source electromagnetic (CSEM) methods. Applications of high-resolution conductivity imaging include the mapping of groundwater, resource exploration and reservoir characterization, subsurface processes monitoring, and general geological mapping of the crust of the earth.

Project Description: In spite of great progress in EM methods many fundamental questions relating to resolution, depth of exploration, required bandwidth in frequency and spatial sampling rate remain to be answered. To resolve some of these questions the follow ing four main tasks have been selected in this project: (1) Improvement of the q-domain imaging method using the wavefield transform and tomographic inversion; (2) Development of an approximate analysis and imaging method using Born inversion; (3) Development of a rapid and practical 3-D inversion scheme; (4) Development of a borehole time-domain EM system. Some of these tasks are driven by the pressing need to interpret an increasing amount of field data available to us. This data is now in the frequency domain, at only a few frequencies, and can only be interpreted with the products of tasks 2 and 3 . However, the evident success of the q-domain tomographic imaging process strongly argues for the development of a suitable wideband borehole system (task 4).

Results: The summary of this year's research consists of improvement of the q-domain imaging method, Born inversion, 3-D nonlinear inversion, and finally the status of the borehole TDEM system.

The wavefield transform method has been modified for frequency-domain data. Preliminary study shows that accurate travel time can be obtained using as little as $\mathbf{2 0}$ frequency-domain data. This development significantly reduces the stringent requirement of having to have so many samples either in the time or frequency domain.

The Born inversion scheme was further improved using an iterative scheme. Related works have been reported (Alumbaugh and Morrison, IEEE Trans. on Geosci. and Rem. Sen., 1993; Alumbaugh and Morrison, sub. to Geophysics, 1994; Wilt et al., ac cept. Geophysics, 1994).

Crosshole EM data sets obtained before and after a steam injection experiment at Lost Hills (M. Wilt of LLNL, personal comm.) have been interpreted using the improved 3-D nonlinear inversion code. The result clearly shows that the bulk of the steam went below the level of injection point. This result has been independently verified (C. Torres-Verdin of Schlumberger Doll Research, personal comm.).

Development of a prototype downhole TDEM transmitter is slightly ahead of schedule. The transmit- 
ter current is bipolar and its tum-off time is less than $2 \mu \mathrm{s}$. Six ferrite cores are used to boost the effective magnetic moment. Maximum on-time current is 12 Amps resulting in a magnetic moment of $300 \mathrm{Amp}$ $\mathrm{m}^{2}$. The bench-scale transmitter was put into an 8-footlong plastic tube and was field-tested. An EM47 receiver coil was used to detect the magnetic field. The result was remarkably good at short distances. But when the receiver was placed farther away from the transmitter the signal became noisy. The origin of the noise seemed primarily from pickups along wires and static leakage at the transmitter.

D. Center for Computational Seismology (CCS) (T. V. McEvilly [510-486-7316; Fax 510-4865686; E-mail tvmcevilly@lbl.gov] and E.L.Majer [510-486-6709; Fax 510-486-5686; E-mail elmajer@lbl.gov])

Objectives: The objectives of this project are:

1. Maintain a state-of-the-art computing environment in support of various seismological and other geophysical research programs.

2. Develop new methods in this environment for imaging the subsurface and its processes and new methods for visualizing the results.

3. Apply such methods to real research problems in U.S. Department of Energy scientific programs.

Project Description: CCS provides a core research facility for many Basic Energy Sciences programs as well as other government and private industry research ventures. A wide variety of software and hardware is developed and maintained to support highlevel research. Research focuses on subsurface imaging using active and passive sources at scales ranging from meters to whole-Earth dimensions. Research activities in the previous year include the processing and interpretation of vertical seismic profiles for fracture detection and fault delineation, seismic reflection imaging, cross-hole seismic profiling for twodimensional imaging and fracture detection between wells, and processing and analysis of microearthquake data for imaging of geothermal fields. The wide range of CCS research content is demonstrated in the listing of recent publications available through email from E. L. Majer (see address in heading).

Present resources available to users of CCS include:

- Solbourne 902 and 602 compute server and file server with over 25 Gbytes of data storage.

- Multiple Sun workstations, X-terminals, and Macintosh computers for desktop use.

- 9-track and 8-mm tape drives, color printer, and 36-in. black and white plotter for seismic sections.

- Various commercial processing packages including DISCO, ProMAX, SierraSeis, AIMS, NAG, SAG, and CA DISSPLA.

- Internet access for visitors.

Results: The major accomplishments of CCS come largely from the breadth of research support provided by CCS and the cross-fertilization of applications and fundamental studies. Primary strength are in elastic wave generation and propagation, inverse methods, data processing, and tomographic imaging methods. A list of reports, peerreviewed journal articles, and $\mathrm{Ph} . \mathrm{D}$. theses that acknowledge the support of CCS can be obtained by email from T. V. McEvilly and E. L. Majer.

\section{E. Non-Linear Elasticity and Seismology (V. A. Korneev 1510-486-7214; E-mail korneev@geo.lbl.gov],T.V.McEvilly [510-486-7347; Fax 510-486-5686; E-mail mcevilly@geo.lbl.gov],K.T.Nihei [510-486-5349;E-mail kurtn@geo.lbl.gov], and L.R.Myer [510-486-6456;E-mail myer@geo.lbl.gov])}

Objectives: The project aims to understand basic nonlinear elastic phenomena in rock materials at wide scales, and to find the ways of nonlinearity detection and use for rock properties identification. It is anticipated that the results of this nonlinear research may be useful for characterizing earth materials with nonlinear parameters, for explaining the frequency content of seismograms, for monitoring strain fields in 
the earth's crust, and perhaps for improved elastic wave illumination technique for topographic imaging at many scales in the earth.

Project Description: The approach is comprehensive and includes integrated components in theoretical studies, laboratory experiments, and field investigations. Theoretical study includes studies of nonlinear distortion of the single propagating elastic pulse, as well as evaluation and mathematical description of the nonlinear scattering of elastic waves due to their interaction. This study provides information for the best design of experiment for nonlinearity observations. Experimental laboratory studies include static stress-strain measurements of different rock samples to determine values of nonlinear elastic constants. Dynamic laboratory measurements provide data for nonlinear waveforms distortion during loading and unloading cycles and different intensity levels of primary sources. Field seismic experiments serve for nonlinear effects detection using seismic vibrators.

Results: A theoretical study of time-domain solutions for 1-D nonlinear elastic wave propagation predicted the strongest nonlinear effects for the cases of single compressional wave propagation, for single compressional or shear wave propagation through a longitudinally pre-stressed elastic material, and for shear wave propagation in a shear pre-stressed elastic material. A special series of laboratory experiments were performed on the stack of the steel plates to obtain data that could be compared with the theoretical results. The curvature of the static stress-strain curve gave the largest expected nonlinearity for the range of stresses in the interval 0.5-1.0 MPa. These results reveal a good qualitative agreement between the theory and laboratory experiments. The measurements in sandstone of $P$ and $S$ velocities at different static stresses and dynamic strain amplitudes and static stress-strain curves experiments provided a link between nonlinear pulse propagation measurements and the micromechanical processes which occur at the grain level which is essential to further theoretical developments. The static stress-strain measurements also show considerable hysteresis with no permanent set. Other theoretical investigation was concerned with the nonlinear interactions of two elastic waves, where among 54 possible combinations only 10 result in resonant scattering. Analytical expressions for the scattering coefficients were obtained for all possible types of interactions, where except for the interactions of $\mathrm{SH}$ waves, the amplitudes of the scattered waves are directly proportional to the nonlinear elastic constants. We have used three different sets of field data in a search for effects of nonlinear elasticity. The Parkfield earthquakes and Vibroseis were used as energy sources. The somewhat surprising observation implies that effective $Q$ is linearly proportional to frequency, or that some fortuitous mechanism operates to balance attenuation and harmonic generation. Another possible explanation is that the harmonics are generated at the receiver or in recording/analysis. Other field studies have also been ambiguous but tantalizing. The studies searching for generation of a difference frequency give the most promising results, yet they too are inconclusive.

\section{F . Energy Partitioning of Seismic Waves in Fractured Rock (L. R. Myer 1510-486-6456; Fax 486-5686; E-mail myer@lbl.gov], N. G.W. Cook, and K.T. Nihei)}

Objectives: The objectives of this work are to: (1) investigate the partitioning of energy between seismic body waves, guided waves, and scattered waves produced by sources of finite size and bandwidth which are transmitted, reflected, and channeled along single and multiple fractures; (2) determine optimum source and receiver configurations for exciting and detecting these waves; (3) determine the effects of spatial variations in the fracture properties on seismic wave propagation; and (4) examine the effects of a finite fracture on seismic waves.
Project Description: This project consists of a combination of laboratory experiments and numerical simulations on single and multiple fractures. The laboratory experiments are being conducted on artificial fractures in aluminum with calculable fracture stiffnesses. Numerical studies are being performed concurrently using propagator matrix and boundary integral equation codes. In these numerical codes, fractures are modeled as a discontinuity boundary condition. By performing laboratory measurements and numerical simulations together, we can first evaluate 
the accuracy of the discontinuity fracture model for modeling the seismic properties of dry and fluid-filled fractures and then use the numerical model to obtain detailed quantitative information about the effects of source frequency, angle of incident, fracture stiffness, and fracture heterogeneity.

Results: Current research efforts have concen trated on the partitioning of seismic energy along a single, dry fracture in an elastic medium of infinite extent. Numerical analysis of the velocity and particle motion characteristics of the various seismic waves which propagate along the surfaces of a fracture reveal that there are two types of interface waves, both of which have elliptical particle motion, but which travel close to the compressional and Rayleigh wave velocities. Numerical results also predict the existence of head waves that leak off of the fracture surface and are sensitive to the stiffness of the fracture.

\section{G. Coupled Thermal-Hydraulic-Mechanical Processes in Petroleum Reservoirs (C.-F.Tsang [510-486-5782; Fax 510-486-5686; E-mail chinfu@lbl.gov] and J.Noorishad [510-486-4905; Fax 510-486-5686; E-mail J_Noorishad@lbl.gov])}

Objectives: Development and application of the numerical simulator ROCMAS for analysis of thermalhydraulic-mechanical processes in saturated fractured porous media.

Project Description: The work involves development of the formulation equations and numerical algorithms that simulate the simultaneous occurrences of heat flow, fluid flow, and deformation in the complex environments of geologic media. Coupled equations of conservation of mass, momentum, and energy are used. The solution of the initial and boundary value problem is then expressed as a finite element matrix formulation. The use of proper constitutive models that govern the macroscopic behavior of the media is a critical aspect of this development. Realistic models of pre- and post-failure mechanical behavior of brittle and ductile continua as well as fractured continua are considered, along with temperature-dependent fluid density and viscosity and stress-dependent fracture permeability. Treatment of material nonlinearities, in the context of an incremental loading path, is another crucial part of the work. Alternative schemes of linearization, mainly based on the Newton-Raphson method, are employed.

Results: Within the context of plasticity, an algorithm for shear band development is implemented. With this capability, failure of rocks with randomly distributed and oriented fractures can be more realistically treated.

A yield function suitable for development of oriented plasticity is formulated and the proper algorithms are added to the ROCMAS code. This feature allows study of plastic failure in rocks along equally distributed ubiquitous fracture sets.

Both of the above mentioned developments are fundamental steps in constitutive law homogenization needed for rock mass modeling.

\section{H. Controls on Pull-Apart Basin Evolution: Integrated Geological, Geophysical and Modeling Studies (Patrick L. Williams [510-486-7156; Fax 510-486-4159; E-mail plw@geo.lbl] and Thomas V.McEvilly)}

Objectives: In- a variety of Earth science and technology problems it is becoming increasingly critical to identify and characterize in three dimensions the geologic structure of sedimentary basins. This project will develop a better understanding and predictive capability for the three-dimensional (3-D) structure of extensional sedimentary basins. The purpose of this work is the integration of surface geology and high- resolution subsurface geological and geophysical data in full 3-D basin representation.

Project Description: This project is directed at the development of a predictive capability for the 3-D structure of pull-apart basins. Stage one of this work is the integration of surface geology and high-resolution subsurface geological and geophysical data in full 3-D basin representation. This project will complete 3-D 
representations, or "empirical models," of the bounding geometry, structural elements, stratigraphy, and sedimentology of selected basins. This provides a point of departure (and constraints) for stage two of the project: the development of a new generation of 3-D numerical or "theoretical mechanical basin models". The development of realistic mechanical models of an extensional basin's evolution will require the encoding of accurate basin geometries and deformation history. Subsequent modeling will test how fault geometry and fault displacement affect basin structure in three dimensions.

Results: Highlights for technology transfer and value-to-industry are direct and prominent in this project. This project was initially stimulated by interest from Exxon Production Research Company in the evolution and geometry of pull-apart basins. Instrumentation and computing methods have been identified, acquired, and developed that will greatly increase the resolution of subsurface imaging programs. Development and application of advanced imaging methods has been primarily supported by this project, and will result in several publications. Our studies of specific pull-apart basins in the San
Francisco Bay area have contributed directly to the understanding of tectonic (earthquake) hazards to structures including industrial facilities, transportation structures and lifelines. With industry participation, we are demonstrating the capability of advanced imaging tools for investigations of subsurface structure for environmental remediation and characterization of geological hazards. (1) We have advised industrial facilities (oil-refineries, land fills), California DOT, and municipalities in regard to the geological hazards associated with a large pull-apart basin north of Oakland, California. (2) Our work on a small pullapart basin in Fremont, California, has provided an "archeological record" of the timing of Bay Area earthquakes. (3) We have regularly provided data to local media to share our new understanding of complex active fault patterns in California. (4) We have developed a model of pull-apart controls to geothermal energy production and brought that model to the attention of industrial and U.S. Navy geothermal producers. (5) We are conducting a "proof of capability" of advanced geophysical methods for study of faults and bridge crossings in the San Francisco Bay Area.

\section{CATEGORY:}

Geochemistry

PERSON IN CHARGE: S. M. Benson

\section{A. Thermodynamics of High Temperature Brines (K. S. Pitzer [510-486-5456; Fax 510-642- 6911;E-mail kspitzer@lbl.gov])}

Objectives: This project covers theoretical and experimental studies concerning the thermodynamic properties of aqueous electrolytes and other systems at high temperatures. The components important in natural waters and other geochemical fluids are emphasized. The resulting data are important in understanding various geological processes, in exploiting geothermal and other natural resources, and in fission-product waste disposal. Moreover, this information has a wide range of applicability, since similar fluids arise in many industrial processes and in high-pressure steam power plants.
Project Description: The project includes both experimental and theoretical programs. The experimental program involves measuring heats of mixing or dilution of solutions at temperatures extending above $350^{\circ} \mathrm{C}$ and pressures to $1 \mathrm{kbar}$. The new calorimeter is being tested and measurements will proceed for the mixing of $\mathrm{NaCl}$ (aq) with $\mathrm{CaCl}_{2}$ (aq).

Results: Recent theoretical results include an equation for $\mathrm{CaCl}_{2}-\mathrm{H}_{2} \mathrm{O}$ extending to solid saturation. Equilibrium with the saturating solid hydrate is also a part of this treatment, and improved property values are obtained for the solids. The temperature range extends 
to $523 \mathrm{~K}$ where the equilibrium is with anhydrous $\mathrm{CaCl}_{2}$. This was a joint project in which ORNL was primarily responsible for an equation valid to
$4.5 \mathrm{~mol} \cdot \mathrm{kg}^{-1}$, while the more concentrated range to solid saturation, which is $30.8 \mathrm{~mol} \cdot \mathrm{kg}^{-1}$ at $523 \mathrm{~K}$, was developed in this project.

\section{B . Integrated Isotopic Studies of Geochemical Processes (Donald J. DePaolo [510-486-4975, 510-643-7686; Fax 510-486-5686,E-mail depaolo@garnet.berkeley.edu or ddepaolo@geo.lbl.gov] and B.Mack Kennedy [510-486-6451,Fax 510-486-5686,E-mail bmkennedy@geo.lbl.gov])}

Objectives: Combine high-precision measurements of isotopic ratios in natural materials with mathematical models to understand the spatial and time scales of geochemical processes of interest for energy management.

Project Description: Current effort is concentrated on $\mathrm{Sr}, \mathrm{Ca}, \mathrm{O}, \mathrm{C}, \mathrm{He}, \mathrm{Ne}, \mathrm{Ar}$, and $\mathrm{Nd}$ isotopic ratios, and on problems of mass transport in fluid-rock systems, interpretation of past global climatic change, stratigraphy and structure of sedimentary basins, and crustal magmatic and tectonic processes. A mathematical basis for the application of isotopic measurements of fluids and rocks to the field-scale parameterization of hydrological systems is a major effort of the Center. This approach is supplemented by systematic measurements of relatively simple natural systems, and by the development of improved sampling and measuring techniques to enhance information return. Emphasis in development is on microsampling of geological materials, on highprecision measurement of the small amounts of recovered material, and on rapid, automated low-blank chemical separation of trace elements. Other efforts of the Center are aimed at geochemical techniques for dating and correlation of sedimentary and volcanic rocks, and for understanding the timescales and mechanisms of crustal processes such as extensional faulting, mountain building, and volcanism. These efforts are aimed at improving geological characterization for regulatory purposes, and at improving subsurface characterization of sedimentary reservoirs.

Results: (1) One and two-dimensional models of isotopic evolution of migrating groundwaters in saturated media have been developed and applied to the interpretation of isotopic data in subsurface vein deposits at Yucca Mountain, Nevada. Sr isotopic measurements in groundwater at LBL have also been made and give unique information about the subsurface water movement. (2) New Nd isotopic measurements of postcaldera silicic lavas at Long Valley, Califomia provide a time-series that is interpreted to indicate that the current system near Mono Lake may be accumulating magma capable of producing a large explosive eruption. (3) He isotopic measurements in the Geysers geothermal system were used to delimit the extent of separate hydrothermal systems. (4) 0 isotopic data on carbonate from estuarine sediments in San Francisco Bay have been used in concert with $\mathrm{Sr}$ isotopes to reconstruct the salinity of the bay, and hence the freshwater inflow from the Sacramento and San Joaquin Rivers for the past 6000 years. (5) $O$ isotopic measurements in altered basalt and interlayered carbonate in the Kilauea East Rift give new information on water flow in the fossil hydrothermal system. 


\section{PERSON IN CHARGE: S. M. Benson}

\section{A. Hydrothermal Chemistry (S. Flexser [510-486-4816; Fax 510-486-5686])}

Objectives: Investigation of rock-fluid interactions, particularly as recorded in clay mineralogy, in hydrothermal and lower-temperature environments.

Project Description: Alteration mineralogy, isotopic composition, and radioelement distribution in rock matrix and fracture lining are combined with characterization of downhole fluid to reconstruct the thermal and chemical conditions associated with rockfluid interaction and alteration. Isotopic fractionation curves for clay minerals, mainly smectites, as a function of alteration temperature and clay mineralogic and chemical composition, are being developed and refined for use as geothermometers.

Results: The focus of this project has shifted to detailed analysis of isotopic compositions (oxygen and hydrogen) and mineralogic variations of clay minerals. Samples spanning a broad range in alteration temperatures have been collected from two chemically distinct environments: the East Rift Zone of Kilauea volcano, Hawaii, and the Long Valley caldera, California. In the Kilauea samples, smectite has been identified at depths corresponding to temperatures of $40^{\circ} \mathrm{C}$ to greater than $300^{\circ} \mathrm{C}$. This presents the opportunity to examine isotopic fractionation of smectite over almost the entire range of temperatures at which it forms, as well as, in the higher-temperature samples, where it co-exists with both interlayered chlorite-smectite and chlorite. The Long Valley samples were obtained from the Long Valley Exploratory Well on the resurgent dome (in collaboration with Vicki McConnell, Univ. of Alaska), and from drillholes in the west moat. Smectite in these samples also formed over a broad temperature range, but in silicic tuffaceous rocks, and in part co-existing with interlayed illite smectite and illite.

Work thus far has mainly been directed toward preparation of purified separates of clay phases from these samples by high-gradient magnetic separation. $X$ ray diffraction analysis of these separates is also under way, for structural characterization of clay phases, and for quantification of proportions of mixed phases in cases where mono-mineralic separates were not be obtainable. This enables the measurement of meaningful isotopic ratios for these separates, and construction of phase-specific fractionation curves.

\section{B . Pre-Drilling San Andreas Fault Zone Characterization: Isotopic and Chemical Composition of Fault Zone Fluids (B. Mack Kennedy 1510-486-6451; Fax 510-486-5686; E-mail mkennedy@ux5.lbl.gov) and K. Nishiizumi [510-643-9361; Fax 510-486-5686; E-mail kuni@sunspot.ssl.berkeley.edu])}

Objectives: The objective of the San Andreas Fault Zone Drilling Project (SAFDP) is to answer fundamental questions about the mechanics of deformation and slip within a major plate-bounding continental fault zone. The main focus is why the SAF is weak, both absolutely and in a relative sense compared with the adjacent plate interiors. The low strength appears to be caused by high fault zone fluid pressures. A critical factor discriminating between fault-weakening models is the origin of fault zone fluids and the hydraulic connectivity between the fault zone, country rocks, and underlying basement. These questions can be addressed, in part, by geochemical and isotopic studies of regional and local fluids and their host aquifers.

Project Description: The current effort is an initial survey of fluid types and provenances likely to contribute to the SAF zone. Sampling sites have been 
restricted to the main segment of the SAF between the Mojave and San Francisco Peninsula segments and selected to insure a representative sampling of fluids from Great Valley, Franciscan, and Salinian hosts. This is a collaborative project with a research group headed by Y. Kharaka, Water Resource Division, USGS, Menlo Park, CA. and LLNL's Accelerator Mass Spectrometry Facility. The LBL/UCB research team will (1) measure the isotopic and chemical composition of the noble gases, $\mathrm{He}$ through $\mathrm{Xe}$, (2) determine the abundances of the cosmogenic and nucleogenic isotopes ${ }^{36} \mathrm{Cl},{ }^{14} \mathrm{C}$, and ${ }^{129} \mathrm{I}$, and (3) provide a detailed petrologic study of fluid source and host rocks to include the micro distribution and host phases of parent and target nuclei related to the production of radiogenic and nucleogenic isotopes.
Results: Although this project was only recently initiated, 38 fluid samples have been collected along and adjacent the main segment of the SAF covering the region from just south of the Mojave segment to the San Francisco Peninsula. Of these 38 features, 20 could be sampled for noble gas measurements and 22 for both $\mathrm{Cl}$ and $\mathrm{I}$ isotopic measurements. Preliminary noble gas results (1) confirm the previously reported anomalously high helium isotopic composition in the Sierran Granite hosted Arrowhead Warm Spring (0.45 Ra) immediately south of the Mojave segment and (2) found that a moderately concentrated artesian water at Parkfield, CA., did not contain excess helium, implying a short fluid residence time within the creeping section.

\section{Geophysical Measurements Facility (GMF) (T. V. McEvilly 1510-486-7316; Fax 510-486- 5686; E-mail tvmcevilly@lbl.gov],H.F.Morrison [510-642-3804; Fax 510-642-3805], and E.L.Majer [510-486-6709; Fax 510-486-5686; E-mail elmajer@lbl.gov])}

Objectives: The objectives of this project are to:

1. Maintain a state-of-the-art multi-disciplinary field instrumentation facility in support of various environmental, geophysical, and hydrogeological research programs at Lawrence Berkeley Laboratory (LBL).

2. Assist in developing (a) new instrumentation and field methods for investigating the subsurface and its processes and (b) in-field visualization of results.

3. Provide professional in-field training for scientific staff and management of complex and varied field studies required in U.S. Department of Energy scientific research programs.

Project Description: GMF is the focal point for an extensive inventory of complex scientific equipment used for projects at several national laboratories, and is responsible for maintenance, upgrading, training, and field operations for this hardware. Although individual research projects provide funds for specific operations in the field, GMF funding provides the infrastructural support. GMF is a valuable and necessary core function, supporting a broad range of field research activities with an excellent complement of modern geotechnical instrumentation. GMF allows for management of a growing complement of sophisticated field instrumentation and associated support vehicles and of test and maintenance gear for LBL and its Earth Sciences Division. The facility addresses the problem of poor readiness of hardware when needed for research projects (with resulting unacceptable mobilization costs incurred by individual projects) by maintaining equipment between uses by research projects. GMF supports projects ranging from deepwell geothermal fluid sampling to hydrogeological and geochemical measurements in groundwater to highresolution cross-well tomography and operation of modern digitally telemetered microearthquake recording networks.

Results: The major accomplishments of GMF are largely in the quality and breadth of field support provided by the facility and in the influence of this resource on LBL research breadth and quality. A list of reports and publications for which GMF was used for data collection can be obtained by e-mail from $T$. V. McEvilly (address in heading). Examples for 1994 include velocity structure of the Long Valley Caldera, microearthquake clusters in the study of fault zone dynamics, and application of the seismic displacement discontinuity theory to laboratory and cross-well data. 


\section{A. Modification of Fracture Transport Properties of Rocks by Mechanical and Chemical Processes (W. B.Durham [510-422-7046; Fax 510-423-1057; E-mail durham1@llnl.gov] and B.P. Bonner)}

Objectives: This project aims to understand the hydraulic and mechanical properties of individual fractures in crustal rock, and to identify processes by which joints are modified or resist modification over long time scales.

Project Description: The project is a laboratory study of the relationships between applied normal stress, joint normal deformation, joint fluid conductivity, and joint shape. Samples are usually lowpermeability granitic rocks containing a single fracture, and measurements of permeability and deformation are made in a pressure vessel under pressures to $160 \mathrm{MPa}$. We identify systematics of the above relationships, and look for models that satisfy these systematics, or, since modeling has not reached the level of detail that is definable by our measurements, we try to develop explanations of our own for observed behavior. We have the means to vary parameters such as surface roughness and normal force to see the effect they have, and we have the means for physically measuring the shape of surfaces and joint space at a fine scale to help us understand the physical mechanisms behind the phenomena we observe macroscopically. An important premise of the work is that the elastic and inelastic deformation and fluid permeability of a fracture are functions of its physical shape, and that the relevant characteristics of the physical shape can follow from a statistical treatment of the fracture as a random process.

Results: Samples of Harcourt (South Australia) granite have been run though the experimental system in exhaustive detail and have confirmed the trends observed earlier in Westerly granite. The two granites different somewhat in composition and are strikingly different in grain size, Harcourt having grains roughly $10 \times$ larger in linear dimension than Westerly. However, the conductance of water through man-made joints in both rocks is similar: if the joints are well mated, the dependence of flow on joint aperture diverges strong from the parallel plate approximation; if the joints are offset slightly, the application of high normal pressures (to $160 \mathrm{MPa}$ ) does not close the joints sufficiently to cause the large increase in flow path tortuosity that is responsible for breakdown of the parallel plate approximation. In other words, the parallel plate approximation works well, except for the most interesting case of very small aperture, and nonmated joints in granite have sufficient mechanical strength to prevent apertures from getting small. Our work this year has focused on trying to understand discrepancies between lab observations and popular numerical models and simulations, and on using microscopic surface analysis to understand the mechanically resilient nature of joints in hard rock. Currently several papers are being prepared for publication that will define our understanding of the physics of hydraulic conductivity in joints of small aperture. These publications will serve as a basis for determining through experiment and observation the modification of flow by water-rock interaction (precipitation and dissolution). 


\section{B . Poroelasticity of Rock (B. P. Bonner [415-422-7080; Fax 415-423-1057; E-mail bonner1@llnl.gov]; joint research with H.Wang, University of Wisconsin)}

Objectives: To improve treatment of poroelastic problems involving the coupled processes of deforma tion and fluid flow by obtaining improved theoretical estimates of the poroelastic coefficients and performing experiments designed to test and extend the theory.

Project Description: Coupled problems involving both deformation and fluid flow cross the traditional disciplines of rock mechanics, seismology, and geohydrology. A general theory is needed to address these problems in a consistent way. The theoretical approach taken here, in collaboration with $\mathrm{J}$. Berryman, is to obtain improved methods of calculating the poroelastic coefficients by removing the restrictive assumptions inherent to existing theory. The experimental approach, undertaken in collaboration with $\mathbf{H}$. Wang at the University of Wisconsin and D. Green of Ohio University, is to collect measurements of the poroelastic coefficients, or of quantities that depend directly on them, over as broad a frequency range as possible. Samples of well characterized natural and synthetic sandstone are tested using traditional ultrasonic methods as well as with unique low-frequency methods.

Results: During FY93, synthetic "sandstones" have been manufactured from glass beads to span the porosity range from 2 to $40 \%$. The dynamic elastic constants, pore pressure buildup (Skemptons) coefficient, permeability, and low-frequency shear modulus and attenuation have all been measured for this material for comparison with parallel measurements for Berea and Massillon sandstones. Measurements of the low frequency shear modulus and attenuation were completed for several different permeability Berea sandstones containing pore fluid from $30 \mathrm{mHz}$ to $180 \mathrm{~Hz}$. The results were integrated with ultrasonic measurements by Green and Wang, and presented at the AGU Spring annual meeting. The theoretical component of the project demonstrated that microstructural assumptions, which are often concealed in mathematical obscurity, critically affect the ability of theory to predict elastic constants of porous rocks. Using our data for fused beads and literature data for glass foams due to Brace and Walsh, it was demonstrated that a theory sensitive to microstructure can predict the bulk modulus porosity relation for porosities to $40 \%$. The results appeared in Geophysical Research Letters. Improved treatments of poroelastic effects can be applied to a wide variety of problems including wave propagation in saturated rock, simulation of underground flow, hydrofracturing, and measurements of in-situ stress from borehole measurements of strain and breakouts.

\section{The Role of Carbon and Temperature in Determining Electrical Conductivity of Basins, Crust, and Mantle (A. G. Duba 1510-422-7306; Fax 510-423-1057; E-mail alduba@llnl.gov]; joint researchwith T.J. Shankland,LANL)}

Objectives: The intent of this work is to compre hend the electrical conduction mechanisms in carbonbearing rocks and in mantle minerals for the purpose of relating electrical conductivity $(\sigma)$ measured in the field to formation conditions and existing state of crustal rocks and to temperatures in the mantle.

Project Description: Electrical conductivity de pends strongly on temperature $T$ and on the presence of other phases such carbon, fluids, or ore minerals at the lower temperatures of the crust and basins. Thus, one research approach is to measure $\sigma$ of mantle minerals as functions of temperature, orientation, oxygen fugacity
$\mathrm{fO}_{2}$, and iron content. These data supply the best models for "electrogeotherms" yet available. Another approach is to document textures of carbon in crustal rocks from basins and metamorphic zones and relate them to rock conductivity. In this case texture of carbon distribution is mapped with electron microscopy in the same samples used for conductivity measurement.

Results: The accepted hypothesis that electrical conductivity of saturated crustal rocks decreases with pressure is not necessarily true. Conductivities of fresh drill cores from the German deep-drilling project show a remarkable increase with pressure even as conducting 
fluids are squeezed out. In these rocks solid grainboundary phases suffered minimal weathering or oxida tion because they were measured soon after recovery at the surface. [In contrast, specimens from outcrops have their solid-phase connections broken by pressure and temperature release as well as chemical alteration during normal uplift, and their conductivities show the usual decrease with pressure.] In the case of the German rocks, the oxide ilmenite was identified as a grain boundary phase. In addition, we discovered trace amounts of carbon in the cleavages in amphiboles (the major mineral phase in these rocks) that could serve as a bridge between ilmenite grains. Thus, a combined effect involving ilmenite grains plus carbon films on amphibole cleavage surfaces is implicated in the "anomalous pressure effect" that is increasingly identi - fied with the presence of solid phase conductors.

Another positive pressure effect is found in rocks from the Yukon-Tanana Terrane near the Denali Fault Zone in Alaska. Here the good conductor responsible for the effect is seen to be grain boundary carbon that probably resulted from metamorphic processes associated with thrust faulting of new terranes. Because there is an extensive region of high conductivity in a zone ex tending over several hundred kilometers with depth varying from 5 to $25 \mathrm{~km}$, a possible scientific drilling target for evaluation of hydrocarbon potential may be indicated. In other research, conductivities of silicates and melts at temperature and controlled oxygen fugacity were measured and related to point defect structure in silicates.

\section{Oxygen and Cation Diffusion in Oxide Materials (F. J. Ryerson 1510-422-6170; Fax 510- 422-1002; E-mail Ryerson@s91.es.llnl.gov] and K.D.McKeegan,University of California at Los Angeles, Dept. of Earth and Space Sciences, Los Angeles, CA 90024 [310-825-3580; Fax 310-825- 2779;E-mailkdm@argon.ess.ucla.edu])}

Objectives: The objective of this work is to measure the diffusion parameters for various cations and oxygen in important rock-forming minerals in order to constrain both geochemical transport processes and diffusive mechanisms affecting physical properties such as creep and electrical conductivity.

Project Description: Diffusion rates are strongly affected by temperature, pressure, crystal orientation. They may also depend upon additional vari ables such as oxygen fugacity and the activity of water in the system. We are conducting experiments in which all of these variables are controlled and selectively varied. The pressures of current experiments (concentrating on olivine, plagioclase, diopside, gamet and spinel) range from 1 atmosphere to $10 \mathrm{GPa}$. The primary analytical tool used in these investigations is an ion microprobe.

Results: It is well known that garnets can preserve zonation in major elements trace elements and radiogenic isotopes. Since these characteristics are sensitive to the $P-T$ history of garnet growth, such zonation pattems can be inverted to extract $P-T-t$ information about the rocks in which they are found. More recently, there have been a number of investigations in which zonation in the oxygen isotopic composi- tion of metamorphic garnets has been used to constrain various aspects of the fluid history of the sample. The extent to which any information recovered from gamet zoning can be used to characterize its growth history will be in part dependent upon the rate of diffusive relaxation of that primary zonation. We have started a series of oxygen self-diffusion experiments on 3 different almandine-spessartine garnets. These experiments were conducted at one atmosphere between $900-1000^{\circ} \mathrm{C}$ under controlled oxygen fugacity using ${ }^{18} \mathrm{O}$-enriched $\mathrm{CO}$ and $\mathrm{CO}_{2}$; oxygen fugacities lie between the ironwüstite and nickel-nickel oxide buffers. It is certain that some of the materials investigated are unstable under these conditions, however, all of the materials investigated can be preserved in a metastable state under our experimental conditions. Typically, lower oxygen fugacities are more conducive to preservation of the highly polished surfaces, preventing the formation of new phases. In all cases, the sample has been annealed in isotopically normal gases prior to the introduction of the ${ }^{18} \mathrm{O}$-enriched gases, to ensure that high quality surfaces are maintained.

Depth profiles of the tracer ${ }^{18} \mathrm{O}$ have been obtained for three gamet samples using the Cameca ims 1270 ion microprobe which was recently installed at UCLA. 
The profiles were generated by sputtering with a $\mathrm{Cs}^{+}$ primary beam and analyzing negative secondary ions. A normal incidence electron flood gun was used to neutralize surface charging. This configuration has important advantages for the analysis of oxygen depth profiles compared to our previous analytical technique which utilized an ${ }^{16} \mathrm{O}$ - primary beam in the Cameca $3 \mathrm{~F}$ at LLNL. In addition to allowing us to measure the ${ }^{16} \mathrm{O}$ profile without contamination from implanted primary ions, with the $\mathrm{Cs}+$ primary beam it is possible to obtain sputter rates more than 10 times higher than those achieved with the ${ }^{16} \mathrm{O}-$ beam. This allows the measurement of a complete depth profile in less than 15 minutes instead of the several hours that were required with the $3 \mathrm{f}$. Diffusion coefficients for this pyrope garnet annealed at $900^{\circ} \mathrm{C}$ is $\sim 2 \times 10^{-21} \mathrm{~m}^{2} \mathrm{~s}^{-1}$, which agrees reasonably well with values previously determined by under hydrothermal conditions.

In conjunction with Quentin Williams and Daniel Farber at UC-Santa Cruz, we conducted the first measurements of cation diffusion in the high pressure $\beta$ and $\gamma$-phases of $\mathrm{Mg}_{2} \mathrm{SiO}_{4}$. The experiments were performed in both a piston cylinder and in a multianvil pressure apparatus at $1200^{\circ} \mathrm{C}$ and pressures up to $14 \mathrm{GPa}$. Oriented samples of San Carlos olivine were placed in contact with $\mathrm{Ni}_{2} \mathrm{SiO}_{4}$ powder, and this couple was then contained in a $\mathrm{Ni}$ metal capsule along with
NiO to produce an oxygen buffer. Two different types of profiles were produced. At pressures below 3.3 GPa, Ni-olivine is stable, and a simple binary diffusion profile is obtained through electron microprobe analysis. At higher pressures, Ni-olivine converts to $\beta$-phase and then $\gamma$-phase, producing a composite profile. Analysis of these profiles not only allows the diffusion coefficients in all of the coexisting phases to be determined, but the compositional discontinuities at the phase boundaries also allows us to de termine the binary $\mathbf{P}-\mathrm{X}$ phase loops within the system. This method may have great utility in allowing these types of phase diagrams to be constructed with a minimum number of experiments. When combined with our results for $\alpha$-olivine these data document that the diffusion rates in the high-pressure phases are each $\sim 3$ orders of magnitude faster than that in the low-pressure olivine phase. These faster diffusion rates indicate that the deep upper mantle is dramatically more efficient at mixing chemical heterogeneities than the shallow upper mantle. Indeed, our calculations suggest that chemical diffusion in the transition zone, when coupled with convective thinning can effectively erase the chemical signature of subducted oceanic crust in between 200 and $300 \mathrm{Myr}$, or approximately $60 \%$ of the time required within the $\alpha$-olivine dominated upper mantle.

\section{E. Linear and Nonlinear Mechanics of Rocks (J. G. Berryman [510-423-2905; Fax 510-422- 1002;E-mailberryman@s123.es.llnl.gov])}

Objectives: Our major objective is to understand factors affecting physical properties of rocks in order to improve our ability to predict rock behavior from knowledge of rock components. One new tool we have to accomplish this objective is the recent discovery of exact results in poroelasticity and thermoelasticity for two component composite rocks. This project exploits these as well as other new results, with the expectation that new insight into the linear and nonlinear mechanics of rocks will result. Such insight may prove important for understanding earthquake source mechanisms and for oil field engineering practices related to drilling and pumping. Also, such information is important for interpretation of seismic field data.
Project Description: Modeling of idealized twomineral component rocks will be one of the main thrusts of the effort. Recent advances show that it is possible to compute all the compressibilities (jacketed, unjacketed, jacketed pore, and unjacketed pore) exactly for certain models. Although very general results on effective-stress rules for various physical properties of rocks have already been published, more explicit applications to examples of well consolidated and poorly consolidated rocks have not yet been reported. The new approach based on exact results offers promise of analytical and/or numerical modeling capability from linear to semilinear to fully nonlinear deformation of rocks, including rocks containing cracks, within the same basic theoretical framework. 
Results: Through a combination of theoretical and experimental work, we have achieved a new level of understanding of the importance of microstructure to the physical properties of rocks and how various theoretical methods contain implicit assumptions about microstructure that must be matched appropriately to rock fabric before good predictions can be made. We have also shown how to improve agreement between theory and experiment in nominally two component composites by carefully taking into account small amounts of porosity (less than one percent by volume) that have often been ignored, yet are sufficient to create serious discrepancies between theory and experiment. The resulting three component theoretical analyses are easy to do and produce sensible results. In collaboration with a visitor on sabbatical from industry, we have begun de- veloping a new theory of the elastic behavior of granular materials and/or cracked materials under uniaxial stress and have discovered that in some common situations, although the resulting constants are transversely isotropic as expected, there are only four independent constants rather than the five normally anticipated. In collaboration with researchers at Princeton and New York University, we have also developed a method for obtaining rigorous bounds on the shear modulus of viscoelastic composites such as rocks that contain mixtures of two viscoelastic constituents. This work extends and completes the previous work of the collaborators on the bounds for the bulk modulus of viscoelastic composites, and furthermore shows how well various realizable theoretical models produce results consistent with the bounds.

\section{F. Basic Research on Nonlinear Elastic Phenomena in Rock (B. P. Bonner 1510-422-7080; Fax 510-423-1057; E-mail bonner1@llnl.gov]; joint research with T.J. Shankland and P. A. Johnson, LANL, and T. V. McEvilly and L. Myer, LBL)}

Objective: As rocks are loaded by finite stresses, their mechanical response can no longer be approximated by a linear relation-Hooke's law. The objective of this project is to determine the conditions, e.g., rock morphology, strain amplitude, and fluid saturation, etc., which control the magnitude of the nonlinear response at low frequencies, and thus determine if nonlinear effects can be exploited for seismic applications such as rock mass characterization, strong motion and advanced imaging methods.

Project Description: This project is part of an integrated theoretical and experimental effort directed at quantifying and modeling nonlinear response under conditions relevant near the earth's surface. It is well known that features of the microstructure, including pores, macro and micro fractures, and the composition and position of pore fluid phases control rock properties such as seismic velocity, shear strength, and permeability. Little is known about how rock responds to moderate stress at seismic frequencies. This component of the project makes use of a unique laboratory appara tus, a torsional oscillator, to apply moderate stresses to rock samples to determine how the low frequency nonlinear response and microstructural characteristics are related. The nonlinear response in shear is determined by measuring the amplitude dependence of the shear modulus and attenuation and vibration distortion caused by the nonlinear sample. These fundamental laboratory experiments should lead to several applications, including improved simulations of the strong motions associated with explosions and earthquakes, new methods of rock characterization using finite amplitude seismic sources and the possibility of a low frequency, directed source created by nonlinear wave mixing. Such a source would be useful in boreholes and would be ideal for imaging with seismic tomography.

Results: Previous measurements demonstrated that strong nonlinear effects occur in rock with internal discontinuities ranging in scale from macroscopic fractures to microcracks. Additional torsional measurements are being made to characterize nonlinear shear response for a variety of rocks ranging from a highly indurated, low porosity graywacke form the Geysers geothermal field to porous sandstones with permeabilities ranging from 100 to $600 \mathrm{mD}$. The objectives of the experiments are to understand the mechanisms responsible for the observations and to evaluate the generality of the results. Results currently available identify two micromechanical mechanisms that contribute to the observed nonlinear effects. Partial slip along open, internal microfractures causes the shear compliance to become strain dependent, producing a nonlinearity in 
nominally dry rocks. At least in fractured rock, evidence for the partial slip nonlinearity persists to strains near $10^{-7}$, although the effects are small, requiring particular care in the measurement. The second type of nonlinearity seen in shear at low frequencies occurs when water vapor is allowed to condense onto internal pore surfaces. This nonlinearity generally overshadows that observed in nominally dry rocks, and has several distinguishing features. For example, for both granite and sandstone, nonlinear attenuation reaches a limiting value at strains near $10^{-5}$, and then decreases. Harmonic distortion increases monotonically, demon- strating that energy is transferred to parasitic vibrations at harmonic frequencies of the driving stress. The details of the underlying process are as yet unknown, but mechanisms now being considered include modification of partial slip, stretching and breaking of fluid films, and movement of contact lines between liquid, gas and solid phases. The material model that includes mechanical hysteresis proposed by Guyer and McCall at LANL as part of this project appears sufficiently general to describe nonlinearities caused by partial slip and adsorbed pore fluids.

\section{G. Effects of Heterogeneity on the Fracture of Rock (S. C. Blair 1510-422-6467; Fax 510- 423-1057; E-mail blair@s55.es.llnl.gov] and L.R. Myer, Lawrence Berkeley Laboratory [510-486- 6456])}

Objectives: The objective of this research is to understand how microscale (or grain scale) heterogeneity affects macroscopic mechanical behavior of rocks, and to study the process of progressive fracture of rock in compression, and evaluate the role of crack interaction in rock deformation and fracture. Moreover, this work also aims to investigate the relationship of static to dynamic moduli (in collaboration with LBL) and to characterize the role of heterogeneity at a variety of scales in fracture and the scaling properties of rocks.

Project Description: This project is concerned with simulation of rock deformation and fracture at grain and larger scales. A field theory model for rock fracture has been developed and is being used to per form two types of studies including; a parameter sensitivity analysis to determine how heterogeneity in different microscale parameters affects behavior in the simulated compression tests; and a detailed analysis of the process of fracture in a few selected trails to interrogate the macroscopic stress strain curve and determine how the macroscopic stress-strain behavior is related to the formation of cracks, and partitioning of energy in the simulation. Finally, percolation theory in being used to analyze output from the model, in order to investigate scaling relationships in fracture processes.

Results: A parameter sensitivity analysis was conducted using the field theory model to determine how variation of several independent parameters affects behavior in the simulated compression tests. Independent parameters that were explored include: site strength, site geometry, lattice type and size, confining pressure, and stress path. The dependence of model behavior on these parameters was evaluated in terms of macroscopic stress-strain behavior, ultimate strength derived from the stress-strain curve, crack patterns, and percolation threshold. Results show that the model produces realistic stress-strain curves and that ultimate strength for uniaxial simulations had a strong inverse dependence on geometric heterogeneity, but was independent of heterogeneity in site strength, and may depend on the mean site strength. This indicates that in compression macroscopic mechanical behavior is more sensitive to grain geometry than to mineralogy of grains and small changes in the amount of heterogeneity in grain geometry make a big difference in the peak strength of rock in compression. Moreover, percolation thresholds are much lower than those predicted from purely random models. Percolation threshold and peak strength decrease with increasing size, indicating that crack interaction becomes more important as size increases.

The model was also used to relate macroscopic stress-strain behavior to the formation of microcracks and to strain energy due to cracks. Analysis shows strain softening to be associated with crack extension. Two patterns of cracking were found including spa- 
tially uncorrelated, non-interacting cracks that have little effect on macroscopic deformation, and spatially correlated interacting cracks associated with extension or linking of larger cracks. These cause strain softening and large changes in crack strain energy.

CATEGORY:

Geochemistry

PERSON IN CHARGE: F. J. Ryerson

\section{A. Thermodynamic and Transport Properties of Aqueous Geochemical Systems (Joseph A. Rard [510-422-6872; Fax 510-422-0208] and Donald G. Miller [510-422-8074; Fax 510- 422-6363;E-maildmiller@llnl.gov])}

Objectives: The objectives of this project are to (1) measure precise and accurate osmotic/activity coefficients, densities, and Fickian diffusion coefficients for aqueous brine salts and their mixtures and osmotic activity coefficients for sulfuric acid and acidic sulfate mixtures; (2) develop reliable methods to estimate such properties for multicomponent solutions from binary solution properties; and (3) calculate generalized transport coefficients.

Project Description: The general techniques of classical thermodynamics and of linear irreversible thermodynamics are being used to understand and model equilibrium and transport processes in brines and other aqueous electrolyte mixtures relevant to en ergy programs. Being measured are osmotic/activity coefficients and solubilities by the isopiestic method, densities by pycnometry, and diffusion coefficients by use of Rayleigh and Gouy interferometry.

One goal is to measure highly accurate data of the above types for systems directly related to geochemical brines, radioactive waste isolation, and environmental pollutants. A second goal is to develop estimation methods for accurate predictions of these properties for aqueous electrolyte solutions of arbitrary complexity, using the accurate new data as test systems. Transport data are being analyzed as Onsager transport coefficients and osmotic/activity coefficients with extended Pitzer's equations, both of which should be capable of yielding reliable estimates for mixed electrolytes.
Results: A new plate reader was built for reading the photographic records of diffusion experiments, and it was automated with the help of Dr. Manfred Zeidler, Jr. and Prof. John Albright of Texas Christian University. Diffusion experiments were completed for aqueous $\mathrm{K}_{2} \mathrm{SO}_{4}$ at $25^{\circ} \mathrm{C}$ using the high-precision Gosting Diffusiometer at Texas Christian University. Twenty one experiments were performed from 0.005 to $0.62 \mathrm{~mol} \cdot \mathrm{kg}^{-1}$ (near saturation), and about half of them have already been analyzed with the automated plate reader. Densities were also measured.

Isopiestic experiments were performed at $25^{\circ} \mathrm{C}$ for aqueous $\mathrm{CaCl}_{2}$ solutions up to about 9 mol.kg-1, which is about $1.5 \mathrm{~mol} \mathrm{~kg}^{-1}$ above saturation, and for low molalities of $\mathrm{H}_{2} \mathrm{SO}_{4}$. Isopiestic measurements a $25^{\circ} \mathrm{C}$ were also performed for aqueous mixtures of $\mathrm{H}_{2} \mathrm{SO}_{4}+\mathrm{MgSO}_{4}$ at three fixed molality ratios in the acid-rich region; 54 data points have now been measured, which cover the water activity range of $0.7462 \leq$ $a_{w} \leq 0.8850$. These experiments are continuing.

A major effort was made in writing papers for publication in joumals. During this period four were published and five more were submitted for publication, one of which is in press. These include the last of the experimental diffusion studies on the $\mathrm{NaCl}+\mathrm{MgCl}_{2}$ system at $25^{\circ} \mathrm{C}$ and the first at $35^{\circ} \mathrm{C}$, a comprehensive analysis of the thermodynamics of aqueous $\mathrm{H}_{2} \mathrm{SO}_{4}$ from 0 to $55^{\circ} \mathrm{C}$, and other papers on transport properties and thermodynamics of aqueous electrolytes. 


\section{B. Experimental Determination of Mineralogical Controls on U-Th-Pb Redistribution: Implications for Crust/Mantle Differentiation (H.F. Shaw 1510-423-4645; Fax 510-423-1057; E-mail shaw4@llnl.gov] and F.J.Ryerson [510-422-6170; Fax 510-422-1002; E-mail ryerson@s91.es.llnl.gov])}

Objectives: The objective of this work is to determine mineral/aqueous fluid and mineral/silicate liquid partition coefficients for a suite of trace elements (U, Th, Hf, $\mathrm{Zr}, \mathrm{Nb}, \mathrm{Ta}, \mathrm{Sr}, \mathrm{Ba}, \mathrm{Rb}$, and $\mathrm{Pb}$ ) under conditions relevant to fluid metasomatism and partial melting in the upper mantle. The results of the project will provide important constraints on the petrogenetic interpretation of trace element, $\mathrm{U}-\mathrm{Th}-\mathrm{Pb}$, and $U$-series disequilibrium data obtained on igneous rocks, particularly those formed in subduction-zone environments.

Project Description: Along with the formation of the earth's core, the differentiation of the crust and mantle represents the major chemical fractionation process occurring on the earth. The nature of this process has been constrained by a wide variety of trace element and isotopic analyses of crust- and mantle derived samples. Effective utilization of these data requires a quantitative understanding of the fractionation of the elements of interest between minerals and both silicate melts and aqueous fluids. For many elements, however, the relevant mineral/melt partition coefficients are poorly known and there is an almost complete lack of data for the partitioning of trace elements between minerals and aqueous fluids. The experimental data generated in this project will provide quantitative information of the partitioning of trace elements of geologic interest between minerals and melts and aqueous fluids, with emphasis on the partitioning of $\mathrm{U}, \mathrm{Th}, \mathrm{Pb}$, and the high field strength elements ( $\mathrm{Zr}, \mathrm{Hf}, \mathrm{Nb}, \mathrm{Ta}$ ). Partition coefficients for elements of interest are being obtained as a function of $\mathrm{fO}_{2}, \mathrm{~T}, \mathrm{P}$ and fluid or melt composition. Experimental charges are produced using standard and newly developed techniques that utilize one-atmosphere gas-mixing furnaces and high-pressure piston-cylinder devices. The trace element composition of the charges is being measured primarily by quantitative ion microprobe techniques, supplemented by electron microprobe analyses and solid-source mass spectrometry.

Results: The partitioning of $\mathrm{U}, \mathrm{Th}, \mathrm{Pb}, \mathrm{Ba}, \mathrm{Sr}, \mathrm{Nb}$ and $\mathrm{Ta}$ between aqueous fluids (with and without added $\mathrm{Cl}^{-}$and $\mathrm{CO}_{3}{ }^{2-}$ ) and rutile, clinopyroxene, or thopyroxene, pyrope, olivine, and párgasitic amphi- bole under upper mantle conditions has been studied. Using these data, together with literature data for $\mathrm{Sr}$ and $\mathrm{Pb}$ isotopic compositions of Pacific island arc basalts (IABs), the calculated composition of a fluid in equilibrium with the average Pacific IAB source is ${ }^{87} \mathrm{Sr} /{ }^{86} \mathrm{Sr}=0.7036,{ }^{207} \mathrm{~Pb} /{ }^{204} \mathrm{~Pb}=15.57, \mathrm{Sr} \sim 500 \mathrm{ppm}$ and $\mathrm{Pb} \sim 30 \mathrm{ppm}$. The subarc fluid composition is consistent with a mixture of fluids from both altered MORB ( $\sim 96 \mathrm{wt} \%)$ and sediment ( $\sim \mathrm{wt} \%)$, with $\sim 96 \%$ of the $\mathrm{Sr}$ from the former, and $\sim 70 \%$ of the $\mathrm{Pb}$ from the latter. Although the mass fraction of sediment-derived fluid in the subarc fluid may be minor, sedimentary input for $\mathrm{Ba}(0-50 \%)$, Th $(53-88 \%), \mathrm{U}$ (61-83\%), in addition to $\mathrm{Pb}$, can be significant. Our results are consistent with, and provide additional support for models of slab input to IAB sources. Preliminary results indicate that metasomatism by water-rich fluids and silicate melts will produce similar, but distinguishable trace element signatures in island-arc basalts (IABs).

Experiments were conducted to determine partition coefficients for $\mathrm{Ti}, \mathrm{Rb}, \mathrm{Ba}, \mathrm{Sr}, \mathrm{Zr}, \mathrm{Nb}, \mathrm{Ta}, \mathrm{Hf}, \mathrm{Pb}$, $\mathrm{U}$, and Th between pargasitic amphibole and a synthetic hydrous silicate liquid. $\mathrm{Rb}, \mathrm{Ba}, \mathrm{Nb}$, and $\mathrm{Ta}$ are dramatically less compatible in pyroxene than in amphibole, while other elements, such as Th, U, Hf, and $\mathrm{Zr}$, have similar compatibilities. Because of these differences, liquids produced by small degrees of partial melting of amphibole-bearing mantle sources, or by high-level fractionation of amphibole, should have distinctively lower Th-normalized $\mathrm{Rb}, \mathrm{Ba}, \mathrm{Nb}$, and $\mathrm{Ta}$ concentrations than melts from amphibole-free systems.

Using mineral-melt partition coefficients determined in this project, the isotopic evolution of the uranium-series nuclides ${ }^{238} \mathrm{U},{ }^{230} \mathrm{Th},{ }^{226} \mathrm{Ra}$, and ${ }^{231} \mathrm{~Pa}$ during partial melting in an ascending column of mantle was modeled. The observed $\left[{ }^{230} \mathrm{Th}\right]$ and [231 $\mathrm{Pa}$ ] excesses in e-MORB and n-MORB can be generated by initiating melting in the gamet stability field at varying depths, and these excesses can be preserved during equilibrium transport of the melt at geologically reasonable rates through the overlying spinel lherzolite. 


\section{Compositional Kinetic Modeling of Oil and Gas Formation (Alan K. Burnham [510-422- 7304; Fax 510-422-3118])}

Objectives: The overall objective of the project is to develop and test models of petroleum generation, migration, and thermal stability. The ultimate goal of this work is to reduce the cost of petroleum exploration and production by improving the reliability of integrated basin analysis, a modeling technique that incorporates many aspects of geology, geophysics, geochemistry, and hydrology to determine when and where oil is generated, migrates, and accumulates.

Project Description: Oil and gas generation kinetics and oil destruction kinetics are measured by a variety of experimental techniques, including isothermal hydrous pyrolysis, temperature-programmed py rolysis using various detectors, and sealed capillary tube pyrolysis. An increasing portion of the effort is directed to the kinetics of oil cracking to understand the floor for oil survival and formation mechanisms of natural gas. Mathematical techniques and computer programs of varying complexity are being developed to predict oil and gas generation, including the effects of maturation on oil composition, and expulsion of the oil from the source rock. The computational approaches are tested against geological data. Reliable modeling can improve oil exploration efficiency, and technology transfer is an important part of this work.
Results: Two significant accomplishments during the past year were the development of an appropriate kinetic model for well-preserved, homogeneous algal kerogens and the measurement of the rate constant of isotopically labeled hexadecane in hexadecane and three dissimilar oils.

Previous work had shown that the conversion of some algal kerogens to oil and gas did not follow either a first-order or parallel reaction model but was consistent in some respects with a serial reaction model. Further experiments and kinetic analysis development during the past year showed that the serial reaction model did not satisfy all observed results for both constant heating rate and isothermal pyrolysis conditions, but a simple nucleation model did. A new version of the KINETICS analysis code that included the nucleation model was released.

Previous efforts to develop composition kinetic models of oil cracking have been limited by insufficient data showing the fate of different types of oil components within a complex matrix. We conceived and demonstrated a new isotopic method based on adjacent C-13 labels for measuring the cracking rate of compounds doped at low levels into whole oils. The first major result from this method is that rate of hexadecane destruction is nearly equal in three dissimilar oils but only $60 \%$ as fast as in neat hexadecane. 
CONTRACTOR:

CONTRACT:

CATEGORY:
LOS ALAMOS NATIONAL LABORATORY

University of California

Los Alamos, New Mexico 87545

W-7405-ENG-36

Geophysics and Earth Dynamics

\section{PERSON IN CHARGE: \\ M. Fehler}

\section{A. Imaging of Reservoirs and Fracture Systems Using Microearthquakes Induced by Hydraulic Injections (L. House [505-667-1912; Fax 505-667-8487; E-mail house@lanl.gov] and M. Fehler)}

Objectives: This work aims to characterize and image hydraulically fractured rock volumes using arrival times and waveforms of microearthquakes induced by the fracturing.

Project Description: In spite of the extensive use of hydraulic fracturing by the oil and gas and geothermal industries, the fluid paths created by the fracturing are usually not well known. That information is crucial, however, for most effectively exploiting the fractured reservoirs. Hypocenters of the induced microearthquakes give some information about the fluid paths, but do not provide the spatial resolution or amount of detail that are needed.

This study is developing methods of analysis to extract more information about the fluid system created by hydraulic fracturing from the arrival times and waveforms of microearthquakes induced by the fracturing. Microearthquakes are much more energetic sources, particularly for shear waves, than the artificial sources used in active experiments. Moreover, because they are distributed throughout the rock volume that is to be interrogated, they provide better resolution of the rock properties than would be possible with antificial sources.

Two principal analysis methods are used. First is a velocity tomography approach that simultaneously determines a three-dimensional velocity structure and new hypocenters for the earthquakes. The creation of fluid paths within the rock will decrease both the compressional and the shear wave velocities within the fracture system, but particularly the shear wave velocity. The velocity tomography is intended to identify these changes. Second, conspicuous secondary seismic phases that arrive after the direct $P$ and $S$ waves provide the information needed to identify and locate features in the rock that scatter seismic waves effectively. These features are presumed to be major fluid pathways.

Results: Recent new results from this work include improved imaging of scatterers in crystalline rock, derived from improvements in both methodology and data analysis. Improvement to the methodology has been to fully integrate the three-dimensional, time-varying velocity structure derived from the velocity tomography into the imaging analysis. The imaging uses diffraction stacking (summation) to migrate secondary arrivals and image the scatterers that produced them. Imaging of the scatterers depends critically on correctly calculating travel times between the microearthquake hypocenters, the scatterers, and the recording instrument. Using the time-varying three-dimensional velocity structure has yielded images of seismic scatterers that are simpler, and more spatially focused than previous images. These images are more easily interpreted than the diffuse images obtained previously, and are more physically credible. Smaller but still significant improvements have been obtained by recalculating the hypocenters of the microearthquakes using the velocity structure from the velocity tomography, and more precisely picked arrival times from the microearthquakes.

Small amounts of seismic anisotropy were esti- 
mated from well log data and shown to able to account for large travel time anomalies calculated for some sta tions by the velocity tomography. The data available are inadequate to fully constrain the amount of anisotropy. Yet, even slight anisotropy can have a dramatic effect on seismic velocities and travel times, and that anisotropy may have to be taken account of in the imaging analysis.

In addition a new, high quality microearthquake data set was collected from hydraulic fracturing in sed- imentary rock. This hydraulic fracturing was done in collaboration with an oil and gas company and should be suitable for analysis by both the velocity tomography and the imaging of scatterers to yield insight into the internal structure of the fracture system. The high quality of the data acquired from this experiment and the fact that it was done in a sedimentary strata make analysis of this data set particularly pertinent to the hydraulic fracturing done by the oil and gas industry.

\section{B. The Role of Carbon and Temperature in Determining Electrical Conductivity of Basins, Crust, and Mantle (T. J. Shankland 1505-667-4907; Fax 505-667-8487; E-mail shankland@ seismo5.lanl.gov]; joint research with A.G.Duba, LLNL)}

Objectives: The intent of this work is to compre hend the electrical conduction mechanisms in carbonbearing rocks and in mantle minerals for the purpose of relating electrical conductivity $(\sigma)$ measured in the field to formation conditions and existing state of crustal rocks and to temperatures in the mantle.

Project Description: Electrical conductivity de pends strongly on temperature $T$ and on the presence of other phases such carbon, fluids, or ore minerals at the lower temperatures of the crust and basins. Thus, one research approach is to measure $\sigma$ of mantle minerals as functions of temperature, orientation, oxygen fugacity $\mathrm{fO}_{2}$, and iron content. These data supply the best models for "electrogeotherms" yet available. Another approach is to document textures of carbon in crustal rocks from basins and metamorphic zones and relate them to rock conductivity. In this case texture of carbon distribution is mapped with electron microscopy in the same samples used for conductivity measurement.

Results: The accepted hypothesis that electrical conductivity of saturated crustal rocks decreases with pressure is not necessarily true. Conductivities of fresh drill cores from the German deep-drilling project show a remarkable increase with pressure even as conducting fluids are squeezed out. In these rocks solid grainboundary phases suffered minimal weathering or oxida- tion because they were measured soon after recovery at the surface. [In contrast, specimens from outcrops have their solid-phase connections broken by pressure and temperature release as well as chemical alteration during normal uplift, and their conductivities show the usual decrease with pressure.] In the case of the German rocks, the oxide ilmenite was identified as a grain boundary phase. In addition, we discovered trace amounts of carbon in the cleavages in amphiboles (the major mineral phase in these rocks) that could serve as a bridge between ilmenite grains. Thus, a combined effect involving ilmenite grains plus carbon films on amphibole cleavage surfaces is implicated in the "anomalous pressure effect" that is increasingly identified with the presence of solid phase conductors.

Another positive pressure effect is found in rocks from the Yukon-Tanana Terrane near the Denali Fault Zone in Alaska. Here the good conductor responsible for the effect is seen to be grain boundary carbon that probably resulted from metamorphic processes associated with thrust faulting of new terranes. Because there is an extensive region of high conductivity in a zone extending over several hundred kilometers with depth varying from 5 to $25 \mathrm{~km}$, a possible scientific drilling target for evaluation of hydrocarbon potential may be indicated. 


\section{Basic Research on Nonlinear Elastic Phenomena in Rock (P. A. Johnson [505-667-8936; Fax 505-667-8487; E-mail johnson@ cuzco.lanl.gov] and T.J. Shankland; joint research with B. Bonner, LLNL, and T. McEvilly and L. Myer, LBL)}

Objectives: Research objectives are first, investigate the physical manifestations of nonlinear elasticity, including those indicating reservoir/repository characteristics and those affecting seismic observations; second, characterize nonlinear properties of rocks; and third, study the possibility of developing a low frequency, directed source by nonlinear elastic wave mixing of two primary frequency waves.

Project Description: Because rocks contain easily compress microstructure such as cracks and grain junctions, they display strong elastic nonlinearity. Our approach is to use this feature to examine new classes of geophysical phenomena. Experimentally we examine spectral band shifts and production of harmonics by propagating waves, resonant frequency shifts caused by the large strains possible in bar resonance, and torsional harmonics (LLNL). Materials studied include the crystalline rocks basalt and granite as well as the model reservoir rock Berea sandstone. For each experiment we have been developing theories describing effects of crack density, fluid content, stress-strain hysteresis, and anisotropy on nonlinear interactions; there is emphasis on the effects of different kinds of nonlinearity on wave propagation. There is cooperation with LBL on field experiments employing vibratory sources.

Results: We previously demonstrated that pure tone signals generate harmonics progressively along the wave propagation path in rock at strain levels as low as $10^{-7}$. The experiments confirmed predictions from nonlinear elasticity theory that the second harmonic amplitude grows linearly with propagation distance, with the square of the input frequency, and with the square of the fundamental amplitude. For a signal having a broad frequency distribution, the distribution flattened with wave propagation distance due to creation of harmonic, sum, and difference frequencies, as confirmed by Green's function theoretical studies. Flattening increased the apparent high frequency rolloff significantly. Thus, large shifts of spectral content mean that seismic frequency content observed in the far field may not represent the true character of a source. Other wave propagation studies in sandstone show that amplitudes of cubic nonlinear intermodulation frequencies such as $\left(2 f_{1}-f_{2}\right)$ progressively grow with dis tance. The difference frequency has been more elusive, due in part to velocity dispersion in the bar and in part to strong cubic nonlinearity in rocks.

The fundamental (Young's) mode resonant peak in a bar of rock can reveal nonlinear moduli at high excitation levels. In all rock samples resonant frequencies (and thus the moduli) shift downward with increasing drive amplitude indicating "softening" nonlinearity. In extreme cases the frequency drops by as much as $25 \%$ over a strain interval of approximately $10^{-7}$ to $4 \times 10^{-5}$. We have now derived a full nonlinear elastic description of the nonlinear resonance that includes both quadratic and cubic nonlinearity.

\section{Tracer Tomography in Geological Reservoirs (David R. Janecky [505-665-0253; Fax 505- 665-4955; E-mail janecky@lanl.gov] and W.Dale Spall [505-667-2772])}

Objectives: This project is developing approaches to evaluate large-scale porous flow heterogeneities and integrated chemical processes by focusing on multicomponent injected tracers, coupled with detailed characterization of natural chemical compositional variability in space and time. Coupled processes of interest include spatially distributed flow, dispersion, sorption, partitioning, displacement, and chemical reactions. Applications and basic geochemical information tailored to petroleum reservoir, geothermal, and environmental systems are being developed in consultation with industry.

Project Description: New classes of conservative and reactive nonradioactive organic tracers for both laboratory and field experiments are being defined and tested using stable isotopic labeling schemes. Laboratory experiments, including chromatography and core floods, provide basic geochemical information in 
well-constrained systems, which isolate aspects of natural processes for evaluating and quantifying flow and reaction processes.

Interpretation of multicomponent tracer information in a consistent, integrated framework requires integration of computational models, including classical and non-equilibrium thermodynamics chromatographic models, coupled fracture and matrix permeability models, lattice gas automata models, and large-scale hydrologic models.

Results: Development of labeled organic compounds focused initially on use of deuterium. Working with industry, commercial sources are been developed for relatively large amounts of isotopically labeled compounds. A range of labeled compounds are on hand for laboratory experiments and relative large quantities of labeled compounds have been utilized for experiments by an industrial collaborator. The choice of stable isotope labeled organic molecules as tracers provides significant advantages in simultaneous multicom - ponent analysis; however, it also requires a commensurate emphasis in complex analytical methods. Development of GC/MS analyses for environmental samples and expertise developed through analytical work for oil shale processing programs, along with continuously improving analytical equipment, has been combined to successfully complete analyses of labeled organic compounds in gas and liquid petroleum matrices, in addition to water.

Detailed evaluation of our initial multicomponent tracer experiment below the Mammoth Terraces in Yellowstone National Park indicates general consistency between a range of simple tracers as a function of the first acid dissociation constants. Laboratory HPLC experiments are providing information on processes that produce complex peak shapes, similar to some found in the field experiment. In collaboration with Mobil Exploration \& Producing, US, a multicomponent tracer experiment was initiated in a petroleum reservoir.

\section{CATEGORY: Geochemistry}

PERSON IN CHARGE: D. Janecky

\section{A. ${ }^{230} \mathrm{Th}-{ }^{238} \mathrm{U}$ Disequilibrium in Geologic Systems Using Solid Source Mass Spectrometry (M. T. Murrell I505-667-4299; Fax 505-665-4955; E-mail 099691@INCDP3 LANL.GOV], K.W.W. Sims, D. A. Pickett, and S. J. Goldstein)}

Objectives: The goals of this project are to use uranium-series disequilibria to provide improved capabilities for Quaternary dating and to provide unique information on the rate of magma generation and transport in the mantle.

Project Description: Previously, we have developed mass spectrometric methods for measuring ${ }^{230} \mathrm{Th} /{ }^{238} \mathrm{U},{ }^{226} \mathrm{Ra} /{ }^{230} \mathrm{Th}$, and ${ }^{231} \mathrm{~Pa} /{ }^{235} \mathrm{U}$ disequilibrium which have significant advantages over decay counting methods. Current emphasis is on using these techniques to better understand the causes and extent of $\mathrm{U}-\mathrm{Th}-\mathrm{Pa}$ fractionation during basalt petrogenesis. If it can be shown that these fractionations are a result of the melt generation and segregation processes (and not some secondary process such as volatile exsolution or melt/fluid interaction) then measurement of $\mathrm{U}$ - disequilibria in young volcanic rocks can provide unique and important constraints on melting in the mantle. These issues are critical to understanding the mechanisms that control dynamic geologic processes, such as the formation of the Earth's crust and in evaluating geologic hazards associated with volcanism.

Results: To investigate the causes of U/Th fractionation during basalt petrogenesis, precise U-Th and $\mathrm{Sm}-\mathrm{Nd}$ isotopic ratios and concentrations were measured in a series of systematic lavas, from Hawaii and the mid-ocean ridge, which have trace-element and petrological characteristics indicating that they span a large range of melt fraction. U/Th fractionation is compared with the samples major-element chemistry and in- 
ferred $\mathrm{Sm} / \mathrm{Nd}$ fractionation. The results show that U/Th fractionation for Hawaiian lavas, as inferred from ${ }^{230} \mathrm{Th} /{ }^{232} \mathrm{Th}-{ }^{238} \mathrm{U} /{ }^{232} \mathrm{Th}$ isotopic ratios, is corre lated in the expected fashion with $\mathrm{Sm} / \mathrm{Nd}$ fractionation and with other petrological parameters that are sensitive to melt fraction variations. U/Th fractionation can be understood in terms of simple (batch) melting models and reasonable melt fractions $(0.25 \%$ to $5 \%)$ under Hawaii. New data on MORB confirm that they are much more fractionated than Hawaiian lavas, and thus a special process operates under mid-ocean ridges to enhance the fractionation of $U$ from $T h$. We have also measured ${ }^{235} \mathrm{U}-231 \mathrm{~Pa}$ disequilibrium in a wide variety of rock types and find $\mathrm{Pa}$ enrichment to be the general rule. A general correspondence between the ${ }^{235} \mathrm{U}-$ ${ }^{231} \mathrm{~Pa}$ data and that for U-Th disequilibrium supports the idea that such enrichments are also a result of melting and/or melt transport process. The ${ }^{235} \mathrm{U}-{ }^{231} \mathrm{~Pa}$ system hold great promise for future studies of volcanic rocks because it is more sensitive to magmatic processes than $T h / U$ and decays away less rapidly than $\mathrm{Ra} / \mathrm{Th}$ :

\section{B . Geochemistry of Technetium (D. B. Curtis [505-667-4845; Fax 505-665-4955; E-mail dcurtis@LANL.gov],P.R.Dixon,J.T.Fabryka-Martin, and D.J.Rokop)}

Objectives: The objective of this project is to develop and use methodologies that utilize radioactive nuclides, produced by natural nuclear processes in rocks and minerals, to study fission product and actinide release, transport, and secondary retention processes in the geologic environment.

Project Description: Many radionuclides exist naturally solely as a result of production by nuclear processes. Because of their mode of production, they exist in nature in very low abundances. Some of these nuclides, such as ${ }^{99} \mathrm{Tc}$ and ${ }^{239} \mathrm{Pu}$, are the only naturally occurring isotopes of these elements and thus provide the opportunity to obtain unique information regarding the geochemical behavior of rare elements. We have developed methods to of measure abundances of these natural nuclear products. Our techniques for measuring ${ }^{99} \mathrm{Tc}$ allow us to maintain blank levels at $6 \times 10^{-15} \mathrm{~g}$, and detection limits of $1.5 \times 10^{-14} \mathrm{~g}$. We are able to reproduce a measured mass of $5.62 \times 10^{-13}$ ${ }^{99} \mathrm{Tc}$ with a precision of $1.5 \%$ in replicate analyses of uranium ore standard. Measured ${ }^{99} \mathrm{Tc}$ abundance in the standard ore is within the range of concentrations maintained by equilibrium nuclear processes. We interpret this as a measure of accuracy, our results representing less than $20 \%$ deviation from the actual ${ }^{99} \mathrm{Tc}$ abundance in this sample. Because these nuclides have mean radioactive lifetimes of $10^{4}$ to $10^{5}$ years, studies of their geochemistry characterize the effects of geolog ically modern processes on element transport and retention. Concentrations of the radionuclides are measured in groundwater, rocks, and minerals. These re - sults are integrated into an understanding of mass transport processes using interpretative tools provided by models of nuclide production, geochemical speciation and solubility, and mass transport. Information produced by the work is used to support assessments of conformance of designs of geologic radioactive waste repositories to long-term performance objectives.

Results: The uranium deposit at Cigar Lake represents the largest uranium reserve in the world. It is 450 $m$ below the surface of the Athabasca Sandstone in the northern region of the Canadian province of Saskatchewan. The ore is a compact feature found at the unconformity between the Proterozoic sandstone and underlying metamorphic basement rock. Average uranium content of the ore is $8 \%$ uranium, with zones of extreme enrichment up to $55 \%$. This highly enriched rock is enclosed in a clay-rich matrix which is in-turn surrounded by a "quartz-rich" halo. Uranium minerals are predominantly oxides of reduced uranium with minor occurrences of the silicate mineral coffinite. Uranium minerals appear to have suffered little alteration since hydrothermal processes ceased on the order of $10^{9}$ years ago.

The clay-rich matrix and halo surrounding the uranium mineralization are believed to play an important role in the long-term preservation of the uranium ore zone. The clay-rich rocks have relatively low hydraulic conductivities. Water in the overlying aquifer is effectively diverted over and around the relatively impermeable ore. In addition the clay-rich rocks are enriched in iron sulfides producing redox buffered waters in which 
uranium bearing minerals are very poorly soluble. In the extremely uranium-rich rock at Cigar Lake, measurable quantities of technetium are produced by natural nuclear reactions. The natural fission product is produced within uranium minerals, which serve as the primary host. In an undisturbed system, in which tech netium remains within its primary host phase, the rela tive abundances of technetium and its parent element uranium are limited to a well defined range. Abundances that differ from this range are the result of processes the have enriched or depleted one of these elements relative to the other.

In the apparently benign physiochemical system at Cigar Lake, we see the results of processes, operative within the last $10^{6}$ years, that have released technetium from its primary host, transported it over distances, and retained it within secondary host phases. In the most uraniferous samples, technetium deficiencies are small to undetectable, providing the means to establish upper limits on technetium release rates of the order of $10^{-6}$ $\mathrm{yr}^{-1}$. Rates of this magnitude manifest highly preferential release of technetium relative to uranium from their host minerals. Two to ten times enrichments of technetium are found in samples from within the ore zone containing smaller uranium concentrations. These technetium enrichments appear to be highly localized. In the highly reduced environment of the Cigar Lake deposit, technetium retention might be facilitated by coprecipitation with sulfide minerals, or retained by sorption onto mineral surfaces.

Similar studies of plutonium at Cigar Lake have thus far shown no unambiguous evidence of the relatively dynamic geochemical behavior shown by technetium.

\section{Dating Young Surfaces Using Cosmogenic He and Ne (Jane Poths [505-665-2636; Fax 505-665-6637;E-mailJPOTHS@LANL.GOV])}

Objectives: To understand quantitatively the processes affecting use of cosmogenic noble gases a chronometers for dating young $(<0.5 \mathrm{Ma})$ surfaces.

Project Description: Geomorphic surfaces start accumulating cosmogenic $\mathrm{He}$ and $\mathrm{Ne}$ once they are created, e.g., by flood or volcanic eruption. The concentrations of cosmogenic $\mathrm{He}$ and $\mathrm{Ne}$ can be determined by ultra-sensitive mass spectrometry, providing the ages of such events. We are determining the conditions under which the assumptions inherent in this new technique are satisfied. This testing is being performed on surfaces in the arid Southwestem U.S. formed by two processes: lava flows ( 3 to $250 \mathrm{ka}$ ) and paleoshorelines. Our approach includes: (1) comparison with dates from other experimental techniques, (2) use of in situ cosmogenic ${ }^{14} \mathrm{C}$ to monitor erosion, (3) determining reproducibility for multiple samples from a single surface, and (4) use of $\mathrm{He} / \mathrm{Ne}$ ratios to identify additional components and check for gas loss. These results will provide the timescale for geochemical evolution of volcanic fields, and the timing of climatic events recorded by lake highstands.
Results: Effort has focused on cross calibration between ${ }^{3} \mathrm{He}$ surface exposure dates and those from other techniques. Encouragingly, ${ }^{3} \mathrm{He}$ and $\mathrm{Ar}-\mathrm{Ar}$ dating of lava flows shows good agreement for some of our samples ( 50 to $250 \mathrm{ka}$ ). It is also evident from our work that magmatic "excess" ${ }^{40} \mathrm{Ar}$ is widespread in olivine from young lavas, and might be affecting other, discrepant Ar ages. Seven out of nine volcanic fields examined contain this excess ${ }^{40} \mathrm{Ar}$. Cross calibration between ${ }^{3} \mathrm{He}$ and cosmogenic ${ }^{36} \mathrm{Cl}$ surface exposure ages shows agreement $<20 \mathrm{ka}$, but discrepancies a older dates. In one case in question, the helium date agrees with a date based on U-Th disequilibrium. In an effort to find an independent method of evaluating surface preservation, the trapped noble gases have been measured in a depth profile from the McCartys ( $3 \mathrm{ka}$ ) lava flow. Although the ${ }^{40} \mathrm{Ar}^{*} / 20 \mathrm{Ne}$ ratio increases with depth, the correlation is not pronounced enough to give a useful marker of depth below the surface. Cosmogenic noble gases from samples of a Lake Tecopa (Califormia) shoreline provide an upper limit of $150 \mathrm{ka}$ for the timing of the lake highstand. The combination of cosmogenic $\mathrm{He}$ and $\mathrm{Ne}$ has proven invaluable in deconvoluting the noble gas signature in these samples. 


\section{A Search for Evidence of Large Comet or Asteroid Impacts at Extinction Boundaries (M. Attrep, Jr. [505-667-0088; Fax 505-665-4955; E-mail mattrep@lanl.gov])}

Objectives: Objectives of this investigation are to identify chemical signatures in the geological record from large-body impacts, massive volcanism, changes in sedimentation rate, reducing or oxidizing water conditions, etc., in relation to the known extinction boundaries in the fossil record. We also investigate the environmental consequences of local releases of ultrahigh amounts of energy (impacts), help establish and develop the field of chemostratigraphy, and establish geochemical time markers in the geological record.

Project Description: We had made our analytical measurements by means of neutron activation analysis using our reactor at Los Alamos. This activity has been diminished because the reactor at Los Alamos has been out of operation and appears to be so indefinitely. Meanwhile we have been irradiating our samples at the University of Missouri Research Reactor (Columbia). We use these irradiation facilities for determining the more rare elements, the platinum group elements (Ir, $\mathrm{Au}, \mathrm{Os}, \mathrm{Re}$, and $\mathrm{Pt}$ ), we use radiochemical methods. This includes the irradiation of samples in high neutron fluxes, radiochemical separation of the individual ele ment, and gamma spectrometric measurements. Our limit of detection for Ir, for example, is about one part per trillion level.

Results: Our studies over the past year have included sections of extinction zones from numerous global sites. The Cretaceous-Tertiary boundary studies in Guatamala and Montana have been completed. We are continuing analyzing samples from the melt from the Manson meteorite impact structure in lowa and sedimentation deposits in South Dakota related to the impact. To date we have not observed any iridium associated with this impact. We have finished an exten sive study of the iridium concentrations in a section in Europe at the Jurassic-Cretaceous which showed no iridium anomaly. We have also completed a Ordovician-Silurian section in Argentina. Results indicate that the iridium anomaly $(\sim 100 \mathrm{ppT})$ is observed there and coincides with the weak iridium anomaly at other global sites. A late Devonian section in the Yukon has also been analyzed.

\section{E. Direct Speciation of Metal Ions by Optical Spectroscopies (C. D. Tait [505-665-0008; Fax 505-665-3166; E-mail cdtait@lanl.gov] and D.R. Janecky)}

Objectives: To further understand the effects of organic compounds in geologic systems, temperaturedependent organic complex formation of metal cations and silicon are being spectroscopically investigated. Spectroscopic techniques are being developed that support studies of the migration and maturation of natural organic compounds forming petroleum reservoirs by interrogating individual fluid inclusions.

Project Description: Organic compounds are pervasive in geologic systems, and considerable geo chemical effects ensue from their migration and accu mulation. Migration of organic chemicals have important indirect effects such as porosity development through water-rock interaction, and the transport or sequestering of complexed metal cations, with both positive (ore deposits) or negative (hazardous mixed organic/radionuclide waste) consequences. Ultimately, these macroscopic effects depend upon the geochemistry of the system, including detailed metal and $\mathrm{Si}$ complexation by organic species under different conditions of, for instance, temperature, $\mathrm{E}_{\mathrm{h}}$, and ligand concentration. Migration and maturation of an organic source is also a key component of the diagenetic history of an oil field and must also be understood to model processes in generalized and in specific reservoirs. Realistic modeling in turn may be useful in locating new wells, and again, geochemical information on a molecular scale is required for realistic modeling. To determine the molecular-scale species information re quired for modeling of complex organic ligands and inorganic ions, spectroscopic experimental methods including UV/Vis and IR absorption, Raman scattering, luminescence, and NMR spectroscopies are important contributors. Integration of a suite of spectroscopic techniques allows the investigation of chemical speciation even in complex media or in microscopic-sized samples (i.e. fluid inclusions).

Results: Complexation experiments between 
REEs and carboxylic acids have been performed in collaboration with Dr. Scott Wood (Univ. of Idaho), and spectroscopic signatures for the low solubility $\mathrm{Nd}$ and $\mathrm{Er}$ - oxalate complexes were found using photoacoustic absorption spectroscopy. The REEs serve as models for actinide species (e.g. $\mathrm{Nd}^{3+}$ for $\mathrm{Am}^{3+}$ ) to help determine the potential mobility of radionuclides from waste sites, especially those containing mixed wastes or in sites with significant organic carbon in the soil. Raman and UV/Vis absorption spectra for a series of As-S complexes were also completed.

Significant progress has been made in adapting luminescence and Raman spectroscopies to microscopes to non-destructively study the organic species and compounds in individual fluid inclusions. To get more structure-specific luminescence data, synchronously scanned luminescence is being used. In laboratory samples, the sharp peak from perylene has been observed down to $5 \mathrm{ppm}$. In actual field samples, spectra from Guaymas Basin samples have shown individual fluid inclusions with 2-3 aromatic rings versus others with 4-5 rings, with perylene also possibly contributing. This demonstrates that spatially resolved spectra allow for different chemistries to be identified in fluid inclusions. More specific chemical identifications can be obtained with Raman spectroscopy. In contrast, Raman spectroscopy seeks to avoid luminescence as this can mask the Raman signal. Excitation in the red/near IR was utilized to avoid this luminescence. After considerable instrumental development, Raman spectra have been obtained from the aromatic breathing region of the spectrum $\left(\sim 1000 \mathrm{~cm}^{-1}\right)$ from field sam ples from the Guaymas Basin.

\section{CATEGORY: $\quad$ Solar-Terrestrial Interactions}

\section{PERSON IN CHARGE: S. Peter Gary}

\section{A. Energy Transport in Space Plasma (S. P. Gary [505-667-3807; Fax 505-665-3332; E-mail pgary@lanl.govl)}

Objectives: The long-term goal of this research is to understand the flow of plasma energy in the nearEarth space environment from a small-scale point of view. The objective of this research is to use plasma theory, simulations, and data analysis to express the consequences of plasma microinstabilities as concise relationships that may be used in large-scale models of space plasmas that describe the solar-terrestrial interaction.

Project Description: Plasma distribution functions and parameters observed by Los Alamos instru ments on scientific spacecraft as well as computer simulations developed at Los Alamos are used to carry out fundamental studies of plasma instabilities and associated transport in and near the solar wind, the Earth's bow shock, and the terrestrial magnetosphere.

Results: The most important accomplishment of this program in 1993 has been the development of upper bounds for proton temperature anisotropies in the
Earth's magnetosheath and outer magnetosphere. In both cases, linear dispersion theory was used to establish concise analytic expressions for the proton anisotropy at thresholds of the proton cyclotron instability. Then one-dimensional hybrid computer simulations were used to show that the nonlinear consequences of instability growth were to drive ion parameters toward these thresholds, so that anisotropies greater than threshold should not be observed. Proton observations from Los Alamos plasma instruments on a geosynchronous satellite have been examined and have confirmed that the theory/simulation results do indeed represent an upper bound on the hot proton temperature anisotropy in the terrestrial magnetosphere. These anisotropy limits can provide closure relations for anisotropic fluid models of solar-terrestrial plasmas, and may significantly improve the predictive accuracy of such models. 


\section{B . The Solar Wind-Magnetospheric Interaction (J. Birn [505-667-9232; Fax 505-665-3332; E-mail jbirn@lanl.gov] and E.W. Hones, Jr. [505-667-4727])}

Objectives: The goal of this research is to further the understanding of the Earth's magnetosphere, coupled to the fast-flowing solar wind plasma on the one hand and to the ionosphere on the other.

Project Description: The focus of this research is the large-scale structure and dynamics of the Earth's magnetosphere, using theory, numerical modeling, and correlative studies of data from multiple sites within and near the magnetosphere (including the Earth itself as well as scientific satellites).

Results: The major achievements in 1993 concemed discoveries about the evolution of the near magnetotail region prior to substorm onset and, in particular, the formation of a thin current sheet in that region which appears to be crucial in the initiation of substorm dynamics. Using linear perturbation theory it was shown that the formation of a singular current sheet is the direct consequence of nonuniform driving external electric fields. The presence of a thin current sheet was also included in a three-dimensional iterative approach to self-consistent equilibrium models of the inner magnetotail.

The influence of energy constraints and their release on the stability and dynamic evolution of the magnetotail was studied through linear perturbation theory and nonlinear MHD simulations. It was found that the release of the usual adiabatic or isothermal energy constraint in an isobaric model (in which the pressure stays constant in a moving plasma element) can drastically reduce stability so that the tail becomes unstable even under the ideal magnetohydrodynamic condition. The consequence of this instability is the spontaneous formation of a thin current sheet, providing a suitable model for the observed rapid current sheet formation in the late growth phase prior to substorm onset.

\section{Energetic Particle Acceleration (G. D. Reeves [505-665-3877; Fax 505-665-4414; E-mail reeves@lanl.gov])}

Objectives: The goal of this research is to develop a better understanding of the Earth's energetic particle environment near geosynchronous orbit.

Project Description: This effort concerns the analysis of data from a series of geosynchronous spacecraft which carry Los Alamos energetic particle detectors. The energies measured range from tens of $\mathrm{keV}$ to hundreds of $\mathrm{MeV}$. The lower end of this range lies somewhat above the thermal plasma energies and is therefore sensitive to local acceleration processes such as magnetospheric substorms. The higher end of the energy range is in the realm of cosmic rays and is therefore well suited to the study of energetic particles which can penetrate the Earth's magnetic field such as galactic cosmic rays and particles produced in solar flares.

Results: A significant result of 1993 involves the testing of magnetic field models using geosynchronous and low-altitude spacecraft. We compare particle spectra measured at geosynchronous orbit by Los Alamos instruments with particle spectra measured at $800 \mathrm{~km}$ altitude by the polar-orbiting DMSP spacecraft. DMSP measures different spectra at each magnetic latitude. As it crosses the magnetic latitude which is magnetically connected to geosynchronous orbit the spectra match. Sometimes this occurs where it is expected to but often the actual magnetic mapping is 5-10 degrees different than predicted. We are analyzing these matches systematically and comparing the results to several popular magnetic field models to determine the best model and to test strengths and weaknesses of those models.

A related project involves the comparison of energetic particle energization at geosynchronous orbit to auroral observations on the ground. It is now known that geosynchronous orbit is magnetically connected to the region in which auroras are commonly observed. It is often assumed that the process which energizes particles at geosynchronous orbit is the same process which energizes the particles that produce the auroras. However, this has not yet been experimentally established. In one study we found that the observations a geosynchronous orbit matched sume of the observations on the ground while some of the observations were quite disparate. We concluded that either (a) the magnetic mapping was considerably different 
( $>10 \mathrm{deg}$ ) than predicted by current models or (b) auroral and geosynchronous particle populations do not always correspond to one another.

D. Radiation from Space and Astrophysical Plasmas (G. R. Gisler [505-667-1375; Fax 505-
665-4414; E-mail gisler@sstcx1.lanl.gov])

Objectives: The goal of this research is to understand how relativistic charged particles originate in both astrophysical and Solar System plasmas, and how these energetic particles couple with background thermal plasma and electromagnetic radiation.

Project Description: This research uses magnetohydrodynamic computer simulation codes as well as plasma theory to study problems in astrophysics and space plasma physics.
Results: The most important accomplishment of 1993 came from our continued magnetohydrodynamic simulations of field-line twisted jets from protostars. One axial boundary of a cylindrical domain containing plasma and a large-scale magnetic field is set rotating. The field stress produced by the twisting accelerates matter away from the rotating disk, up to a substantial fraction of the Alfven velocity near the disk. Farther away, in the diverging field, the velocities become super-Alfvenic. A fairly well collimated, robust, magnetically confined outflow is produced. 


\section{A. Super-Resolution in Shallow Geophysics (A. J. Witten [615-574-5805; Fax 615-574-5788], A. J. Devaney, and S. Norton)}

Objectives: The objective for this project is enhanced resolution in shallow geophysical imaging, particularly for ground-penetrating radar, by the exploitation of evanescent waves (waves that exponentially decay in space, rather than propagate). These waves contain information at higher spatial frequencies than propagating waves and, thus, promise to be a means of achieving super-resolution.

Project Description: This effort seeks to invert an analytical relationship between acquired electromagnetic data and the so called "object function" that characterizes the spatial distribution of subsurface inhomogeneities. This relationship is known as the generalized projection slice theorem (GPST) and specifically relates the spatial Fourier transform of the acquired data at frequency $\omega$ to the two-dimensional spatial Fourier transform of the object function. Thus, the GPST provides a mapping of $\delta\left(K_{x}, K_{z}\right)$ into $\hat{u}(K, \omega)$, where $\hat{\theta}$ is the twodimensional spatial Fourier transform of the object function evaluated at horizontal spatial frequency $\mathrm{K}_{\mathrm{x}}=\mathrm{K}$ and vertical (depth) spatial frequency $K_{z}=\left(k^{2}-k^{2}\right)^{1 / 2}, a$ is the spatial Fourier transform with respect to measurement location of the measured data, $\boldsymbol{K}$ is the transform variable associated with this measurement location, and, for a wave speed $c_{0}, k=$ $\omega k_{0}$. For $|\alpha| \leq k$, both spatial frequency components, $\left(\mathrm{K}_{\mathrm{x}}, \mathrm{K}_{\mathrm{z}}\right)$ are real and the GPST can be inverted by standard Fourier transform methods to yield a reconstructed image of the object function. This image is a low pass filtered rendering as a result of the spatial frequency cut off $|\boldsymbol{k}| \leq k$. Eliminating this restriction serves to reduce the low pass filtering and thereby allowing greater spatial resolution that is limited, in principle, only by spatial sampling and signal to noise ratio. This potential increase in spatial resolution is referred to in this study as super-resolution. The difficulty in implementing a super-resolution signal processing algorithm is that, for $|k|>k$, the vertical spatial frequency becomes imaginary and standard Fourier inversion cannot be applied.

Results: Three approaches to super-resolution signal processing have been investigated. These are composite Fourier-singular valued decomposition (SVD) and Fourier-regularization as well as analytical continuation onto the real $\mathrm{K}_{\mathrm{z}}$ axis followed by Fourier inversion. Of these three methods, it was found that regularization was slightly superior to SVD, and both were superior to analytical continuation that exhibited instabilities with increasing target depth. Applying the selected regularization procedure to simulated data, super-resolved images were achieved. Specifically, for a target at about one-quarter wave length deep or less, the image exhibited a sharpness consistent with the spatial sampling rather than a sharpness limited by the low pass filter $|\mathrm{k}|<\mathrm{k}$. As the target becomes deeper, the imaginary part of $\mathrm{K}_{\mathrm{z}}$ becomes more negative, consequently reducing the super-resolved contribution. It was found that resolution decreased with increasing target depth and, at target depth of three-quarters of a wave length the super-resolved image was essentially identical to the conventionally resolved image.

The above described super-resolution algorithm has 
been applied to two field data sets. The first was broad band radar (200 $\mathrm{MHz}$ to $1 \mathrm{GHz}$ ) acquired over seven buried aluminum plates. Consistent with the results based on simulated data, it was found that the ratio of wave length to target depth was too small to achieve super-resolved images. The second data set considered was $25 \mathrm{MHz}$ center frequency radar data acquired over the top of the Oak Ridge National Laboratory in situ vitrification (ISV) melt. At $25 \mathrm{MHz}$, the melt zone is approximately one-half wave length deep, a situation more conducive to super-resolution. The application of the super-resolution signal processing algorithm provided an image of the melt zone that was superior to the conventional image in that it provided an improved definition of the extent of this zone, consistent with that achieved with simulated data. Within the melt zone itself, the super-resolved image exhibited a pattern of random variations in object function not evident in the conventionally reconstructed image. Currently, it is not clear if these features are real. However, it is believed that they are image artifacts associated with spatial aliasing. Work is currently proceeding on the inclusion of anti aliasing filters in the signal processing.

In addition to these results: (1) A method has been developed for determining the optimum sampling parameters to achieve a desired resolution, based upon target size, depth, and background attenuation; (2) A spatially coherent gain function has been derived to allow imaging, both conventional and super-resolved, in an attenuating background; and (3) An image enhancement method, based upon projections onto a convex set, has been developed to minimize image artifacts with spatially limited measurement geometries.

\section{CATEGORY: Geochemistry}

PERSON IN CHARGE: J. B. Ball

\section{A. Geochemistry of Crustal Processes To High Temperature and Pressure $(D . J$. Wesolowski [615-574-6903; Fax615-574-4961;E-maildqw@ornl.gov],D.R. Cole,J.C.Seitz, and J.Horita)}

Objectives: This project provides fundamental information on the geochemical processes governing the elemental and isotopic distributions in the Earth's crust. Experimental geochemical methods are used to gain a sufficient understanding of these processes for modeling the evolution of natural systems pertinent to magma/hydrothermal and hydrocarbon energy resources and the environmental aspects of energy utilization.

Project Description: Aqueous systems are investigated at temperatures ranging from 0 to $800^{\circ} \mathrm{C}$ and pressures from 1 bar to 4 kilobars with a unique array of hydrothermal facilities that permit studies of metal complexation, mineral solubilities, acid ionization, activity coefficients, and reaction kinetics. Studies of stable isotope partitioning between minerals and fluids in experimental and natural systems help delineate the mechanisms and rates of fluid-rock interactions, fluid fluxes, and paleotemperatures. A limited number of field studies of active and ancient geochemical systems are pursued in order to demonstrate applications of the results of the experimental and modeling efforts, and to help identify gaps in the ability to quantitatively model geological processes.

Results: The behavior of organic acids in natural waters may play an important role in elemental transport and permeability development/destruction in oil and gas reservoirs, aquifers, geothermal systems, and waste repositories. During this period, measurements of the dissociation constants of succinic acid $\left(0-225^{\circ} \mathrm{C}, 0-5\right.$ molal $\mathrm{NaCl}$ brines), formic acid $\left(0-250^{\circ} \mathrm{C}, 0-5\right.$ molal $\mathrm{NaCl}$ brines), and benzoic acid $\left(0-250^{\circ} \mathrm{C}, 0-5\right.$ molal $\mathrm{NaCl}$ brines) were completed and modeled using empirical equations that permit accurate extrapolation and interpolation. Experiments were also initiated on the complexation of $\mathrm{Al}^{3+}$ and $\mathrm{Cd}^{2+}$ by oxalate, mal- 
onate and succinate, and on the complexation of $\mathrm{Nd}^{3+}$ by acetate, in $0-5$ molal $\mathrm{NaCl}$ and sodium trifluoromethanesulfonate brines to $125^{\circ} \mathrm{C}$.

Other aqueous studies included: (1) Completion of experimental measurements and modeling of the formation constants of $\mathrm{MgOH}^{+}$, an important species in hypersaline oilfield and geothermal brines, to $250^{\circ} \mathrm{C}$ in 0 5 molal $\mathrm{NaCl}$ brines; (2) Completion of an experimental and modeling study of the sorption of hydrogen ions on the surface of the mineral rutile, $\mathrm{TiO}_{2}$, in $0-1$ molal $\mathrm{NaCl}$ brines to $250^{\circ} \mathrm{C}$; and (3) Completion of construction of a new hydrogen-electrode potentiometric cell that will allow measurements of the solubility of minerals in brines to $300^{\circ} \mathrm{C}$, with continuous and precise monitoring of $\mathrm{pH}$.

Modeling of previous stable isotope exchange experiments demonstrates that exchange rates in the system calcite- $\mathrm{CO}_{2}-\mathrm{H}_{2} \mathrm{O}$ over a wide range of fluid compositions to $700^{\circ} \mathrm{C}$ and 1000 bars are governed by the degree of chemical equilibrium, with rates decreasing as equilibrium is approached. Order-of-magnitude differences have been discovered between rates calculated for carbon and oxygen isotope exchange at a given temperature, suggesting that the exchange mechanisms for carbon and oxygen are decoupled and that a simple surface species such as $\mathrm{CO}_{3}{ }^{2-}$ or $\mathrm{HCO}_{3}{ }^{-}$cannot con- trol the rate of both carbon and oxygen isotope ex change.

Linear correlations have been observed between experimentally determined rates of mineral-fluid oxy gen isotope exchange and the average interatomic distances between cations and oxygen in a particular mineral. Regression of the available data for surface-reaction-controlled exchange yields predictions of rates for a large number of silicates and carbonates for which data are currently lacking.

Carbon and oxygen isotopic compositions of pedogenic carbonates (deposited by plant roots) in paleosols of the western U.S. and Canada have provided the basis for paleoclimate reconstructions of the middle and late Cretaceous periods in this region. There is a noticeable decrease in oxygen isotope values of paleosols with increasing latitude. A pronounced enrichment in the ${ }^{13} \mathrm{C}$ contents of middle Cretaceous paleosols is observed, compared with late Cretaceous samples. This implies that soils of the middle Cretaceous were infused with larger amounts of atmospheric $\mathrm{CO}_{2}$, or that atmospheric $\mathrm{CO}_{2}$ of that time was isotopically enriched compared with the late Cretaceous. These results place constraints on mean annual temperatures and atmo spheric $\mathrm{CO}_{2}$ levels during this period.

\section{B . Thermodynamic Mixing Properties of C-O-H-N Fluids (J. G. Blencoe 1615-574-7041; Fax615-574-4961; E-mail jblencoe@blencoe.chem.ornl.gov], J. C. Seitz, and D. B. Joyce)}

Objectives: Thermodynamic data for $\mathrm{C}-\mathrm{O}-\mathrm{H}-\mathrm{N}$ fluids (hydrothermal waters, natural gas, etc.) are insufficient in quantity and quality to permit formulation of accurate equations of state for natural fluids in the Earth's crust, which are composed predominantly of $\mathrm{H}_{2} \mathrm{O}, \mathrm{CO}_{2}, \mathrm{CH}_{4}, \mathrm{H}_{2}$ and $\mathrm{N}_{2}$. Such equations find wide application in solving geochemical problems, including geothermal and hydrocarbon reservoir hydrodynamics modeling, thermochemical calculations of the stabilities of hydrocarbons and alteration minerals, permeability changes in reservoirs, contaminant transport, and global cycling of greenhouse gases.

Project Description: Experiments are performed with $\mathrm{H}_{2} \mathrm{O}, \mathrm{CO}_{2}, \mathrm{CH}_{4}, \mathrm{~N}_{2}$, and mixtures of these gases at pressure-temperature conditions similar to those encountered in deep aquifers, sedimentary basins, and geothermal fields. The pressure-volume-temperature relationships of pure gases, binary, and ternary mixtures are determined with unprecedented precision in a unique vibrating-tube densimeter designed to perform in the range $50-450^{\circ} \mathrm{C}$ and $100-3500$ bars. The activity-composition relationships of gas mixtures are studied in another unique facility, a hydrogen-service, internally heated pressure vessel capable of operation with several thousand bars of hydrogen pressure, with an overall operating range up to 10 kilobars at 100 to $1200^{\circ} \mathrm{C}$. Novel Raman spectroscopic studies of gas mixtures, performed in collaboration with scientists at Washington University and the U.S. Geological Survey, complement these approaches. Equations of state are developed from the experimental results, cou pled with literature data.

Results: J. C. Seitz completed his Ph.D. studies at ORNL and was awarded a DOE Distinguished 
Postdoctoral Fellowship to continue his work on the pressure-volume-temperature (PVT) properties of C$\mathrm{O}-\mathrm{H}-\mathrm{N}$ gases using the vibrating-tube densimeter, as well as his studies of their Raman spectroscopic parameters. During this period, PVT measurements were completed for binary and ternary mixtures in the $\mathrm{CO}_{2}-$ $\mathrm{CH}_{4}-\mathrm{N}_{2}$ system at $50-300^{\circ} \mathrm{C}$ and $100-1000$ bars. Work was also initiated on a polythermal, polybaric equation of state for this system, and modifications of the densimeter were designed and tested for the analysis of gas mixtures containing water. J. G. Blencoe organized a symposium at the 1994 Spring American Geophysical Union meeting, entitled "Thermodynamic properties of Fluids at High P and T," at which these results and the work described below were presented.

Data from more than 20 sources on the thermodynamic properties of $\mathrm{H}_{2} \mathrm{O}-\mathrm{CO}_{2}$ mixtures were assembled and analyzed for consistency, including excess enthalpy and volume, activity/composition relationships, and phase equilibria. A 14-parameter $\mathrm{P}, \mathrm{T}$ explicit equation of state has been developed for this mixture span- ning the range 0 to 10,000 bars and 100 to $1200^{\circ} \mathrm{C}$. The equation is based explicitly on data from mixtures, unlike common MRK models, and reproduces the data, including solvus data, extremely well. The equation reduces to ideal mixing at low pressure, and extrapolates to reasonable values at very high pressure. Part of this effort also involved development of a new mathematical technique for analyzing molar volume data for $\mathrm{H}_{2} \mathrm{O}-$ gas systems.

Raman spectroscopic parameters for pure $\mathrm{CO}_{2}$, pure $\mathrm{CH}_{4}$, and 5 binary mixtures have been collected for the $v_{1}$ band of $\mathrm{CH}_{4}$ and the $v_{1}$ and $2 v_{2}$ bands of the Fermi diad for $\mathrm{CO}_{2}$ at pressures of 10 to 700 bars at room temperature. It was demonstrated that these parameters permit the non-destructive determination of internal pressures and gas compositions in individual fluid inclusions from several natural settings. Ulimately, this information will be incorporated into fundamental models of the molecular interactions of $\mathrm{C}$ $\mathbf{O}-\mathbf{H}-\mathbf{N}$ gases.

\section{Fundamental Research in the Geochemistry of Geothermal Systems (D. J. Wesolowski [615-574-6903;Fax 615-574-4961;E-mail dqw@ornl.gov],J.Horita, and D.R. Cole)}

Objectives: The objective of this project is to provide fundamental information on elemental and isotopic speciation, distributions, and exchange reactions which play pivotal roles in a wide range of geological processes, but which specifically impact reservoir dynamics, corrosion, and heat extraction in active geothermal systems.

Project Description: At Oak Ridge National Laboratory, a long-term basic research program in experimental hydrothermal geochemistry, stable isotope geochemistry, and igneous petrology has lead to the development of unique methodologies for extracting rigorous and unambiguous information on a wide range of geochemical processes. This capability permits the efficient and definitive examination of specific problems hampering the ability to quantitatively model fluidrock interaction processes related to the discovery and exploitation of geothermal resources. Research topics in this project are selected in close cooperation with geothermal industry representatives and are frequently augmented by parallel research on more applied aspects of the same problems funded by the U.S. Department of Energy's Geothermal Program.

Results: Current topics within this project include the aqueous geochemistry of aluminum, which affects permeability development and scaling in geothermal systems, and the effects of dissolved salts on the partitioning of the stable isotopes of hydrogen and oxygen between geothermal brines and other phases, which is central to the use of stable isotopes in elucidating fluid sources, fluxes, and reservoir dynamics.

The solubility of boehmite-AlOOH-was successfully determined in a new potentiometric cell (see A above) with continuous, in situ $\mathrm{pH}$ monitoring, at 150 and $200^{\circ} \mathrm{C}$. The cell exhibits absolute stability over periods up to one month, and solubilities were successfully reversed at several temperature/pH conditions, with $\mathrm{pH}$ ranging from 1 to 10 . The preliminary results are entirely consistent with the model recently published on aluminum speciation in $\mathrm{NaCl}$ brines at lower temperatures, based on previous studies in this project of gibbsite solubility and potentiometric titrations of $\mathrm{AlCl}_{3}-\mathrm{NaCl}-\mathrm{HCl}$ solutions.

The effect of $0-6$ molal $\mathrm{NaCl}$ on ${ }^{18} \mathrm{O} /{ }^{16} \mathrm{O}$ and $\mathrm{D} / \mathrm{H}$ 
ratios in coexisting brine and water vapor have been determined from 10 to $350^{\circ} \mathrm{C}$. $\mathrm{NaCl}$ has almost no effect on the vapor oxygen isotope composition to $200^{\circ} \mathrm{C}$, with a measurable effect increasing from 200 to $350^{\circ} \mathrm{C}$. $\mathrm{D} / \mathrm{H}$ ratios of water vapor over $\mathrm{NaCl}$ brines are markedly enriched, relative to vapor over pure water of the same isotopic composition, the salt effect increases linearly with salinity, and the slope of the salt effect is a simple function of temperature, reaching a minimum at about $150^{\circ} \mathrm{C}$. The effect of $\mathrm{NaCl}$ on both the hydrogen and oxygen isotopic compositions of water vapor over $\mathrm{NaCl}$ brines is sensibly relatable to the critical point for a given salinity. Preliminary partial exchange experiments involving 0,1 and 4 molal $\mathrm{NaCl}$ brines and the mineral calcite are entirely consistent with the salinity effect on water liquid/vapor partitioning, demonstrating that dissolved salts alter the relative activity coefficients of the isotopic water molecules $\mathrm{H}_{2}{ }^{16} \mathrm{O}, \mathrm{H}_{2}{ }^{18} \mathrm{O}$, and $\mathrm{HD}^{16} \mathrm{O}$ in the liquid phase.

The effect of $0-6$ molal $\mathrm{CaCl}_{2}$ on oxygen and hy- drogen isotope partitioning has been studied to $200^{\circ} \mathrm{C}$. Unlike $\mathrm{Na}^{+}, \mathrm{Ca}^{2+}$ has a large effect on the oxygen isotopic composition of coexisting water vapor, with the vapor over $\mathrm{CaCl}_{2}$ brines having much lower ${ }^{18} \mathrm{O} /{ }^{16} \mathrm{O}$ ratios than vapor over pure water of the same isotopic composition. The effect of $\mathrm{CaCl}_{2}$ on $\mathrm{D} / \mathrm{H}$ partitioning is, to a first approximation, similar to the effect of $\mathrm{NaCl}$ at the same total chloride concentration at a given temperature.

Finally, extensive new data were collected on the partitioning of hydrogen and oxygen isotopes between pure water liquid and vapor, spanning the range from the freezing point to the critical point. Continuous and precise mathematical expressions have been formulated for the partitioning of both isotopes between coexisting water liquid and vapor of this range, and the results are consistent with a semi-theoretical model relating the isotopic water molecule vapor pressures to the critical density of $\mathrm{H}_{2}{ }^{16} \mathrm{O}$, and assuming ideal mixing of the isotopic molecules.

\section{Stable Isotope Systematics of Burial Diagenesis in the Alberta Deep Basin: An Ion Microprobe Study (L.R. Riciputi [615-576-4839; Fax 615-576-8559; E-mail riciputilr@ornl.gov] and D.R. Cole)}

Objectives: The principle objective of this research is to use elemental and isotopic compositions, coupled with detailed mineralogical and fluid inclusion studies, to quantify the mass transfer processes influencing porosity and permeability during burial diagenesis of carbonates and clastics. Development of ion probe methodologies for isotopic analysis of geological materials has been a secondary objective.

Project Description: In this project, the micronscale spatial resolution, elemental and isotopic imaging, and quantitative trace element and isotope ratio capabilities of ORNL's Cameca $4 f$ ion microprobe are being developed and used in studies of fluid-rock interactions associated with burial and hydrocarbon generation in sedimentary basins. The probe studies are augmented by information obtained from a variety of other geochemical techniques, including conventional gas-source isotope ratio mass spectrometry, electron microprobe, scanning electron microscopy, neutron activation, and fluid inclusion microthermometry. These techniques have been applied to a studies of fine-scale chemical and isotopic diagenetic features of carbonates of the Nisku and Obed Formations, important petroleum and natural gas host rocks in the Alberta Basin, and recently in clastic sediments from the North Sea and Appalachian Basin.

Results: Unlike the diagenetic pattern for shales, diagenetic sulfide formation in Alberta Basin carbonates takes place late in the diagenetic sequence, after the initialization of regional fluid-flow. $\delta^{34} \mathrm{~S}$ variations in Obed Formation sulfides correlate with texture. Six different types of sulfide texture have been recognized. Later-formed sulfides are much more enriched in ${ }^{34} \mathrm{~S}$ than earlier phases, suggesting late inorganic (thermogenic) sulfate reduction.

Variations in $\delta^{34} \mathrm{~S}$ exceeding 100 per mil over distances of less than $1 \mathrm{~cm}$ have been documented in fault zones in natural gas reservoir rocks in the North Sea, in a preliminary study conducted in collaboration with scientists from Exxon Production Research, Inc. In both the North Sea and Alberta Basin rocks, correlations are observed between the trace element contents of sulfides and their isotopic compositions, suggesting redox and fluid-chemistry control on the trace element behavior.

Large variations were observed (orders of magni- 
tude) in the rare earth element (REE) contents and patterns of Cambrian and Ordovician carbonates west of the Appalachian Fold Belt. These patterns reflect changes in regional fluid sources during diagenesis. This is the first time that large changes in REE contents have been noted for diagenetic carbonates.
Ion microprobe techniques were developed for the measurement of $\delta^{18} \mathrm{O}$ in insulators (silicates, sulfates, carbonates, phosphates, etc.). One per mil precision in oxygen isotope analysis of quartz, feldspar, clinopy roxene and calcite was demonstrated.

\section{E. Experimental Studies of Fundamental Stable Isotope Exchange Reactions $(D$. R. Cole [615-574-5473, Fax615-574-4961,E-mail me@cole.chem.ornl.gov], J. Horita, and D.J. Wesolowski)}

Objectives: The objective of this project is to obtain reliable information on the partitioning of the stable isotopes of oxygen, carbon, and hydrogen among minerals and fluids of critical importance in defining fluid-rock interaction parameters, such as fluid sources and fluxes, temperatures, and duration of fluid-rock interaction, in a variety of settings including oil, gas, and geothermal reservoirs, sedimentary basins, and waste repositories.

Project Description: This new project is currently focussed on: (1) the oxygen isotope partitioning between aqueous fluids and the minerals hematite, $\mathrm{Fe}_{2} \mathrm{O}_{3}$, and magnetite, $\mathrm{Fe}_{3} \mathrm{O}_{4}$, in the $100-500^{\circ} \mathrm{C}$ range; and (2) the exchange rates and equilibrium fractionations of hydrogen and carbon isotopes among gaseous species in the system $\mathrm{H}_{2} \mathrm{O}-\mathrm{CO}_{2}-\mathrm{CH}_{4}-\mathrm{H}_{2}$. The possible role of carboxylic acids, such as acetic acid, which are found in significant quantities in natural waters, will be investigated as possible catalysts or reaction intermediaries, in promoting the sluggish exchange of isotopes in these systems. Novel experimental methods are used to promote recrystallization and/or synthesis of the iron minerals, and natural and synthetic catalysts for exchange among the $\mathrm{C}-\mathrm{O}-\mathrm{H}$ gases are investigated.

Results: $A \mathrm{CO}_{2}$ laser-fluorination system was designed and obtained from Merchantek, Inc. for the rapid and reliable extraction of oxygen from refractory minerals such as the iron oxides, for subsequent mass spectrometric analysis in the form of $\mathrm{CO}_{2}$ gas. A new Finnegan MAT 252 gas-source, isotope ratio, mass spectrometer was installed and brought on line. Ion microprobe methods for the precise measurement of oxygen isotope ratios in magnetite and hematite with spatial resolution on the order of 10 microns have been refined using a Cameca $4 \mathrm{f}$ ion microprobe. Experimental systems for equilibration of iron oxides with water in gold bags and teflon bladders, including a titration system for in situ synthesis of iron oxides, have been designed. A rapid-quench cold seal system rated for hydrogen service was designed and obtained from Tempress, Inc., for studies of gaseous exchange in the $\mathrm{C}-\mathrm{O}-\mathrm{H}$ system. Finally, samples of ultrapure, well-crystallized, submicron-sized hematite and mag netite were obtained and isotopically characterized; and ${ }^{13} \mathrm{C}$-enriched methane for exchange studies with $\mathrm{CO}_{2}$ of natural ${ }^{13} \mathrm{C}$ abundance was obtained.

Experiments were initiated on the recrystallization of submicron sized hematite and magnetite in the presence of a large excess of water containing 0.1 molal acetic acid at $335^{\circ} \mathrm{C}$. These experiments utilize four isotopically distinct waters, which will allow determination of the equilibrium fractionation and the degree of overall isotopic exchange using the Northrup-Clayton technique. Previous investigations of the thermal de composition of acetic acid in the presence of these minerals, conducted in another project in this laboratory, demonstrated that under the experimental condi tions, both the fine-grained hematite and magnetite starting materials should be converted to 40-50 micron, perfectly euhedral magnetite octahedra (hematite start ing material), and dodecahedra (magnetite starting material) after a period of several months. These coarse crystals are expected to grow essentially in isotopic equilibrium with the aqueous solution and will be amenable to both conventional and ion microprobe analysis, even permitting examination of possible dif ferences in isotopic composition of different crystal faces within the same mineral. 
Richland, Washington 99352

CONTRACT:

DE-AC06-76RLO 1830

CATEGORY:

Geochemistry

PERSONS IN CHARGE: Anthony C. Hess and Maureen I. McCarthy

\section{A. Theoretical Characterization of the Physics and Chemistry of Soil Minerals (A.C. Hess [509-375-2052; Fax 509-375-6631;E-mail ac hess@pnl.gov] and M. I. McCarthy [509-375-6824; Fax 509-375-6631; E-mail mi_mccarthy@pnl.gov])}

Objectives: This program is designed to provide the theoretical basis for understanding a broad range of complex subsurface processes. It complements many of the experimental efforts presently supported by OBES/Geosciences and will serve as a broad-base link between several experimental and theoretical projects. The goal of this program is to investigate the microscopic properties of minerals and mineral interfaces that directly affect the macroscopic transport of contaminants through the subsurface. The knowledge obtained from in-depth studies on several classes of mineral-contaminant systems are used to construct a general understanding of soil physics. This is, in turn, used to predict the behavior of a broad range of subsurface minerals and contaminants. The knowledge gained from these studies may also be directly transferred to large-scale subsurface transport models and remediation design models.

Project Description: An integrated theoretical approach is used which combines methods from $a b$-initio quantum mechanics and classical mechanics. The emphasis of the research is two fold. One aspect applies existing methods to the study of known geochemically important systems. This involves using the ab-initio time-independent periodic Hartree-Fock method to study the electronic structure and physical properties of bulk solids, clean surfaces and interfaces. Molecular dynamics and molecular mechanics techniques are employed, in conjunction with the quantum mechanical calculations, to study interfacial dynamics.
The second area of emphasis concentrates on the refinement and development of new theoretical methods for treating progressively more complex environmentally important systems. This activity has centered upon the development of a fully self-consistent periodic and non-periodic Gaussian basis density functional method which operates at peak performance on parallel computer architectures. This research program is jointly supported by OBES/Geosciences and OBES/Chemical Sciences.

Results: A characterization of selected water/mineral interfaces is being undertaken to determine the reactivity of minerals in the saturated and unsaturated zones. The adsorption and chemidissociation behavior of water on metal oxide surfaces and silicates constitute some of the most fundamental processes in geochemistry. The presence of molecular water over layers and adsorbed chemidissociation products on such surfaces strongly influence the transport properties and chemical transformation of contaminants in the subsurface environment.

The study of the structure and reactivity of the sur faces of $\mathrm{a}-\mathrm{Al}_{2} \mathrm{O}_{3}$ is a fundamental component in a series of studies designed to understand the complex chemistry of aluminum oxides, hydroxides, oxyhydroxides, and more complex iso-structural compounds such as a-Fe ${ }_{2} \mathrm{O}_{3}$. These and related compounds are common constituents of soils and have a significant effect on the chemistry of the subsurface. In this study we employed periodic Hartree-Fock (PHF) theory (as 
implemented in CRYSTAL92) to investigate both the extent and character of the surface relaxation. Additional studies investigated the adsorption of $\mathrm{H}_{2} \mathrm{O}$ on the $(0001)$ surface. Using this approach we have found that not only do the outermost aluminum atoms undergo a large relaxation toward the first layer of surface oxygen atoms, but the surface relaxation proceeds in a concerted manner (although to a lesser extent) several layers into the bulk material. In the final opti mized structure the outermost aluminum atoms are found to be both trigonally coordinated to and nearly coplanar with the surface oxygens. In addition to studies of the clean (0001) surface we have also investigated the response of both the unrelaxed and relaxed surfaces to the addition of molecular $\mathrm{H}_{2} \mathrm{O}$. In those studies the water was oriented such that the oxygen atom of the water molecule was directly above a surface aluminum atom. The results predict water to chemisorbed by $21.7 \mathrm{kcal} / \mathrm{mol}$ and $14.7 \mathrm{kcal} / \mathrm{mol}$ to the unrelaxed and relaxed surface, respectively. A small, but non-negligible reconstruction of the relaxed surface structure in the presence of water was also observed.

The PHF method (CRYSTAL92) and the embedded cluster method (EMBED) have both been used to study the chemistry of the water/MgO interface. These methods, although closely related, asymptotically describe different macroscopic objects. In the PHF method, the model surface is composed of an infinite number of defects separated from each other at fixed distances and orientations. In the case of the embedded cluster approach, the object being considered is an in finite periodic surface with a single defect site. In part, the purpose of this study is to assess the practical effects of defect-defect interactions on the observed chemistry and to evaluate several properties difficult to obtain in the periodic formulation. Specifically, several types of reactive sites on the (001) face of $\mathrm{MgO}$ have been characterized, with special reference to their ability to adsorb and dissociate molecular water in the presence of simple structural defects such as a step. The presence of a single step on $\mathrm{MgO}(001)$ has a remarkable effect upon the chemistry of the system. It is first observed that a single water molecule is chemisorbed to the step by $\sim 19 \mathrm{kcal} / \mathrm{mol}$ and that the chemidissociation reaction is exothermic (a similar result is found using the PHF approach). The embedded cluster approach allowed us to consider both two and four hydroxylated sites on the $\mathrm{MgO}$ step. For the addition of a single water molecule, chemidissociation was found to be energetically favored by $53 \mathrm{kcal} / \mathrm{mol}$, for the addition of another chemidissociated water molecule (which completely hydroxylates the step) the reaction was favored by $82 \mathrm{kcal} / \mathrm{mol}$. Optimization of the $\mathrm{OH}$ and $\mathrm{H}$ atoms using EMBED revealed that the adsorbed groups assumed a bent geometry with respect to the defected surface plane.

Another component of this research effort examines the chemical properties of clays and zeolites. These materials are chemically active species in the subsurface that may also be employed as in situ waste containment barriers or ion-exchangers/catalysts in some remediation technologies. Silica-sodalite is a felspathoid that serves as a model zeolite and is composed of tetrahedral $\mathrm{Si}$ and bridging $\mathrm{O}$ forming 4- and 6-rings. Its overall structure is a truncated octahedron with chemical formula $\mathrm{SiO}_{2}$. Most natural and synthetic members of the sodalite family contain additional tetrahedral species, such as Al, electrostatically coupled extraframework ions (e.g. $\mathrm{Na}_{+}, \mathrm{TMA}_{+}$) and encapsulated neutral species (e.g., $\mathrm{NaCl}$ and Ethylene Glycol). Our initial studies focused on characterizing the properties of the fully siliceous lattice, in the absence of substituted ions and counterions. The purpose of this work is to ascertain the level of theory needed to describe the properties of zeolites. This entails careful determination the dependence of the structural properties on basis set, the contribution of basis set superposition errors (BSSE) to the rare gas diffusion barriers, and the importance of correlation in determining the chemical and physical properties of a zeolite. Although pure silica-sodalite is an ideal structure, it provides a valid benchmark for testing and developing basis sets that can be used to treat more complicated structures. This study represents the first systematic investigation of basis set effects on the bulk properties of zeolites. Diffusion processes were investigated by studying the model system of rare gas atoms moving through the sodalite cage. The computed barrier heights for moving a gas atom along the C3 axis towards the 6-oxygen ring in silica sodalite were $5.61,13.18$ and $62.11 \mathrm{kcal} / \mathrm{mol}$ for $\mathrm{He}, \mathrm{Ne}$ and Ar, respectively. Similar studies have now been performed to determine the motion of Group Ia cations $(\mathrm{Na}, \mathrm{K}, \mathrm{Rb}$, and $\mathrm{Cs}$ ) through Analcime structure types. 


\section{B . Surface Structure and Chemistry of Carbonate Minerals (D. R. Baer [509-375-2375; Fax}

509-375-5965; E-maildr_baer@pnl.gov] and J.P.LaFemina)

Objectives: The purpose of this program is to develop a fundamental, microscopic understanding of the structure and chemistry of carbonate surfaces, including the interactions between adsorbates and mineral surfaces.

Project Description: This project involves an interdisciplinary theoretical and experimental effort designed to gain a fundamental, molecular level understanding of carbonate mineral surface structure and chemistry. Carbonate minerals are particularly important in the global $\mathrm{CO}_{2}$ cycle and in subsurface contaminant migration processes. The availability of large single-crystals allow fundamental measurements to be made on well defined surfaces. By linking experimental studies of geochemical reactions on single-crystal surfaces with semiempirical and first-principles quantummechanical model calculations to describe the surface and interfacial structure and chemistry, a systematic study of the factors controlling the surface chemistry of carbonate minerals can be made. In particular, the effects of substitutional impurities and other point chemical defects on the structure and geochemical reactivity of carbonate mineral surfaces and interfaces can be isolated and quantified. Moreover, this improved microscopic understanding will eventually provide insights into the behavior of these materials in natural systems.

The approach to meeting program goals, involves three interdependent areas of effort: development of semiempirical models for the structure and chemistry of the calcite cleavage surfaces; vacuum studies of the structure and chemistry of the cleavage surface; and comparison of surfaces in vacuum with those in model geochemical environments.

Results: A series of $a b$ initio density functional computations of bulk calcite, qualitatively characterizing the structural and electronic properties of this material have been completed. For comparison with the calculations, the bandgap was measured using reflection energy loss spectroscopy and the valence band density of states was examined by $x$-ray photoelectron spectroscopy. The agreement between the theory and experiment was excellent. Based upon the success of the bulk calculations, a semiempirical tight-binding total energy model for computing the surface relaxation of the calcite cleavage surface has been developed. The results agree with LEED and AFM images which indicate that the surface does not relax.

The dissolution of calcite and the influences of adsorbates on calcite dissolution are being measured using atomic force microscopy (AFM). Measurements in pure water and in solutions at equilibrium with calcite show that Mn and Silicates in solution change the surface structure on calcite and change the mode of dissolution of step edges in specific directions. The velocities of different structures of steps vary by a factor of 2.5. An apparent activation energy of dissolution is $0.61 \mathrm{eV}$. The addition of $\mathrm{Na}_{2} \mathrm{SiO}_{3}$ to the solution causes the shape of pits to change from nearly square to half rounded.
CATEGORY:

\section{PERSONS IN CHARGE:}

Energy Resource Recognition, Evaluation, and Utilization Harlan P. Foote, George E. Wukelic, and John S. Risch

A. Geosciences Data Integration/Virtual Environments (H. P. Foote [509-376-84I8; Fax 509372-2857; E-mail hp foote@pnl.gov], G. E.Wukelic [509-376-5860; Fax 509-372-2857; E-mail ge_wukelic@pnl.gov],J.S.Risch [509-376-4445; Fax 509-372-2857; E-mail js_risch@pnl.gov])

Objectives: The objective of this project is to investigate the applicability of emerging Immersive
Virtual Environments (IVE) technology to geoscientific data analysis and modeling. 
Project Description: Although geosciences data are increasingly acquired, analyzed, and modeled threedimensionally, most data analysis systems in common use utilize two-dimensional user-interfaces. For certain 3-D tasks, such as position or orientation specification, or graphical display control, traditional 2-D interface tools have often proven cumbersome and inefficient. The purpose of this research is to develop and evaluate 3-D user interface tools in terms of specific 3-D geoscientific data analysis and modeling tasks. The primary focus is on the demonstration and determination of the usefulness of IVE (aka Virtual Reality) technology to improved understanding of geophysical processes. IVE systems, specifically integrated high-performance graphics computers, wide-field-of-view stereoscopic display devices, and six-degree-of-freedom position tracking systems, when linked with detailed earth sci ences data, can effectively put geoscientists in a 3-D space along with their data and conceptual models. Benefits of this approach may include more efficient and intuitive interactions with 3-D computer models and improved understanding of spatial relationships among multidimensional phenomena. Although the current focus of this work is on IVE technology, tech niques developed under this project are expected to be applicable to other 3-D display and input technologies as they become available (e.g. holographic displays).

Results: Research under this project related to the applicability of IVE technology in the geosciences was initiated in October 1993. FY94 efforts to date have concentrated primarily on the establishment of an IVE facility at PNL, including equipment acquisition, integration, and testing. The current focus of this work is on the development of a variety of low-level IVE-based interface tools for facilitating 3-D conceptual model development and revision. Software under development includes algorithms for accelerating the stereo display of complex 3-D data sets and models to real-time (i.e., 30 frames/sec) speeds, interactive visualization tools for dynamically exploring volumetric data, and interface tools for graphically querying spatially referenced databases and interactively editing 3-D model geometries. Developed low-level tools will be used to support high-level modeling applications including 3-D stratigraphic modeling, 3-D geostatistical data analysis, and 3-D fluid flow modeling. Additional work is addressing human-factors issues related to optimal human-computer interface design for a variety of common geoscientific modeling tasks.

In addition to the previously described technical work, a proposal is currently under development to apply concepts developed under this project to domestic oil \& gas exploration and production problems under the DOE Advanced Computational Technology Initiative (ACTI). The proposed ACTI project will be conducted in collaboration with petroleum industry scientists and researchers at other DOE laboratories.

\section{PERSONS IN CHARGE: Nels R. Larson and Donald W. Slater}

\section{A. DOE Insolation Studies (N. R. Larson 1509-376-4333; Fax 509-372-2857; E-mail nels@solar.pnl.gov])}

Objectives: What effects do stratospheric aerosols from major volcanic eruptions have on the solar resource, and how do their size distributions and geographical distributions evolve? How much do aerosols in the lowest kilometer of the atmosphere, where they may be generated and influenced by human activities, affect the solar resource?
Project Description: Radiometric instruments developed within this program at Pacific Northwest Laboratory measure the direct, diffuse, and total shortwave solar spectral flux. These data are analyzed using physical models to inferstratospheric and tropospheric aerosol optical depths and abundances.

Volcanic eruptions can introduce significant quanti- 
ties of gases into the stratosphere that subsequently condense to form aerosols that may persist for several years. The radiometers measure the physical, temporal, and spatial evolution of these aerosols to understand their influence on the solar energy available at Earth's surface. These effects are then compared with the radiative effects of aerosols generated by human activities within the lowest portion of the atmosphere during periods when no significant stratospheric aerosols are present to obtain a measure of their relative influences on the solar resource.

Results: Radiometer data from the States of Washington, Colorado, and New York showed that stratospheric aerosols resulting from Mt. Pinatubo's eruption in June 1991 had three distinct maxima in optical depth. In a manner similar to what was observed earlier for El Chichon's aerosols, the maxima occurred during the three winters following the eruption. Pinatubo's effect on the solar beam was greater than El Chichon's by about $30 \%$, having reduced the energy available in the mid-visible region of the spectrum by about 14,9 , and $4 \%$ during successive winters. These data compared well with lidar and satellite measurements of Pinatubo's stratospheric aerosols over Germany and the central United States. The effect of aerosol attenuation on the solar beam was observed to be more dependent upon latitude than upon longitude, indicating that it is necessary to measure optical depths over as large a range of latitudes as possible in order to assess the potential effect of a large amount of aerosol on global climate. While satellite data can provide such spatial coverage, it can be inadequate in providing high enough temporal coverage over most regions of the globe. Hence, the need was identified for a network of radiometers to provide long-term measurements of the latitudinal distribution of atmospheric aerosols. Analysis of radiometer data in the semi-arid, mixed urban and rural basin region of southeastern Washington indicates that low-altitude aerosols cause a loss of about $5 \%$ of the direct solar beam on average. While this is only one-third of the amount of attenuation caused during Pinatubo's aerosol maximum at the same site, the low-altitude aerosols are essentially always present.

\section{B . Operation of DOE Aeronomy Observatory (D. W. Slater [509-376-8423; Fax 509-372-2857; E-maildw_slater@pnl.gov])}

Objectives: The objective of this research program is to broaden our understanding of the mechanisms governing the transfer of energy within the earth's magnetosphere-atmosphere system, specifically the thermospheric response to large scale energy influxes from near-earth space.

Project Description: This task addresses the need for critical observations to test our understanding of, and confidence in, the current computational models used to describe energy exchange within the thermosphere. Optical remote sensing techniques are used to monitor large portions of the upper atmosphere above the United States for characteristic optical signatures, which are related to the intensity, spatial and temporal characteristics of the energy influx.

Results: This year witnessed the conclusion of the development period for the newest version of the PNLdeveloped automated CCD low-light-level imaging system, capable of monitoring numerous atomic and molecular atmospheric emission lines of interest.
Control software was developed that allows fully autonomous operations at any selected field site. Initial testing of the completed system occurred at the sites near Richland, WA, and Bear Lake, UT; 6 months of operation at these sites was successfully completed. An extensive data set consisting of modeled and in situ measurements describing the atmosphere, ionosphere, and ring current composition was used to calculate energy exchange rates between plasmaspheric electrons and ring current ions. Results showed a major, variable energy flow dependence on ring current composition and energy spectrum, particularly during geomagnetic storm phases characterized by large populations of energetic hydrogen ions. Calculated effects of this energy flow into the thermosphere yielded generally good agreement with emission rates of the atomic oxygen red line as monitored by the PNL airglow imagers. The red line is used as a diagnostic tool to define regions that are experiencing large-scale heating due to energy in flux from the magnetospheric energy reservoir. 


\section{A. 3-D Electromagnetic Data Inversion (Gregory A. Newman [505-844-8158; Fax 505-844- 7354;E-mail ganewma@california.sandia.gov])}

Objectives: Develop 3-D electromagnetic data inversion capabilities in the frequency band below $30 \mathrm{MHz}$. Use the capabilities to image the earth's electrical properties and describe geologic systems.

Project Description: Data inversion capabilities are being developed for 3-D reconstructions of electrical conductivity and dielectric permittivity within the earth. The inversion algorithm is using electromagnetic (EM) data below $30 \mathrm{kHz}$ arising from electric and magnetic dipole transmitters. The inversion capability will provide fundamental understanding of the earth's electrical properties and be highly useful in characterizing environmental waste sites and map zones of mobilized oil in enhanced oil recovery projects.

The 3-D reconstruction of electrical data is being carried out by the inversion of an integral equation. This equation predicts the EM fields that arises from the earth's 3-D electrical properties. Because inversion is non linear, the problem is solved iteratively by updating the fields from the previous electrical model update; the fields are calculated directly from Maxwell's equations using finite differences. The data inversion capability is to be tested using synthetic data with random noise. Field data will then be inverted to further access the robustness and reliability of the inversion capability.

Results: The EM inversion project has seen continued development of the 3-D finite difference scheme for the forward modeling problem; extensions include a method to efficiently model the air-earth interface, which is critical for environmental applications. A manuscript on the forward solution has been prepared with specific application to airborne EM modeling which is being submitted to the journal GeoExploration. There has also been continued development of a cross-well inversion algorithm that allows adequate parameterization of the interwell region, using the above-mentioned 3-D forward modeling algorithm. The code has been successfully applied to synthetic data and also field data from a salt-water experiment. A journal article describing the method and the field application has been accepted by Geophysics.

\section{B . Micromechanics of Failure in Brittle Geomaterials (Joanne T. Fredrich [505-844-2096; Fax 505-844-7354; E-mail fredrich@energylan.sandia.gov] and Teng-fong Wong, State University of New York at Stony Brook)}

Objectives: The objectives of this project are to provide a fundamental understanding of the effects of grain boundary structure and cementation, damage state, and load path on the deformation and failure mode of brittle porous and nonporous geologic materi- als by measurement of mechanical behavior under high pressure and deviatoric stress, quantitative microstructural characterization of pristine and deformed samples, and theoretical analysis.

Project Description: Knowledge of the failure 
behavior of rocks is important for several energy-related applications, including reservoir engineering, oil and gas exploration and production, underground disposal of nuclear waste, and drilling technology. The experimental investigation will provide a detailed understanding of the micromechanical processes associated with the brittle failure of geomaterials and includes triaxial tests following various load paths which are defined by the ratio $K$ of the change in the radial confining (horizontal) stress to the change in the axial (overburden) stress. Tests are conducted to various stages of failure and include measurement of strain and acoustic emission. The micromechanical failure pro- cesses are further elucidated and characterized quantitatively using light microscopy, laser scanning confocal microscopy, and scanning electron microscopy. Work focuses on porous carbonate and siliciclastic rocks, al though related experiments are also being performed on low-porosity crystalline rocks in order to study completely the effect of certain parameters. The results of the laboratory tests and microstructural studies are used to guide analyses using fracture mechanics and continuum plasticity theories.

Results: This project was initiated in the last quarter of FY 1994.

\section{Laboratory and Theoretical Analyses of Transport Paths in Single Natural Fractures (S. R. Brown [505-844-0774; Fax 505-844-7354; E-mail srbrown@sandia.gov], N. G.W. Cook, L. R. Myer, and G. Yang, University of California at Berkeley and Lawrence Berkeley Laboratory)}

Objectives: Fluid flow in fractured rock is an important phenomenon to understand in connection with energy production and containment or disposal of wastes. The objective of this project is to address several outstanding questions of the effects of void topology on flow and transport in single fractures by quantitative, visual observations and measurements of singleand two-phase flow.

Project Description: We have developed a method for obtaining precise replicas of real fracture surfaces using transparent epoxy resins. These replicas will be used to examine flow in the fracture void space using digitized optical imaging and nuclear magnetic resonance imaging (NMRI). In parallel work, we are examining single- and two-phase flow in irregular fracture aperture distributions using graph theory, effective medium theory, and percolation theory to analyze the topology of the conducting network of void space. This work emphasizes that the topology of the network is of at least as much importance as the conductance of the individual elements in determining fluid flow. The topological characteristics of the preferred paths at different scales will be analyzed to study the effects of scale on flow and dispersion in fractures. Numerical predictions based on graph theory will be compared with experimental observations of multi-phase flow.
Results: Field specimens of several natural rock joints were collected. Matched two-dimensional images of the surface topography of each fracture surface were measured allowing the fracture aperture distributions to be calculated. Silicon rubber molds of the fracture surfaces were made in preparation for NMRI experiments.

A simple mathematical model which requires only three parameters for a complete description of a rough fracture in rock has been fully developed and documented. This model has been implemented on a com puter and the code has been used by Berkeley collaborators for preliminary studies of fracture flow using graph theory.

In collaboration with J. B. Walsh (MIT), the mathematical model of a single fracture has been used to guide development and test statistical formulations of flow and transport in single fractures. A new "effective medium theory" (EMT) has resulted, which includes short-range spatial correlations in aperture heights. This new EMT substantially improves upon the accuracy of predictions over that of traditional versions of the theory.

In collaboration with R. L. Bruhn (U. of Utah), the concept of two rough surfaces contacting to form a fracture has been extended to a large scale, leading to the development of a conceptual model of the formation of voids and veins along geologic faults. 


\section{Shear Strain Localization and Fracture Evolution in Rocks (W. R. Wawersik 1505-844- 4342; Fax 505-844-7354; E-mail wrwawer@sandia.gov], D.J. Holcomb, and W. A. Olsson)}

Objectives: The objective of this research is an improved understanding of the mechanism of the formation of faults and fractures in rock, and the prediction of their causative stresses, location, orientation, thickness, and spacing. Specifically, the research examines the applicability to fracture formation of a theory by Rudnicki and Rice that describes faulting as a constitutive instability leading to a localization of shear deformation from a homogeneous pattern of deformation.

Project Description: An experimental program is undertaken that entails four parts. (1) A systematic evaluation of the Rudnicki-Rice constitutive parameters under axisymmetric and truly multiaxial stress states. Several rock types are used, including Tennessee marble and Gosford sandstone. (2) Experiments to measure and compare the actual and predicted development of strain localization in axisymmetric and plane-strain compression. (3) Multiaxial stress tests on pressurized thin-walled cylinders with superimposed torsion to investigate special phenomena leading to strain localization at relatively small deformations. (4) Post-test petrographic observations concerning the details of shear banding and the potentially accelerating effects of imperfections in experimental boundary conditions. The foregoing research is integrated with a parallel theoretical study by Rudnicki.

Results: Two series of axisymmetric tests on Tennessee marble (TM) and Gosford sandstone (GS) were completed with associated measurements of the dilatancy factors, slope of the yield surface, incremental elastic moduli, and incremental plastic tangent moduli. Additionally, plane-strain testing was initiated for TM and is continuing with improved strain measurements for the determination of constitutive responses. Strain localization in axisymmetric compression in TM occurred during strain-softening ("post-peak") as indicated by stress-strain data, post-test observations, and diffuse patterns of microseismic events monitored and located by an array of fifteen transducers. Similar ex periments on GS are in progress. Strain localization in TM under plane-strain conditions appeared to develop suddenly during strain-hardening ("pre-peak"). Corresponding diagnostic acoustic emission locations are currently being evaluated. First measurements of the ratio of incremental shear moduli at relative orientations of $45^{\circ}$ indicate relative reductions with strain in TM so as to accelerate faulting. Destabilizing effects are also indicated by the formation of comers in the TM yield surface.
CATEGORY:

PERSON IN CHARGE:
Geochemistry

M. C. Walck

\section{A. Effects of Microscopic Reactions and Buoyancy on Macroscopic Transport in Geologic Media: a Lattice Gas Study of Retardation and Dispersion (Harlan $W$. Stockman [505-844-0975; Fax 505-844-7354; E-mail hwstock@sandia.gov])}

Objectives: Use Lattice Gas Automata (LGA) to determine effects of surface reactions and buoyancy on macroscopic transport of solutes and colloids through geologic media; test common dispersion and retardation approximations.

Project Description: The macroscopic dispersion and retardation coefficients can be approximated from models proposed by Turner (1958, Chem. Eng. Sci., v 7 p 156), Aris (1959, Proc. Royal Soc. v 252A p 538) and Golay (1958, Gas Chromat., p 36). These models view the fracture or porous medium as one or more straight channels lined with stagnant dead-end pores, and use several simplifying assumptions to derive macroscopic coefficients from the microscopic ge- 
ometry and molecular diffusion and sorption rates. Such approximations are widely applied, but are rarely tested for accuracy.

This project uses LGA to calculate 1st and 2nd moments of solute distributions for flow through a variety of geometries, ranging from simple Tumer structures to more complex, irregular fractures lined by porous walls. The results of LGA calculations are fitted to the approximations suggested by Turner and others, which yield apparent molecular diffusion and distribution coefficients. By comparing the input diffusion and distribution coefficients used in the LGA calculations, one can assess the accuracy of the approximations, estimate scaling effects, and suggest experimental strategies for obtaining greatest accuracy. Applications include modeling ${ }^{129} \mathrm{I}$ and ${ }^{14} \mathrm{CO}_{2}$ transport through wetwalled fractures in tuff.

Results: The first portion of the study was a benchmarking and validation exercise. The LGA runs were found to be in excellent agreement with the Taylor-Aris formula for the effective diffusion coefficient $\left(D_{\text {eff }}=D_{m}+(U \times W)^{2} /\left(210 D_{m}\right)\right.$, where $D_{m}$ is the molecular diffusion coefficient, $U$ is the average channel flow speed, and $W$ is the channel width). Testing the accuracy of sorption algorithms proved more difficult, since there are no analytical solutions for flowing systems and finite reaction rates. However, it was possible to model time-dependent sorption in non-flow ing systems, by fitting the LGA results to the differen- tial equation for sorption; the predicted and measured ratios of reaction rates agreed to better than $0.5 \%$.

In the second part of the study, LGA calculations were performed for long, thin channels (aspect ratios up to 200 ) with varied adsorption coefficients, buoy ancy and wall geometries. A slug of solute was injected into fully developed flow, and the 1st and second moments of the distribution tracked through the numerical experiment. The 1st moment is the average slug posi tion, and the time derivative of the 2 nd moment is 2 times the effective dispersion coefficient. The observations of Reejhsinghani et al. (1966, AIChE J. v $12 \mathrm{p}$ 916) were confirmed; i.e., small density differences were found to cause factor 2 to 5 errors in the measured diffusion coefficient in the early stages of an experiment. The Golay equation for apparent dispersion in a flowing channel was found to be inaccurate for the conditions of the study, but the simple retardation equation gave the correct slope for the 1st moment within a few characteristic diffusion times for Damkohler numbers less than 2 . The Turner equation for dispersion in a channel with wall embayments was found to be reasonably accurate.

A substantial part of this project is the development of efficient and accurate LGA codes. Several methods for improving calculation speed were tested this year. Algorithms for dissolution and precipitation are currently under development.

\section{B . Mineral Hydrolysis Kinetics (Henry R. Westrich 1505-844-9092; Fax 844-7354; E-mail hrwestr@sandia.gov],R.T.Cygan,P.V.Brady, and W.H.Casey)}

Objectives: Provide a fundamental understanding of the aqueous dissolution of simple silicate minerals, such as orthosilicates, by measurement of their dissolution kinetics, chemical and structural characterization of their reacted surfaces, and simulation of the mineralsurface interface. Measured dissolution rates are also used to model the carbon cycle and global climate.

Project Description: Silicate mineral weathering can be successfully predicted if the kinetics of mineral dissolution can be related to ligand-exchange reactions where the rate-controlling step is cleavage of a similar metal-oxygen bond with an unchanged cation coordination chemistry. This relationship is being tested with a comprehensive experimental, analytical, and theoreti- cal program using ortho- and inosilicate minerals. Batch dissolution measurements of endmember and mixed-cation ortho- and inosilicates were measured at $25-50^{\circ} \mathrm{C}$ under acid conditions. Structural and chemical characterization of acid-reacted minerals was done by electron (SEM/TEM) and ion beam (ERD/RBS) techniques, as well as by interpretation of vibrational (Raman) spectra. We are simulating the solid-liquid interface using ionic modeling techniques, which provide a direct atomistic method for refining microscopic reaction mechanisms. These data are also being used to understand macroscopic geochemical cycling phenomena, especially global climate.

Results: The dissolution rates of orthosilicate 
minerals seem to correlate well with the rates of solvent $\left(\mathrm{H}_{2} \mathrm{O}\right)$ exchange around the aquated cation. Homovalent substitutions of cations dramatically affect mineral reactivities and calculated mineral lattice ener gies. Calculated lattice energies of perfect three-dimensional crystals do not correlate well with water exchange rates probably because important interactions, such as relaxation of bonds among surface atoms, are missing from these ionic calculations. Calculations of the (001) Ca-olivine surface indicate limited relaxation of the surface structure (to a depth of $\sim 3$ è) by rotation of the isolated silicate tetrahedra to minimize the total lattice energy.

Dissolution of silicates in soils consumes $\mathrm{CO}_{2}$, and over long periods of time ( $t>10^{5} \mathrm{yrs}$ ) is the primary sink for atmospheric $\mathrm{CO}_{2}$. Consequently, laboratory silicate dissolution rates are critical input for models of the carbon cycle and climate. The measured dissolution rates of the main acid-consuming $\mathrm{Ca}$ and $\mathrm{Mg}$ silicates, as a function of temperature and $\mathrm{P}_{\mathrm{CO}_{2}}$, show that soil $\mathrm{CO}_{2}$ does not have a direct effect on weathering rates. Increases in soil $\mathrm{CO}_{2}$ is thought to affect dissolution only indirectly by fertilizing plant growth and the production of corrosive organic acids. This hypothesis is being tested in the lab and in the field.

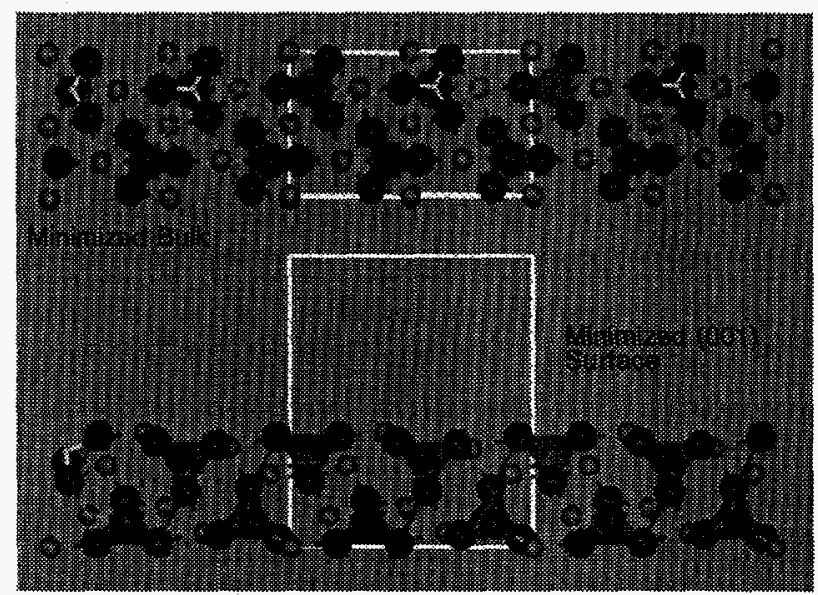

\section{Cation Diffusion Rates in Selected Silicate Minerals (Randall T. Cygan [505-844-7216; Fax 505-844-7354; E-mail rtcygan@sandia.gov], H. R. Westrich, and Craig S. Schwandt)}

Objectives: Determine experimental cation diffusion coefficients for garnet and pyroxene minerals at temperatures less than $1000^{\circ} \mathrm{C}$ for evaluating disequilibrium behavior in geological, nuclear waste, energy, and materials concerns.

Project Description: Evaluation and modeling of geochemical processes related to nuclear waste, energy, and materials problems will require the accurate determination of cation diffusion data in a variety of silicate minerals. A new technique for the preparation of diffusion couples using thin film technology was developed in an effort to evaluate the relatively slow diffusion of $\mathrm{Mg}^{2+}, \mathrm{Mn}^{2+}$, and $\mathrm{Ca}^{2+}$ in phases such as garnet and pyroxene (where diffusion rates are on the order of $10^{-22}$ to $10^{-16} \mathrm{~m}^{2} / \mathrm{sec}$ in the temperature range of $700^{\circ}$ to $1000^{\circ} \mathrm{C}$ ). Resistive evaporation of enriched stable isotopes onto polished mineral surfaces is used to create a thin film-mineral diffusion couple. Diffusion couples are annealed in a controlled oxygen fugacity furnace for periods up to three months in order to provide a diffusive penetration depth of approximately 0.2 microns. Depth profiles of the tracer isotope are obtained using an ion microprobe and are then fit to appropriate diffusion models to obtain precise and reproducible diffusion coefficients.

Results: An experimental matrix of grossular and enstatite samples was used to determine respectively ${ }^{44} \mathrm{Ca}$ and ${ }^{25} \mathrm{Mg}$ self-diffusion coefficients, and Arrhenius parameters, for the temperature range of $800^{\circ} \mathrm{C}$ to $1000^{\circ} \mathrm{C}$. Calcium diffusion is described by an activation energy of $155 \pm 10 \mathrm{~kJ} / \mathrm{mole}$ and a pre-exponential factor of $7.2 \pm 2.2 \times 10^{-16} \mathrm{~m}^{2} / \mathrm{sec}$. These data were obtained at oxygen fugacities equivalent to the QFM buffer and are an order-of-magnitude slower than ${ }^{25} \mathrm{Mg}$ diffusion in pyrope under similar conditions. There was no oxygen fugacity dependence observed for additional experimental anneals performed at $1000^{\circ} \mathrm{C}$ for ${ }^{44} \mathrm{Ca}$ diffusion in grossular. The Arrhenius data for ${ }^{25} \mathrm{Mg}$ diffusion in enstatite were obtained at relatively reducing conditions (IW buffer). Theanisotropy of $\mathrm{Mg}$ diffusion in this orthorhombic mineral is represented by three Arrhenius lines with activation energies ranging from $255 \pm 23 \mathrm{~kJ} / \mathrm{mole}$ for the (001) orientation to $345 \pm 38 \mathrm{~kJ} / \mathrm{mole}$ for the (100) orientation. These results are in very good agreement with the theoretical values obtained by an analysis of 
$\mathrm{Fe}-\mathrm{Mg}$ order-disorder kinetics of enstatite pyroxene (Ganguly and Tazzoli, 1994, American Mineralogist, in press.)

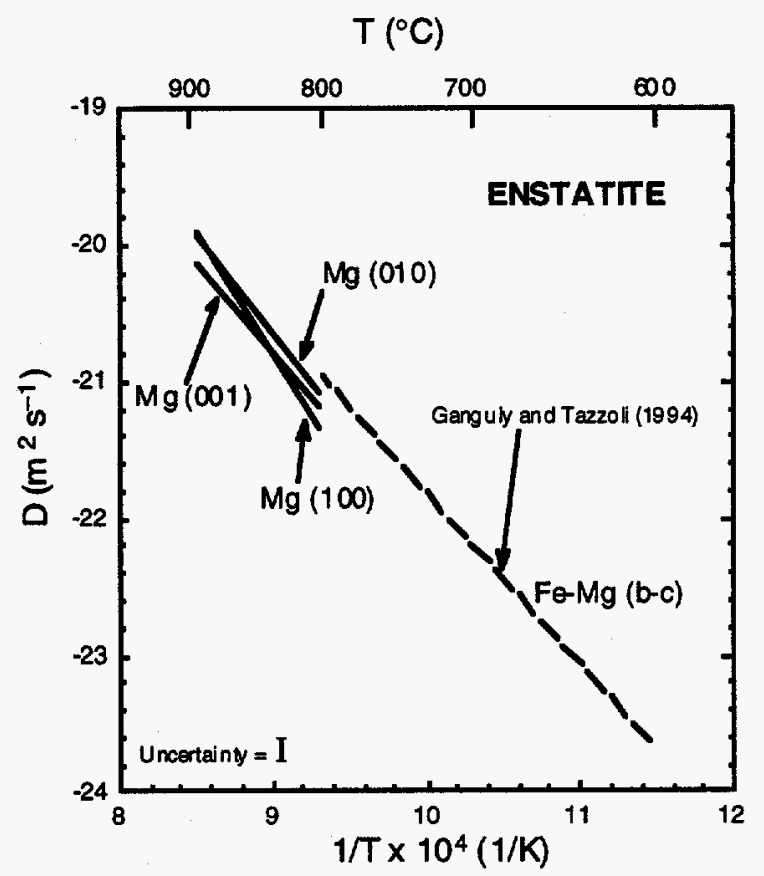

\section{Isotopic and Mineralogical Indicators of Infiltration and Vertical Fluid Movement in Unsaturated Zones of Semiarid Terrain (Steven J. Lambert [505-844-7876; Fax 505-844- 7354; E-mail sjlambe@sandia.gov])}

Objectives: To determine how the depth, volume, and rate of infiltration, and groundwater traveltime between surface and subsurface are governed by the seasonal distribution of episodic precipitation and storm intensity; to investigate the relationships between meteoric events and the transient and steady-components of infiltration and groundwater-recharge in a desert environment.

Project Description: This work seeks to identify climatic and hydrological parameters that govern recharge, and which potentially contribute to contaminant transport in unsaturated zones. In arid and semiarid terrain the uncertainty in the recharge term (used in water budget calculations) is commonly large; furthermore, losses due to evapotranspiration in the root zone may be significant. A natural cavern system developed in fractured limestone, underlying a desert environment, provides for direct measurement and sampling of water recharging an unsaturated zone, without the perturbations of borehole-sampling. Specifically, time-series (monthly) data are obtained for subsurface flux; concentrations of natural isotopic tracers $\left({ }^{18} \mathrm{O}\right.$ and deuterium) in both the infiltrate water and surface precipi- tation are measured in samples collected during flux measurements. Domains of unsaturated flow, represented by variations in flux (indicative of changes in hydrostatic potential) and tracer concentration (indicative of mass transport) are then correlated with surface recharge events using local precipitation records and the variations in tracer concentration in precipitation.

Results: Monitoring of flux and $\delta^{18} \mathrm{O}$ values of precipitation and recharge to the unsaturated zone continued in Carlsbad Cavern, New Mexico. The record of monthly infiltration rates at 13 permanent catchment stations is now complete through June, 1994, and the ${ }^{18} \mathrm{O}$ record is complete for rainfall and infiltrate through January, 1994. The correlations of flux and tracer concentration between surface and subsurface water reflect two discrete travel times for groundwater in different parts of the unsaturated zone: transport through the root zone from the surface to the top of a standing watercolumn within the subcutaneous layer (the "pulse" travel time), and mass transport from the top of the standing water-column to its bottom, representing ar rival of fluid in the main unsaturated zone. 
In order to determine pulse travel-times, numerical derivatives of the infiltration rate are compared with a 15-day moving average of the amounts of local rainfall accumulated in a 24-hour period, and the most significant increases in infiltration rate are tentatively ascribed to clusters of significant meteoric events. Similarly, the arrival of groundwater bearing seasonally-dependent fingerprint (lower- ${ }^{18} \mathrm{O}$ for storms originating over the Pacific Ocean, higher- ${ }^{18} \mathrm{O}$ for storms from the Gulf of Mexico) is used as the basis for estimating mass traveltime. The numerical derivatives of the monthly $\delta^{18} \mathrm{O}$ records of infiltration are compared with an $18 \mathrm{O}$ input function, defined as the product of the precipitation collected during a day and the deviation of its $\delta^{18} \mathrm{O}$ value from $-7.75 \%$, the mean value for Carlsbad Cavern groundwater. The resulting input function is also smoothed using a 15-day moving average. An example of these correlations, for a sampling station at $\sim 100$ meters depth, indicates a travel time of 8 to 9 months from the surface to the top of the standing water column, and $\sim 15$ months from the surface through the subcutaneous layer into the main unsaturated zone.

\section{CATEGORY:}

\section{Energy Resource Recognition, Evaluation and Utilization}

\section{PERSON IN CHARGE: M. C. Walck}

\section{A. Geoscience Research Drilling Office (GRDO) (P. Lysne [505-844-8885; Fax 505-844-3952; E-mail pclysne@sandia.gov], A. Sattler, and R. Jacobson)}

Objectives: The objectives of the GRDO are to support research scientists requiring drilling and other field operations to investigate processes in the earth's crust; to advance downhole measurements in harsh environments; and to maintain scientific links with the Department of Energy/Geothermal Division, the Ocean Drilling Program (ODP), and industry.

Project Description: GRDO support includes implementation of drilling and logging programs, consultation regarding permitting issues, and development of cost estimates for field activities. Industry ties are made through interactions involving downhole measurements in geothermal and hydrocarbon wells. Interactions with the ODP center about the JOIDES Downhole Measurement Panel (DMP) which is chaired by Peter Lysne.

Results: The GRDO wrote and revised an Operations Plan for the Katmai Project, a proposed activity that would extract continuous core from the site of the 1912 eruption in the Valley of Ten-Thousand Smokes, Katmai National Park, Alaska. The Plan formed the basis of Draft Environmental Impact Statement prepared by an independent outside consulting firm, and it detailed the logistics and drilling programs, including reclamation efforts. An extensive out- reach program was maintained that included federal, state, and local officials, Native American associations, and environmental groups. Unfortunately, the National Park Service preferred that no drilling action take place. Hence, GRDO work regarding Katmai has terminated.

The DMP is wrestling with the issue of standards for tools used within the ODP; progress here will impact other geoscience programs since quality issues provide a key ingredient for developing interactions with industrial organizations. In the past, ship's time had been wasted when tools were deployed before undergoing a review regarding engineering design and data integrity. Thus, the ODP has implemented a set of Guidelines for Third-Party-Tool Development, and the review process is the responsibility of the DMP. These Guidelines allow for the progression of Principal Investigator-instigated tools from the Development Stage that allows certain sea tests, to the Certified Stage where the success of an entire cruise can be contingent upon the proper operation of a tool. Several tools were passed by the DMP for operation at the TAG hydrothermal system located at $26^{\circ}$ North on the MidAtlantic Ridge. Output plumes (smokers) at this system exceed $380^{\circ} \mathrm{C}$. 


\section{B . Development of a Smart, High-Temperature Fluid-Sampling Tool (P. Lysne [505-844- 8885; Fax 505-844-3952; E-mail pclysne@ sandia.gov])}

Objectives: Past fluid-sampling tools have leaked when withdrawn from holes drilled into geothermal formations. The goal of the present program is to develop a proper sampling device compatible with a borehole environment in excess of the critical point of sea water $\left(407^{\circ} \mathrm{C}, 298.5\right.$ bars $)$; another version of the sampler is designed to gather steam samples at similar temperatures, but much lower pressures.

Project Description: Sampling devices that use one-way valves similar to those found in an internal combustion engine leak when withdrawn from liquidfilled wells possessing even a modest temperature gradient. This possibility exists whenever the thermal contraction of the trapped fluid causes the pressure internal to the tool to fall below the local hydrostatic pressure of the borehole. Another issue becomes important in steam-filled wells; specifically either sampling ves sels need be inordinately large and heated if gas-phase samples are to be collected and maintained, or, if the steam is allowed to condense, large heats-of-fusion must be accommodated within the Dewared sampling system. A final issue deals with the deployment of sampling systems. Due to the unreliability of electrical wirelines at high temperature, the samplers will be battery operated and data stored on board. Such "memory" devices are highly reliable, but they do not transmit diagnostic information to the surface. Thus, the present tools are being designed around computing systems that are smart. For example, the samplers can be programmed to trip when measured pressures and temperatures indicate that the tool has reached the closest approach to, for example, the critical point of sea water in any given hole.

Results: All components of the pressure and temperature sensing/recording system have been built and tested in geothermal wells. The tool and ancillary equipment are all transportable by passenger air service so they are available for deployment on short notice anywhere in the world. Issues surrounding the sampling sub-system have centered on dissipating the heat introduced into the Dewar when samples are taken, and two solutions have been found. The sampler vessel itself is surrounded by a eutectic material that melts at a low temperature. The latent heat of this transformation provides an effective heat sink for the condensation of steam and the cooling of hot fluids. Furthermore, the vessel is immersed in a bath of Fluorinert, a very inert liquid dielectric used in the electronics industry. This bath provides additional heat-sink capability, and should it boil, subsequent condensation of the vapor couples all components within the Dewar to the heat source. Effectively, the entire inner portion of the tool becomes part of the heat sink. 


\section{PART II OFF-SITE}


GRANTEE:

PERSON IN CHARGE:
GRANT:

TITLE:
UNIVERSITY OF ALASKA

Geophysical Institute

Fairbanks, Alaska 99775-7320
DE-FG06-91ER13530

\section{A Study of Magnetic Reconnection Processes and Plasma Processes in the Magnetosphere and the Solar Corona}

L. C. Lee (907-474-7410; Fax 907-474-7290;

E-mail fflcl@acad3.alaska.edu) and S.-I. Akasofu

Objectives: To examine and understand (1) the basic plasma processes associated with magnetic reconnection, (2) the formation and eruption of solar prominences and flares, and (3) the coupling between the solar wind and the Earth's magnetosphere.

Project Description: This project deals with the magnetic reconnection processes that play an important role in the transfer of mass, momentum and energy of the solar wind into the Earth's magnetosphere, the formation and eruption of solar prominences, and the onset of solar flares. The methodology of this study encompasses theoretical analyses and computer simulations. Specifically, the major research topics are: (1) the magnetohydrodynamic (MHD) simulation of the formation and eruption of solar prominences by photospheric motions, (2) the structure of reconnection layers in the magnetosphere studied by analytical theory and MHD and particle simulations, (3) the 3-D MHD simulation study of the generation of fieldaligned currents and Alfvén waves by magnetic reconnection at the dayside magnetopause, and the interpretation of the multiple brightening of poleward moving auroral forms observed in the polar ionosphere, and (4) the generalized Ohm's law as well as the force balance and momentum transport near an $\mathrm{X}$ type neutral line investigated by $2-D$ particle simulations.

Results: Computational study on the response of magnetic arcades to footpoint motions reveals that a current layer can develop in a sheared magnetic arcade when converging footpoint motions are imposed. In the magnetic island formed by magnetic reconnection, the condensation of plasma by thermal instability creates a Kuperus-Raadu type prominence. The prominences are found to erupt when the footpoint shear and convergence exceed critical values.

In the study of the structure of reconnection layer, Petschek's symmetric reconnection model is generalized by including an asymmetry in magnetic field and plasma density, a finite guide field $\left(B_{y}\right)$, the ion kinetic effect, and a large plasma flow in the magnetosheath. The hybrid simulation results show many resemblances to satellite observations at the magnetopause.

It is found in MHD simulations that Alfvén waves carrying field-aligned currents (FACs) can be generated by 3-D reconnection processes. Propagation of the Alfvern waves and FACs from the magnetopause to the ionosphere can explain how the poleward-moving auroral forms are created.

Particle simulations show the presence of a weakly anisotropic and skewed velocity distribution near the X-line during magnetic reconnection, which produces off-diagonal elements of the plasma pressure tensor. The momentum transport associated with the off-diagonal terms mediates an outward transfer of the $y$-momentum from the region near the $X$-line. 
GRANTEE:
TITLE:

PERSONS IN CHARGE:

GRANT:
UNIVERSITY OF ALASKA

Geophysical Institute

Fairbanks, Alaska 99775-0800
DE-FG06-92ER14232

Katmai Scientific Drilling Project

J. C. Eichelberger and S. E. Swanson (907-474-5530;

Fax 907-474-7290; E-mail eich@dino.gi.alaska.edu)
Objectives: This project tests models for explosive eruption of and subsequent chemical and heat transport ina silicic igneous system through planned three-dimensional exploration of an exemplary young volcano. Near-term objectives under this grant are to constrain rates of magmatic degassing, mixing, and crystallization and to characterize contents of the vent.

Project Description: The Katmai Project is part of the national Continental Scientific Drilling Program, which seeks to understand fundamental processes of crustal evolution through three-dimensional investigation of the continental crust. The 1912 eruption near Mt. Katmai on the Alaska Peninsula was the outstanding volcanic event of this century in the United States, and indeed in the world. The eruption is ideally suited to investigation of explosive volcanism because it is relatively simple, both in terms of geologic setting and chronology of the event itself. Objectives of the project are to improve models for explosive eruptions, to determine the source and mechanisms of metals transport in fumaroles of the 1912 ignimbrite, and to establish the rates and mechanisms of ongoing cooling of the system. The project was selected for implementation based upon peer-and panel-reviews by DOE, National Science Foundation, and the U.S. Gêological Survey (USG) and a panel review (as to suitability of the site) by the National Academy of Sciences. The approximately 40 scientists involved in the project come from numerous universities, the USGS, and several DOE laboratories. About half of this group was active during the surface phase of the project. The main surface effort took place in 1989-90, when a coordinated suite of geophysical surveys defined a $2-\mathrm{km}$-diameter vent for the eruption buried beneath its own ejecta at the head of the Valley of Ten Thousand Smokes. This work also provided evidence of a huge magma body still present beneath the region. The project plan called for drilling into the 1912 vent over a 2 -year period. Two holes would provide a complete cross section of the vent and sam ple its still-cooling feeder to a depth of $1.2 \mathrm{~km}$. An environmental impact statement was written under the management of the Alaska Region Office of the National Park Service (NPS).

Tasks under this grant are coordination of the project and a surface-based investigation of the degassing and mixing behavior of the 1912 magmas. The former effort consisted primarily of representing the project during the National Environmental Policy Act (NEPA)-mandated process. The second task uses the exceptional suite of variably quenched $1912 \mathrm{mag}$ matic material to investigate the timing and processes of volatile release and magma mixing. The suite encompasses rapidly quenched air-fall pumice, blocks of pyroclastic vent fill (breccia) rapidly quenched during ejection in late explosions, and Novarupta lava ranging from glassy to fully crystallized. The vent-fill ejecta also provide the best indication of what would be encountered in drilling, and a chemical baseline by which post-emplacement mass transport within the vent could be assessed.

Following completion of the NEPA Process, NPS planned to issue a record of decision. The drilling, if approved, would provide an unprecedented view of the processes and structures that give rise to explosive eruptions as well as new insights into processes of ore 
formation and hydrothermal circulation.

Results: The first phase of work under this grant focused on breccia blocks to interpret internal structure and processes of the vent. Above the fragmentation level (calculated to be about $500 \mathrm{~m}$ depth), the vent should consist of an annulus of rhyolite- and andesite-rich vitrophyre or its crystalline equivalent, formed during the close of the first day dominantly rhyolitic outburst, enclosing an inner cone of welded dacite-rich breccia material formed similarly during waning stages of the dacite-dominant second and third days. Although occurrence of surface-derived material in vent breccia requires some downward motion of components comprising the breccia, modestly elevated water contents, andesite-enrichment relative to erup tives, and textural contrasts to ignimbrite suggest that vent breccia may not be simple fall-back, but could represent material that aggraded on vent walls at depth, gradually constricting the vent. Ejection of such material without vesiculation suggests rapid cooling in situ, a conclusion now verified with heating experiments, which in turn suggests invasion of ground water into the vent during the eruption. A pyroclastic dike discovered in vent breccia provides evidence that intrusion of Novarupta lava began immediately after the explosive phase. It also suggests a possible mech anism for formation of thin dikes of viscous magma at shallow depth: The mafic component in Novarupta Dome is derived from andesitic magma, rather than dacitic magma as previously supposed, and has crystallized substantially in response to mixing with its cooler host.

The second phase of work focused on determining the chemical response of the dominant rhyolitic magma to decompression and emplacement. Glass inclusions in phenocrysts in tephra, matrix glass in tephra, matrix glass in pyroclastic dike, matrix glass in glassy lava, and matrix glass in partially crystalline lava allow changes in melt composition to be traced. In results that mirror those from drilling at Obsidian Dome, it appears that water is lost almost instanta neously during decompression, and that halogens are substantially retained and later lost during crystallization. An unexpected and important difference at Novarupta is that subsidence of its vent region quenched an active crystallization front, preserving chemical boundary layers in adjacent melt. Large changes in $\mathrm{K}$ concentration, and smaller and opposite changes in $\mathrm{Na}$ concentration, were found to occur in melt during crystallization (Fig.1).

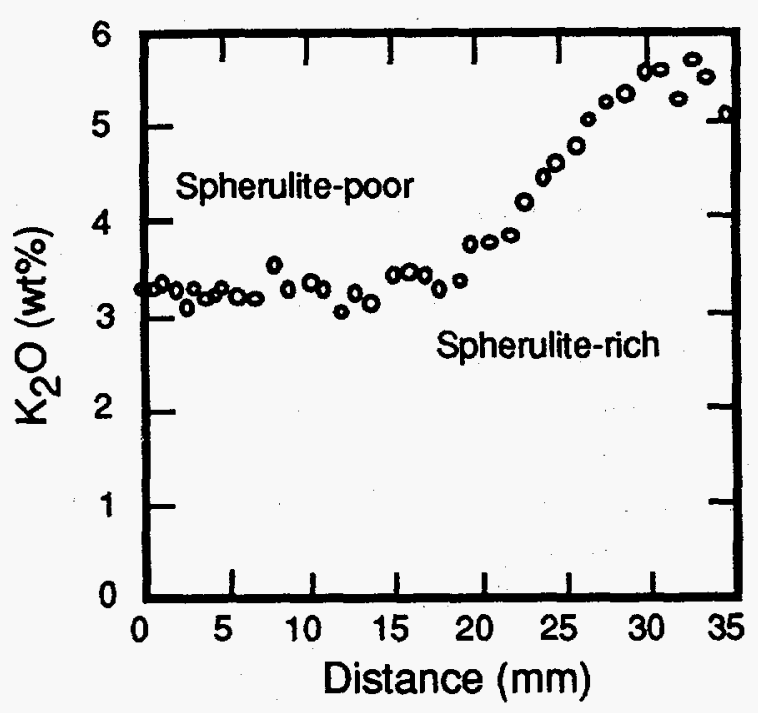

Fig. 1. Profile of glass composition across spherulitepoor to spherulite-rich transition in the interior of Novarupta Dome. The reverse effect, $K$ depletion, is found in a $10-\mu \mathrm{m}$-thick boundary zone adjacent to spherulites.

The NEPA Process came to an unexpected halt, when NPS determined that it lacked authority to permit the proposed drilling. Though completed in public draft form, the EIS will not be published. The PI has prepared two manuscripts for publication documenting the history of this process and analyzing the outcome. He is working with appropriate agencies to encourage development of improved policies concerning research on public lands. 
GRANTEE:

GRANT:

TITLE:

PERSON IN CHARGE:
AMERICAN GEOLOGICAL INSTITUTE 4220 King Street

Alexandria, Virginia 22302-1507

DE-FG05-94ER75979

U.S.-Russian Geoscience Student Exchange Program

Edward M. Davin (703-379-2480; Fax 703-379-7563)
Objectives: Support administration and operation of the U.S.-Russian Geoscience Student Exchange Program.

Results: In July ten students who had completed their 5-year course in geoscience at Russian universities were selected to participate in the exchange program. The students plan to enter careers in petroleum exploration and development in Russia. Final selection was based on results of personal interviews with U.S. faculty advisors from the three participating universities: University of Texas at Austin, Texas A\&M University and Colorado School of Mines. On August 2, the students arrived in the U.S. and were given a three-day cultural orientation program at
Meridian House International, Washington, D.C. The week of August 8, the students participated in an ori entation program in the Houston offices of the sponsoring oil companies, Amoco, Texaco, Exxon and Conoco. Time did not permit travel to the offices of Mobil in Dallas. The program covered the range of knowledge and skills required to evaluate oil/gas prospects and consisted of lectures, laboratory tours and demonstrations. This orientation was requested by the faculty advisors to guide the students in their course selection. On August 13, the students arrived at their assigned universities where they will spend two semesters. 


\section{GRANTEE:}

PERSON IN CHARGE:
GRANT:

TITLE:

\section{AMERICAN MUSEUM OF NATURAL HISTORY \\ Department of Mineral Sciences \\ New York, New York 10024}

\section{DE-FG02-92ER14265}

The Role of Carbon and Temperature in Determining Electrical Conductivity of Basins, Crust, and Mantle

E. A. Mathez (212-769-5379; Fax 212-769-5339;

E-mail mathez@amnh.org)
Objectives: Determine the influence of carbon abundance and distribution on electrical conductivities of mantle, deep crustal and sedimentary rocks.

Project Description: This is a collaborative project with A. G. Duba (Lawrence Livermore National Laboratory) and T. J. Shankland (Los Alamos National Laboratory) to investigate the effect of carbon on electrical conductivities of rocks. The great sensitivity of conductivity to small concentrations of fluids, ores and carbons and also to temperature make electromagnetic methods a unique probe of the Earth. For the most part conductivity profiles have been interpreted without consideration of the effects of carbon because carbon contents of crystalline and some sedimentary rocks are low. However, in the few rocks in which its distribution has been studied in detail, carbon has been found to be present along microfrac tures and mineral grain boundaries. This raises the possibility that carbonaceous compounds form interconnected networks over megascopic regions and thus exert a dominant influence on bulk-rock conductivities, even in rocks in which concentrations are small.

The research involves mapping the distribution of carbon in microfractures and grain boundaries of rocks, characterizing the carbons on these natural surfaces and correlating carbon distribution, connectivity and concentration with electrical conductivity. The investigations are focused mainly on mantle peridotites, deep crustal rocks and oil shales. The data will provide the basis to derive relationships describing conductivity of carbon-bearing rocks at conditions relevant to basins, crust and mantle.
Results: The influence of carbon on electrical conductivity of mid-crustal rocks of the YukonTanana terrane near the Denali Fault Zone, south-central Alaska, has been studied. We have been able to associate anomalous electrical conductivity with a specific carbon-bearing fracture in one sample and demonstrate from the petrographic relations that the fracture formed prior to deformation, which occurred in the deep crust.

A petrographic and stable isotope study has been made of graphite distribution in a suite of regionally metamorphosed graphitic carbonate rocks from the Waits River Formation, northeast Vermont. In the vicinity of younger plutons, the rocks are thermally metamorphosed. The low- and medium-grade ( $\mathrm{T}=$ $450-490^{\circ} \mathrm{C} ; \mathrm{P}=4 \mathrm{~kb}$ ) rocks contain $\approx 1 \%$ graphite. In the former 1-2- $\mu \mathrm{m}$ flakes of graphite are distributed evenly throughout; in the latter graphite is concentrated near porphyroblasts. The $\delta^{13} \mathrm{C}$ and $\delta^{18} \mathrm{O}$ of the graphite, carbonate and bulk silicate residue of the low and medium grade rocks are similar, which together with the petrographic observations indicate that carbon was redistributed on the scale of $\mathrm{mm}$ to $\mathrm{cm}$ but not involved in the metamorphic reactions. Highgrade rocks $\left(\approx 525^{\circ} \mathrm{C}\right)$ typically contain only $\approx 100$ ppm carbon (as graphite) and exhibit lower $\delta^{13} \mathrm{C}$ and $\delta^{18} \mathrm{O}$ values. The isotopic data and time-integrated mass fluxes computed from mineral assemblages suggest that graphite depletion was caused by influx of large quantities of magmatic water in the vicinity of the plutons.

Electrically conductive rocks from one of the 
KTB boreholes of southern Germany have been studied. In certain ilmenite- and rutile-bearing amphibolites carbon has been found to exist along cleavage surfaces of amphibole. The high electrical conductiv- ity of some samples is due to the fact that carbon on individual amphibole cleavage planes forms bridges between nearby but unconnected $\mathrm{Fe}$-Ti oxide grains. 
GRANTEE:
GRANT:

TITLE:

PERSON IN CHARGE:
ARIZONA STATE UNIVERSITY

Center for Solid State Science \& Department of Geology

Box 871704

Tempe, Arizona 85287-1704

\section{DE-FG03-94ER14414}

A Microanalytical (SIMS) Study of the Trace Element and Isotopic Geochemistry of Diagenetic Silicates

Richard L. Hervig (602-965-3107; Fax 602-965-9004 ; E-mail hervig@csss.la.asu.edu) and Lynda Williams (602-9650829; Fax 602-965-9004 ; E-mail atlbw@asuvm.inre.asu.edu)

Objectives: We are obtaining microanalyses of oxygen isotopes in authigenic silicates to determine their variation in hydrocarbon-producing sedimentary rocks. These analyses can be used to constrain the processes occurring during diagenesis and hydrocarbon migration.

Project Description: One of the most commonly used chemical variables for fingerprinting source or temperature changes in minerals is the oxygen isotopic ratio $\left(\delta^{18} \mathrm{O}\right)$. However, it is difficult to separate authigenic from detrital quartz, and the variation in the $O$ isotopic content of authigenic minerals in sedimentary rocks is poorly known. In 1992 we developed a secondary ion mass spectrometry (SIMS) technique to measure directly oxygen isotopes on the scale (10$20 \mu \mathrm{m}$ ) of many authigenic minerals in thin section. These measurements (errors of $1-2 \%$ ) are allowing us to determine how fluid chemistry changes during diagenesis or fluid migration, and could (in the latter case) suggest a source of the fluids. We have applied this new technique (as well as conventional SIMS trace element microanalysis techniques) to diagenetic minerals in oil producing wells of Alberta and the Gulf of Mexico sedimentary basin.

Results: We obtained $120 \delta^{18} \mathrm{O}$ measurements on $\sim 10-\mu \mathrm{m}$ spots in authigenic and detrital quartz from Mississippian sandstones of the Western Canada sed- imentary basin. Detrital quartz shows a large range in $\delta^{18} \mathrm{O}$ (5 to $25 \%$ ) which overlaps the analyses of authigenic cements $(20-34 \%)$. Combining these data with the burial history and precipitation sequence of minerals indicates that quartz initially precipitated from meteoric water at temperatures as low as $25^{\circ} \mathrm{C}$ and no higher than $45^{\circ} \mathrm{C}$. This event effectively occluded pores in samples from the central portion of the basin, but minor quartz precipitation continued up $\sim 80^{\circ} \mathrm{C}$ at the basin margin. Bulk analyses of these samples gave $\delta^{18} \mathrm{O}$ of $13.4 \%$ for detrital quartz and $19.8 \%$ for authigenic quartz. Thus bulk isotopic analyses bias the interpretation of the timing of diagenetic quartz precipitation to much higher temperatures. The SIMS measurements in diagenetic silicates can identify discrete episodes of precipitation allowing a more accurate interpretation for the timing of diagenetic events.

We have initiated a study of authigenic quartz from the Gulf of Mexico sedimentary basin.

An'essential component of oxygen isotope microanalysis is cathodoluminescence (CL) microscopy of the analyzed phases. CL allows detrital quartz to be distinguished from overgrowths, even when the $a b$ sence of dust rims limits the usefulness of optical microscopy. 
GRANTEE:

GRANT:

TITLE:

PERSONS IN CHARGE:
BROWN UNIVERSITY

Department of Geological Sciences

Providence, Rhode Island 02912

\section{DE-FG02-90ER14144}

\section{Grain Boundary Transport and Related Processes in Natural Fine-Grained Aggregates}

R. A. Yund and J. R. Farver (401-863-1931; Fax 401-863-2058;

E-mail ray@gech031.geo.brown.edu)

Objective: The objective of this study is to experimentally determine transport rates of geologically and environmentally important chemical species through natural and hot-pressed aggregates of common mineralogies over a range of temperatures, pressures, and coexisting fluid compositions. The results provide much needed data on the nature of grain boundaries in rocks and the rates of transport of chemical components through rocks. Applications of these data include evaluating the retentiveness of different geological medium for the isolation and confinement of nuclear and chemical waste, modeling the migration of hydrocarbons through different rock types to refine exploration and development strategies for more efficient oil and natural gas recovery, and determining patterns of circulation of hydrothermal meteoric water and associated ore-body deposition and geothermal energy systems.

Project Description: Grain boundary transport rates are determined in natural and hot-pressed aggregates of common mineralogies either "as-is" or after texturally equilibration with $\mathrm{H}_{2} \mathrm{O}_{2} \mathrm{CO}_{2} \pm \mathrm{NaCl}$ fluids. The physical nature of the sample textures and grain boundaries are characterized using transmission electron microscopy and scanning electron microscopy. The transport rates are determined from profiles of isotopic tracers measured using an ion microprobe (SIMS).

Results: Fine-grained monomineralic feldspar aggregates have been successfully hot-pressed and oxygen, potassium and calcium grain boundary diffusion rates have been measured in these aggregates as well as in a natural feldspar sample. Hot-pressed forsterite aggregates have been produced and used to study magnesium grain boundary diffusion rates over a five orders of magnitude range of confining pressures as well as a range of temperatures and water present or absent conditions. Effective grain boundary widths of $-3 \mathrm{~nm}$ have been determined for forsterite and for anorthite aggregates, and the values are similar to the maximum physical grain boundary widths determined using high resolution TEM imaging. In addition, oxygen and calcium volume diffusion rates have been determined in calcite single crystals and calcium grain boundary diffusion rates in natural (Solnhofen limestone) and hot-pressed calcite aggregates, extending our data base to geologically important non-silicate mineralogies.

Important observations from these studies include: (1) Hot-pressed aggregates provide excellent analogs to natural samples for grain boundary diffusion determinations. (2) Oxygen (as molecular water) grain boundary diffusion rates are similar, at least under hydrothermal conditions, in all three feldspar end member compositions as well as in fine-grained quartz aggregates. (3) The presence of water as a charge-compensating layer dissolved within the grain boundaries has only a modest $(\approx$ a factor of 5$)$ effect on cation grain boundary diffusivities. (4) There is a broad range of grain boundary diffusion rates for different cation species in different mineralogies. (5) The effective grain boundary width is similar to the physical grain boundary width and is $\sim 3 \mathrm{~nm}$. (6) Confining pressure has only a small effect (activation volume $\approx$ $1 \mathrm{~cm}^{3} /$ mole) on grain boundary diffusion rates. 
GRANTEE:

GRANT:

TITLE:

PERSON IN CHARGE:
CALIFORNIA INSTITUTE OF TECHNOLOGY

Division of Geological and Planetary

Sciences, Pasadena, California 91125
DE-FG03-93ER14311

The Southern Sierra Nevada Continental

Dynamics Project-Caltech Activities

Robert W. Clayton (818-395-6909; Fax 818-564-0715;

E-mail clay@seismo.gps.caltech.edu)

Objectives: The main objective of this study is to determine whether the Southem Sierra Nevada Moun tain Range is supported by a crustal root. A further objective is to deduce the relationship of this range to the adjoining Death Valley extensional province.

Project Description: To address these questions, two seismic profiles were executed. The first was a N-S profile running from Ridgecrest to Chafant Valley. The second was an E-W profile from Death Valley to Coalinga. Each profile utilized approximately 700 receivers (seismometers) and 10 shot points, spanning a distance of more than $400 \mathrm{~km}$. The field experiment was carried out by 10 academic and government institutions. In addition the NPE shot of Sept 22, 1993 was recorded on the E-W receiver line.

Results: The first objective of the study was answered by the analysis of the data from a shot point in
Owens Valley on the E-W profile, along with the recording of the NPE shot on the same line. Shot point 5 (Olancha, Owens Valley) showed that the PmP phase (P reflection from Moho) has nearly equal travel time when observed to the west (reflection points under the Sierras) or to the east (reflection points under Panamint Valley). The NPE recording also shows that there is no anomalous behavior of $\mathrm{Pg}$ (mid-crust phase) or Pn (Moho phase). These two observations indicate that there is no crustal root under the Southern Sierras. These have been verified by finite-difference modeling of the seismograms.

Problematically, the NPE recordings also indicate that their is no Mantle root to support the Sierras (i.e. no anomalous mantle arrivals). This then leaves open the question as to what is holding the Sierra Mountain range up. 
GRANTEE:

GRANT:

TITLE:

PERSONS IN CHARGE:
CALIFORNIA INSTITUTE OF TECHNOLOGY

Division of Geological and Planetary Sciences

Pasadena, California 91125

DE-FG03-89ER13445

\section{Infrared Spectroscopy and Hydrogen Isotope Geochemistry of Hydrous Silicate Glasses}

S. Epstein (818-356-6100; E-mail epstein@arms.gps.caltech.edu) and E. Stolper (818-356-6504; Fax 818-568-0935;

E-mail ems@expet.gps.caltech.edu)

Objectives: The focus of this project is the combined application of the methodologies of experimental petrology, infrared spectroscopy, and stable isotope geochemistry to understanding the behavior of volatile components, particularly water and carbon dioxide, in natural and synthetic silicate melts and glasses.

Project Description: This project integrates (1) a laboratory component directed toward the development of analytical techniques and a solid understanding of the physical chemistry of volatile components in melts and glasses through carefully controlled ex periments and syntheses, and (2) a field-oriented component in which these techniques and chemical principles are applied to specific petrological and volcanological problems. A key feature of this project is the combination of methodologies from stable isotope geochemistry with those from experimental petrology and mineralogy. A unique aspect of the project is the explicit focus on the roles played by different species of dissolved water and carbon dioxide in silicate melts and glasses (e.g., molecules of $\mathrm{H}_{2} \mathrm{O}$ and hydroxyl groups; molecules of $\mathrm{CO}_{2}$ and carbonate ion complexes). Many seemingly complex behaviors of volatiles in liquids, glasses, and magmas can be simply and quantitatively explained if the speciation is understood and taken into account.
Results: (1) The diffusion of $\mathrm{CO}_{2}$ in rhyolitic glasses and melts was measured at $450-1050^{\circ} \mathrm{C}$ and 500-1050 bars. These results contribute to a quantitative understanding of bubble growth, degassing, and eruption of silicic magmas. (2) Infrared techniques were used to measure concentrations of $\mathrm{H}_{2} \mathrm{O}$ and $\mathrm{CO}_{2}$ in volcanic glasses, especially in inclusions in phenocrysts from recent eruptions. These data are providing constraints on the role played by volatile components in igneous processes. (3) The solubility of $\mathrm{CO}_{2}$ in rhyolitic liquid was measured at pressures up to 1,500 bars. These results demonstrate that Henry's law is valid in mixed $\mathrm{H}_{2} \mathrm{O}-\mathrm{CO}_{2}$-bearing melts at high levels in the crust and allow quantitative modeling of the degassing of magmas. (4) The fractionations of $O$ isotopes between $\mathrm{CO}_{2}$ vapor and crystalline albite, al bitic glass and melt, and rhyolitic glass and melt were measured at temperatures up to $950^{\circ} \mathrm{C}$. These results are critical for quantitative interpretations of observed distributions of oxygen isotopes between minerals, melts, and gases in the earth's crust and mantle. (5) The fractionation of C-isotopes between $\mathrm{CO}_{2}$ vapor and rhyolitic glass and melt was measured at temperatures of $800-1200^{\circ} \mathrm{C}$. These results are useful for understanding measured ${ }^{13} \mathrm{C} /{ }^{12} \mathrm{C}$ ratios of magmas and magmatic gases. 
GRANTEE:

TITLE:
CALIFORNIA INSTITUTE OF TECHNOLOGY

Division of Geological and Planetary Sciences

Pasadena, California 91125

\section{GRANT:}

\section{DE-FG03-88ER13851}

Isotope Tracer Studies of Diffusion in Silicates and of Geological Transport Process in Aqueous Systems Using Actinide Elements

\section{PERSON IN CHARGE: $\quad$ G. J. Wasserburg (818-395-6139; Fax 818-796-9823)}

Project Description: We have determined the concentration of dissolved ${ }^{238} \mathrm{U}\left({ }^{\mathrm{C} 238} \mathrm{U}\right),{ }^{234} \mathrm{U} /{ }^{238} \mathrm{U}$ activity ratio $\left(\delta^{234} \mathrm{U}\right),{ }^{232} \mathrm{Th}$ and ${ }^{230} \mathrm{Th}$ in fresh and brackish water from the Baltic Sea by the use of TIMS. The brackish waters range in salinity from that of sea water (SW) to a minimum of $2.536 \%$ at the innermost part of the Baltic Sea. ${ }^{C 238} \mathrm{U}$ in oxygen-saturated surface waters ranges from $3.245 \mu \mathrm{g} / \mathrm{kg}$ in SW to $0.274 \mu \mathrm{g} / \mathrm{kg}$ in the least saline water and shows generally conservative behavior. Two samples from anoxic deep waters show up to $48 \%$ depletion in C238 $\mathrm{U}$ compared to the conservative mixing line. $8^{234} \mathrm{U}$ varies from $155 \%$ in $\mathrm{SW}$ to $331 \%$ in the innermost part of the Gulf of Bothnia. The decrease in ${ }^{C 238} \mathrm{U}$ and increase in $\delta^{234} \mathrm{U}$ going from South to North in the Baltic Sea agree with the lithology of the drainage basins (Precambrian crystalline basement in the north and Phanerozoic sediments and carbonates in the south). The $\delta{ }^{234} \mathrm{U}$ in the brackish water does not follow a simple mixing line indicating that the riverine inputs into the Baltic are not well mixed. $8^{234} \mathrm{U}$ in the Kalixälven river show higher values (693-761\%o) during spring and summer discharge and lower values during fall and winter (559-625\%). We infer that U-rich water from peat-lands is a plausible source for increased $\delta^{234} \mathrm{U}$ during spring and summer discharge. ${ }^{C 232} \mathrm{Th}$ and ${ }^{\mathrm{C} 230} \mathrm{Th}$ in river water vary between $9-19 \mathrm{ng} / \mathrm{kg}$ and $0.21-0.081 \mathrm{pg} / \mathrm{kg}$ respectively and reflect the importance of increased abundance of small particulates $(<0.45 \mu \mathrm{m})$. The ${ }^{232} \mathrm{Th} /{ }^{238} \mathrm{U}$ in river water is about 40 times less than in detrital material. In the brackish water, the ${ }^{232} \mathrm{Th} /{ }^{238} \mathrm{U}$ drops 2 orders of magnitude in the low salinity region
$(<5 \%$ ) reaching a value close to that of sea water at a salinity of $7.5 \%$. Most transported ${ }^{232} \mathrm{Th}$ must be deposited in the low salinity regions of the estuary. Entering the estuary, thedetrital particulates sediment out rapidly, whereas the non-detrital phase is removed more slowly, causing a marked increase of ${ }^{230} \mathrm{Th} /{ }^{232} \mathrm{Th}$ in the brackish water. In seawater, ${ }^{230} \mathrm{Th} /{ }^{232} \mathrm{Th}$ is closer to river input and detrital material than in brackish water. We conclude that in the deep sea, Th is dominated by windblown dust and can be used to monitor the dust flux.

We have obtained high-precision ${ }^{234} \mathrm{U}^{238} \mathrm{U}-$ ${ }^{230} \mathrm{Th}$ ages of corals at two sites from the Caribbean to establish a sealevel curve for this region to compare isostatic changes in the geoid for intermediate and far field regions. Samples are from cores in two reefs in tectonically stable Florida (Fowey Rocks and Alligator Reef) and in Galeta Reef in E. Panama. Samples are largely Acropora palmata, which grows within $5 \mathrm{~m}$ of sealevel. The depth-age relationships from the two locations overlap and form a smooth curve with the exception of one sample. The apparent rate of sealevel change averages $1.9 \mathrm{~m} / \mathrm{ka}$, with a maximum of $4 \mathrm{~m} / \mathrm{ka}$ from $9000 \mathrm{a}$ to $6700 \mathrm{a}$. The Florida-Panama "sealevel" curve is distinctly higher than for Barbados, with a difference in depth between the curves of about $5 \mathrm{~m}$ at $8500 \mathrm{a}$ and $19 \mathrm{~m}$ at $11000 \mathrm{a}$ (U-Th ages). The oldest section of the curve corresponds to part of the timescale of the second meltwater pulse inferred by Fairbanks (1989) where a change of $10 \mathrm{~m} / \mathrm{ka}$ is observed in the Barbados curve; there is no evidence of such rapid change in the Florida coral reefs. This demonstrates that meltwater 
input rates cannot be easily derived from local sealevel curves. The present Florida data provide a strict lower limit to sealevels in the Caribbean. The difference between the Abrolhos and Florida-Panama curves is likely due to differential changes in the geoid and to redistributions of water masses. 
GRANTEE:
GRANT:

TITLE:
UNIVERSITY OF CALIFORNIA AT BERKELEY

Department of Geology and Geophysics

Berkeley, California 94720
DE-FG03-91ER14200

\section{Experimental Measurement of Thermal Conductivity in Silicate Liquids}

\section{PERSON IN CHARGE:}

I. S. E. Carmichael (510-642-2577; Fax 510-643-9980)
Objectives: The thermal conductivity of silicate liquids is the most poorly known of their transport properties. These data are paramount for understand ing the thermal evolution of magma systems, or the formation of glass for industrial purposes.

Project Description: This project is designed to measure the thermal conductivity of a variety of iron free silicate liquids, covering part of the range found in nature, as a function of temperature and composition at $1 \mathrm{bar}$. The temperature range is from the liquidus of each composition to $\sim 1600^{\circ} \mathrm{C}$. The apparatus to measure thermal conductivity has been developed from the transient hot-wire technique that has been used for accurate primary measurements of fluids, and minimises uncertainties due to convection and radiation. A test cell has been fabricated which is unreactive with silicate liquids and provides isothermal conditions at high temperatures.

Results: Measurements of thermal conductivity $(\lambda)$ have been made for liquid $\mathrm{CaMgSi}_{2} \mathrm{O}_{6}, \mathrm{Na}_{2} \mathrm{SiO}_{3}$ and $\mathrm{CaNa}_{4} \mathrm{Si}_{3} \mathrm{O}_{9}$ over a range of temperatures. Unfortunately both liquid $\mathrm{K}_{2} \mathrm{SiO}_{3}$ and Fe-bearing sili cate liquids react with the Pt container, or with the $\mathrm{Rh} / \mathrm{Ir}$ filaments, and could not be measured. For $\mathrm{CaMgSi}_{2} \mathrm{O}_{6}$ thirty-five measurements were made using both $\mathrm{Rh}$ and Ir filaments and the mean values at each temperature are plotted in the figure, with the error bars representing \pm two sigma of the replicate measurements at each temperature. Fifteen measurements were made on liquid $\mathrm{Na}_{2} \mathrm{SiO}_{3}$ which are also plotted, and thirteen on liquid $\mathrm{CaNa}_{4} \mathrm{Si}_{3} \mathrm{O}_{9}$ which are not plotted.

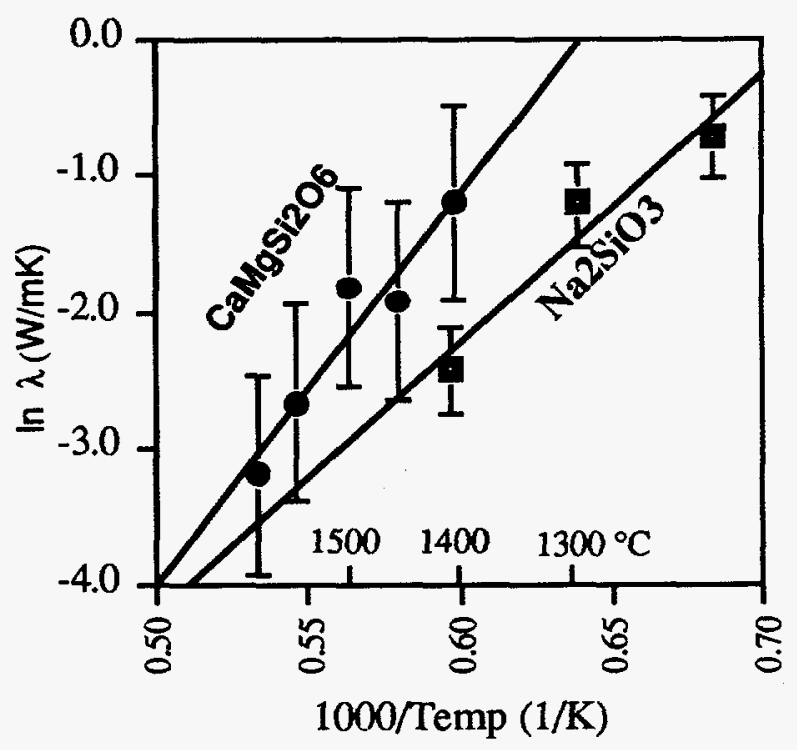

Least-squares regression of the individual data points gives:

$\ln \lambda\left(\mathrm{CaMgSi}_{2} \mathrm{O}_{6}\right)=27678 / \mathrm{K}-17.74$

$\ln \lambda\left(\mathrm{Na}_{2} \mathrm{SiO}_{3}\right)=20319 / \mathrm{K}-14.45$

$\ln \lambda\left(\mathrm{CaNa}_{4} \mathrm{Si}_{3} \mathrm{O}_{9}\right)=9520 / \mathrm{K}-8.10$.

The magnitude of the activation energies for the first two liquids are similar to those for viscous flow and mass diffusion. 
GRANTEE:
GRANT:

TITLE:

PERSON IN CHARGE:
UNIVERSITY OF CALIFORNIA AT BERKELEY

Department of Geology and Geophysics

Berkeley, California 94720
DE-FG03-85ER13419
Advective-Diffusive/Dispersive Transport of Chemically
Reacting Species in Hydrothermal Systems

Harold C. Helgeson (510-642-1251; Fax 510-643-9980; E-mail brogie@garnet.berkeley.edu)
Objectives: To achieve a better understanding of the effects of thermodynamics and chemical mass transfer on the occurence, evolution, and development of energy resources in the crust of the Earth.

Project Description: The major scientific and technical issues of concem in this project are:

1. How reactive are organic molecules at elevated temperatures and pressures in sedimentary basins?

2. How prevalent are metastable equilibrium states involving these molecules and the minerals and waters in source rocks and reservoirs?

3. What is the role of oxygen fugacity relative to temperature and pressure in breaking down organic matter to hydrocarbons and the maturation of petroleum in source rocks?

4. What are congruent and incongruent solubilities of detrital minerals in oil-field waters, and what diagenetic role do organic species in petroleum play at the oil-water interface in determining these solubilities and generating secondary porosity resulting from mineral dissolution?

5. What is the role of water and hyperthermobarophilic microbes in the generation and maturation of petroleum at depths in excess of $\sim 3 \mathrm{~km}$ ?

Results: During the past year, research efforts have been concerned primarily with calculation of the standard and excess thermodynamic properties of aqueous species and electrolytes over a wide range of pressure and temperature, and application of the results to calculation of the aqueous solubilities of petroleum and authigenic mineral assemblages in hy- drocarbon reservoirs. Experimental data avaliable in the literature were used to generate extended-term Debye-Hückel parameters $\left(b_{\gamma}\right)$ for dissociated aqueous $\mathrm{KCl}, \mathrm{KOH}$, and $\mathrm{NaOH}$, which permit accurate calculation of activity coefficients of the electrolytes over a wide range of pressure and temperature. Dissociation constants of $\mathrm{HCl}^{0}$ retrieved from lowtemperature vapor pressure data and high-temperature conductance measurements were used to calculate standard partial molal thermodynamic properties and revised HKF equations of state coefficients for the species. Experimental concentrations of $\mathrm{HCl}$ in $\mathrm{KCl}-$ $\mathrm{HCl}$ solutions saturated with mineral assemblages in the system $\mathrm{K}_{2} \mathrm{O}-\mathrm{Al}_{2} \mathrm{O}_{3}-\mathrm{SiO}_{2}-\mathrm{H}_{2} \mathrm{O}-\mathrm{HCl}$ were then used to generate Setchènow coefficients $\left(b_{\gamma, n}\right)$ for $\mathrm{HCl}^{0}$ in $\mathrm{KCl}$ solutions at high temperatures and pressures. These values were found to be similar in magnitude to those of $\mathrm{NaCl}^{0}$ in aqueous $\mathrm{NaCl}$ solutions, but substantially lower than those for $\mathrm{HCl}^{0}$ in aqueous $\mathrm{HCl}$ solutions. In addition, aqueous solubilities of nonane $\left(\mathrm{C}_{9} \mathrm{H}_{20}\right)$ with activities ranging from 1.0 in pure nonane to 0.1 and 0.01 in crude oil have been calculated at $\sim 120^{\circ} \mathrm{C}$ and 400 bars as a function of oxygen fugacity in a generic oil-field water containing representative concentrations of $\mathrm{NaCl}, \mathrm{CaCl}_{2}, \mathrm{MgCl}_{2}$, and $\mathrm{FeCl}_{2}$ in equilibrium with minerals in the system $\mathrm{CaO}-\mathrm{MgO}-\mathrm{FeO}-\mathrm{CO}_{2}-\mathrm{O}_{2}-\mathrm{H}_{2} \mathrm{O}$. In the presence of calcite, the oxidative solubilities resulting from the formation of aqueous $\mathrm{CO}_{2}$, n-carboxylic acids, and other oxidized organic aqueous species from $n$ alkanes in crude oil are several orders of magnitude greater than their stoichiometric counterparts. 
GRANTEE:

GRANT:

TITLE:

PERSON IN CHARGE:
UNIVERSITY OF CALIFORNIA AT DAVIS

Department of Land, Air and Water Resources and the Department of Geology and the Department of Chemistry

Davis, California 95616

\section{DE-FG03-92ER14307}

A New Method for Determining Excess Gibbs Energies in Binary Metal-Carbonate Solid Solutions

William H. Casey (916-752-3211; Fax 916-752-1552;

E-mail whcasey@ucdavis.edu) and Peter A. Rock (916-752-0940;

Fax 916-752-8995)

Objectives: Our objective is to establish a new electrochemical cell method for determining the Gibbs energies of impure carbonate minerals, binary carbonate solid solutions, and hydroxycarbonate minerals.

Project Description: The thermodynamic properties of carbonate solid-solutions are difficult to study because secondary phases precipitate during a typical solubility experiment and because slow gas evolution complicates dissolution calorimetry. Solubilities have been estimated by extrapolating transient concentration data and by conducting the experiments in the presence of solutes that retard rates of precipitation. Both methods have been criticized as inaccurate but are widely used for lack of superior alternatives.

We designed metal-carbonate electrodes of the third kind that avoid some of these difficulties. Our electrode involves a metal (e.g., $\left.\mathrm{Cd}^{\circ}\right)$ in contact with a slightly soluble salt of the metal (e.g., $\mathrm{CdCO}_{3}(\mathrm{~s})$ ) and provides a measure of the activity of a dissolved salt with a common anion and a cation that is not directly electroactive (e.g., $\mathrm{CaCO}_{3}(\mathrm{~s})$ ). The apparatus is referred to as a double cell when two complete, interconnected, electrochemical cells are employed in series opposition. A potential is generated in one cell by equilibrium with pure $\mathrm{CaCO}_{3}$ (s) while the other contains a solid solution (e.g., $\mathrm{Ca}_{x} \mathrm{Cd}_{1-\mathrm{x}} \mathrm{CO}_{3}(\mathrm{~s})$ ). For example, a cell suitable for studying the $\mathrm{Ca}_{\mathrm{x}} \mathrm{Cd}_{1-\mathrm{x}} \mathrm{CO}_{3}$ (s) system is:
$\mathrm{Cd}\left(\mathrm{Hg}\right.$, two phase) $\left|\mathrm{CdCO}_{3}(\mathrm{~s}), \mathrm{CaCO}_{3}(\mathrm{~s})\right|$

$\mathrm{CaCl}_{2}\left(\mathrm{aq}, m_{1}\right) \mid \mathrm{Hg}_{2} \mathrm{Cl}_{2}$ (s) $|\mathrm{Hg}(\mathrm{l})-\mathrm{Hg}(\mathrm{l})| \mathrm{Hg}_{2} \mathrm{Cl}_{2}$ (s) $\mid$

$\mathrm{CaCl}_{2}\left(\mathrm{aq}, m_{2}\right), \mathrm{CdCl}_{2}\left(\mathrm{aq}, m_{3}\right)$ ।

$\mathrm{Ca}_{x} \mathrm{Cd}_{1-x} \mathrm{CO}_{3}(\mathrm{~s}), \mathrm{CdCO}_{3}(\mathrm{~s}) / \mathrm{Cd}(\mathrm{Hg}$, two phase)

The sum of the electrode reactions yields the equation for the net cell reaction:

$\mathrm{CaCO}_{3}(\mathrm{~s})+x \mathrm{Ca}^{+2}\left(\mathrm{aq}, m_{2}\right)+(1-x) \mathrm{Cd}^{+2}\left(\mathrm{aq}, m_{3}\right)$

$+2 \mathrm{Cl}^{-}\left(a q, 2 m_{2}+2 m_{3}\right)$

$=\mathrm{Ca}_{x} \mathrm{Cd}_{1-x} \mathrm{CO}_{3}(\mathrm{~s})+\mathrm{Ca}^{+2}\left(\mathrm{aq}, m_{1}\right)+2 \mathrm{Cl}-\left(\mathrm{aq}, 2 m_{1}\right)$

Introduction of the Nernst equation and mean ionic activity coefficients yields:

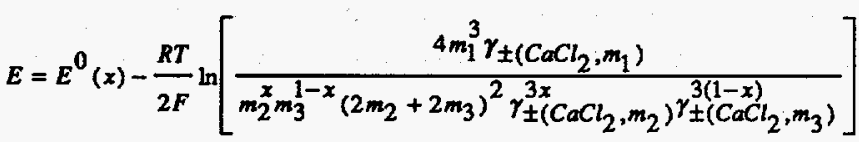

Measurement of $E$ at known molalities $\left(m_{1}, m_{2}\right.$ and $\left.m_{3}\right)$, together with values of the mean ionic activity coefficients, gives $E^{o}(x)$ for the cell reaction:

$\begin{aligned} \mathrm{CaCO}_{3}(\mathrm{~s})+(1-x) \mathrm{Cd}^{+2}(\mathrm{aq})= & \mathrm{Ca}_{x} \mathrm{Cd}_{1-x} \mathrm{CO}_{3}(\mathrm{~s}) \\ & +(1-x) \mathrm{Ca}^{+2}(\mathrm{aq})\end{aligned}$

from which $\Delta G^{\circ}{ }_{\mathrm{f}}\left[\mathrm{Ca}_{x} \mathrm{Cd}_{1-x} \mathrm{CO}_{3}(\mathrm{~s})\right]$ can be calcul ated. Similar cells can be constructed for studying 
other solid-solution minerals or mixed-anion solids such as hydroxycarbonate minerals.

Results: Excess Gibbs energies for mixing $\left(\mathrm{G}^{\mathrm{E}}\right)$ in two binary carbonate systems are shown in Fig. 1. In the $\mathrm{Ca}_{x} \mathrm{Cd}_{1-x} \mathrm{CO}{ }_{3}(\mathrm{~s})$ system, the $\mathrm{G}^{\mathrm{E}}$ values are consistently less than zero for $0.0 \ll 1.0$, indicating that the solid solutions are stable relative to a mechanical mixture of the end-member components. Conversely, in the $\mathrm{Ca}_{x} \mathrm{Sr}_{1-x} \mathrm{CO}{ }_{3}$ (s) system (Fig. 1B), $\mathrm{G}^{\mathrm{E}}$ values are positive for the compositional range $0.0<<0.85$, indicating that these solid solutions are unstable relative to a mechanical mixture of the end-member compositions. Although such compositions can be synthesized, they spontaneously unmix with time. Magnitudes of the $G^{E}$ values shown in Fig. 1 are very sensitive to choice of $G^{\circ}$ falue for the end-member phase.

These cells are a significant advance over conventional solubility measurements because: (1) rever- sibility can be determined quickly and unambiguously, (2) they have higher sensitivity and precision than solubility experiments; and (3) the cell measurements can be interpreted without appeal to complicated models of the solute speciation or to corrections for liquid-liquid junction potentials. The precision of the measured cell voltages for reversible double cells is in the range of \pm 0.05 to $0.50 \mathrm{mV}$, which makes the method sufficiently sensitive to detect small changes in the Gibbs energies. Evidence that the cell reactions are reversible includes demonstration of Nernstian response to changes in electrolyte composition, and an absence of significant hysteresis in cell current-voltage and current-temperature (10$35^{\circ} \mathrm{C}$ ) plots. This electrochemical method therefore provides a direct measure of the desired thermodynamic data, as opposed to techniques that obtain similar data from small differences between large numbers.
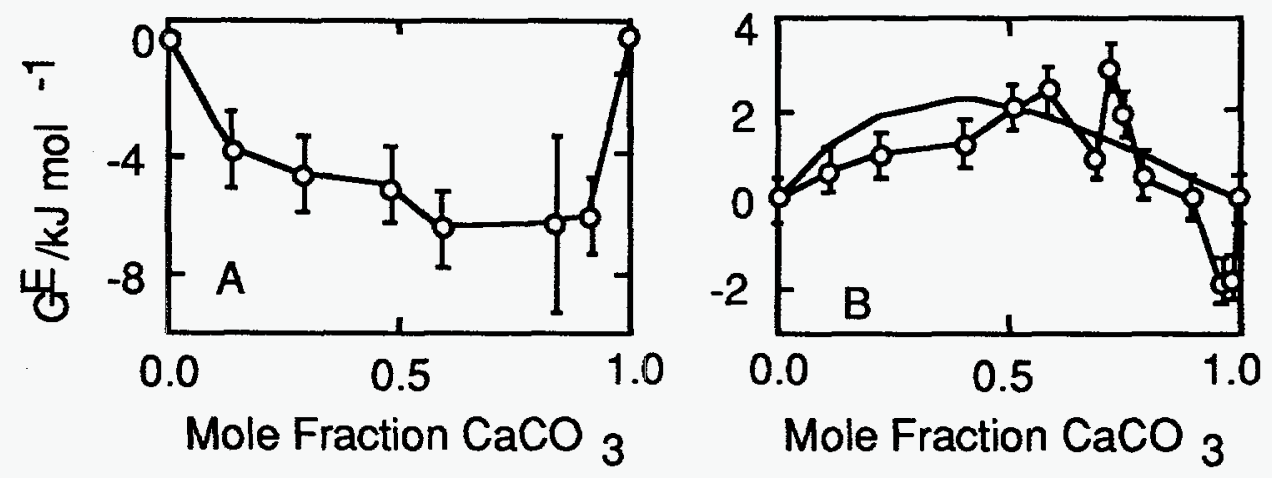

Fig. 1. $\mathrm{G}^{\mathrm{E}}$ values for solids in the $\mathrm{Ca}_{\mathrm{x}} \mathrm{Cd}_{1-\mathrm{x}} \mathrm{CO}_{3}(\mathrm{~A})$ and $\mathrm{Ca}_{\mathrm{x}} \mathrm{Sr}_{1-\mathrm{x}} \mathrm{CO}_{3}$ (B) binary systems. The line in (B) corresponds to smoothed estimates from solubility experiments of Busenberg and Plummer (1987), Geochim. Cosmochim. Acta 51, 1393. 


\section{GRANTEE:}

TITLE:

PERSON IN CHARGE:
UNIVERSITY OF CALIFORNIA AT DAVIS

Department of Geology

Davis, California 95616
GRANT:

DE-FG03-92ER14240

\section{Energetics of Melts from Thermal Diffusion Studies}

C. E. Lesher (916-752-9779; Fax 916-752-0951;

E-mail lesher@.geology.ucdavis.edu)
Objectives: This research program characterizes mass transport by diffusion in geological fluids in response to thermal, solubility, and/or chemical gradients to obtain quantitative information on the thermodynamic and kinetic properties of multicomponent systems.

Project Description: Thermal diffusion is the phenomenon of chemical migration in response to heat flow along a thermal gradient. The details of this response are conditioned by the thermochemical properties and constitution of the substance. Silicate liquids undergo substantial thermal diffusion (Soret) differentiation, while the response in sulfide, carbonate, and aqueous fluids to an imposed temperature gradient is varied. The experimental observations of this differentiation are used to evaluate the form and quantitative values of solution parameters, and to quantify ordinary diffusion coefficients, heats of transport, and activation energies of multicomponent liquids. The diffusion, solution, and element partition coefficients determined for these geological fluids form a data base for understanding magmatic crystallization behavior and for evaluating geothermal, ore deposit, and nuclear waste isolation potentials. Thermal and isothermal diffusion experiments are conducted using the one atmosphere gas mixing apparatus, rapidquench cold seal apparatus up to $0.3 \mathrm{GPa}$, piston cylinder device at pressures between $0.7-3.5 \mathrm{GPa}$, and a simplified multianvil device above $3.5 \mathrm{GPa}$. The electron and ion microprobes, and the infra-red spec- trometer are used in the characterization of experimental run products.

Results: During the past year we completed construction of the experimental petrology laboratory for thermal diffusion work at UC Davis. Current experimental capabilities include two 1-atm gas mixing furnaces, a rapid-quench cold seal apparatus, three piston cylinder devices, and a Walker-style multianvil device driven by a 1000 -ton Clifton press equipped with a computer controlled hydraulic system. Among the research activities of the last year we conducted thermal diffusion experiments at very high pressure on magmatic silicate liquids in an attempt to use the recovered heats of transport and chemical potentials as monitors of changing speciation with pressure, expanded on our preliminary study of large (4-7\%o) mass-dependent oxygen isotope Soret fractionation in silicate liquids at high temperature, documented small $(<1 \%$ ) oxygen isotope fractionation under isothermal conditions between liquids of contrasting bulk composition, began studies of Soret separations of water and carbonate species in naturally occurring silicate liquids, discovered that self diffusion coefficients for $\mathrm{Si}$ and $\mathrm{O}$ in basaltic liquid are indistinguishable suggesting cooperative diffusion of these species, expanded our theoretical treatment of chemical diffusion using Darken's theory of ion mobility, and initiated a comprehensive study of thermal, self and chemical diffusion of multicomponent liquids of the system $\mathrm{CaO}-\mathrm{MgO}-\mathrm{SiO}_{2}$. 
TITLE:

PERSON IN CHARGE:

\section{K-Feldspar Thermochronometry}

T. M. Harrison (310-825-7970; Fax 310-825-4396;

E-mail tmh@argon.ess.ucla.edu)
Objectives: The ${ }^{40} \mathrm{Ar} /{ }^{39} \mathrm{Ar}$ method can furnish information about both the internal distribution of ${ }^{40} \mathrm{Ar} *$ and $\mathrm{Ar}$ diffusion parameters. The multi-diffusion domain model (MDD) has shown promise in explaining various effects seen in the laboratory and has been successfully applied to a variety of energy-related problems. The objective of this research is to develop K-feldspar ${ }^{40} \mathrm{Ar} /{ }^{39} \mathrm{Ar}$ thermochronometry into a robust tool for assessing upper-crustal thermal histories.

Project Description: In our formulation of the MDD model, the form of the Arrhenius plot and age spectrum are a function of the diffusion parameters for each discrete domain (activation energy, E, and frequency factor, $D_{0}$ ), the domain distribution parameters (domain size, $\rho$, and volume fraction, $\phi$ ), and the thermal history. Since the diffusion parameters may be obtained directly from the Arrhenius plot and we have two independent measures of $\rho$ and $\phi$ (the Arrhenius plot and age spectrum), we have sufficient information to obtain a solution for the thermal history. Both the underlying assumptions and general predictions of the theory can be tested through laboratory investigations, including diffusion experiments and direct imaging (using visible light, $x$-rays, and TEM methods), or through study of argon isotopic variations in natural $\mathrm{K}$-feldspars.

Results: We have continued development of an approach that takes advantage of the differential release of excess ${ }^{40} \mathrm{Ar}\left({ }^{40} \mathrm{Ar} E\right)$ between contiguous isothermal heating steps, due to decrepitation of fluid inclusions, to derive a correction for ${ }^{40} \mathrm{Ar}_{\mathrm{E}}$
Differences in age and $\mathrm{Cl} / \mathrm{K}$ between successive temperature pairs commonly yield a single, well-correlated array on a $\log \Delta\left({ }^{40} \mathrm{Ar} * / \mathrm{K}\right) w . \log \Delta(\mathrm{Cl} / \mathrm{K})$ plot that identifies the Cl-correlated composition of ${ }^{40} \mathrm{Ar}_{\mathrm{E}}$ affecting that sample. Over two dozen K-feldspar samples measured in this way yield distinct ${ }^{40} \mathrm{Ar}_{\mathrm{E}} / \mathrm{Cl}$ ratios, varying from $1.1 \times 10^{-3}$ to $4.2 \times 10^{-6}$, that make possible the recovery of otherwise unobtainable thermochronological information. The cutoff in the ${ }^{40} \mathrm{Ar}_{\mathrm{E}} / \mathrm{Cl}$ distribution at a ratio of $10^{-3}$ may either reflect argon saturation in mid-crustal fluids or an upper limit on the time between deuteric alteration and cooling below argon closure in $\mathrm{K}$-feldspar. To further investigate this phenomenon, we hydrothermally synthesized fluid inclusions in quartz from an argon saturated brine of varying salinity ( 0 to $35 \mathrm{~mol} \% \mathrm{NaCl}$ ). Initial results confirm that $\mathrm{Ar} / \mathrm{Cl}$ ratios of $10^{-3}$ are attainable. The $\mathrm{Cl}$ correction method has been used to recover thermal history information from highly contaminated K-feldspars obtained from boreholes into the still-active Eldzhurtinskiy hydrothermal system. Following correction for Cl-correlated ${ }^{40} \mathrm{Ar}_{\mathrm{E}}$, a sample retrieved at a temperature of $220^{\circ} \mathrm{C}$ yields zero ages over the first $3 \%$ of ${ }^{39} \mathrm{Ar}$ release, consistent with predictions of MDD modeling. These results place important constraints on the timing of emplacement and the subsequent thermal evolution of this pluton and demonstrate the potential of this method for assessing geothermal histories. Characterization of Madagascar orthoclase $\left(\mathrm{Or}_{93}\right.$ ) by TEM and ${ }^{40} \mathrm{Ar} /{ }^{39} \mathrm{Ar}$ was undertaken to assess its suitability for planned diffusion studies. 
TITLE:

PERSONS IN CHARGE:
Oxygen and Cation Diffusion in Oxide Materials

K. D. McKeegan (310-825-3580; Fax 310-825-2779;

E-mail kdm@argon.ess.ucla.edu)
Objectives: The objective of this work is to measure the diffusion parameters for various cations and oxygen in important rock-forming minerals in order to constrain both geochemical transport processes and diffusive mechanisms affecting physical properties such as creep and electrical conductivity.

Project Description: Diffusion rates are strongly affected by temperature, pressure, crystal orientation. They may also depend upon additional variables such as oxygen fugacity and the activity of water in the system. We are conducting experiments in which all of these variables are controlled and selectively varied. The pressures of current experiments (concentrating on olivine, plagioclase, diopside, garnet and spinel) range from 1 atmosphere to $10 \mathrm{GPa}$. The primary analytical tool used in these investigations is an ion microprobe.

Results: It is well known that garnets can preserve zonation in major elements trace elements and radiogenic isotopes. Since these characteristics are sensitive to the $P-T$ history of garnet growth, such zonation patterns can be inverted to extract $P-T-t$ information about the rocks in which they are found. More recently, there have been a number of investiga tions in which zonation in the oxygen isotopic composition of metamorphic garnets has been used to constrain various aspects of the fluid history of the sample. The extent to which any information recovered from gamet zoning can be used to characterize its growth history will be in part dependent upon the rate of diffusive relaxation of that primary zonation. We have started a series of oxygen self-diffusion experi- ments on 3 different almandine-spessartine gamets. These experiments were conducted at one atmosphere between $900-1000^{\circ} \mathrm{C}$ under controlled oxygen fugacity using ${ }^{18} \mathrm{O}$-enriched $\mathrm{CO}$ and $\mathrm{CO}_{2}$; oxygen fugacities lie between the iron-wüstite and nickel-nickel oxide buffers. It is certain that some of the materials investigated are unstable under these conditions, however, all of the materials investigated can be preserved in a metastable state under our experimental conditions. Typically, lower oxygen fugacities are more conducive to preservation of the highly polished surfaces, preventing the formation of new phases. In all cases, the sample has been annealed in isotopically normal gases prior to the introduction of the ${ }^{18} \mathrm{O}$-enriched gases, to ensure that high quality surfaces are maintained.

Depth profiles of the tracer ${ }^{18} \mathrm{O}$ have been obtained for three gamet samples using the Cameca ims 1270 ion microprobe which was recently installed at UCLA. The profiles were generated by sputtering with a $\mathrm{Cs}^{+}$primary beam and analyzing negative secondary ions. A normal incidence electron flood gun was used to neutralize surface charging. This configuration has important advantages for the analysis of oxygen depth profiles compared to our previous analytical technique which utilized an ${ }^{16} \mathrm{O}^{-}$primary beam in the Cameca 3F at LLNL. In addition to allowing us to measure the ${ }^{16} \mathrm{O}$ profile without contamination from implanted primary ions, with the $\mathrm{Cs}^{+}$primary beam it is possible to obtain sputter rates more than 10 times higher than those achieved with the ${ }^{16} \mathrm{O}^{-}$beam. This allows the measurement of a complete depth 
profile in less than 15 minutes instead of the several hours that were required with the $3 \mathrm{f}$. Diffusion coefficients for this pyrope garnet annealed at $900^{\circ} \mathrm{C}$ is $\sim 2 \times 10^{-21} \mathrm{~m}^{2} \mathrm{~s}^{-1}$, which agrees reasonably well with values previously determined by under hydrothermal conditions.

In conjunction with Quentin Williams and Daniel Farber at UC-Santa Cruz, we conducted the first measurements of cation diffusion in the high pressure $\beta$ and $\gamma$-phases of $\mathrm{Mg}_{2} \mathrm{SiO}_{4}$. The experiments were performed in both a piston cylinder and in a multianvil pressure apparatus at $1200^{\circ} \mathrm{C}$ and pressures up to 14 GPa. Oriented samples of San Carlos olivine were placed in contact with $\mathrm{Ni}_{2} \mathrm{SiO}_{4}$ powder, and this couple was then contained in a $\mathrm{Ni}$ metal capsule along with $\mathrm{NiO}$ to produce an oxygen buffer. Two different types of profiles were produced. At pressures below 3.3 GPa, Ni-olivine is stable, and a simple binary diffusion profile is obtained through electron microprobe analysis. At higher pressures, Ni-olivine converts to $\beta$ phase and then $\gamma$-phase, producing a composite pro- file. Analysis of these profiles not only allows the diffusion coefficients in all of the coexisting phases to be determined, but the compositional discontinuities at the phase boundaries also allows us to determine the binary P-X phase loops within the system. This method may have great utility in allowing these types of phase diagrams to be constructed with a minimum number of experiments. When combined with our results for $\alpha$-olivine these data document that the diffusion rates in the high pressure phases are each $\sim 3$ orders of magnitude faster than that in the low pressure olivine phase. These faster diffusion rates indicate that the deep upper mantle is dramatically more efficient at mixing chemical heterogeneities than the shallow upper mantle. Indeed, our calculations suggest that chemical diffusion in the transition zone, when coupled with convective thinning can effectively erase the chemical signature of subducted oceanic crust in between 200 and $300 \mathrm{Myr}$, or approximately $60 \%$ of the time required within the $\alpha$-olivine dominated upper mantle. 
GRANTEE:

GRANT:

TITLE:

PERSON IN CHARGE:
UNIVERSITY OF CALIFORNIA AT SANTA BARBARA

Institute for Crustal Studies

Santa Barbara, California 93106

DE-FG03-91ER14211

Physical Modeling of Sedimentary Basins, Magma Mechanics, and Molecular Dynamics of Geological Solutions

F. J. Spera (805-893-2260; Fax 805-893-8649;

E-mail spera@magma.geol.ucsb.edu)
Objectives: (1) Determination of the thermodynamic and transport properties of melt and supercooled liquids in the system $\mathrm{NaAlSiO}_{4}-\mathrm{SiO}_{2}$ by molecular dynamics. (2) Investigation of time-dependent thermohaline convection in low-porosity permeable media. (3) Dynamics of basaltic magma underplating and implications for the origin and diversifica tion of crustal anatextic magma. (4) Simulations of the withdrawal and eruption of magma from density- and viscosity-stratified magma bodies. (5) Laboratory rheological study of melts in the system $\mathrm{NaAlSiO}_{4}-$ $\mathrm{SiO}_{2}$ at $10^{5} \mathrm{~Pa}$ and temperatures in the range 1100 to $1400^{\circ}$.

Project Description: The transport of mass, momentum, heat and chemical species at both macroscopic and microscopic scales in the crust is vital to an understanding of the evolution of magmatic, hydrothermal and sedimentary basin systems. This work involves a number of sub-projects including study of the properties of sodium aluminosilicate melts by laboratory and numerical experiment, investigation of the dynamics of magma origin, ascent and withdrawal and study of the dynamics of thermohaline porous media convection. Description of additional work is given by my collaborator David A. Yuen at the University of Minnesota (this volume).

Results: Laboratory experiments indicate that all melts in the system $\mathrm{NaAlSiO}_{4}-\mathrm{SiO}_{2}$ are examples of strong fluids characterized by Arrhenian activation energies for viscous flow which are independent of temperature but which depend on composition $\left(\mathrm{E}_{\mathrm{a}}\right.$ (silica) $\approx 515 \mathrm{~kJ} / \mathrm{mol} ; \mathrm{E}_{\mathrm{a}}$ (nepheline) $\approx 320 \mathrm{~kJ} / \mathrm{mol}$ ). MD simulations indicate that many thermodynamic and transport properties may be adequately predicted using pairwise-additive effective pair potentials. Activation energy for oxygen self diffusion in nepheline melt is circa $150 \mathrm{~kJ} / \mathrm{mol}$ at $3 \mathrm{GPa}$ and 2500 kelvins. Ionic conductivity of $\mathrm{NaAlSiO}_{4}$ melt is about $100 \mathrm{mho} / \mathrm{m}$ with an activation energy of $65 \mathrm{~kJ} / \mathrm{mol}$. This is similar to the MD and laboratory value of $58 \mathrm{~kJ} / \mathrm{mol}$ for sodium self-diffusivity.

Magma withdrawal calculations enable one to forward model the removal of magma at high rates of discharge through conduit systems connected to density- and viscosity-stratified magma bodies within the crust. Extensive results have been obtained and are published in the Journal of Geophysical Research. Non-Newtonian magma properties have a demonstrable effect on magma withdrawal. Finally, time-dependent simulations of thermohaline convection in fractured (equivalent) porous media show that, at fixed porosity and thermal Rayleigh number, as the salinity Rayleigh number (Rs) increases the dynamics change from convective steady-state at low Rs to chaotic flows at higher Rs and finally to conductive steady state at the highest Rs. The eulerian chaos observed may be relevant to the interpretation of fluid inclusions in that fluid salinities at a fixed location may vary chaotically in time. 
GRANTEE:

GRANT:

TITLE:

PERSONS IN CHARGE:
CARNEGIE INSTITUTION OF WASHINGTON

Geophysical Laboratory 5251 Broad Branch Road, NW

Washington, D.C. 20015-1305

DE-FG02-93ER14400.A000

Water-Rock Interaction in the Earth's Upper Mantle: Application of Combined Stable Isotope and Infrared Spectroscopic Analytical Techniques
D. R. Bell (202-686-2410; E-mail dbell@gl.ciw.edu), F. R. Boyd, and D. Rumble
Objectives: To trace the nature and extent of interactions between mantle rocks and hydrous melts or fluids using IR spectroscopic measurements of the concentration and speciation of $\mathrm{H}$ combined with $\mathrm{H}$ and $O$ isotope systematics of coexisting mantle minerals.

Project Description: Present indications are that interactions between mantle rock and mobile hydrous phases play an important role in the Earth's global $\mathbf{H}$ cycle, and strongly influence internal geophysical and geochemical processes. These processes may leave a chemical and isotopic imprint of their operation in mantle rocks, which is the subject of our investigation. Polarized single crystal IR absorption spectroscopy is used to determine the $\mathrm{OH}$ content and both laser-fluorination $(\mathrm{O})$ and conventional $(\mathrm{H})$ extraction techniques combined with mass spectrometry to measure stable isotope compositions of minerals from mantlederived xenoliths. Suites of rocks which are the products of specific mantle processes, such as partial melt ing, crystal fractionation and metasomatism, were selected in order to evaluate the importance of bulk composition, inter-phase partitioning and mineralfluid exchange in producing the observed variation of mantle $\mathrm{OH}, 18 \mathrm{O} / 16 \mathrm{O}$ and $\mathrm{D} / \mathrm{H}$. Correlation patterns between $\mathrm{OH}$ and stable isotope compositions in the minerals will be sought as a means of defining the role of fluids and fluid recycling in the mantle. Possible development of heterogeneous mantle reservoirs of $\mathbf{H}$, $\mathrm{D}$ and $18 \mathrm{O} / 16 \mathrm{O}$ related to age and tectonic setting is also under investigation.
Results: Much of our initial effort has gone into bringing the $\mathrm{H}$ and $\mathrm{O}$ extraction systems to their current fully operational status. The newly constructed laser-fluorination line has now yielded satisfactory $O$ isotope results on standard materials and the upper major mantle minerals. $\mathrm{O}$-isotope analysis of minerals in a primitive anhydrous lherzolite, and in a traverse through amphibole spinel lherzolite adjacent to a hydrous vein, in the well characterized mantle xenolith Ba-2-1 from Dish Hill, California, have recently begun. The $\mathrm{H}$-extraction line and on-line $\mathrm{D} / \mathrm{H}$ mass spectrometer have been calibrated for quantitative manometric analysis of $\mathrm{H}_{2}$ and $\mathrm{H}$-isotope analysis respectively. Major and minor element content, hydrogen concentration and $\mathrm{D} / \mathrm{H}$ ratio have been determined on a suite of 17 mantle-derived megacryst and vein amphiboles from Dish Hill, Califomia. The majority of the samples define a uniform $\mathrm{H}$ content of $1.0 \mathrm{wt} . \%$ $\mathrm{H}_{2} \mathrm{O}$ and $\delta \mathrm{D}_{\text {SMOW }}$ of $-46 \%$, which may represent primary mantle values, but not necessarily that of bulk $H$ in the mantle beneath Dish Hill. These data contrast with previous studies which report heterogeneity of $\mathbf{H}$ and $\mathrm{D} / \mathrm{H}$ in similar amphiboles. This result provides a starting point for investigation of $\mathrm{D} / \mathrm{H}$ variation during vein-wallrock interaction in sample $\mathrm{Ba}-2-1$ and other composite or metasomatized samples. Sample preparation and survey electron microprobe analysis for spectroscopic measurements, investigation of $\mathrm{D} / \mathrm{H}$ in structural $\mathrm{OH}$ in augite from Dish Hill, and of bulk variations in mantle $\mathrm{D} / \mathrm{H}$ related to tectonic environment are in progress. 


\section{GRANTEE:}

TITLE:

\section{GRANT:}

\author{
THE UNIVERSITY OF CHICAGO \\ Center for Advanced Radiation Sources \\ $5640 \mathrm{~S}$. Ellis Avenue \\ Chicago, Illinois 60637
}

PERSON IN CHARGE:
DE-FG02-92ER14244
Synchrotron X-Ray Microprobe and Microspectroscopy: Technical Development for Advanced Photon Source Research and Low Temperature Geochemistry Applications

\author{
S. R. Sutton (312-702-9930; Fax 312-702-5454; \\ E-mail sutton@bnlx26.nsls.bnl.gov)
}

Objectives: The objectives are to develop and apply a synchrotron-based $x$-ray microprobe that can be used to determine the composition, structure, oxidation state, and bonding characteristics of earth mate rials with trace element sensitivity and micrometer spatial resolution.

Project Description: The project focuses on enhancements to the $\mathrm{x}$-ray fluorescence microprobe on beamline $X 26$ at the National Synchrotron Light Source (NSLS), Brookhaven National Laboratory. Geochemical problems that are under investigation include the nature of hydrothermal fluid inclusions, toxic metal and radioisotope speciation in low level wasteforms and contaminated sediments, determinations of the chemical histories of contaminated sites through microanalytical studies of indigenous organisms, and redox chemistry of $\mathrm{Mn}$ at the root-soil interface and its role in agriculturally relevant plant diseases. The goal is to extend this research at the Advanced Photon Source, the next generation of synchrotron radiation source at Argonne National Laboratory scheduled for commissioning in 1995.

Results: The NSLS x-ray microprobe (XRM) is capable of (1) trace element analyses $(\leq 1 \mathrm{ppm})$ with 5-micrometer spatial resolution and (2) x-ray absorption spectroscopy analyses with $\leq 100$-micrometer spatial resolution and $\leq 100$-ppm sensitivity. A 13-element $\mathrm{Ge}$ detector was commissioned. Successful tests of microslits and a microfocusing KirkpatrickBaez mirror to be used at the Advanced Photon Source were conducted at NSLS. A method based on $\mathrm{x}$-ray absorption near edge structure (XANES) was developed to quantify $\mathrm{Fe}^{2+} / \mathrm{Fe}^{3+}$ ratios in oxides and silicates with microbeam resolution. Oxidation state mapping techniques were developed for samples with a particular element in multiple, co-existing states. This method was applied to Se in water-saturated sediments (collaboration with Lawrence Berkeley Laboratory) and $\mathrm{Mn}$ in the rhizosphere of wheat roots attacked by the take-all fungus (collaboration with Purdue University). In the former experiment, it was shown that soluble $\mathrm{Se}^{6+}$ was reduced to the less mobile $\mathrm{Se}^{4+}$ and insoluble $\mathrm{Se}^{0}$ in the regions of high microbial activity, i.e., immediately adjacent to the decaying roots. In the latter, the observed microdistribu tions supported the hypothesis that the oxidation of $\mathrm{Mn}^{2+}$ to $\mathrm{Mn}^{4+}$ is intimately involved in the fungal in fection process. 
GRANT:

TITLE:

PERSON IN CHARGE:
DE-FE-02-92ER14233

\section{Crystal Chemistry of Hydroxyl and Water in Silicate Minerals}

Joseph R. Smyth (303-492-5521; Fax 303-492-2606;

E-mail joesmyth@vaxf.colorado.edu)
Objectives: The first objective is a greater under-standing of the exchange mechanisms of hydrated cations in natural zeolites that are present at Yucca Mountain, NV. The second objective is to evaluate the hypothesis that nominally anhydrous high pressure minerals may harbor a large reservoir of hydroxyl, and thus water, deep within the Earth and that this reservoir may have exchanged with and buffered the water of the planet's hydrosphere over geologic time.

Project Description: The hydration of various cations substituting into the abundant natural zeolite, clinoptilolite, may control sorption and migration of radionuclides at the Nevada Test Site and Yucca Mountain Nuclear Waste Repository. Cation exchange experiments have been performed to produce single crystals of $\mathrm{K}, \mathrm{Na}, \mathrm{Cs}, \mathrm{Mg}, \mathrm{Ca}, \mathrm{Sr}$, and $\mathrm{Ba}$ varieties of this material. Cation positions and hydration geometries are being determined at $100 \mathrm{~K}$ for these samples by $x$-ray single crystal diffraction methods. The stability of hydroxyl-bearing, but nominally anhydrous, silicates such as omphacite, wadsleyite (beta $\mathrm{Mg}_{2} \mathrm{SiO}_{4}$ ), rutile, and stishovite may control magma generation in the mantle, and these phases together with some nominally hydrous phases may constitute a reservoir of $\mathrm{H}$ in the Earth as large as the oceans. The mechanisms of hydroxyl incorporation into these phases are being investigated by $\mathrm{x}$-ray and neutron crystallographic methods.
Results: In cation exchange experiments on natural clinoptilolite, the alkalis, $\mathrm{Na}, \mathrm{K}$ and $\mathrm{Cs}$, are observed to exchange readily, whereas exchange of the alkaline earths, $\mathrm{Ca}, \mathrm{Sr}$ and $\mathrm{Ba}$, is much slower. It appears that charge-coupling to the framework causes fixation of the divalent $\mathrm{Ca}$ ions which reduces their ability to exchange.

Crystal structure refinements have been completed for twelve biotite micas, a triclinic IIb4 chlorite, hydrous and anhydrous rutile and stishovite, three clinohumites, ten hydrous and anhydrous omphacites. Also, structure refinements for a hydroxyl-rich chondrodite and four $\mathrm{Cl}$ and hydroxyl amphiboles have been carried out. Four manuscripts on this work have been submitted for publication in refereed journals.

A crystallographic model has been constructed for incorporation of $\mathrm{H}$ in wadsleyite,(beta- $\mathrm{Mg}_{2} \mathrm{SiO}_{4}$ ) which is generally believed to make up 50 percent or more of the Transition Zone of the Earth ( 400 to 525 $\mathrm{km}$ depth). The model predicts strong c-polarization of the IR O-H stretching absorption and high solubility of trivalent cations $\mathrm{Al}, \mathrm{Cr}$ and ferric iron. It also predicts up to $3.3 \mathrm{wt} \% \mathrm{H}_{2} \mathrm{O}$ may be incorporated in this phase. This would be several times more water than is currently in the hydrosphere and implies that the amount of water on the surface may be buffered by a reservoir of hydrous silicates in the Transition Zone. A Letter on this work has been submitted to American Mineralogist. 
GRANTEE:

GRANT:

TITLE:

PERSON IN CHARGE:
UNIVERSITY OF COLORADO

CIRES/Dept. of Geol. Sciences

Boulder, Colorado 80309-216
Objectives: The effect of fluids on the complex modulus of porous rocks is being investigated. The aim of the study is to provide a tool for monitoring changes in fluids near toxic and nuclear waste sites as well as aid in the detection and recovery of hydrocarbons.

Project Description: Fluids interact with rocks in various ways. Not only the physical properties of the rock matrix and of the fluid are important in the interaction, but also the chemical properties of both. To gain an understanding of the interaction a set of experiments are being performed. These experiments have been designed to allow for the measurement of few variables at one time.

Results: Surface forces between solids and fluids are being measured in thin cracks. Two microscope slides create a wedge with adjustable aspect ratio, thus simulating a crack. The introduction of liquid into the crack causes the two plates to bend in response to surface forces. The deflection of the slides is measured and gives a direct measure of the surface forces. Surface forces are a function of the chemical compo- sition of the fluid and the property of the crack surface.

Viscous effects as well as surface forces are being studied in oscillating cracks. The modulus as well as the attenuation of sinusoidal displacements are measured over a large frequency range.

The permeability of sintered glass and porous rock samples is measured at pressures on the order of capillary pressures. Again fluids with different chemical and physical properties are used.

Finally the complex moduli of samples of sintered glass and of porous rock are measured. The attenuation and modulus are functions of the properties determined in the above experiments. Computer modeling uses the individually measured parameters to understand the bulk properties of the sintered glass and rock samples. Based on typical surface energy values $\left(150 \mathrm{~mJ} / \mathrm{m}^{2}\right)$ measured in the static crack experiment the entire absorption (Q 100) of Lyon's sandstone (model rock) can be explained in terms of irreversible wetting of crack surfaces. 
GRANTEE:

TITLE:
GRANT:
COLORADO SCHOOL OF MINES

Department of Geophysics

Golden, Colorado 80401
DE-FG02-89ER14079

Computational Methods for Improving the Resolution of Subsurface Seismic Images

Ken Larner (303-273-3428)
Objectives: Anisotropy is ignored in most seismic data processing today, despite the fact that the earth is known to exhibit considerable anisotropy. The objective of this project is to extend previous studies of positioning errors in poststack migration to study of both focusing and positioning errors in prestack migration.

Project Description: Building on the extensive numerical modeling tests of errors in poststack-migrated data and on errors in the action of dip-moveout on seismic data, one aspect of the project is a numerical study of the implications for errors in prestack migration. Another is the continuing development of algorithms for doing poststack and possibly prestack depth migration based on anisotropic models for the propagation medium. The two approaches being developed-Gaussian beam migration and stable explicit finite-difference migration - offer different degrees of efficiency and steep-dip accuracy. The Gaussian beam method is capable of steep dip accuracy, as well as efficiency for 2-D poststack and prestack migration. While the finite-difference approach does not give the same degree of accuracy for steep dips, it should be particularly efficient for 3-D applications.

Results: Using Gaussian beam migration developed for isotropic media, we have performed prestack isotropic migration on modeled data for transversely isotropic media with vertical symmetry axis (VTI media) and in which velocity varies with depth only. To first order, when derived stacking velocities are used for the migration, the lateral positioning errors are independent of source-to-receiver offset for reflector dip as large as 90 degrees. Thus, significantly, lateral positioning errors for prestack migration are the same as those for poststack migration. However, for these experiments, offset-dependent depth errors arise (even for horizontal reflectors) due to the fact that stacking velocity generally differs from true vertical velocity for VTI media. Current quantitative numerical experiments to document offset- and dip-dependent error for a full range of anisotropic media characterized by the four Thomsen anisotropy parameters support the conclusion that, for vertically inhomogeneous VTI media, prestack depth migration errors are well characterized by those previously observed for poststack migration, errors that were previously found to dependent primarily on just the one the Thomsen parameter "delta."

The recently developed stable explicit algorithm for efficient poststack and prestack depth migration in transversely isotropic (TI) media with any angle of symmetry axis (in two dimensions) shows dip-limited accuracy that is dependent in predictable ways on the Thomsen parameters "delta" and "epsilon." For VTI media, the algorithm can accomplish 3D poststack depth migration via use of the efficient McClellan transformation. The Gaussian beam approach to depth migration in TI media, although slower, gives excellent reflector positioning, amplitude, and waveform accuracy for all reflector dips, up to and beyond 90 degrees. 
GRANTEE:

GRANT:

TITLE:

PERSON IN CHARGE:
U.S. DEPARTMENT OF ENERGY CORE AND SAMPLE REPOSITORY

c/o RUST Geotech Inc.

P.O. Box 14000

Grand Junction, Colorado 81502-5504
None (B \& R KC040101)

U.S. Department of Energy, Core and Sample Repository

Larry M. Fukui (303-248-6172; Fax 303-248-6040;

E-mail gjcore@gjpomail.doegjpo.com)
Objectives-Project Description: The DOE Core and Sample Repository provides the scientific community with ready access to geologic samples and information, ensures proper preservation and storage of samples and data, maintains records of sample requests, and to promotes the use of sample inventory and data by qualified investigators.

Results: The DOE Core and Sample Repository (Repository) distributed 100 samples to five scientists in fiscal year 1993 and 173 samples to six scientists in fiscal year 1994 (3/4 complete). Presently, about 90 investigators have over 4000 samples selected from the more than 13,900 meters $(45,000$ feet $)$ of drill core residing in the Repository.

The Repository had an exhibit at the VIIth International Symposium on the Observation of the Continental Crust Through Drilling in Santa Fe, NM, April 25-30, 1994. 
GRANTEE:

GRANT:

TITLE:

PERSON IN CHARGE:
COLUMBIA UNIVERSITY

Lamont-Doherty Earth Observatory

Palisades, New York 10964
DE-FG02-86ER13287

Energetics of Silicate Melts from Thermal Diffusion Studies

D. Walker (914-365-8658; Fax 914-365-3183;

E-mail dwalker@ldeo.columbia.edu) and

M. C. Johnson (914-365-8712; E-mail krikitt@ldeo.columbia.edu)
Objectives: This research program characterizes mass transport by diffusion in geologic fluids in response to thermal, solubility, and/or chemical gradients to obtain quantitative information on the thermodynamic and kinetic properties of multicomponent systems.

Project Description: Thermal diffusion is the phenomenon of chemical migration in response to heat flow along a thermal gradient. The details of this response are conditioned by the thermochemical properties and constitution of the substance. Silicate liquids undergo substantial thermal diffusion (Soret differentiation), whereas the response in sulfide, carbonate, and aqueous fluids to an imposed temperature gradient is varied. The experimental observations of this differentiation are used to evaluate the form and quantitative values of solution parameters and to quantify ordinary diffusion coefficients, heats of transport, and activation energies of multicomponent liquids. The diffusion, solution, and element partition coefficients determined for these geological fluids form a data base for understanding magmatic crystal- lization behavior and for evaluating geothermal, ore deposit, and nuclear waste isolation potentials. Thermal and isothermal diffusion experiments are conducted using 1-bar gas-mixing furnaces, piston cylinder devices between 7 and $35 \mathrm{~kb}$, and a simplified multianvil device above $35 \mathrm{~kb}$.

Results: High-pressure and temperature Soret diffusion experiments with carbonates, sulfides, and silicates were made possible through extensive technical advances in pressure media, gasketing configurations, and furnace materials for multianvil assemblies. Other multianvil labs will benefit from this development work. Efforts to study Soret diffusion in aqueous sulfates have been hampered by the magnitude $(1 \%)$ of the expected signal. Iterative attempts have resulted in developing an analytical protocol based on weighing small quantities of solution after holding the solution in a temperature gradient for several weeks. In collaboration with colleagues at IBM, synthesis of novel precursors for high-temperature superconductors has been undertaken at high pressure. Many new copper oxides and sulfides have been discovered. 
GRANTEE:

PERSON IN CHARGE:
TITLE:

\section{GRANT:}

\author{
UNIVERSITY OF CONNECTICUT \\ Department of Marine Sciences \\ 1084 Shennecossett Road \\ Groton, Connecticut 06340-6097
}

\section{DE-FG02-94ER14448}

Hydrogeologic Processes: Building and Testing Atomistic- to Basin-Scale Models-Support of a Chapman Conference

Thomas Torgersen (203-445-3441; Fax 203-445-3484;

E-mail Torgers@Uconnvm.Uconn.edu)
Objectives: Given the well-defined societal need to construct integrated and parametrically realistic coupled models of fluid flow in Earth systems and the present computational ability to do so, the objective of this project is to convene a conference that will focus on: (1) model building, (2) model testing, and (3) scaling of hydrogeologic processes.

Project Description: A Chapman Conference will be convened to bring together the skills and results of top researchers from the diverse fields of the Earth sciences now conducting reseearch in coupled fluid and mass transport in permeable hydraulic media. Critical components of the meeting are the methodologies available and necessary to: (1) develop and test the parameterizations for modelling the physical, chemical, mechanical and thermal processes in hydrogeologic flow below the gridscale of the model; (2) develop and test the parameterizations for modelling the physical, chemical, mechanical and thermal processes in hydrogeologic flow beyond the gridscale of the model; (3) define the necessary computational requirements, approaches and demands to model on these scales and define the necessary mechanisms of investigator interaction with a general model.

Results: The conference was convened in Lincoln, NH, June 6-9, 1994 with over 70 researchers from diverse fields of the Earth sciences (hydrology, petrology, metamorphic petrology, quantum mechanical chemistry, fluid geochemistry, acoustic and electrical geophysics, rock mechanics and mathematics). The meeting assessed the state of the art and the means and mechanisms to build and test process models that produce probabilities rather than just possibilities. With the realization that (1) field and laboratory studies supply valuable constraints on the initial conditions, boundary conditions and parameterizations of hydrogeological process models and (2) models supply the observationalist with valuable insight into the implications and requirements of the system as he has envisioned it, considerable progress and synthesis was made. An overall conclusion began to emerge that the issue is not intractable. The wealth of new techniques and disciplines now focused on specific components of these processes and parameters in space and time has reached a point where new bridges can be built and this exchange of information allows the Earth sciences to focus on the right questions. When we address the right questions with the multiplicity of tools techniques and disciplines at our disposal, it will be possible to build realistic processes into hydrogeological models whose parameterizations can be tested through observations on both long and short time and space scales. 
GRANTEE:

GRANT:

TITLE:

PERSONS IN CHARGE:
UNIVERSITY OF DELAWARE

Department of Chemistry and Biochemistry

Newark, Delaware 19716

DE-FG02-89ER14080.A003

Development of an Experimental Database and Theories For

Prediction of Thermodynamic Properties of Aqueous

Electrolytes and Nonelectrolytes of Geochemical Significance at Supercritical Temperatures and Pressures

R. H. Wood (302-831-2941; Fax 302-831-6335;

E-mail rwood@brahms.udel.edu) and Everett L. Shock (314-726-

4258; Fax 314-935-7361; E-mail shock@zonvark.wustl.edu)
Objectives: The objective of this research is to measure heat capacities and volumes of key compounds of importance to predictions of geochemical phenomena at high temperatures and pressures. A second objective is to use the key compounds as a database together with simulations to develop empirical and theoretical methods for predicting a wide variety of other compounds.

Project Description: Measurements of volumes and heat capacities of a wide variety of organic electrolytes and nonelectrolytes at temperatures from 25 to $325^{\circ} \mathrm{C}$ will be made. This will allow the development of group additivity schemes to predict a very wide variety of organic species containing these functional groups. Previous measurements on $\mathrm{H}_{2} \mathrm{~S}, \mathrm{CO}_{2}, \mathrm{CH}_{4}$, $\mathrm{NH}_{3}$, and $\mathrm{H}_{3} \mathrm{BO}_{3}$ are being analyzed to find correlations which can predict other species. Molecular dy. namics simulations of the chemical potential of aqueous methane, ethane, and propane at temperatures from 600 to $1200^{\circ} \mathrm{C}$ and water densities from 0 to $1 \mathrm{gm} / \mathrm{cm}^{3}$ have been made. Revisions of the equations of state for aqueous ions and nonelectrolytes to allow better predictions of properties at high temperatures and pressures will be developed.

Results: The volumes and heat capacities of aqueous solutions of 1-propanol, propanoic acid, pyridine, 1,4-butanediol, propylamine, adipic acid, succinic acid, propionamide, 1,6-hexanediol, 1,4-butanediamine, 1,6-hexanediamine, phenol, sodium acetate, propylamine hydrochloride, sodium propionate, and sodium benzenesulfonate have been measured at temperatures up to $250^{\circ} \mathrm{C}$. Results of the comparison of the Born model and the compressible continuum model to data on aqueous electrolytes up to $420^{\circ} \mathrm{C}$ and with simulations of the chloride ion in water at $450^{\circ} \mathrm{C}$ and $0.012 \mathrm{~g} / \mathrm{cm}^{3}$, as well as $727^{\circ} \mathrm{C}$ and $0.35 \mathrm{~g} / \mathrm{cm}^{3}$ have been published. It has been found that the equation of Harvey, Sengers and Tanger is much more accurate in the critical region than that of Shock et al. If we know the volumes we can quite accurately estimate the heat capacities of these substances. There are also reasonable correlations of the magnitude of the critical effects, both volume and heat capacity, with critical points and Henry's law constants. 


\section{GRANTEE:}

PERSONS IN CHARGE:
TITLE:

GRANT:

\section{UNIVERSITY OF SOUTH FLORIDA}

Department of Marine Science

St. Petersburg, Florida 33701
DE-FG05-92ER14300

Clay Mineral Diagenesis in the Monterey Formation, California

J. S. Compton and W. M. Sackett (813-893-9158; Fax 813-893-

9189; E-mail compton@marine.usf.edu)
Objectives: To study the progressive burial diagenesis and alteration of discrete vitreous volcanic ash beds to bentonite and metabentonite beds to determine the origin and mass balance of clay mineral reactions.

Project Description: Clay minerals are a significant constituent and are an important factor in silica, carbonate, and organic matter diagenesis of the Miocene Monterey Formation. Many of the clay minerals form as a result of progressive burial diagenesis and overlap with the burial depths associated with oil generation and migration. The mineral, elemental, and isotopic composition of Monterey rocks will be used in this study to (1) quantify the clay mineral reactions that occur in vitreous volcanic ash layers as they undergo increasing burial diagenesis (glass to bentonite to metabentonite), (2) test the hypothesis that the illitization.of smectite is limited by the availability of potassium, and (3) determine the relation of clay mineral reactions to the maturation of organic matter. The results of this study will provide detailed analysis of the significance of clay minerals in the complex di agenesis of these hydrocarbon source and reservoir rocks.

Results: The Miocene Monterey formation contains more than $\mathbf{5 0}$ discrete volcanic layers. The mineralogy and chemical composition of these discrete volcanic ash layers were studied in order to understand better the glass to smectite and the smectite to illite reactions and, in particular, to quantify the mass transfer of elements into and out of the volcanic layers during alteration. Lateral variations in diagenetic grade of Monterey Formation rocks exposed in southcentral coastal Califomia allow equivalent volcanic layers to be traced from areas of low to increasingly higher burial metamorphism. Volcanic layers in laminated, opal-A diatomite contain both vesicular and nonvesicular glass shards and variable amounts of quartz and feldspar. Other than slight hydration, the glass shards appear unaltered. The vitreous ash has a rhyolitic composition, high in silica, potassium and sodium, and a REE pattern that shows enrichment in the light REE and a negative Eu anomaly. Ash layers from different areas can be correlated on the basis of their chemical composition. The preservation of these Miocene-age glasses may be a result of the high silica activities predicted for the pore water of adjacent rocks rich in biogenic (opal-A) silica. Alteration of the glass to smectite (bentonite layers) occurs across the diatomite (opal-A) to porcelanite (opal-CT) silica transformation. Smectitic clay flakes are observed in SEM photomicrographs to form directly on glass shard surfaces. Smectite flakes become increasingly abundant with increasing alteration. Complete conversion of glass to smectite, however, does not appear to occur. Remnant glass shards are observed in even the most extensively altered beds. The alteration to smectite results in the loss of potassium, silica, sodium, rubidium and the REEs and an increase in magnesium, aluminum, and water. The alteration appears to proceed by both replacement of glass shards and leaching of the glass, leaving a residual, aluminum-rich glass. Many of the bentonite layers are rich in iron which occurs mostly as pyrite and marcasite. The zeolite material, clinoptilolite, is commonly observed in bentonite layers. The highly smectitic illite/smectite becomes increasingly illitic at depths be- 
low the opal-CT to quartz silica transition. The source of potassium required for the illitization of smectite appears to be limited in the Monterey formation as most of the ash layers, as well as surrounding rocks, contain plagioclase rather than potassium feldspar. The limited availability of potassium results in the transformation of smectite to kaolinite as well as illite and minor amounts of chlorite and ferroan dolomite. In addition to potassium, some of the illite forms from ammonium derived from the degradation of organic matter in these organic-rich, hydrocarbon source and reservoir rocks. Correlation of bentonite and metabentonite layers on the basis of chemical composition is difficult because of the large chemical changes that occur during alteration. However, combining available biostratigraphy and strontium isotope stratigraphy may provide enough age control to match volcanic layer sequences of different areas. 
GRANTEE:

GRANT:

TITLE:

PERSON IN CHARGE:

\author{
INDIANA UNIVERSITY \\ Department of Chemistry \\ Bloomington, Indiana 47405
}

\section{DE-FG02-91ER14175}

\section{Mechano-chemical Self-Organization and Nonlinear Dynamics in Sedimentary Basins}

P. Ortoleva (812-855-2717; Fax 812-855-8300;

E-mail ortoleva@ucs.indiana.edu)
Objectives: A sedimentary basin is viewed as a nonequilibrium reaction-transport-mechanical system. As a result, phenomena such as reaction front fingering, stylolites, diagenetic bedding and episodic fluid release from overpressured domains are put in the unified framework of instability and nonlinear dynamics and implications for petroleum are drawn.

Project Description: These phenomena are modeled and simulated numerically. Rate laws for stress mediated reactions, and the dependence of rock meology, permeability and dispersion on texture, mineralogy and fracture parameters are set forth. A quantitative model is constructed based on equations of conservation of mass, force balance, and incremental stress rheology. The models are simulated numerically. When small scale features (such as stylolites, differentiated layering or fractures) affect the basin scale dynamics, and conversely, homogenization techniques are used to make the calculations practical. Parallel numerical algorithms are also developed and implemented.

Results: A Debye-Hückel/osmotic model was developed to explain the properties of the water film between stressed grain contacts needed in the expression for the rate of pressure solution. A statistical model of pressure solution mediated texture change and compaction in multi-mineralic systems was developed; it is the first to solve this very important and difficult problem. These two theories play a key role in understanding the kinetics of diagenetic banding and compaction.

Two and three dimensional basin simulators capturing fluid flow, aqueous chemistry, mineral reactions (including pressure solution) have been developed. They are being used to predict reservoir quality and distribution within a basin and the role of nonlinear phenomena in fluid migration and trapping.

Two numerical strategies for implementing our three dimensional incremental stress model of basin deformation have been developed. The models and codes integrate poroelasticity, plasticity, pressure solution and hydrofracturing in a unified, self-consistent model. Preliminary results of the finite difference and finite element numerical schemes compare well with simple analytical test cases. 
GRANTEE:

GRANT:

TITLE:

\author{
THE JOHNS HOPKINS UNIVERSITY \\ (Subcontract to Lehigh University) \\ Department of Earth and Planetary Sciences \\ 34th and Charles St. \\ Baltimore, Maryland 21218
}

\title{
DE-FG02-89ER 14074
}

HRTEM/AEM and SEM Study of Fluid-Rock Interactions: Interaction of Copper-, Silver-, Selenium-, Chromium-, and Cadmium-Bearing Solutions with Geological Materials at NearSurface Conditions, with an Emphasis on Phyllosilicates

\author{
PERSONS IN CHARGE: $\quad$ D. R. Veblen (410-516-8487; Fax 410-516-7933) and \\ E. S. IIton (610-758-5834; Fax 610-758-3677)
}

Objectives: This project is investigating the mechanisms by which oxidation-reduction reactions at the mineral-fluid interface and in the interiors of crystals attenuate multivalent elements in near-surface aqueous systems. We are also developing XPS into a quantitative method for determining $\mathrm{Fe}(\mathrm{III}) / \mathrm{Fe}(\mathrm{II})$ in silicates.

Project Description: This project is investigating the interaction of silver-, copper-, selenium ( $\mathrm{Se}^{4+}$ and $\mathrm{Se}^{6+}$ ) -, and chromium ( $\mathrm{Cr}^{6+}$ )-bearing solutions with ferrous phyllosilicates such as biotite, a potential reducing agent, under both oxic and anoxic conditions. Reduced forms of selenium and chromium are less soluble and less toxic than oxidized forms. The reduction of copper and silver during weathering can be an important process in the supergene enrichment of both these elements.

The objectives of the experimental work are to examine the surfaces and interior portions of the reacted phyllosilicates with transmission electron microscopy (TEM), analytical electron microscopy (AEM), scanning electron microscopy (SEM), and $x$ ray photoelectron spectroscopy (XPS). The combination of these techniques will help to determine the oxidation state and form of the sorbed species. This information provides constraints on the physical and chemical conditions that are required for the mobi- lization or attenuation of these elements from or by phyllosilicates. Another important parameter in the sorption experiments is the concentration of $\mathrm{Fe}(\mathrm{III})$ in the near-surface of biotite. In this regard, the XPS is being calibrated to quantitatively determine $\mathrm{Fe}$ (III)/Fe(II) in the near-surface of silicates. An outgrowth of this work is a project to develop XPS into a microbeam technique for determining $\mathrm{Fe}(\mathrm{III}) / \mathrm{Fe}$ (II) in minerals in thin sections. Such a method would replace unwieldy bulk analytical techniques and aid geoscientists in fields as diverse as petrology and environmental geochemistry.

Results: This past year, work focused on the kinetics of coupled sorption-reduction of $\mathrm{Cr}(\mathrm{VI})_{\text {aq }}$ at the biotite-fluid interface and the development of XPS into a microbeam technique for determining $\mathrm{Fe}(\mathrm{III}) / \mathrm{Fe}$ (II) in minerals in thin sections. The work has shown, in a definitive manner, that $\mathrm{Cr}(\mathrm{VI})_{\mathrm{aq}}$ is sorbed and reduced to $\mathrm{Cr}$ (III) at the biotite edge-fluid interface, and now the kinetics of this process are being investigated as a function of $\mathrm{pH}$, ionic strength, $\mathrm{fO}_{2}$, and $\mathrm{K}{ }_{a \mathrm{aq}}$. One of the more striking results of the experiments is that there appear to be three distinct kinetic regimes: very rapid sorption and reduction in the first minute, followed by a slower linear reaction over several hours, and finally an even slower reaction that extends to at least 120 hours. Initial results of XPS 
$\mathrm{Fe}$ (III)/Fe(II) analyses of biotites in metapelite thin sections show a positive correlation with bulk Mössbauer biotite analyses. We are now concentrating on developing a set a standards and refining preparation techniques. An interesting result has been the discovery that $\mathrm{Fe}(\mathrm{III}) \%$ increases linearly as a function of time exposed to the high-flux x-ray beam. Extrapolation to time equal to zero yields the correct results. 
GRANTEE:

GRANT:

TITLE:

PERSON IN CHARGE:
LEHIGH UNIVERSITY

Department of Earth and Environmental Sciences

Bethlehem, Pennsylvania 18015

DE-FG02-93ER14373

\section{Surface and Solution-Interface Geochemistry of Lead Sulfide and Lead Selenide Minerals}

Carl O. Moses [610-758-4907; Fax 610-758-3677;

E-mail com0@lehigh.edu]

Objectives: In this project, we are investigating the aqueous reactivity of sulfide minerals and their selenide analogues (endmember and solid-solution compositions). In particular, we seek a comprehensive and integrated understanding of reactivity based on fundamental high-vacuum surface chemistry and the rates of aqueous exchange and dissolution reactions. Our present focus is on $\mathrm{PbS}$ and $\mathrm{PbSe}$.

Project Description: Sulfide minerals play important roles in determining the distribution and mobility of metals and sulfur in the hydrosphere. Their instability in oxic environments can make them a source of their components to the environment, while their stability in anoxic environments can make them a sink for such components. The research approach integrates information from mass transfer experiments in aqueous solution with information from surface chemistry studies using high-resolution X-ray photoelectron spectroscopy and field-emission scanning electron microscopy. Research goals include characterizing surface stoichiometry, determining the depth of surface-chemical alterations during gas- or solution-phase exposures, identifying changes in surface morphology during exposures, determining the scope of environmental controls on exchange and release rates, establishing reaction mechanisms for exchange and dissolution, and determining the range of mineral solution interface properties that are environmentally relevant. The $\mathrm{PbS}-\mathrm{PbSe}$ system was selected for this investigation because its crystal chemistry and electronic structure are well-understood, their solid solution is complete and ideal, and mass transfer processes at their solution interfaces, which have implications for environmental quality, are incompletely understood.

Results: Pristine baseline surface composition: Prerequisites for our experiments are (1) the synthesis of specimens with well-controlled stoichiometry (i.e., pure $\mathrm{PbS}$, pure $\mathrm{PbSe}$, or intermediate $\mathrm{PbS} / \mathrm{PbSe}$ compositions in the solid solution) and (2) the preparation of a reproducible surface composition that reflects the bulk composition in a predictable way and is free of adventitious contamination. For our purposes, evacuated-tube syntheses, using high-purity starting materials prepared in a controlled atmosphere, are working well. X-ray diffraction analyses verify that the bulk lattice dimensions are consistent with those predicted by stoichiometry. The intermediate solid-solution compositions are being tested to the limits of electron optical techniques for true solid solution. We have established a method for preparing pristine surfaces that will meet some of our experimental needs. The vapor pressures of both endmembers ( $\mathrm{PbS}$ and $\mathrm{PbSe}$ ) are relatively high at modest temperatures $\left(\sim 10^{-4}\right.$ torr at $\sim 550^{\circ} \mathrm{C}$ ). Based on this property, we have developed a vacuum-deposition method that allows us to carry out the preparation in the fast-entry port of Lehigh's SCIENTA ESCA-300 XPS instrument, which has a base pressure of $\sim 10^{-7}$ torr. Small (1 to 2 $\mathrm{mm}$ ) pieces of the sulfide mineral are evaporated on a tungsten heater, and the material is deposited on a $\mathrm{Si}$ substrate mounted to an XPS stub inverted over the heater. We have achieved the deposition of a finegrained material that appears to preserve the stoi- 
chiometry of the original specimen (further testing is required to verify this). We have been able to demonstrate that (1) vacuum deposition in the fast-entry chamber can produce a surface that is completely free, at the limits of XPS detection, of any adventitious carbon or oxygen and is therefore suitable as a pristine baseline reference surface, (2) this surface can be stored in the XPS analysis chamber (base pressure 109 to $10^{-10}$ torr) without acquiring adventitious carbon or oxygen for periods of at least $24 \mathrm{~h}$ (sufficient for our experiments), (3) this surface can be exposed to the high-power $\mathrm{x}$-ray beam for at least $15 \mathrm{~h}$ without significant alterations to its surface stoichiometry, and (4) this material, which is very easily produced, is appropriate for high-resolution XPS spectra of both core-level and valence-band emissions, although it cannot be used for angle-resolved spectra. In order to obtain high-quality angle-resolved data, we need a flat single-crystal surface with minimum dimensions on the order of $0.5 \times 5 \mathrm{~mm}$. We have not yet achieved true epitaxial growth in our vacuum-deposition experiments and are working on improved control of the evaporation process, including the modification of a small Knudsen (molecular-beam) cell, and on im proved control of the deposition process by trying other substrates, including $\mathrm{NaCl}$ and natural $\mathrm{PbS}$ surfaces. X-ray photoelectron diffraction: Photoemission intensities collected over a range of polar and azimuthal orientations of the detector-surface geometry reveal angular anisotropy that contains information related to the geometric arrangement of atoms in the material (x-ray photoelectron diffraction, XPD). Interpreting that information requires an inverse modeling approach in which the geometric and other pa- rameters for computer simulations of emission are adjusted until a reasonable match is obtained with experimental observations. Owing to the surface sensitivity of $\mathrm{x}$-ray photoemission, the geometric model obtained by XPD is that of the material surface, as distinguished from the bulk geometry. In parallel with our work on synthesizing a single-crystal pristine surface, we have focused our XPD efforts on (1) refining the computer software required for the simulations and (2) parameterizing the $\mathrm{PbS} / \mathrm{PbSe}$ system for simulations. We have enhanced the simulation software so that it now represents simulated emissions in the same geometric scheme as the experimental geometry and improved its execution speed and presentation of results so that the multiple parameters can be systematically evaluated. Much of our effort in parameterizing the system is also relevant to our valence-band emission simulations. The XPD work provides structural (geometric) information on the surface and surface-adsorbate complexes, while the valenceband work will provide complementary information on the electronic structure of surface states and their modification by adsorbates. We are using HermanSkillman atomic wavefunctions and a modified Hartree-Fock scheme for computing the scattering phase shifts for muffin-tin models of the endmember $\mathrm{PbS}$ and $\mathrm{PbSe}$ compositions. Radial matrix elements and continuum phase shifts are extrapolated from tabulations. The geometric starting point for the simulations is the bulk lattice geometry. We are testing the sensitivity of the simulation to a number of parameters, including geometry, spectrometer work function, number of scattering phase shifts, atomic cluster size, and initial- and final-state electron angular momenta. 
GRANTEE:

GRANT:

TITLE:

PERSONS IN CHARGE:
MASSACHUSETTS INSTITUTE OF TECHNOLOGY

Department of Earth, Atmospheric, and Planetary Sciences

Cambridge, Massachusetts 02139
DE-FG02-86-ER13636

In-Situ Permeability Determination Using Borehole and Seismic Logging Data

M. Nafi Toksoz (617-253-7852; Fax 617-253-6385;

E-mail nafi@erl.mit.edu) and C. H. Arthur Cheng (617-253-7206;

Fax 617-253-6385; E-mail cheng@erl.mit.edu)
Objective: The objective of this project is to identify, locate, and characterize in situ fractures using downhole and surface seismic methods. The goal is to estimate the permeability of these fractures from the way they interact with seismic waves.

Project Description: The purpose of this work is to study methods of determining in-situ permeability or hydraulic conductivity of a fracture or fracture zone using full waveform and shear wave acoustic logging, vertical seismic profiling, and other downhole, crosshole, and seismic imaging techniques. In addition, methods to determine the orientation and extent of natural and man-made fractures are studied. The behavior of full waveform and shear wave logs in a fractured medium is studied using numerical models, laboratory scale model experiments and actual field data. The method of locating a hydrofrac using $\mathrm{mi}$ croearthquake arrival time is being improved by relative and absolute location techniques. The aim is to characterize and image in-situ fractures for the purpose of hydrocarbon production from naturally or artificially fractured reservoirs, nuclear waste disposal planning, and geothermal energy recovery.

Results: During the past year, the model of Stoneley wave propagation in permeable zones was refined to include the case where the formation permeability varies in the borehole axial and radial directions. Using the finite difference approach, such heterogeneities as random heterogeneous permeability variations, multiple fracture zones, and permeable (sand) - non-permeable (shale) sequences can be readily modeled. Numerical simulation results show that the continuous permeability variations in the formation have only minimal effects on the Stoneley wave propagation. Whereas the discontinuous variations (e.g., permeable sand and non-permeable shale sequences) can have significant effects. However, when the Stoneley wavelength is considerably large compared to the scale of heterogeneity variations, the Stoneley wave is sensitive only to the overall fluid transmissivity of the formation heterogeneity. This technique has been applied to interpret the acoustic logging data across a heterogeneous fracture zone. This modeling technique, in conjunction with a variable permeability model, successfully explains the non-symmetric patterns of the Stoneley wave attenuation and reflection at the top and bottom of the fracture zone, while it is difficult to explain these pattems using a homogeneous permeable zone model. This technique can be used as an effective means for characterizing permeability heterogeneities using borehole Stoneley waves.

A fast algorithm for estimating formation permeability from Stoneley wave logs was developed this past year. The procedure uses a simplified BiotRosenbaum model formulation. The input to the inversion is the Stoneley wave spectral amplitudes at each depth and receiver, the borehole fluid properties (velocity and density), the borehole caliper log, the formation density and porosity (from log data), and 
the compressional and shear velocities for the interval of interest. The model uses the borehole caliper and elastic properties to compute the Stoneley wave excitation as a function of frequency, and the porosity and permeability to compute the fluid flow amplitude reduction. This method also uses a reference depth of known permeability and compares amplitude variations at other depths relative to the reference depth. The permeability value obtained from the inversion represents the best fit over all receivers and all relevant frequencies. A processing example in a water well demonstrated the ability of this technique to extract formation permeability from Stoneley wave logs.

Ultrasonic model logging with dipole transducers in aluminum and lucite borehole models were performed to study the propagation of the flexural waves in a fractured or cased borehole. The experimental re- sults show that the flexural wave is much more sensitive to a horizontal fracture than to a vertical one. The propagation of flexural waves in a borehole with an inclined fracture is related to both the polarization of the flexural wave and the direction of the fracture. The experimental results show that a very strong low-frequency flexural wave can be generated by a dipole source in a cased borehole and it propagates with the shear wave velocity of the formation. High-frequency waves generated by a dipole source propagate with the compressional wave and flexural wave velocities of the casing. These laboratory experiments show that dipole logging can be an effective means for determining horizontal and declined fractures and for measuring the formation shear wave velocity in a cased borehole. 
GRANT:

TITLE:
DE-FG02-93ER14322

\section{Electroseismic Characterization of Lithology and Fluid Type in the Shallow Subsurface}

M. Nafi Toksöz (617-253-7852; Fax 617-253-6385;

E-mail nafi@erl.mit.edu)
Objectives: The objective of this research is to theoretically and experimentally study the electrokinetic coupling between seismic and electric fields in the earth. Specifically, we are testing the utility of the electroseismic method to remotely characterize lithologies and pore fluid compositions in shallow subsurface environments.

Project Description: Seismic waves propagating through fluid saturated sediments induce relative motions between the rock grains and the saturating fluid. This relative flow induces an electrokinetic current which results in electric fields which are observable at the earth's surface. The electrokinetic coupling is a function of both the rock lithology (i.e., porosity and permeability) and the pore solution chemistry. The goal of this project is to use the electroseismic method to remotely characterize subsurface lithologies and fluid types in shallow subsurface environments which are typically encountered in environmental and groundwater investigations. This research involves: (1) theoretical development of the electroseismic governing equations in porous media and numerical modeling of the electroseismic response for realistic geologic conditions; (2) controlled laboratory experi ments to quantify the effects of lithology and fluid chemistry on the electroseismic response; and (3) field experiments at several different locations.

Results: This year the governing equations for the coupled electromagnetics and acoustics of porous media have been derived and numerical algorithms for modeling the coupled seismic/EM wave propogation through layered media have been developed. These numerical models have been used to study the sensitivity of the theoretical electroseismic response to variations in the subsurface fluid chemistry, elastic properties, permeabilities, and the effects of the source/receiver geometries. Laboratory experiments on fluid saturated sandstones confirm that the electroseismic signals are electrokinetic in origin and that they are sensitive to both the rock lithology and the solution conductivity. Comparisons with available field data look encouraging. Plans for additional field experiments have been made. We have selected several sites, and purchased and tested a field data acquisition system. 
GRANTEE:

GRANT:

TITLE:

PERSONS IN CHARGE:
MASSACHUSETTS INSTITUTE OF TECHNOLOGY

Dept. of Earth, Atmospheric, and Planetary Sciences

77 Massachusetts Avenue

Cambridge, Massachusetts 02139
DE-FG02-94ER14431

\section{A High-Precision MT Study of the Mid and Lower Crustal San Andreas Fault Zone}

Theodore Madden (617-253-6854; Fax 617-253-6385;

E-mail trm@halley.mit.edu) and Randall Mackie
Objectives: To study the variations in the electrical conductivity of the mid and lower crustal parts of the San Andreas Fault system in central California using magnetotelluric measurements.

Project Description: The relative and absolute weakness of the San Andreas Fault can be explained if the slip zone of the fault contains excess fluids with high fluid pressures relative to the rest of the fault zone and adjacent crust. Fluids in the fault zone have also been invoked to explain the behavior of the creep ing section of the fault zone, and they may also play an important role in the earthquake cycle of the locked section of the fault. It has been suggested that any fluids in the fault zone may come from the lower crust, and if this is the case, then high-conductivity lower crustal channels created by the pore fluid paths should be resolvable using high-quality magnetotelluric measurements. This project will involve making magnetotelluric measurements across the Carizzo Plains section of the fault in the first year, and the Mojave section of the fault in the second year, and is associated with the San Andreas Deep Drilling Project.

Results: This project was only recently initiated data will be collected during the fall of 1994 and the analysis of that data will follow shortly thereafter. 


\section{GRANTEE:}

TITLE:
UNIVERSITY OF MIAMI

Rosenstiel School of Marine and Atmospheric Sciences

Miami, Florida 33149

\section{GRANT: $\quad$ DE-FG05-9214253}

\section{PERSON IN CHARGE:}

Testing the Correlation Between Sequence Stratigraphy, Seismic Reflectors and Diagenetic Changes in Carbonates: Evaluation of Fluid Flow During Early and Late Diagenesis
Objectives: To assess and model fluid flow in carbonate platform margins, especially evaluate how early diagenesis influences permeability and fluid path ways in the burial environment. In particular, test the hypothesis that early strata-bound diagenesis is related to variations in sea level and the resulting changing flow regimes.

Project Description: Two experiments are planned to constrain the fluid flow within carbonate platforms. The first experiment relies on two core borings and open holes on the western margin of Great Bahama Bank. This study includes the (1) assessment of the fluid evolution by means of geochemical tracing in core material and bore hole fluids, (2) borehole experiments that give information about the heat flow in the platform, the flow direction and the position of aquifers within the sedimentary sequences, and (3) modeling the fluid flow of the platform margin.

A second experiment is designed to test our findings from the modem environment in ancient systems, namely two isolated Upper Devonian platforms (Miette and Ancient Wall) in Alberta, Canada. The main objectives of this study are (a) to evaluate diagenetic zones within the sequence stratigraphic framework with a special emphasis on diagenetic and physical properties changes associated with sequence boundaries, and (b) to investigate to what degree burial diagenesis obliterates early strata-bound diagenetic signals.

Results: Analysis of the core borings reveals how fluctuations in sea level control both facies and early diagenesis in carbonate platforms. The diagenetic fluids consist of meteoric and normal marine sea water. A diagenetic pattern is observed that does not increase downhole but is highly variable and follows the stratigraphic framework, i.e., changes between diagenetic zones occur predominantly across sequence boundaries. Furthermore, a comparison of the Sr-isotope dates of cemented intervals and dolomite separates indicate that diagenesis can be related to early development of stratal patterns. Petrophysical analyses of the cores and individual samples show the relationship between porosity, pore types and velocity and permeability as well as the relationship between these parameters and the various diagenetic fabrics. This findings imply that (1) the seismic reflector is the combined result of facies and diagenesis which both are effected by changes in sea level, and (2) permeability variations occur across depositional surfaces and sequence stratigraphic important surfaces. As a result these surfaces are prone to act as flow barriers and create a large anisotropy between vertical and horizontal flow. Thus, fluid pathways are mainly controlled by the stratal pattern, which can be imaged by seismic signals. 
GRANTEE:

GRANT:

TITLE:

PERSONS IN CHARGE:
UNIVERSITY OF MICHIGAN

Department of Geological Sciences

1006 C.C. Little Building

Ann Arbor, Michigan 48109-1063

\section{DE-FG02-94ER14412} Applications of ICP Magnetic Sector Multicollector Mass
Spectrometry to Basic Energy Research

Alexander N. Halliday (313-764- 1435; Fax 313-763-4690;

E-mail a.halliday@um.cc.umich.edu) and Chris M. Hall
Objectives: To accurately determine the ages of, and source of components in, hydrothermal mineralization and diagenesis in order to evaluate the mechanisms responsible for the formation of economic base metal and hydrocarbon accumulation. To understand the controls on the chemistry of the oceans with particular reference to hafnium. To determine the mechanisms of entrapment of pollutants in sediments.

Project Description: This research project will develop the new technique of ICP multicollector mass spectrometry and apply the methods to a variety of problems in low temperature geochemistry. These will include new methods of dating sulfides such as longlived isotopic chronometers $\left({ }^{115} \mathrm{In}^{115} \mathrm{Sn}\right)$ and higher sensitivity applications of established geochronometers, such as Lu-Hf dating of phosphates. Laser ablation in situ isotopic measurements should be possible for dating and determining the origins of components in low temperature overgrowths and fine grained diagenetic minerals, such as $\mathrm{U}-\mathrm{Pb}$ measurements of zircon, anatase and sphene and Sr isotopic measurements in carbonates and feldspars. High sensitivity Hf isotopic studies of seawater and metalliferous sediments will be used to evaluate the Hf isotope geochemistry of the oceans. Precise isotope dilution measurements of transition metals and platinum group elements in dust, seawater and sediments will be used to evaluate the controls on the chemistry of the oceans and the mechanisms of entrapment of pollutants in sediments.

Results: This project has only just started and the accomplishments so far are as follows. The prototype ICP magnetic sector multicollector mass spectrometer has been installed and commissioned at the University of Michigan. Following performance evaluation and instrument characterization, the absolute abundances of isotopes of tin have been measured with precisions improved by up to an order of magnitude over those of currently accepted values. An efficient chemical separation technique for $\mathrm{In}$ and $\mathrm{Sn}$ in $\mathrm{Zn}, \mathrm{Cu}$ and $\mathrm{Fe}$ sulfides has been successfully developed. The predicted ${ }^{115} \mathrm{Sn}$ anomaly that results from the decay of ${ }^{115}$ In, has been measured in sulfides. Precise isotopic measurements of molybdenum, tellurium, hafnium, tungsten and platinum have been made. A new NdYAG laser ablation microsampling device on line to the mass spectrometer for in situ isotopic analysis at high precision has been commissioned and tested with accurate measurements of $\mathrm{Sr}, \mathrm{W}$ and $\mathrm{Pb}$ on standard silicate materials. 
GRANTEE:

GRANT:

TITLE :
UNIVERSITY OF MINNESOTA, TWIN CITIES

Department of Geology and Geophysics

Minneapolis, Minnesota 55455

DE-FG03-91ER14212

Physical Modeling of Sedimentary Basins, Magma Mechanics, and Molecular Dynamics of Geological Solutions

PERSON IN CHARGE: $\quad$ D. A. Yuen (612-624-1868; Fax 612-624-8861;

E-mail davey@krissy.msi.umn.edu)

Objectives: (1) Determination of the effects of lithospheric phase transitions in the evolution of sedimentary basins. (2) Investigation of time-dependent thermal convection with variable viscosity on lithospheric thinning. (3) Investigation of stress-distribution in the lithosphere from time-dependent convection with variable viscosity. (4) Dynamics of basaltic magma underplating and implications for the origin of crustal anatexic magma.

Project Description: The transport of mass, momentum, heat, and chemical species at both macroscopic and microscopic scales in the crust and lithosphere is vital to an understanding of the evolution of magmatic, hydrothermal and sedimentary basins. This work involves a number of sub-projects including the study of the effects of lithospheric phase transitions, role of viscous heating in crustal magma dynamics, stress-distribution in the lithosphere and lithospheric thinning. Description of additional work is given by my collaborator, Frank J. Spera, at the University of California, Santa Barbara (this volume).

Results: A simple model for sedimentary basin formation, which combines both stretching and phase transitions occurring together in the lithosphere, has been proposed, and two important aspects in sedimentary basin formation are addressed: (1) the explanation of the domal uplift preceding rifting, and (2) the ability of the model to explain the contradiction between small amount of crustal stretching and the large amount of thermal subsidence without the need to in- voke differential stretching between the crust and mantle. Numerical simulations have been conducted to study the causes for the sudden sag in basins in the late stages.

Numerical simulations of thermal convection with Newtonian and non-Newtonian temperature-dependent viscosity have shown that non-Newtonian rheology is much more efficient in thinning the lithosphere. A video has been made portraying these differences and it has been deposited with the American Geophysical Union as part of a paper to Geophysical Research Letters. Stress-focusing by variable viscosity convection is found to occur under realistic mantle conditions. Such strong concentration of stress, produced by plumes, may fracture part of the lithosphere. Viscous heating is found to be important in convection driven by both compositional and thermal forces. Temperature increases of a couple of hundred degrees may result from the ascent of compositional diapirs in the lower lithosphere. The effects of viscous heating can contribute to about the same as that for chondritic abundance in the lithosphere. Locally the magnitude of viscous heating can be as large as 50 to 100 times chondritic in the high Rayleigh number regime. From these studies in the last 6 months, we conclude that shear heating is really important in mantle and lithospheric dynamics, as these simulations have been carried out in both 2- and 3-D configurations with sufficiently high spatial resolution. 


\section{GRANTEE:}

GRANT:

TITLE:
NATIONAL ACADEMY OF SCIENCES/

NATIONAL RESEARCH COUNCIL

Board on Earth Sciences and Resources

Washington, D.C. 20418

DE-FG05-89ER14061

Board on Earth Sciences and Resources, Committee on Seismology, U.S. Geodynamics Committee, Committee on Geodesy, Geophysics Study

PERSON IN CHARGE:

Jonathan G. Price (202-334-2744; Fax 202-334-1377;

E-mail JPRICE@NAS.EDU)

Objectives: The Board on Earth Sciences and Resources coordinates the National Research Council's advice to the federal government on solid earth science issues related to research, education, the environment, geologic hazards, resource utilization, and economic development.

Project Description: The Board provides information and advice to the government through committees of volunteer geoscientists drawn from academia, industry, and government. The primary purpose of these committees is to respond to requests from the Executive Branch, Congress, and federal agencies for information or advice on specific issues before the government. The committees also serve as a forum for discussions and exchange of information among government, university, and industry scientists and policy makers. The Board strives to provide accurate and timely advice that can be used for wise decision making by preparing reports and bringing scientists and policy makers together at workshops, symposia, and forums. The Board also coordinates activities of various U.S. National Committees, including those for the International Union of Geodesy and Geophysics, the International Union of Geological Sciences, the International Geographical Union, and the International Union for Quaternary Research.

The major committees of the Board and their areas of oversight include: Committee on Earth Resources (national energy and mineral resource issues); U.S. Geodynamics Committee (solid-Earth sci- ence issues); Committee on Geodesy (research and applications of geodetic data); Mapping Science Committee (spatial data handling and analysis issues); Committee on Seismology (seismology related to research, hazards, and verification); Committee on Geophysical and Environmental Data (national and international data policies and services).

Additional ad hoc committees and panels are formed to address topics that fall outside the purviews of these committees.

Results: The Committee on Earth Resources completed a report to the Department of Energy on its Accelerated Oil Program Plan. The report Environmental Information for Outer Continental Shelf Oil and Gas Decisions was published with the Board on Environmental Studies and Toxicology. The committee is currently examining constraints on the availability of aggregate resources.

The U.S. Geodynamics Committee completed work on two reports: The National Geomagnetic Initiative and Mount Rainier, Active Cascade Volcano. Two studies in Geophysics, Global Surficial Geofluxes: Modern to Glacial and The Effects of Past Global Change on Life, are in preparation.

The Committee on Geodesy is preparing two reports, Airborne Geophysics and Precise Positioning: Scientific Issues and Future Directions and Forum on NOAA's National Spatial Reference System.

The Committee on Seismology is also preparing two reports. The first will review probabilistic earth- 
quake-hazard estimates at nuclear power plant sites; the other will advise the Advanced Research Projects Agency on seismological research related to the comprehensive test ban treaty.

The Committee on Geophysical and Environmental Data is evaluating proposals to create World Data Centers for Ecosystems, Hydrology, Satellite Oceanography, Climate, Earth Radiation Budget, and Socioeconomic Data. The committee is preparing a report, Restrictions on the International Exchange of
Scientific Data, and has two reports in press: 1993 Review of WDC-A for Meteorology/ National Climate Data Center and 1993 Forum on Global Change Data and Information Systems Implementation Plan.

The Mapping Science Committee's report Toward a Coordinated Spatial Data Infrastructure for the Nation has been incorporated into a recommendation in Vice-President Gore's National Performance Review and was the subject of a Presidential Executive Order. 
GRANTEE:

GRANT:

TITLE:

PERSON IN CHARGE:
NATIONAL ACADEMY OF SCIENCES/

NATIONAL RESEARCH COUNCIL

Committee on Seismology

Board on Earth Sciences and Resources

Washington, D.C. 20418

DE-FG02-94ER14445

Study of High Performance Computing in Seismology

Kevin D. Crowley and William E. Benson (202-334-2744;

E-mail kcrowley@nas.edu)

Objectives: The National Research Council is assessing the status and future of high-performance computing in seismology. This study is being conducted by the Board on Earth Sciences and Resources' Committee on Seismology, which will meet three times over a 12-month period to perform the assessment. This objectives of this study are to: (1) address the nature and scale of current problems in computational seismology; (2) identify major computational challenges in seismology, and assess where emerging technologies may be decisive; and (3) assess what is needed from technology to meet these computational challenges.

Project Description: At its first meeting in October, 1994, the committee sponsored a workshop at the San Diego Supercomputer Center at which about 30 experts from academia, industry, and government provided briefings on technical issues related to the seismology and high-performance computing. The workshop was attended by a total of about 70 scientists and federal program managers.

Results: The committee will prepare a National Research Council report that will integrate the results of this workshop into its deliberations and findings. The report should be published in the summer of 1995. The report will be prepared in sufficient quantities for distribution to workshop participants, sponsors, and other interested parties in accordance with NRC policy. 


\section{GRANTEE:}

GRANT:

TITLE:

PERSON IN CHARGE:
UNIVERSITY OF NEW MEXICO

Department of Earth and Planetary Sciences

Albuquerque, New Mexico 87131-1116

\section{Impact Deposits at the Manson Impact Structure: Diagenesis and Post-Impact Thermal History}

L. J. Crossey (505-277-5349; Fax 505-277-8843;

E-mail LCROSSEY@UNMB.UNM.EDU)
Objectives: The objectives of the study are to provide a detailed description of authigenic and alteration mineralogy from diverse lithologies encountered in several Continental Scientific Drilling Program (CSDP) cores from the Manson impact structure (drilled 1992-1993).

Project Description: Core materials from the Manson impact site (Manson, Iowa) will be examined in order to evaluate post-impact alteration processes. Evaluation of alteration will be based on petrologic, mineralogic, and geochemical investigations of core materials; including target strata, disturbed and disrupted strata, ejecta, breccias, microbreccias, and impact melt. The study of multiple cores will permit development of a regional model of post-impact history. In addition to standard petrographic techniques, $x$-ray diffraction analysis of fine-grained separates will be employed for mineral identification. Textural analysis will be performed with scanning electron microscopy (including energy-dispersive $x$-ray analysis) of fracture surfaces, vugs, and pores within breccia matrix. Geochemical analyses of authigenic phases will be obtained through electron microprobe analysis of selected samples.

Results: Two-hundred and fifty samples have been analyzed from four holes drilled on the flank of the central uplift at the Manson impact site (M1, M7, M8, and M10). Samples are categorized as Type I (a systematic downhole coverage of each lithology en- countered in the core) and Type II (veins, fracture surfaces, and vugs). Lithologies examined include sedi mentary clast breccias and crystalline clast breccias (of two types: a high-temperature "melt matrix" with abundant recrystallized clasts, and lower-temperature "sandy matrix" material, still bearing numerous shock features). X-ray diffraction analysis of fine-grained matrix separates from Type I samples reveals ubiqui tous expandable mixed-layer clays, with systematic variations in proportion of chlorite. Trace element geochemical analysis of Type I samples (performed in collaboration with Randy Korotev and co-workers at Washington University, St. Louis, MO) reveals distinct differences between the two types of crystalline clast breccias. In addition, the crystalline basement rocks are interpreted as the source for both crystalline clast breccia types. Petrographic analysis and scanning electron microscopy of Type II samples indicates the presence of a high-temperature hydrothermal system (deposition of minerals including gamet, ferroactinolite, and laumontite in fractures and vugs). Quartz, chlorite, expandable mixed-layer clays, calcite, pyrite, and gypsum have also been noted, with chlorite coprecipitating with quartz, and calcite consistently a late-stage product. Geothermal modelling indicates that the hydrothermal system was driven by heat within the central uplift, and operated for 105106 yrs. 
GRANTEE:

GRANT:

TITLE:

PERSON IN CHARGE:
SANTA FE INSTITUTE

1660 Old Pecos Trail Suite A

Santa Fe, New Mexico 87501

DE-FG0394-ER14425

Complex Systems in the Earth Sciences: Predictability, Mitigation and Reduction of Natural Hazards (a workshop held January 5-9, 1994, in Santa Fe, New Mexico)

John B. Rundle (303-492-5642; Fax 303-492-1149;

E-mail rundle@cires.colorado.edu), Donald Turcotte, and William Klein

Objectives: Convene a workshop to explore applications of the new sciences of complexity to the development of techniques for evaluating the hazards posed by a variety of natural disasters.

Project Description: Natural hazards such as earthquakes and severe floods are a continual menace to large segements of the population worldwide. Recently the United Nations has focused attention on this global problem by declaring the 90 's the Decade of Natural Hazard Reduction. Natural hazards can cause severe economic hardship locally and, in an ever more complex and interactive world economy, dislocations that are felt in areas far beyond the region of a specific event. An example is the recent series of catastrophic earthquakes, hurricanes, floods and fires that have called into question the ability of private insurers to cover the economic losses. To explore how new methods developed in studying nonlinear complex systems might help in evaluating the risks posed by these hazards, a workshop on Reduction and Predictability of Natural Disasters was held at the Santa Fe Institute on January 5-9, 1994. It is intended that this workshop be the first effort at a long term program in this area at the Santa Fe Institute.

Results: The Santa Fe Institute was founded in 1985 to study the emergent properties of complex nonlinear systems seen in a diversity of fields, from physical science to economics to biology. During the workshop, which brought together 25 geologists, geophysicists, hydrologists, physicists, and mathemati- cians, a wide variety of natural disasters and hazards were considered. These include earthquakes, landslides, floods, tsunamis, hurricanes, and tornadoes. The general theme of the meeting was the application of the techniques of statistical mechanics to problems in the earth sciences. Important questions considered included:

(1) What are the statistics of earthquake occurrence, and what is the largest event that can occur in a region?

(2) What are the statistics for the occurrence of very large floods and storms such as hurricanes? Is there any physical basis for application of a particular statistical relation, i.e. fractal, log normal, etc?

(3) Can flood statistics be obtained from studies of meteorological conditions plus the hydrology of river basins?

(4) Have human modifications such as agriculture, flood control projects and channelization made the flooding problem more severe in some cases?

(5) What is the validity of using the probability distribution of small events to predict the occurrence of large, extremal events?

A recurrent theme of the presentations was the application of the modem techniques of statistical mechanics with particular focus on dynamical systems concepts including fractals, multifractals, chaos, nucleation, self-organizing systems, and critical phenomena. 
GRANTEE:

GRANT:

TITLE:

PERSON IN CHARGE:
THE CITY COLLEGE OF THE CITY UNIVERSITY OF NEW YORK

Benjamin Levich Institute \& Department of Physics

New York, New York 10031

DE-FG02-93-ER14327

Stochastic Transport in Heterogeneous Flows and Media

Joel Koplik (212-650-8162; Fax 212-650-6835;

E-mail koplik@sci.ccny.cuny.edu)
Objectives: We will obtain a description of the transport of passive tracer in flow through porous media with highly-correlated strong disorder, relating measurable tracer characteristics to the geometry and statistical description of the reservoir.

Project Description: This research will seek a better understanding of fundamental physical laws that govern stochastic transport processes in heterogeneous media with macroscopically correlated disorder. For composites with "block" disorder, conventional macroscopic transport equations generally do not apply, and we will attempt to formulate the appropriate composition laws that permit a macroscopic description of transport in such systems. The superdiffusiver motion of Brownian particles in a randomly stratified flow field will then be investigated. Steady-state and first-passage characteristics of this system appear to be controlled by exceptional fluctuations, leading to a multiplicity of basic time scales in the system. We plan theoretical and numerical studies to determine the appropriate mascrocopic description. We will also explore the unusual transport properties of Brownian particles which are driven by prototypical random flow fields. Finally, we propose to examine the firstpassage characteristics in source-sink flow, where the interplay between spatially varying convection and molecular diffusion are anticipated to yield unusual first-passage properties. We will extend these studies to fractured media, where fast transport in fractures competes in a subtle way with slow transport modes.
These latter studies will be closely tied to ongoing experimental work, and will also involve large-scale simulations on parallel processors.

Results: Using a combination of analytic arguments, numerical simulation and laboratory experiment, we have developed a general characterization of planar source-sink flows in terms of the transit-time probability distribution of passive tracer released in the flow. The latter is shown to exhibit (1) a geometry-dependent early arrival regime, (2) a power-law decay regime with exponent determined from the multipole order of the distribution of sources and sinks, (3) a shoulder resulting from reflection from the system boundaries, and (4) an exponential decay regime, with decay constant related to either a diffusive cutoff or to stagnation points in the flow.

In the problem of dispersion in systems with block heterogeneities, we have developed simple calculational methods for time-dependent situations, in terms of analog electrical networks. Even simpler effective medium and related approximations are being explored.

In randomly stratified flow, we have been studying the first-passage time problem, using on the one hand path-integral methods for averaging over statistical ensembles in infinite systems, and on the other, explicit calculations for the case of two-layers. In the latter case, we have a consistent picture for the scaling of the transit time with system size as a function of Péclet number for both early and late arrivals. 
GRANTEE:

GRANT:

TITLE:

PERSON IN CHARGE:
STATE UNIVERSITY OF NEW YORK AT STONY BROOK Department of Applied Mathematics and Statistics

Stony Brook, New York 11794-3600
Three-Dimensional Imaging of Drill Core Samples using Synchrotron Computed Microtomography

W. B. Lindquist (516-632-8361; Fax 516-632-8491;

E-mail lindquis@ams.sunysb.edu)
Objectives: The goal of this work is to produce a suite of computational tools to use in the analysis of the void structure of three-dimensional microtomographic images of porous media. The tools involve graphics, statistical analysis, computational geometry and graph theoretical techniques.

Project Description: Computed-microtomographic (CMT) three-dimensional images, with 2- to 5micron resolution, of core samples are provided by K. W. Jones of Brookhaven National Laboratory using $x$-ray radiation from the National Synchrotron Light Source. The tomograms are then post-processed (filtered) to provide specific grain/pore identification to each voxel in the image. The filtered images are subjected to a variety of analyses based upon the development of the computational tools mentioned above. It is desired that, for any given drill core sample, the entire reduction procedure, from tomographic image data to final analysis output should be done in software, requiring minimal human input.

Results: To date the following major components to the suite of desired software tools have been developed: filtering algorithm; two-point correlation analysis for the spatial distribution of void spaces or grains; medial axis construction which identifies the fundamental "skeleton" of the void space. In addition, statistical and graph theory algorithms have been added to examine the void space "skeleton." For example, shortest path algorithms applied to the medial axis lead to direct measurements of the distribution of the "tortuosity" of the void paths. We are currently proceeding with the application of network flow models to the medial axis to develop the ability to estimate single-phase fluid flow properties through the pore network. 
GRANTEE:

GRANT:

TITLE:

PERSON IN CHARGE:
STATE UNIVERSITY OF NEW YORK AT STONY BROOK Department of Earth and Space Sciences

State University of New York

Stony Brook, New York 11794-2100

DE-FG0294-ER14455

Micromechanics of Failure in Brittle Geomaterials

Teng-fong Wong (516-632-8212; Fax 516-632-8240;

E-mail tfwong@ccmail.sunysb.edu) and Joanne T. Fredrich

(Sandia National Laboratory)
Objectives: The objectives of this project are to provide a fundamental understanding of the effects of grain boundary structure and cementation, damage state, and load path on the deformation and failure mode of brittle porous and nonporous geologic materials by measurement of mechanical behavior under high pressure and deviatoric stress, quantitative microstructural characterization of pristine and deformed samples, and theoretical analysis.

Project Description: Knowledge of the failure behavior of rocks is important for several energy-related applications, including reservior engineering, oil and gas exploration and production, underground disposal of nuclear waste, and drilling technology. The experimental investigation will provide a detailed understanding of the micromechanical processes associated with the brittle failure of geomaterials and includes triaxial tests following various load paths which are defined by the ratio $\mathrm{K}$ of the change in the radial confining (horizontal) stress to the change in the axial (overburden) stress. Tests are conducted to vari ous stages of failure and include measurement of strain and acoustic emission. The micromechanical failure process are further elucidated and characterized quantitatively using light microscopy, laser scanning confocal microcopy, and scanning electron microscopy. Work focuses on porous carbonate and siliciclastic rocks, although related experiments are also being performed on low-porosity crystalline rocks in order to study completely the effect of certain parameters. The results of the laboratory tests and microstructural studies are used to guide analyses using fracture mechanics and continuun plasticity theories.

Results: This project was only recently initiated in the last quarter of FY 1994. 
GRANTEE:
TITLE:

\section{GRANT:}

\section{PERSONS IN CHARGE:}

STATE UNIVERSITY OF NEW YORK AT STONY BROOK

Research Foundation of The State University of New York

Office of Research Services

Stony Brook, New York 11794-3366
DE-FG02-94ER14449

High Precision Radiometric Dating of Sedimentary Materials

G. N. Hanson (515-632-8210; Fax 516632 8240;

E-mail ghanson@ccmail.sunysb.edu) and W. J. Meyers
Objectives: To develop field, petrographic and geochemical criteria to allow high precision $\mathrm{U}-\mathrm{Pb}$ dating of calcretes or caliches enriched in uranium at paleo-exposure surfaces within rapidly deposited sequences of carbonate and clastic rocks

Project Description: The ultimate goal is to obtain radiometric ages with uncertainties of three million years or less for times of sedimentation. Such uncertainties would be much less than those for most epoch or period boundaries within the Paleozoic or early Mesozoic. U-enriched caliches will be selected from soils developed in rapidly deposited sequences.
It is essential that the duration of soil development be less than the analytical uncertainties. We have begun our studies on caliches in the Mesozoic rocks of the Hartford Basin, Connecticut and the upper Paleozoic rocks of the Sacramento Mountains, New Mexico. These studies should also lead to a better understanding of the geochemistry of paleosols including the processes responsible for U-enrichment. They should also provide additional criteria for recognizing erosion surfaces.

Results: This project was only recently initiated. 
GRANTEE:

GRANT:

TITLE:

PERSON IN CHARGE:
NORTHWESTERN UNIVERSITY

Department of Civil Engineering

Evanston, Illinois 60208-3109

DE-FG02-93ER14344

Shear Strain Localization and Fracture Evolution in Rocks

J. W. Rudnicki (708-491-3411; Fax 708-491-4011;

E-mail jwrudn@nwu.edu)

Objectives: To obtain an improved understanding of the occurrence, development and evolution of zones of shear localization (faults) in rocks and their relation to the macroscopic constitutive description, especially that goveming multi-axial response, and microscale mechanisms of deformation.

Project Description: Because of the significance of fractures to energy production, waste disposal, and mineral technologies, prediction of their causative stresses, location, orientation, thickness and spacing is important. This project examines the applicability of a theory of localization that describes faulting as an instability of the constitutive description of homogeneous deformation. Because the predictions depend strongly on the constitutive parameters governing abrupt changes in the pattern of deformation, theoretical work is being done to develop a more realistic and elaborate constitutive model based on the growth and interaction of microcracks and resulting increase in overall compliance of the solid. This constitutive relation is calibrated by comparison with axisymmetric compression tests and then used to predict the response in more complex experiments (compression torsion) with abrupt changes in the pattern of loading. Numerical studies will be used for detailed comparison with experiments to address the effects of realistic geometries and boundary conditions.

Results: A modification of an ad hoc relationship proposed by Costin (J. Geophys. Res., 1983) for the local tensile stress and a critical fracture toughness criterion are used to relate the orientation and length of opening microcracks to the applied loading. The macroscopic damage surface is the inner envelope (in stress space) of the individual planes for microcracks at each orientation. Inelastic strains are predicted by calculating the compliance increase due to an isolated crack in an infinite elastic solid subjected to the local tensile stress from Costin's relation. In simulations of axisymmetric comprssion tests, the calculated compliance increases, including those for transverse and longitudinal shear compliances, are similar to those observed in laboratory experiments. For combined axisymmetric compression ( $s$ ) and torsion $(t)$, axial loading causes the damage surface in $s$ vs $t$ space to evolve from an ellipse to a surface with a sharp vertex at the current stress point. For stress increments directed between the vertex and its forward projection, the response is fully nonlinear in the sense that the tensor relating increments of strain to increments of stress depends on the ratio of stress increments. Such fully nonlinear response is known to affect both the inception and development of localization. 
GRANT:

TITLE:

PERSON IN CHARGE:
DE-F602-93ER14391

Energy Partitioning of Seismic Waves in Fractured Rocks

Laura J. Pyrak-Nolte (219-631-8377; Fax 219-631-9236;

E-mail Pyrak-Nolte@nd.edu)
Objectives: The primary objectives of the proposed research are to investigate through numerical and laboratory investigations: (1) the partitioning of seismic energy between body waves, guided waves, and scattered waves produced by sources of finite size that are transmitted, reflected, and channeled along single and multiple fractures, (2) techniques for exciting these waves, (3) the effect of spatial variations in the mechanical properties along the fracture on seismic wave propagation, and (4) the effects of a finite fracture on seismic waves.

Project Description: Rock masses contain fractures and discontinuities on all length scales that affect the mechanical stability of a rock mass and the flow of fluids through a rock mass. A goal of site characterization for waste isolation or mineral exploration is to detect and characterize the hydraulic and mechanical properties of fractures using seismic techniques. Seismic data are often difficult to interpret because of wave conversions that occur at interfaces. Converted wave modes can arise when seismic waves are propagated through a fractured rock mass and these waves inhibit direct interpretation of the received signals. Because the existence of interface waves has not previously been taken into account in seismic data interpretation, it is important to understand how nonwelded interfaces, such as fractures and joints, give rise to interface waves. In this research project, the partitioning of seismic wave energy into body waves and interface waves caused by fractures (non-welded contacts) is studied through laboratory experiments and numerical analysis.

Results: The specific results for the first year of this project include: (1) the energy in compressional waves propagated along a fracture increases or decreases depending on the amount of energy that is partitioned into interface waves and other converted wave; (2) a converted PS-mode wave that occurs only when compressional waves are propagated along the interface may be a previously unobserved interface wave; (3) the energy in this PS mode wave is affected by changes in fracture stiffness. These results suggest that bulk compressional waves propagated along a fracture can be used to monitor changes in fracture stability without having to measure interface waves.

Currently, the project is focused on quantifying the partitioning of energy between bulk waves and interface waves observed in the experimental data. Analysis tools are being developed that determine the frequency content of a received wave form as a function of time and that yield the dispersive properties of the waves. Preliminary analysis shows that the variation in frequency content of interface waves with time may be used to determine the variation in stiffness within a single fracture. The analysis of existing data sets is being performed to aid in the design of synthetic fractures of calculable stiffness to verify the partitioning of energy into bulk and interface waves. 


\section{GRANTEE:}

TITLE:

PERSONS IN CHARGE:
THE OHIO STATE UNIVERSITY

Department of Welding Engineering

Columbus, Ohio 43210

DE-FG02-89ER13749.A001
Investigation of Ultrasonic Wave Interactions With FluidSaturated Porous Rocks
L. Adler (614-292-1974; Fax 614-292-1266) and P. B. Nagy (614-

292-3655; E-mail pnagy@magnus.acs.ohio-state.edu)
Objectives: The main objective of this research is the investigation of ultrasonic wave propagation in fluid-saturated porous materials. Our objectives are to further develop the (1) slow surface wave inspection and (2) air-saturation techniques for ultrasonic evaluation of porous formations and to adapt these novel techniques to the inspection of highly permeable natural rocks (above $100 \mathrm{mDarcy}$ ). This research effort should find applications in geophysical evaluation of fluid-bearing porous rocks, where parameters such as tortuosity, shape factor, permeability, saturation level, and internal impurity are difficult to measure by conventional techniques using low-frequency acoustic and other methods.

Project Description: In this research project we have continued our investigation of ultrasonic wave propagation in fluid-filled porous materials. Our research effort was focused on two special acoustic wave modes which are uniquely sensitive to the permeable nature of porous media. First, we further developed our airborne slow wave technique towards the ultimate goal of ultrasonic evaluation of inhomogeneous pore structures in reservoir rocks. Second, we continued to pursue our investigation of the recently discovered "slow surface wave" as a practical means to characterize permeable solids such as natural rocks.

Results: Our efforts on the air-saturation slow wave technique were particularly successful in (1) deepening our understanding of the underlying physical interaction between the acoustic wave and the porous formation and (2) improving our technical capabilities to use this novel approach for characteri- zation of inhomogeneous pore structures by means of high-resolution mapping of the local permeability distribution. In order to understand the experimentally observed excess attenuation at high frequencies, we modified our system so that sharply focused "spherical" beams could be also used. In this way, we could distinguish between spatially coherent and incoherent components in the transmitted slow wave. Our experimental results clearly indicated that the loss of the coherent transmission was significantly larger than the accompanying increase in the incoherent field therefore the loss was primarily viscous scattering. As a spin-off of our experimental study of the incoherent nature of the transmitted slow wave, we developed a high-resolution imaging device which can map the local permeability distribution in porous solids.

We recently introduced a novel experimental technique based on the propagation of the so-called slow surface wave on the free surface of fluid-saturated permeable solids with closed surface pores. Our main achievement in this area was the realization that, due to surface tension, practically closed-pore boundary conditions can prevail on the free surface of a liquid-saturated rock in spite of geometrically open pores. Our research efforts during the last year produced two major results in the area of slow surface wave propagation on fluid-saturated permeable solids. First, we successfully adapted a novel laser interferometric detection technique to our experimental system. Second, we conducted a detailed experimental study to determine the quasi-static surface stiffness of different water-saturated porous materials by changing 
the hydrostatic pressure and directly measuring the average surface displacement by an acoustical sensor. These measurements provided the first independent verification of the crucial "closed-pore" assumption used for the free surface of water-saturated porous solids. Furthermore, they revealed a novel acoustic characterization technique based on the direct measurement of the surface stiffness of fluid-saturated permeable solids. This parameter is uniquely sensitive to the shape of the pores and the overall pore size distribution in the material and can be easily measured by the developed ultrasonic method. 


\section{GRANTEE:}

TITLE:

\section{GRANT:}

UNIVERSITY OF OKLAHOMA

School of Geology and Geophysics

Norman, Oklahoma 73019

\section{DE-FG05-913414209}


sulfate. Subsequent to pyrite dissolution, the resulting ferrous solutions were mixed with a basic nitrate solution, resulting in the precipitation of a ferrous hydroxide gel. The gel was converted to magnetite by increasing the temperature of the reaction from $60^{\circ}$ to $90^{\circ} \mathrm{C}$. This simulation corresponds chemically to the equilibration of pyrite in an organically encased, acidic microenvironment surrounded by basic fluids in a carbonate rock. The effects of ligand structure and ligand concentration on pyrite dissolution were assessed using a variety of ferric iron complexes, including phenols, carboxylic acids, ketones and natural and synthetic humic acids in aqueous solution. Results indicate that the extent of pyrite dissolution depends on the total amount of ferric iron in the system and that magnetite formation is reduced or blocked by excess concentrations of uncomplexed ligands. With respect to the precipitation of magnetite by migrating fluids, some experiments on the interactions of organic substances with gel precipitation and magnetite crystallization have been performed. Gels have been precipitated in the presence of organic compounds and several factors which interfere with this process have been identified. Gels have also been converted to magnetite in the presence of organic compounds and, in a separate set of experiments, by the action of an organic freeradical oxidizing agent. 
GRANTEE:

TITLE:

PERSON IN CHARGE:
OREGON STATE UNIVERSITY

College of Oceanic and Atmospheric Sciences

Ocean Admin. Bldg. 104

Corvallis, Oregon 97331-5503

\section{GRANT: $\quad$ DE-FG06-92ER14277}

\section{Multi-station Magnetotellurics}

G. D. Egbert (503-754-2947; Fax 503-737-2064;

E-mail egbert@oce.orst.edu) and H. F. Morrison (University Of

California at Berkeley; 510-642-3804; Fax 510-642-3805)
Objectives: The principal objective of this project is to develop and test new methods for collecting and processing remote reference magnetotelluric data in areas with significant cultural noise, with special em phasis on the "dead band" (approximatedly 0.1$10.0 \mathrm{~Hz}$ ) where signal levels are low and noise levels are high.

Project Description: The project has three aspects: (1) In the first year, data were collected in a series of three station MT arrays which span conditions from very noisy (just south of San Jose, CA) to very remote sites. Our emphasis was on collecting a large volume of dead band data at a small number of sites. Multiple remote sites at varying distances, and in various combinations of noisy and quiet, were included to allow us to characterize spatial and temporal properties of signal and noise, and to test different approaches to remote reference data acquisition. (2) New approaches to remote reference data processing are being developed. We are adapting multivariate and robust statistical methods to the special problems of MT data processing in the dead band. (3) Using the multi-station MT (MSMT) data from our experiment, and other compilations of remote reference MT data, we are testing and comparing various strategies for collecting and processing remote reference MT data.

Results: MSMT data collected within approximately $100 \mathrm{~km}$ of the regional DC electric railway (BART) are contaminated by spatially coherent noise. For sites within this area, standard robust remote reference estimates are seriously biased in the frequency range $0.010-0.25 \mathrm{~Hz}$. Using a distant remote site as a reference dramatically improves impedance estimates. Coherent noise varies in time in a manner consistent with BART being the dominant source-single station and "local" remote estimates obtained from periods when BART is not operating are well behaved. A robust multivariate MT data processing package, based on a generalization of the regression M-estimate to multivariate linear models, has been developed and tested on MSMT, synthetic, and other MT data. This scheme divides the observed signal into three parts: local noise, coherent noise, and uniform source signal. First, local noise power is estimated and localized outliers are cleaned up. This initial step separates local noise from coherent signal, and yields data quality weights for each channel, together with the coherent dimensionality of the signal, a useful diagnostic of the severity of coherent noise. Separation of "coherent noise" from uniform source "signal" with a purely statistical procedure is problematic. Success in this second stage requires additional information. For the MSMT data, knowledge that the distant remote site is uncontaminated, and that the cultural noise and natural sources are uncorrelated, allows a unique separation. We have exploited this to more fully characterize the "BART noise" in space, time, and frequency, and to optimize impedance estimates. More general approaches for identifying and separating coherent noise, based on intermittency and/or the differing spatial/frequency characteristics of coherent noise are nder development. 
GRANTEE:

GRANT:

TITLE:

PERSON IN CHARGE:
PENNSYLVANIA STATE UNIVERSITY

Department of Geosciences

University Park, Pennsylvania 16802
DE-FG02-92ER14251

Cretaceous Shallow Drilling in the U.S. Western Interior: Core Research

M. A. Arthur (814-863-6054; Fax 814-863-7823; Internet:

arthur@geosc.psu.edu) and W. E. Dean (U.S. Geological Survey;

303-236-5760; Fax 303-236-0459; E-mail dean@sedproc.cr.usgs.gov)
Objectives: Construct a subsurface transect of mid-Cretaceous strata that were deposited in the U.S. Western Interior Seaway (WIS), ranging from pelagic, organic-carbon rich, marine hydrocarbon source rocks in Kansas and eastern Colorado to nearshore, coalbearing units in westem Colorado and Utah to provide a basis for paleoenvironmental interpretation of epicontinental, foreland basin organic-carbon burial settings.

Project Description: This project is a multidisciplinary study, by a team of academic and U.S. Geological Survey scientists, of Cretaceous carbonate and clastic rocks in cores along a transect across the old Cretaceous seaway that extended from the Gulf Coast to the Arctic during maximum transgressions. In particular, the study focusses on the Graneros Shale, Greenhorn Limestone, Carlile Shale, and Niobrara Formation and equivalents in cores from six drillholes from western Kansas, southeastern Colorado, and eastem Utah. This series of cores provides unweathered samples and continuous smooth exposures required for geochemical studies, mineralogical investigations, and biostratigraphic studies. Major objectives include: (1) precise timing of sealevel change, rates of subsidence, and facies change; (2) determination of controls on the accumulation, burial, and diagenesis of organic matter; (3) calibration of depositional cycles using high-resolution stratigraphy; (4) determine the paleogeography, paleoclimatology, and paleoceanography of the
Western Interior Seaway.

Results: Cretaceous core from an AMOCO drillhole from western Kansas was released to the USGS in 1992, and description and analysis of this core plus that from a previously acquired well (SchockErrington \#1) in northwestern Kansas constitute the data base for the eastem end of the transect. Three holes that form the western end of the transect, funded by USGS energy programs, were drilled and continuously cored in June, 1991 in the Kaiparowits basin near Escalante, Utah. In June, 1992, a 700-foot hole, funded by DOE, was drilled and continuously cored near Portland, Colorado east of the Florence oil field. This sequence, deposited in relatively deep water on the west side of the WIS, includes cycles of terrigenous-clastic and pelagic-marine sediments to contrast with the pelagic carbonate-dominated cycles of Kansas and the clastic-dominated cycles of western Colorado and Utah. A second, 800-foot hole, also funded by DOE, was drilled in July, 1992 about 10 miles southwest of the Portland hole in Pierre Shale that is the reservoir for hydrocarbons in the Florence field.

Planned geochemical analyses and biostratigraphic-paleoecologic determinations by the WIS research team are nearly completed for all cores. Formal descriptions of the cores are available in a computer data base and will be published as USGS Open-File Repts. A special poster-session was convened by the Principal Investigators at the AAPG-SEPM Annual 
Meeting (1994) in Denver to display the scientific results of the project; all scientific collaborators participated in the session. A publication on the scientific results of the project is planned (SEPM Special Publication) with manuscripts due in January, 1995. The research by the team has resulted in data to be integrated that have resulted in a new but preliminary model of the circulation, productivity and depositional environment of a mid-latitude foreland basin that produces significant hydrocarbon source potential. The model involves variations in sea level in combination with the regional climate regime as the main control on water mass characteristics, structure and organicmatter deposition. 
GRANTEE:
GRANT:

TITLE:

PERSON IN CHARGE:
PRINCETON UNIVERSITY

Department of Geological and Geophysical Sciences

Princeton, New Jersey 08544

\section{DE-FG02-85ER13437}

Thermodynamics of Minerals Stable Near the Earth's Surface
Objectives: The goals of the project are to increase both the data base and the fundamental understanding of the thermodynamics of volatile-bearing mineral phases (amphiboles, micas, clays, zeolites, carbonates) important to surficial, sedimentary, and shallow crustal processes.

Project Description: Using high temperature solution calorimetry, this research determines the enthalpies of formation of hydrous minerals and carbonates. Systematics in energetics of ionic substitutions are sought in order to predict the thermodynamics of complex multicomponent minerals. Mixing properties of mica, amphibole, and carbonate solid solutions are also studied.

Results: The energetics of nonstoichiometric ( $\mathrm{Ca}$ rich) dolomites has been determined. The enthalpy of formation rises very steeply with excess $\mathrm{Ca}$, from values of near $-10 \mathrm{~kJ} / \mathrm{mol}$ for $\mathrm{Ca} /(\mathrm{Ca}+\mathrm{Mg})=0.50$ to zero or slightly positive values for $\mathrm{Ca} /(\mathrm{Ca}+\mathrm{Mg})=$ 0.57 (see Fig. 1). This pronounced destabilization supports the idea of destabilizing intralayer $\mathrm{Ca}-\mathrm{Mg}$ interactions competing with stabilizing interlayer interactions and the thermochemical data will help constrain theoretical models such as those based on the cluster variation method (CVM). Samples along the magnesite-siderite and dolomite-ankerite joins have been synthesized and analyzed, and calorimetry is progressing.

Work on a series of amphiboles has been completed, allowing estimates of the energetics of substitutions along the tremolite-tschermakite join.

A series of synthetic faujasite zeolites showing the substitution $\mathrm{Si}^{4+}=\mathrm{Al}^{3+}+\mathrm{Na}^{+}$has been made and

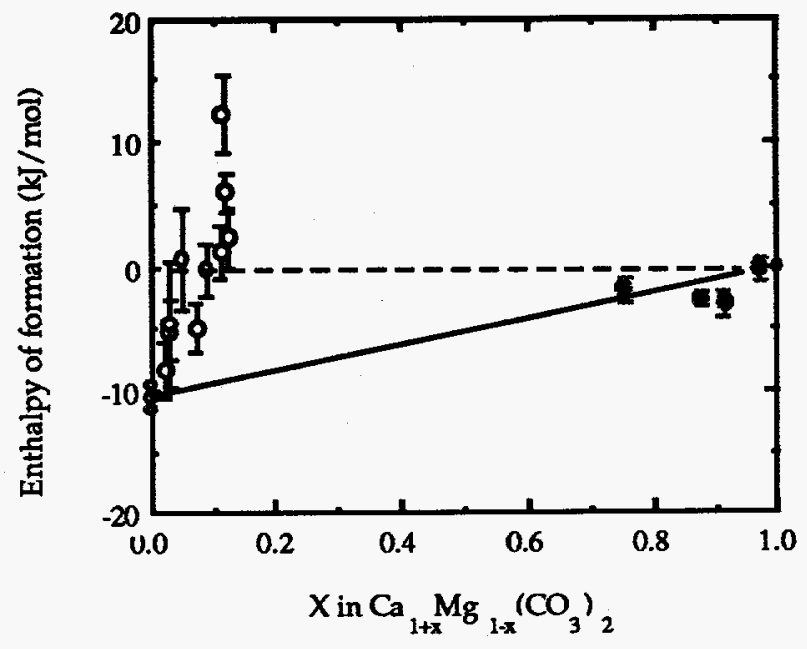

Fig. 1. Enthalpy of formation from $\mathrm{CaCO}_{3}$ and $\mathrm{MgCO}_{3}$ of $\mathrm{Ca}$-rich dolomites and $\mathrm{Mg}$-rich calcites. From Chai, Navrotsky, and Reeder, Am. Min. (submitted).

characterized, and a suite of natural zeolites is being purified, ion exchanged, and characterized for calorimetry. Calorimetry is almost complete on the epidote series, showing $\mathrm{Fe}^{3+}-\mathrm{Al}^{3+}$ substitution.

The energetics associated with dislocations in quartz has been determined to be $\leq 0.6 \mathrm{~kJ} / \mathrm{mol}$ for a dislocation density which represents at least an order of magnitude higher dislocation density than any found in nature.

Energetics of radiation damage in natural zircon have been studied. Metamictization is associated with a large energy increase of $59 \pm 5 \mathrm{~kJ} / \mathrm{mol}$, consistent with pervasive damage on the unit cell or next nearest neighbor scale rather than with microcrystallinity. 
GRANTEE:

GRANT:

TITLE:

PERSON IN CHARGE:
PRINCETON UNIVERSITY

Department of Geological and Geophysical Sciences

Princeton, New Jersey 08544
The Effects of Natural and Radiation Induced Defects on Noble
Gas Transport in Silicates: A Study of Argon Using Laser,
X-Ray, and Electron Microprobes

T. C. Onstott (609-258-6898; Fax 609-258-1274;

E-mail tullis@weasel.princeton.edu)
Objectives: The research goal is twofold. The first is to determine the relationship between argon diffusion and microstructures for K-feldspar from a rock unit with a well-constrained thermal history. The second is to characterize the microstructures resulting from neutron irradiation of K-feldspar.

Project Description: The relative importance of exsolution lamella in $\mathrm{K}$-feldspar in the determination of diffusion parameters for argon in the laboratory was ascertained by performing numerical modelling of the irradiation process.

Results: Integration of the neutron energy distribution for a water-moderated reactor with the most recent cross-section data yields mean recoil energies of $180 \mathrm{keV}$ for ${ }^{39} \mathrm{~K}$ (n,p) ${ }^{39} \mathrm{Ar}, 970 \mathrm{keV}$ for ${ }^{40} \mathrm{Ca}(\mathrm{n}, \mathrm{a})$ ${ }^{37} \mathrm{Ar}$, and $140 \mathrm{eV}$ for ${ }^{37} \mathrm{Cl}(\mathrm{n}, \mathrm{g}){ }^{38} \mathrm{Cl}$ (b) ${ }^{38} \mathrm{Ar}$. Utilizing Monte Carlo simulations of collision cascades, we calculate a mean recoil range of $1620 \AA$ for ${ }^{39} \mathrm{~K}(\mathrm{n}, \mathrm{p}){ }^{39} \mathrm{Ar}, 3780 \AA$ for ${ }^{40} \mathrm{Ca}(\mathrm{n}, \mathrm{a}){ }^{37} \mathrm{Ar}$, and $11 \AA$ for ${ }^{37} \mathrm{Cl}(\mathrm{n}, \mathrm{g}){ }^{38} \mathrm{Cl}(\mathrm{b}){ }^{38} \mathrm{Ar}$. Integration of the recoil range distributions yields a mean depletion depth in a semi-infinite medium of $820 \AA$ for ${ }^{39} \mathrm{Ar}, 1950 \AA$ for ${ }^{37} \mathrm{Ar}$, and $6 \AA$ for ${ }^{38} \mathrm{Ar}$. The concentration gradients generated by recoil-redistribution between thin slabs were then incorporated into standard diffusion equations.

These calculations indicate that the argon release rates and ${ }^{40} \mathrm{Ar} /{ }^{39} \mathrm{Ar}$ age spectrum derived from incre mental heating of exsolved minerals are significantly affected by recoil-redistribution. If the exsolution lamellae are the effective diffusion dimension, the measured activation energy of diffusion for potassium-rich lamellae will be significantly greater than the true value by at least $10 \%$. The age spectra will be discordant even if the feldspar has not experienced a complex or slow cooling history. Incremental step apparent ages will increase with the fraction of ${ }^{39} \mathrm{Ar}$ re leased as the potassium poor lamellae degas. The age spectra will exhibit decreasing apparent ages with increasing fraction ${ }^{39} \mathrm{Ar}$ released as the potassium feldspar lamellae degas. The overall profile of the age spectrum will depend upon the composition of the feldspar and the size of the lamellae.

Finally, the $11 \AA$ mean recoil distance calculated for ${ }^{38} \mathrm{Ar}$ indicates that it is not a proxy for anion-sited excess argon. Instead, published correlation of ${ }^{38} \mathrm{Ar}$ with excess ${ }^{40} \mathrm{Ar}$ probably reflect the degassing of fine-grained, $\mathrm{Cl}$-rich inclusions. 
GRANTEE:
GRANT:

TITLE:
PURDUE UNIVERSITY

Department of Earth and Atmospheric Sciences

West Lafayette, Indiana 47907

\section{DE-FG02-93ER14365}

Rupturing and Ground Deformation During the 28 June 1992 Landers, California Earthquake

\section{PERSON IN CHARGE:}

Arvid M. Johnson (317-494-0250)

Objectives: This project has an overall objective of understanding the form and significance of surface rupture produced by earthquakes. Specific objectives are to describe fracturing and other manifestations of broad belts of ground rupture during the Landers earthquake and to mechanically analyze the structures that form along the belts.

Project Description: Studies of surface rupture can lead to improved understanding of fault geometry and the very nature of faulting. In 1993/94 we completed field mapping of about $10 \mathrm{~km}$ of rupture zones along three faults at scales of 1:400 or more detailed, including rupture belts associated with growth of a tectonic ridge along the Emerson fault zone and rupture belts along the Kickapoo and Homestead Valley fault zones, so we have completed all the detailed mapping we started in 1992. We have mapped much greater stretches using photogrammetric methods. Our field maps show the growth of a spectacular tectonic ridge along the Emerson fault zone, the formation of a rift-like structure where the Kickapoo and Homestead Valley faults join, the formation of en-echelon fault zones along the Kickapoo fault and a new duplex structure and several right- and left-steps that formed on the Homestead Valley fault zone. Since one of the main conclusions of our research is that earthquake rupturing at Landers was accommodated generally not by faults, but rather by belts of shear zones, we decided in 1994 to chair a special session at AGU in Baltimore on The Dynamics of Fault Rupture: The View from Below and Above. The meeting was a great success because we exchanged observations with seismologists and neotectonicists with a wide range of views who addressed the question of whether the belts of shear zones, with widths of 50 to at least $200 \mathrm{~m}$, that we had mapped at Loma Prieta and Landers, might continue into the subsurface. For example, Keiiti Aki, W.G. Li and others presented seismological evidence that such zones at the surface can be recognized at depth as of low-velocity that extend to at least $10 \mathrm{~km}$ depth along the Johnson Valley and Homestead Valley fault zones at Landers.

Results: Our detailed mapping along simple stretches of fault zones at Landers shows that the ground ruptured across broad belts of shearing with clearly defined, sub-parallel walls, oriented NW. Each broad belt consists of a broad zone of mild shearing, extending across its entire width (50 to $200 \mathrm{~m}$ ), and much narrower (a few $m$ wide) shear zones that accommodate most of the offset of the belt and are portrayed by en echelon tension cracks. In response to right-lateral shearing, the slices of ground bounded by the tension cracks rotated in a clockwise sense, producing left lateral shearing, and the slices were forced against the walls of the shear zone, producing thrusting. Even narrower shear zones formed within the narrow shear zones. Although these probably are guides to right-lateral fault segments below, the surface rupturing during the earthquake is characterized not by faulting, but by the formation of shear zones at various scales. We examined the question of how fractures in alluvium might differ from fractures in bedrock by mapping $a .5 \mathrm{~km}$ stretch of surface rupture on the Homestead fault zone. In that interval, where the surface rupture crosses a keel-shaped rib of metamorphic and sedimentary rocks, the fractures and frac- 
ture patterns are indistinguishable from those in the desert alluvium, although the belt of shear zones 
GRANTEE:

GRANT:

TITLE:

PERSON IN CHARGE:
RENSSELAER POLYTECHNIC INSTITUTE

Department of Earth \& Environmental Sciences

Troy, New York 12180-35904

DE-FG02-94ER14432

Transport Phenomena in Fluid-Bearing Rocks

E. B. Watson (518-276-6474; Fax 518-276-8627;

E-mail mary@harold.geo.rpi.edu)

Objectives: The objectives of this project are twofold: (1) to develop and implement a new technique for measuring mineral solubilities and diffusivities of dissolved mineral components in supercritical fluids at pressures up to $3 \mathrm{GPa}$ and temperatures up to $1200^{\circ} \mathrm{C}$; and (2) to characterize the permeability of fluid-bearing rocks under conditions of mechanical equilibrium at lower-crustal to upper-mantle P-T conditions.

Project Description: The efficacy of fluid-assisted geochemical transport at depth in the Earth is controlled by a number of factors, including the solubilities of mineral components in the fluid of interest, the mobility of the fluid through the rock medium, and the diffusion characteristics of dissolved solutes. At the $\mathrm{P}-\mathrm{T}$ conditions prevailing in subduction zoneswhich are widely regarded as the principal sites of chemical cycling in the solid Earth-few data exist to constrain the overall process of chemical transport: information concerning, for example, mineral solubilities and diffusivities and rock permeability are almost non-existent at pressures in excess of $\sim 1 \mathrm{GPa}$. Accordingly, the Rensselaer project involves the experimental measurement of some of these key parameters.

Determination of mineral solubilities and diffusivities in water at upper mantle P-T conditions is being attempted in a piston-cylinder apparatus, using a capsule consisting of two chambers connected by a capillary. By virtue of the temperature gradient in the solid-media pressure cell, the chambers are maintained at slightly different temperatures. This difference leads to dissolution of the mineral of interest (placed initially in the "hot" chamber), diffusion of dissolved components through the capillary, and precipitation in the "cold" chamber. The total amount of material transported from the hot to the cold chamber in a given time depends upon the solubility difference and the diffusivity in the fluid. By executing two experiments differing in duration, it is, in principle, possible to deduce both the solubility difference and the diffusivity. Absolute solubilities are then determined by anchoring the solubility difference data to a known value measured by conventional means.

The rock permeability measurements are made by synthesizing porous "rocks" in the piston-cylinder apparatus. Mineral powders are loaded into a thickwalled capsule with the desired amount of the fluid of interest, and the sample is annealed at high P-T conditions to produce a near-equilibrium microstructure that includes fluid-filled pores. The sample is quenched and recovered from the high-pressure apparatus, and the permeability measurement is made at near-atmospheric conditions-using air or argon-on a specimen having a "quenched-in" porosity. This technique circumvents the difficulty of performing permeability measurements at actual run conditions.

Results: This is a new project, having a 5/1/94 start date. At the time of this writing, the scientific personnel are in place. 
GRANTEE:

GRANT:

TITLE:
RICE UNIVERSITY

Geology and Geophysics

Houston, Texas 77251-1892
DE-FG05-92ER14295

Transition Metal Catalysis in the Generation of Petroleum and Natural Gas

Frank D. Mango (713-527-4880; Fax 713-258-5214)

Objectives: It is proposed that the light hydrocarbons in petroleum, including natural gas, are formed catalytically, through the condensation of $n$-alkenes and hydrogen in fined grained carbonaceous sedimentary rocks. The transition metals are suggested as the catalytic agents. The objective of this research is to test this hypothesis and to explore the catalytic properties of transition metals under realistic geologic conditions.

Project Description: Various natural sources of transition metals including the asphaltene fraction of petroleum and fined grained carbonaceous sedimentary rocks are being analyzed for catalytic activity in the condensation of olefins and hydrogen. Reactions are being conducted in gas manifold systems and in the injector cavity of a HP $\mathbf{5 8 9 0}$ II high-resolution gas chromatography unit with FID detectors.
Results: A fined-grained carbonaceous sedimentary rock moderately rich in transition metals has been found to be catalytically active in converting hydrogen and olefins into gas (Mango et al., Nature 368, 535, 1994). The reaction proceeds under realistic earth conditions and the product is indistinguishable from natural gas in isotopic and molecular composition, marking the first time that natural gas has been generated in the laboratory. Recently, transition metal porphyrins, Nickel and Vanadyl etioporphyrin, have shown similar catalytic activity in natural gas formation. These results verify the existence of an alternative, catalytic pathway to natural gas. If it proves to be significant it could impact on exploration efforts, altering the way in which we view the origin of oil and natural gas in the Earth. 
GRANTEE:

GRANT:

TITLE:

PERSON IN CHARGE:
UNIVERSITY OF SOUTHERN CALIFORNIA

Department of Earth Sciences

University Park

Los Angeles, California 90089-0740

DE-FG03-87ER13807

The Seismology of Geothermal Regimes

K. Aki (213-740-5830; Fax 213-740-0011;

E-mail aki@coda.usc.edu)
Objectives : Development of effective interpretation theory for the analysis of seismic data collected in geothermal areas characterized by strongly heterogeneous subsurface structure and by seismic sources involving interactions among gas, liquid, and solid.

Project Description: Seismic data from active and passive experiments in geothermal areas are extremely complicated because of the strongly heterogeneous earth's structure and seismic sources involving interactions among gas, liquid, and solid. To develop effective interpretation theory for analyzing the data, our current objectives are the following. (1) Development of analysis methods for separately determining the scattering loss and the absorption loss in seismic attenuation as a function of frequency and application of them to various geothermal areas in the world. (2) Three-dimensional modeling of seismic source, path, and site effects on the observed spectra of seismic events in active geothermal areas. (3) Exploration of effective inversion procedures for geometry and mechanical properties of subsurface structure using steady-state (frequency domain) data rather than conventional wave form (time domain) data. These problems are identified as targets of investigation with fruitful outcome in the near future.
Results: We found, from the frequency dependence of scattering $Q$ as well as the non-isotropy of scattering, that the spatial auto correlation of heterogeneity appears to be Gaussian rather than exponential, and the earth becomes very smooth below the scale of a few hundred meters. Comparison of geothermal areas with non-geothermal active areas indicates that both scattering and absorption are not significantly different between them at seismic frequencies $1-20 \mathrm{~Hz}$, except that the volcanic area under central Japan showed a steady temporal change in the coda Q (5-10\% per year), while no change was observed in the neighboring area of high seismic activity. Thus, we began a systematic study of the spatiotemporal distribution of coda $Q$ for southern California, which include the Salton Trough Geothermal area. With regard to the objective (2), we made a survey of methods for seismogram synthesis and decided to pursue the Boundary Element Method using Green's functions specialized for the axisymmetric problem.

With regard to objective (2), we pursued the method of renormalized Born inversion, obtained the special form of Green's function required for the method, and formulated the inverse problem for 1-D layered media. The extension to 2-D and 3-D is straightforward, and currently being carried out. 
GRANTEE:

GRANT:

TITLE:

PERSONS IN CHARGE:
STANFORD UNIVERSITY

Department of Geological and Environmental Sciences, Stanford, California 94305-2115

\section{DE-FG03-93ER14347-A000}

Cation Chemisorption at Oxide Surfaces and Oxide-Water Interfaces: X-Ray Spectroscopic Studies and Modeling

G. E. Brown, Jr. (415-723-9168; Fax 415-725-2199;

E-mail gordon@pangea.stanford.edu) and G. A. Parks
Objectives: This project concerns reactions between metal ions in aqueous solution and oxide surfaces representative of those found in the Earth's crust. These "sorption" reactions partition the metal between fluid and solid phases and must be understood at a molecular level to develop a quantitative understanding of the geochemistry of mineral surfaces and the macroscopic models required to predict the fate of contaminants in the environment. Our objectives are (1) to characterize sorption reactions by determining composition, molecular-scale structure, and bonding of the surface complex(es) produced using di rect sorption measurements; synchrotron-based $\mathrm{x}$ ray absorption fine structure (XAFS) spectroscopy, $x$ ray photoelectron spectroscopy (XPS), and UV/Vis/IR spectroscopy; (2) to investigate how these properties are affected by the solid surface and the composition of the aqueous solution, and (3) to develop molecular level and macroscopic models of sorption processes.

Project Descriptions and Results: Three main thrusts and two supporting investigations have evolved. The first two concern the structure of the host solid and its influence on the sorption complex(es). The third main thrust focuses on the influence of a simple organic complexing ligand on sorption of $\mathrm{Cu}$ (II) by oxides.

Sorption of cobalt(II) on $\mathrm{Al}_{2} \mathrm{O}_{3}$ and $\mathrm{TiO}_{2}$ : We are studying the sorption of $\mathrm{Co}$ (II) on $\alpha-\mathrm{Al}_{2} \mathrm{O}_{3}$ and $\mathrm{TiO}_{2}$ (rutile) to resolve two issues in the sorption of cations onto oxides: (a) what specific surface site(s) (bridging or "atop" oxygen, kink sites, etc.) are involved in sorption; and (b) why do large hydroxide - like clusters form at concentrations below those required for precipitation? To examine these problems, we have used XPS, powder XAFS, and single-crystal grazing-incidence XAFS spectro scopies.

To simplify characterization of sorption sites, we have collected XAFS data on Co adsorbed on several orientations of $\alpha-\mathrm{Al}_{2} \mathrm{O}_{3}$ and $\mathrm{TiO}_{2}$ (rutile) single crys tals for comparison with similar data on powders. These data are still being interpreted, though preliminary inspection shows intriguing differences among the various orientations.

Comparison of the apparent Co(II) sorption densi ties on powdered $\alpha-\mathrm{Al}_{2} \mathrm{O}_{3}$ estimated by traditional solution concentration measurements and by XPS shows that at high uptake the sorbate forms clusters (>30 $\AA$ in radius) while much of the surface is left uncovered. TEM studies of this system are planned to help resolve the sizes and shapes of the $\mathrm{Co}(\mathrm{OH})_{2}$-like clusters. XAFS measurements on the same system has shown aging wet sorption samples for two months increases the average number of $\mathrm{Co} 2$ nd-neighbors relative to the number observed in freshly prepared samples, indicating that the clusters grow with time. This result is in contrast with previous work done on aging of $\mathrm{Co}$ (II)/kaolinite samples, where the number of $\mathrm{Co}$ second-neighbors decreased with time.

Sorption of lead(II) on $\alpha-\mathrm{Al}_{2} \mathrm{O}_{3}$ and $\alpha-\mathrm{Fe}_{2} \mathrm{O}_{3}$ : In an attempt to determine the effect of adsorbents with the same structures but different metal ions on sorption, we are studying modes of lead(II) sorption on the isostructural oxides $\alpha \mathrm{Al}_{2} \mathrm{O}_{3}$ and $\alpha-\mathrm{Fe}_{2} \mathrm{O}_{3}$, using a combination of aqueous sorption measurements, 
XAFS spectroscopy, UV absorption spectroscopy, and chemical modeling.

During the past year we collected XAFS spectra for the environmentally important system $\mathrm{Pb}(\mathrm{II}) / \mathrm{Fe}$ oxides (hematite and goethite), and successfully completed a grazing-incidence XAFS experiment on $\mathrm{Pb}$ (II)/sapphire (102) in-situ, under a water film. Results are intriguing. In the system $\mathrm{Pb}$ (II)/sapphire, $\mathrm{Pb}$ is observed to form surface oligomers under aqueous conditions where polymeric solution complexes are not stable. The observed surface complexes are smaller than the solution analog $\mathrm{Pb}_{4}(\mathrm{OH})_{4}{ }^{4+}$. Fourier analysis of the XAFS data for the system $\mathrm{Pb}$ (II)/Fe oxide suggests that $\mathrm{Pb}$ surface oligomers are also smaller than $\mathrm{Pb}_{4}(\mathrm{OH})_{4}^{4+}$, contradicting published modeling efforts.

Co-sorption of copper(II) and 2,2'-bipyridine: In this project we have observed that, under some conditions, the presence of 2,2'-bipyridine (bpy) enhances sorption of $\mathrm{Cu}$ (II) on amorphous silica, but inhibits sorption of $\mathrm{Cu}$ (II) on $\gamma-\mathrm{Al}_{2} \mathrm{O}_{3}$. We are attempting to determine reasons for this difference through $\mathrm{Cu}$ and bpy sorption measurements, XAFS spectroscopy, and infrared and UV-visible spectroscopy.

Sorption measurements from a 1:2 Cu:bpy solution, in which the predominant aqueous complex is Cu(bpy) 2 , show that the stoichiometric ratio $1: 2$ is preserved on silica, but is variable and closer to $1: 1$ on $\gamma-\mathrm{Al}_{2} \mathrm{O}_{3}$, suggesting that bpy is displaced from some $\mathrm{Cu}(\mathrm{bpy})_{2}$ complexes upon sorption onto alumina. Comparison of IR spectra of aqueous solutions of bpy alone, aqueous $\mathrm{Cu}$ (II) nitrate, aqueous $\mathrm{Cu}$ (II)/bpy complexes and the sorption samples, shows that all sorbed bpy is associated with $\mathrm{Cu}$, suggesting true temary complex formation. Preliminary examination of XAFS spectra of a similar set of samples suggest a Cu-bpy surface structure on silica similar to that of the 1:2 aqueous complex. These results are consistent with the idea that $\mathrm{Cu}(\mathrm{bpy})_{2}$ sorbs on silica, but that the complex is disrupted, possibly forming more than one species on alumina.

Molecular-scale Modeling: We are continuing our efforts to constrain the geometries of metal ion surface complexes and the types of surface sites to which they bind using simple bonding concepts, including the effect of metal-oxygen bond covalencies and Pauling bond valencies on the redistribution of charge on surface functional groups. Using this approach, we are developing a model which correlates the $\log \mathrm{K}$ for surface protonation and the partial charge of surface oxygens or hydroxides which is similar to other published models but with fewer assumptions. We are currently applying this model to the sorption of $\mathrm{Pb}$ (II) and $\mathrm{Co}$ (II) onto oxides and hydroxides. To aid our molecular-level modeling effort, we have purchased a Silicon Graphics work station with DOE funding and have acquired and installed molecular simulation software (Cerius 2 and Biosym). We are beginning to use these packages to visualize oxide surface structures and sorption complexes, and to evaluate, through energy minimization and distance least squares methods, the effect of adsorbates on oxide surface structure.

Macroscopic sorption modeling: Using the surface complexation, electrical triple layer sorption model incorporated in the chemical speciation code HYDRAQL, we have found that the structural and compositional information extracted from XAFS spectra are valuable constraints in selecting sorption reactions. With sorption and XAFS data from earlier investigations, reinterpreted as part of our present $\mathrm{Co}$ (II) sorption study, we have found that incorporation of multinuclear species and precipitation in the sorption model is essential for simulation of both uptake and XAFS-derived 2nd-neighbor stoichiometry, while a much wider range of reactions is capable of simulating the uptake data alone. 
GRANTEE:

GRANT:

TITLE:

PERSON IN CHARGE:
STANFORD UNIVERSITY

Geophysics Department

Stanford University, California 94305-2215

\section{Porous Reservoir Rocks with Fluids: Acoustic and Reservoir Transport Properties}

Amos Nur (415-723-9526; Fax 415- 723-1188;

E-mail nur@pangea.Stanford.edu)

Objectives: The objectives of the research are (1) to relate seismic characteristics of hydrocarbon reservoirs and ground water aquifers to rock soil and pore fluid properties; and (2) apply the results to the design and interpretation of in-situ seismic measurements to obtain subsurface flow description and monitoring. Our research which involves laboratory measurements modeling, and in-situ field studies, and spans several projects.

\section{Contact Laws for Cemented Grains}

Project Description: Analytical solutions are obtained for in cemented granular media subject to general stress when both grain material and cement are elastic. It is found that intergranular cement, even if soft, is load-bearing. Also contact stresses are maximum near the center of the contact region when the cement is soft and maximum at the periphery when the cement is stiff.

Results: These results imply that (1) Whereas uncemented grains will break cemented grains will stay intact, and the cement will fail. (2) Where intergranu lar cementation is present, the grain, will fail before the cement if the cement is strong and stiff. In this case, grain damage will be initiated at the periphery of the cement layer.

\section{Squirt Flow in Fully Saturated Rocks}

Project Description: We estimate velocity/frequency dispersion and attenuation in fully saturated rocks via the squirt-flow mechanism, pore fluid is squeezed from thin soft cracks into the surrounding large pores. The characteristic squirt-flow length porosity and permeability are combined into a single fundamental rock property that does not depend on frequency.

Results: The derived low-frequency velocity limits those predicted by Gassmann's formula. However the high-frequency limits may significantly exceed those given by the Biot theory. The model realistically predicts the observed velocity/frequency dispersion, and attenuation in Limestones, sandstone and granites.

\section{The Effect of Fluid Distribution on Seismic Velocities}

Project Description: To link rock physics with reservoir simulation and seismic monitoring of hydrocarbon reservoirs. We investigate the effects of multiphase pore fluid distributions on the seismic velocity of saturated vs. temperature and pressure. We investi gate two models of fluid distribution: (1) Uniform fluid, and (2) Fluid in patches.

Results: Generally the uniform fluid model shows poor sensitivity to fluid saturation, with a variation in velocity of less than $1 \%$ when gas saturation exceeds $1 \%$. The potholes model shows a variation of velocity with saturation of $7 \%$. We also investigate the effect of patchy oil distillation on seismic velocities during steam flooding. In regions of high oil saturation, the velocity varies by as much as $5 \%$ when using the hydrocarbons produced by distilling a 15 degree API oil. In regions of low oil saturation, there is less than $0.5 \%$ variation in velocity using these components. 


\section{Frequency and Scale}

Project Description: Seismic wave propagation in the earth's crust depends on the size of heterogeneous geological structures relative to wavelength. To study this effect we measured wave-velocities and static Young's modulus of glass beads/epoxy samples. By varying the diameter of the glass-beads, the ratio of wavelength to size varied from 0.2 to 20 .

Results: We have observed a $22 \%$ P-wave velocity dispersion and a $15 \% \mathrm{~S}$-wave velocity dispersion, but no scale effect on the static Young's modulus. Clearly that the observed wave velocity dispersion is due to the wavelength-scale effects.

\section{Seismic Monitoring of Oil Production}

Project Description: We perform a feasibility study on the likelihood of seismically detecting and interpreting the time-varying changes in a reservoir during solution-gas-drive oil production from a horizontal well. This study integrates reservoir engineering fluid-flow simulations, rock physics measurements and transformations, and prestack seismic modeling and migration on a real reservoir model.

Results: We calculate spatial distributions of reservoir rock properties from the fluid-flow simulation data, and map the associated seismic responses at three production-time snapshots: prior to any oil production (Base Survey), after 56 days (Monitor 1), and after 113 days (Monitor 2) of oil production. Multi offset seismic surveys are simulated for each of these three production time. Using realistic seismic acquisition parameters, we are able to successfully detect and monitor dynamic gascap expansion in the reservoir during the fluid-flow simulation of the oil production process. Evidence of gas coning is clearly visible in the prestack-migrated difference sections at realistic seismic noise levels and frequency bandwidth.

\section{Seismic Detection of Residual Contaminants}

Project Description: The key to effective characterization and treatment of contaminated sites is our ability to delineate the spread of contaminants in the shallow subsurface. A promising non-invasive technique is the three-dimensional mapping of seismic velocities, reflections and attenuation. the physical principle of this technique is that the same rock, if filled with different fluids, transmits sound waves differently. There are two main results for this: (a) porefluid compressibility and (b) pore-fluid viscosity.

Results: We present theoretical models which show that at high, but practical frequencies (1$10 \mathrm{kHz}$ ) the effect of pore-fluid viscosity becomes seismically visible and thus allows one to locate residual viscous contaminants left in thin pores and/or between sand grains. This conclusion is supported by a laboratory ultrasonic experiment. 
GRANTEE:

GRANT:

TITLE:

PERSONS IN CHARGE:
STANFORD UNIVERSITY

Department of Geological and Environmental Sciences

Stanford, California 94305-2115

DE-FG03-93ER14366-A000

Experimental Investigation of Kinetics and Rheology During Diagenesis

J. G. Liou (415-723-2716; Fax 415-725-2199;

E-mail liou@pangea.stanford.edu) and B. R. Hacker (415-725-

0045, Fax 415-725-2199; E-mail hacker@pangea.stanford.edu)
Objectives: To determine the dehydration rate of laumontite and its effect on the frictional theology of laumontite.

Project Description: Two processes of enormous economic consequence occur within the upper to middle crust: the formation, migration, entrapment, and degradation of hydrocarbons, and hazardous seismicity. Substantial scientific evidence suggests that both these processes are influenced by devolatilization reactions during diagenesis. However, surprisingly few laboratory studies have been conducted on materials actively undergoing low-grade metamorphism or diagenesis. Because of this, there exists no suitable basis for understanding the rates at which devolatilization occurs, and what effects this process has on deformation at shallow to moderate depths in the crust.

We are conducting a coordinated deformation and kinetic study of an important devolatilization reaction: the breakdown of laumontite. Laumontite is a common zeolite whose equilibrium phase relations and room-temperature frictional behavior are well under stood. Besides serving as a model system for more complicated rocks, laumontite is an important mineral in its own right, particularly for hydrocarbon fields in sandstones and for fault zones in the crust. Hydrostatic experiments are being conducted to investigate (1) the kinetics and mechanism of laumontite dehydration, and triaxial deformation experiments will enable characterization of (2) the effect of differential stress on the reaction and (3) the effect of synkinematic dehydration on the mechanical behavior of rock. We anticipate results of significant import for hydrocarbon exploration and recovery and for understanding the strength and seismic potential of crustal fault zones.

Results: This project was only recently initiated. Our laboratory required substantial renovation before beginning this study. We have purchased much of the necessary upgrades to our facilities, and recently finished calibrated four of our hydrothermal apparatuses. We located and purified $>200 \mathrm{~g}$ of starting material so that all of our hydrothermal and friction experiments will use exactly the same laumontite. Our first two hydrothermal experiments are in progress. 
GRANTEE:

GRANT:

TITLE:

PERSONS IN CHARGE:
STANFORD UNIVERSITY

Department of Geological and Environmental Sciences

Stanford, California 94305-2115

\section{DE-FG03-89ER14081}

Models of Natural Fracture Connectivity: Implications for Reservoir Permeability

D. D. Pollard (415-723-4679; Fax 415-725-0979;

E-mail dpollard@pangea.stanford.edu) and A. Aydin (415-725-

8708; Fax 415-725-0979; E-mail aydin@pangea.stanford.edu)

Objectives: The goals of this project are to document and characterize the geometry of natural fracture systems and their connectivity, to analyze the mechanical aspects of their development, and to evaluate the influence of fracture connectivity on fracture flow.

Project Description: This project seeks to develop working models for fracture connectivity based on detail mapping and observations from outcrops of sedimentary rocks, typical of hydrocarbon reservoirs and ground water aquifers. The physical mechanisms responsible for fracture connectivity are then deduced from computer simulations and laboratory experiments. With a thorough understanding of fracture networks and their connectivity, we apply this new knowledge to predict reservoir permeability. This research has important implications for both the energy industry (e.g. characterization of fractured oil and gas reservoirs) and environmental problems (e.g. storage and migration of contaminants in fractured aquifers). The grant has supported two post-doctoral students and five doctoral students. This period represents a cost-free extension of grant and the last phase of the project.

Results: Field research in previous phases has elucidated the process by which temporal and spatial changes in the state of stress are responsible for the formation of two or more fracture sets. In this period, we focused on the characterization of one and two sets of fractures using wellbore or core data. In a poorly developed fracture system, fracture spacing varies significantly (large standard deviation) depending on the specific locations of scanlines. In well-developed fracture systems, however, fracture spacing is similar (small standard deviation) regardless of the scanline location. These results encouraged us to develop a methodology for inferring the degree of fracture development (fracture saturation) from a single wellbore or from core data, and for estimating the relative drainage distance, that is the maximum flow distance between a borehole and the surrounding rock along fracture pathways.

In previous phases of the project we developed a computer model that simulates the geometric evolution of a fracture set in a controlled laboratory experiment and is consistent with natural fracture geometries. This physically based network simulator (PBNS) produces fracture networks using iterative solutions to the boundary-value problem for multiple cracks in an otherwise homogeneous, isotropic, and linear elastic solid subject to uniform remote stress conditions. In this project period we have developed a methodology for conditioning the PBNS networks to data from seismic surveys and from wellbore logging and flow tests. The advantage of this methodology is that the elastic and fracture characteristics of reservoir rocks and the mechanics of the rock fracture process can be combined with wellbore and other data to estimate the geometry and connectivity of a particular fractured reservoir. 
GRANTEE:
STANFORD UNIVERSITY

Department of Geophysics

Stanford, California 94305-2215
GRANT:

TITLE:

PERSON IN CHARGE:
DE-FG03-90ER14152

Induced Seismicity

P. Segall (415-725-7241; Fax 415-725-7344;

E-mail segall@pangea.stanford.edu)
Objectives: The objective of this project is to develop a fundamental understanding of induced seismicity based on the mechanics of deformable porous media.

Project Description: The goal of this project is to develop a fundamental understanding of earthquakes triggered by energy development. Our intent is to develop appropriate physical models that successfully predict when seismicity is likely to occur, and to determine to what extent these earthquakes can be used to infer conditions within the energy reservoir. The initial phase of the project focused on earthquakes induced by the extraction of oil and gas. The second phase has been to investigate the mechanics of earthquakes induced within geothermal fields. This research involves modeling the thermo- and poro-elastic effects of production and water injection. Global Positioning System (GPS) receivers are used to measure vertical and horizontal deformation associated with geothermal activity. GPS and seismic data are used to test and constrain thermo-mechanical models.

Results: We are focusing on The Geysers geothermal field in northem California. The Geysers is the largest geothermal field in the world, in terms of electrical output, as well as one of the most seismically active areas in California. Previous studies of seismicity at The Geysers suggest that there is a correlation with industrial activity in the region. However, the correlation is not universally accepted, and it is not clear whether the microearthquakes (MEQs) are caused by fluid injection, fluid extraction, or both.

Changes in seismometer coverage within the
U.S.G.S. Calnet over time have made it difficult to directly compare the rate of seismicity with the amount of steam production or volume of injected condensate. These effects are reduced by: (1) Retaining events above a threshold magnitude for which the Calnet catalog is complete; or (2) Retaining events located by a subset of seismometers that were in place for the entire time period. The results for annual averages, using either approach, show an extremely high correlation between seismicity and steam production. The correlation is significant at the $99.9 \%$ level. However, steam production and condensate injection are highly correlated to one another, so that although the correlation demonstrates that the MEQs are induced, it does not identify the mechanism.

A study of the location accuracy using Calnet Pwave arrival times indicates that horizontal position errors are reasonably small. Hypocentral depths are not well enough constrained to study induced seismicity at the scale of individual injection wells. Access to higher quality local data is being sought to address this problem.

Simple models are used to investigate the thermoelastic and poroelastic effects of re-injection of liquid condensate on the stability of pre-existing faults in the reservoir. Temperature changes due to injection of cold liquid into a fracture are computed assuming the fracture is an open parallel sided slot and that convection within the rock parallel to the fracture walls can be neglected. Results indicate that thermo-elastic stresses can be quite significant, and dominate poroelastic effects. 
GRANTEE:

TITLE:
STANFORD UNIVERSITY

Department of Geophysics

Stanford University

Stanford, California 94305-2215

\section{GRANT: \\ DE-FG03-94ER14430}

Scientific Drilling Into the San Andreas Fault Zone and Site Characterization Research and Coordination Efforts

Mark D. Zoback (415-725-9295; Fax 415-725-7344)

Objectives: This project involves planning and coordination activities associated with a long-term proposal to conduct an integrated program of shallow geological and geophysical investigations and deep scientific drilling along the San Andreas fault. This work is being performed in close collaboration with co-Principal Investigators Steve Hickman (USGSMenlo Park), Bill Ellsworth (USGS-Menlo Park), and Lee Younker (Lawrence Livermore National Laboratory).

Project Description: A deep $(\sim 10 \mathrm{~km})$ scientific drilling experiment in the San Andreas fault zone would provide data essential to understanding the structure, composition, mechanical behavior, and physical state of an active, major plate-boundary fault. Toward this end, for the past 2-1/2 years we have been working with an international team of scientist and engineers in proposing a long-term, integrated program of surface-based geological and geophysical investigations and deep scientific drilling along the San Andreas fault system. To help answer fundamental questions conceming fault zone processes we propose coring inclined holes through the San Andreas fault to depths of $10 \mathrm{~km}$ and conducting extensive investigations in the holes and on the recovered materials. These investigations include laboratory measurements of the compositions, physical properties, and deformational behavior of exhumed gouges and pore fluids; measurements of pore pressure, stress, and fluid permeability directly within and adjacent to the fault zone; and studies of P- and S-wave seismic velocity, intrinsic attenuation, and anisotropy of the fault zone and gouge materials. The data from the deviated core holes will provide complete cross sections of the fault zone for compositional, microstructural, and rheological characterization of the fault over a wide depth range. Geophysical logging tools and cross-hole tomographic techniques would also be used to characterize variations in physical properties within and adjacent to the fault zone. Because of the likelihood of hole stability problems within the fault zone, we will conduct as many of the downhole experiments as possible after casing is cemented into the holes. In particular, we anticipate that fluid sampling and measurements of fluid pressure, permeability, and stress within the fault zone will be conducted through perforations in the cemented casing. Upon completion of drilling, seismometers and other instruments will be placed in the holes for long-term monitoring of earthquake locations and source parameters, seismic wave propagation, electromagnetic radiation, fluid pressure, fluid chemistry, temperature, and deformation.

Results: In FY 1994, progress has been made in the following areas: (1) Coordinate site selection studies and integrate data collected into a GIS database, (2) Convene second San Andreas conference, (3) Define engineering needs and establish linkages with private industry, (4) Represent the project to federal, state and local agencies, the public, and the press. 
GRANTEE:

PERSONS IN CHARGE:
GRANT:

TITLE:
TEXAS A\&M UNIVERSITY

Center for Tectonophysics

College Station, Texas 77843-3115
DE-FG05-87ER13711
Mechanical Properties and Modeling of Seal-Forming Lithologies

A. K. Kronenberg (409-845-0132; Fax 409-845-6780; E-mail akk8153@geopsun.tamu.edu), J. E. Russell, and N. L. Carter

Objectives: This research addresses the mechanical properties of two weak sedimentary lithologies, shale and rocksalt, that deform under gravitational and tectonic loads and examines the roles of these lithologies in the development of structural traps and unconventional oil and gas reservoirs.

Project Description: The shapes and physical properties of a wide range of structural traps and barriers to mobile hydrocarbons are governed by the mechanical properties of shale or those of salt and by the loading histories to which they have been subjected. Concurrent experimental and modeling studies are underway to determine the fracture and flow properties of these two lithologies, to determine physically based constitutive relationships that can be applied to geologically relevant conditions, and to make predictions concerning the development and timing of structural traps relative to known depositional histories. Triaxial compression experiments provide mechanical properties for shale and rocksalt over a wide range of conditions $\left(21^{\circ} \mathrm{C} \leq \mathrm{T} \leq 200^{\circ} \mathrm{C}, 7 \leq \mathrm{P}_{\mathrm{e}} \leq 400 \mathrm{MPa}\right.$, $10^{-9} \leq \dot{\varepsilon} \leq 10^{-3} \mathrm{~s}^{-1}$ ) and numerical modeling of salt diapirs with stratigraphic constraints on loading and ascent rates has extended predictions of mechani cal response for rocksalt to strain rates of $10^{-15} \mathrm{~s}^{-1}$.

Results: During this year, the experimental investigation of shale has been extended to the transport and mechanical properties of brine-saturated shales. Permeabilities have been measured using transient pulse methods as a function of mean effective pres sure and triaxial stress state ${ }_{i j}$ Triaxial failure strengths of saturated shales have been measured as a function of externally applied confining pressure, fluid pressure at specimen extremities, and strain rate. Permeabilities decrease systematically as effective pressure is increased while complex changes in permeability are observed with increasing differential stress. Poroelasticity can account for only small fractions of the observed changes in permeabilities, which appear to be governed by inelastic pore collapse and dilatant microcrack formation. Over the strain rates investigated to date $\left(10^{-7} \leq \dot{\varepsilon} \leq 10^{-4} \mathrm{~s}^{-1}\right)$, failure strengths reflect the mechanical response of undrained specimens, and intrinsic $\sigma-\dot{\varepsilon}$ relationships of fully drained (fluid absent) and undrained (fluid present) shale have been compared. Numerical modeling of salt tectonics has been extended to include multiple interfaces and to examine the sensitivity of gravitydriven structures to effective viscosities of overlying sediments. Preliminary models have been developed that follow the evolution of shallow allochthonous salt sheets. The morphologies of salt diapirs and sheets of the Gulf of Mexico of offshore Louisiana and Texas are closely matched by our model results. Morphologies do not appear to be sensitive to different rheologies reported for rocksalt; however, characteristic times for the development of salt structures are strongly affected by choice of rheology, both for the salt units and for the overlying strata. 
GRANTEE:

GRANT:

TITLE:
THE UNIVERSITY OF TEXAS AT AUSTIN

Department of Geological Sciences

Austin, Texas 78712

DE-FG05-92ER14278

Energy Flux and Hydrogeology of Thermal Anomalies in the Gulf of Mexico Sedimentary Basin-South Texas Example

PERSON IN CHARGE:

John M. Sharp, Jr. (512-471-5172; Fax 512-471-9425)

Objectives: The objectives of this study are: (1) to evaluate if observed thermal anomalies in the Gulf of Mexico basin, can be accounted for by heat conduction alone or if convection is a significant perturbing factor, (2) to determine if the present fluid flow regime is amenable to the convection hypothesis; and (3) to develop fluid and heat flux histories compatible with compiled and newly collected data.

Project Description: To address the objectives, an extensive data base of fluid pressures, water chemistries, and formation temperatures was compiled into a geographic information system. Thermophysical properties were characterized by measuring mineralogy, porosity, bulk density, thermal conductivity, and radiogenic heat production of rock samples. Computer codes applicable to variable-density flow and heat transport were analyzed for utilization and codes were written to simulate heat conduction and free convection.

Results: Over 25,000 data points, reflecting fluid pressures, water chemistries, temperatures, and thermal rock properties were compiled. Petroleum production has created significant fluid depressurization which extends beyond individual reservoirs and must be considered noise when mapping predevelopment fluid-flow. Areas were identified in the Frio Formation that have the propensity for free convection. Numerical simulations with the computer code SUTRA indicate that thermohaline convection cells can develop over short time scales $(<30,000$ years) given the observed salinity gradients. The thermal conductivity of Wilcox and Frio sandstones ranges from two to six Watts/meter/Kelvin over a porosity range from zero to $30 \%$. Wilcox sandstones have a higher thermal conductivity than Frio sandstones (with a similar porosity) because of the higher quartz content. The thermal conductivity of Wilcox sandstones and relatively quartz-rich $(>30 \%)$ and clean $(<20 \%$ clay) Frio sandstones can be described with a linear decrease in thermal conductivity with increasing porosity. Thermal conductivity of both sandstones is isotropic. Radiogenic heat is a significant source of heat within the basin, possibly supplying up to $45 \%$ of the surface heat flow. For a given rock type (sandstone or mudrock), Frio rocks produce more heat than Wilcox rocks. 
GRANTEE:

GRANT:

TITLE:

PERSONS IN CHARGE:
THE UNIVERSITY OF TEXAS AT AUSTIN

Department of Geological Sciences

Austin, Texas 78713-7909

DE-FG05-92ER14249

The Role of Mud Rocks in Burial Diagenesis

4

Lynton S. Land (512-471-3534; Fax 471-9425;

E-mail lynton@maestro.geo.utexas.edu), Kitty L. Milliken, and Larry E. Mack

Objectives: To quantify the role of mudrocks in providing the sources and sinks for material $\left(\mathrm{CaCO}_{3}\right.$, $\mathrm{SiO}_{2}$, acid, $\mathrm{K}_{2} \mathrm{O}$, etc.) involved in sandstone porosity loss by cementation and sandstone porosity gain by mineral dissolution.

Project Description: Complex reactions take place in sandstones and mudrocks (shales) during burial as metastable components such as detrital feldspars, unstable heavy (accessory) minerals, smectite, and kerogen are transformed to more stable phases. Mudrocks constitute approximately $2 / 3$ of post-Mesozoic terrigenous sediments in the Gulf of Mexico sedimentary basin, yet our knowledge of the changes that take place in mudrocks during burial is limited to a very few studies of limited geographic extent. This project examines mudrock burial diagenesis in three geographic areas of varying provenance for which data on sand stone diagenesis and formation water chemistry already exist. In addition to conventional whole-rock analyses, modern geochemical (elemental and isotopic), and petrographic (electron beam-induced luminescence and back-scattered electron imaging) techniques are being applied. It is our goal to quantify the behavior of mudrocks as sources/sinks of material in the sand-shale-water system.
Results: Changes in bulk mudrock chemistry (23 samples) occur in a well into Oligocene slope sediments in Kenedy County, Texas, between $7145 \mathrm{ft}$ and $18085 \mathrm{ft}$. Ca, $\mathrm{H}_{2} \mathrm{O}, \mathrm{Sr}$, LREE, $\mathrm{CO}_{2}, \mathrm{Fe}, \mathrm{Li}, \mathrm{Zn}, \mathrm{Si}$, and Ni were either lost from the mudrocks with increasing depth, and/or were initially deposited in lower concentrations than in the deeper samples. $\mathrm{K}, \mathrm{Rb}, \mathrm{Cr}, \mathrm{V}$, $\mathrm{Ba}$ and $\mathrm{U}$ were either added, and/or initially were present in higher concentrations in the deeper samples. $\mathrm{Al}, \mathrm{Ti}, \mathrm{Zr}, \mathrm{HREE}, \mathrm{Th}, \mathrm{Sc}, \mathrm{Pb}, \mathrm{Y}, \mathrm{Na}$, and $\mathrm{Mg}$ all behave similarly, increasing in concentration approximately $20 \%$ over the depth interval sampled. Volume loss has occurred by loss of $\mathrm{Ca}(\mathrm{Sr}) \mathrm{CO}_{3}, \mathrm{H}_{2} \mathrm{O}$ and $\mathrm{SiO}_{2}$. We are unable to model the gain in $\mathrm{K}$ and $\mathrm{Rb}$ as having resulted from variations in detrital sorting, or changes in provenance, and conclude that these elements have been added to the mudrocks.

No systematic changes in $\delta^{18} \mathrm{O}$ occur in quartz, and electron-beam-induced luminescent images do not seem to contain either authigenic quartz or quartz overgrowths on detrital silt grains. Thus $\mathrm{SiO}_{2}$ released during clay mineral transformations is lost from the mudrocks.

Crystallinity measurements of the illite/smectite XRD peaks indicate that illite/smectite continues to react after reaching $80 \%$ illite layers. The addition of $\mathrm{K}$ from a source external to the mudrocks is consistent with this observation. 
GRANTEE:

GRANT:

TITLE:

PERSON IN CHARGE:
THE UNIVERSITY OF TEXAS AT AUSTIN

Department of Civil Engineering

Cockrell Hall 9227

Austin, Texas 78712

DE-FG03-94ER14440/A000

Organization and Hosting of First North American Rock Mechanics Symposium

Priscilla Nelson (512-471-4929; Fax 512-471-6548;

E-mail pnelson@nsf.gov)
Objectives: This grant was awarded to support organization of the First North American Rock Mechanics Symposium and associated workshops, short courses, and field trips of national and international rock mechanics interest.

Project Description: In 1992, the U.S. National Committee for Rock Mechanics (NAS/NAE), and Canadian (CARMA) and Mexican (SMMR) societies, committed to operating a joint symposium during even-numbered years. This is the first such symposium and therefore the most risky. The conference was organized around keynote lectures and presentations including national and international participants practicing in the professions of rock mechanics: civil, mining, and petroleum. The conference proceedings were assembled from refereed and peer-reviewed extended abstracts, and the proceedings was published by Balkema with the volumes distributed at the conference (June 1-3, 1994) in Austin, Texas. Workshops and short courses dealing with subjects as borehole stability, mechanics of weak rock, rock fracture mechanics were successfully offered. Attendance was about 360 people, including about 50 students from the U.S. and abroad.

Results: This project was successfully accomplished. The registration fees were kept a low as possible to promote attendance and underwrite graduate student attendance. The final budget indicates that the operation was effectively non-profit. The proceedings volume was well-produced, and is received well in the rock mechanics community. A copy of the volume has been transmitted to Dr. William Luth, Manager of the Geosciences Program. 
GRANTEE:

GRANT:

TITLE:

PERSON IN CHARGE:
UNIVERSITY OF TULSA

Department of Geosciences

Tulsa, Oklahoma 74104

DE-FG05-88ER13417

Stability of Natural Gas in the Deep Subsurface

Colin Barker (918-631-3014; Fax 918-631-2091;

E-mail GEOS_CGB@vax1.utulsa.edu)

Objectives: The main objective of the research has been to use a combined theoretical and experimental approach to establish deep gas composition, and to understand the factors controlling the distribution of methane and other gases in the subsurface at depths down to about 50,000 feet.

Project Description: Fluid inclusions can provide small samples of gas from deep subsurface environments. The gases in individual fluid inclusions are being analyzed using a fast-scanning, computer-controlled, dual mass spectrometer system. The host minerals are heated in a vacuum system and as each inclusion ruptures it produces a burst of gas lasting about $25 \mathrm{msec}$, and this is analyzed by the mass spectrometers. Their output is digitized and transferred to magnetic tape for subsequent off-line processing which provides the composition for each inclusion (background corrected). In addition, release of each gas as a function of temperature and inclusion size is available. Populations of inclusions can be presented on appropriate ternary diagrams and from 10 to 1000 individual fluid inclusions have been analyzed in a variety of 10 -mgram samples.

Gas composition in deep reservoirs is also being calculated thermodynamically using a free energy minimization program that can handle up to $70 \mathrm{com}$ ponents in 20 phases.
Results: Analytical capabilities have been improved by converting the 12-bit analog-to-digital converter to a 16-bit unit. Initially, increased noise degraded the output, but most of this was eliminated except for one high frequency component that was eventually traced to a defective component on the board. The data-acquisition PC has been upgraded and the post-processing software consolidated onto a network of HP/Apollo Series 9000 workstations. There has been increased emphasis on monitoring gas release as a function of temperature and capabilities have been improved by installing a better temperature controller. Monitoring is useful in understanding locations of gases in minerals, and in establishing rupture temperatures for fluid inclusions with different gas compositions. Quantifying gas composition requires instrument calibration. Determination of cracking patterns for individual gases is straightforward but obtaining relative sensitivities is more difficult. A new calibration line provides known gas mixtures, but the biggest problem remains water. Both rhyolite glasses with calibrated amounts of water (by FTIR), and thermal decomposition of $\mathrm{CsHCO}_{3}$ to give a known $\mathrm{H}_{2} \mathrm{O} / \mathrm{CO}_{2}$ mixture have been used successfully. We have continued to analyze fluid inclusions in a wide range of geologic materials, including some containing a separate oil phase. These could be treated like other samples and ruptured at low enough temperatures that thermal cracking was not a problem. 
GRANTEE:

GRANT:

TITLE:

PERSON IN CHARGE:

\section{U. S. GEOLOGICAL SURVEY \\ 345 Middlefield Road \\ Menlo Park, California 94025}

DE-ASI03-93-ER14338/A000

Causes of the Abnormally High Fluid Pressure in the Uinta Basin, Utah

J. D. Bredehoeft (415-354-3379;

E-mail jbrede@dercamnl.wr.usge.gov)
Objectives: The objective of this study is to investigate the causes of abnormally high pore pressure in the Unita Basin, Utah.

Project Description: The Altamont-Bluebell oil field, in the deepest part of the Unita Basin, has pore pressure that in some places exceeds 0.8 of lithostatic. Ther are two prevailing explanations for the high pore pressure: (1) sedimentary loading and (2) the volume expansion and collapse of porosity associated with the conversion of solid kerogen to liquid oil. The purpose of this research is to test these hypotheses of pressure generation using three-dimensional, multiphase numerical simulation. These simulations will allow us to further investigate the migration of oil within the Uinta Basin.

Results: The sedimentary loading hypothesis was tested using analytical and numerical solutions. The mechanical compaction of sediments is assumed to be the sum of elastic and plastic deformation. The elastic and plastic strain are represented by constitutive relations between porosity and effective stress. Both the analytical and numerical calculations suggest that, depending upon the permeability of the sediments, the over-pressure produced by sedimentary loading alone should dissipate within 10,000 to 1 million years following the maximum depth of burial (burial is thought to have reach maximum during Eocene time).

The effects of oil generation on pressure were evaluated by numerical simulation. The threedimensional model computes the hydrodynamic regime during the basin's evolution and accounts for: (1) the compaction history, (2) the temperature history, and (3) the oil generation history of the basin. All numerical simulations of the basin fluid pressures were conducted using the two-phase (oil and water) numerical flow code, TOUGH2. We have extensively modified TOUGH2 to simulate basin evolutions; all transient effects of sedimentation, uplift, erosin and oil generation on the hydrogeologic and thermal aspects of the basin are considered. Changes in effective stress are explicitly accounted for and facilitated by calculating elastic and inelastic porosity changes. Diagenesis is investigated by reconciling observed values of porosity with modeled results.

Simulation results suggest that the system is most sensitive to: (1) permeability, (2) the initial kerogen content of the rock, (3) the temperature history of the basin, and (4) porosity reduction associate with pore collapse and diagenesis. Our simulations suggest that oil generation is a feasible mechanism to explain high fluid pressures in the Altamont field. 
GRANTEE:

GRANT:

TITLE:
UNIVERSITY OF UTAH

Department Of Geology And Geophysics

717 Browning Bldg.

Salt Lake City, Utah 84112

\section{DE-FG03-93ER14313}

High Resolution Imaging of Electrical Conductivity Using Low Frequency Electromagnetic Fields

PERSON IN CHARGE:

Alan C. Tripp (801-462-2112 or 801-581-4664; Fax 801-581-7065; E-mail actripp@mines.utah.edu)

Objectives: The project seeks to determine means of increasing the resolution of low frequency electromagnetic techniques by means of a-priori information and cooperative inversion.

Project Description: The research concentrates on three topics. The first goal is to improve local optimization by increasing the speed and versatility of the forward solution and by implementing novel methods of data conditioning and inversion regularization. The second goal is to investigate distributed global optimization for EM imaging using optimized forward code. The third goal is to lay a foundation for cooperative inversion of EM data with other data sets.

Results: Optimization of the integral equations 3D electromagnetic forward solution has been completed. This optimization has included improvements in impedance matrix formation, matrix solution, and supercomputer implementation. Advances in the inverse solution are twofold. In the first, means have been found for the DC resistivity case to optimally weight data accounting for a-priori information. This is a procedure which may be generalizable to electromagnetic data inversion. Numerical tests for the DC case demonstrates the technique to be a powerful way of optimizing model resolution as well as assessing the resolving capability of the DC technique independent of a particular array. In the second advance, a foundation for cooperative inversion of EM data with other data sets has been found in cooperative game theory. A very simple application of this formulation is being tested on the petrophysical level with seismic and electrical properties. 
GRANTEE:
UNIVERSITY OF UTAH RESEARCH INSTITUTE

Earth Science Laboratory

391 Chipeta Way, Suite C

Salt Lake City, Utah 84108-1295
GRANT:

TITLE:

\section{DE-FG02-89ER14083}

Tensor, Controlled-Source Audiomagnetotelluric Survey over the Sulphur Springs Thermal Area, Valles Caldera; Structural Implications and Tensor CSAMT Methodology

PERSON IN CHARGE:
Philip E. Wannamaker (801-584-4445; Fax 801-584-4453)
Objectives: The controlled-source audiomagnetotelluric (CSAMT) method is one of the principal electromagnetic techniques used in exploration for geothermal and mineral resources and in reservoir assessment and environmental assessment. Because very little geophysics had been carried out in the Quaternary Valles Caldera, the CSAMT method has been applied to extend knowledge of structure and physical state of the westem caldera from the "point" truth provided by CSDP drilling and surface mapping. However, this data set also has proven interesting in terms of the CSAMT technique itself. Issues here include the validity of the simplified scalar and vector measurement procedures in heterogeneous areas, as well as controls on non-plane wave effects, source field geometry over the survey area, and transmitter overprint effects on the survey fields.

Project Description: In support of CSDP coreholes VC-2A and VC-2B, 45 tensor CSAMT soundings of high quality were obtained with our own equipment over the Sulphur Springs thermal area of the westem Valles Caldera. The tensor approach has the advantage of independence of source field polarization and a complete estimation of the resistivity response regardless of dimensionality. The electric field component across strike was acquired with contiguous dipoles to ensure against undersampling the lateral response variation which can severely reduce certainty in model resistivity. Tensor apparent resistivity, impedance phase, and tipper data were assembled by profile for computer simulation using algorithms developed at UURI.

Results: Model resistivity cross sections have been derived through 1-D finite source and 2-D planewave inversion for all four data profiles in the westem caldera. Modeling indicates a general section from the surface downward of conductive debris flows, vari ably resistive Bandelier Tuff, conductive Paleozoic sediments and resistive Precambrian basement. With lithological thicknesses constrained to be those recovered from coreholes VC-2A, VC-2B and Baca-8, Bandelier Tuff and underlying Paleozoic sedimentary resistivities are variable but generally similar to those inferred outside the caldera and in the Redondo Creek area. No particularly high resistivities possibly corresponding to an implied vapor zone in the upper $500 \mathrm{~m}$ are evident in the CSAMT data. However, Sulphur Creek fault appears to be a locus of large structural relief for all survey lines which cross it; upthrow to the west appears to be about $400-500 \mathrm{~m}$. Comparison and inversion of CSAMT and MT data indicate that available depth of exploration in the plane-wave regime is no better than about $1 / 20$ of the transmitter separation, which is diagnostic of regions with resistive basement (common). On the other hand, the magnetic field data, which are mainly determined by resistivity structure on the scale of the transmitter-receiver separation, can be modeled to yield an effective 1-D host which controls the onset of non-plane wave effects over the survey area. 
GRANTEE:
UNIVERSITY OF UTAH RESEARCH INSTITUTE

Earth Science Laboratory

391-C Chipeta Way

Salt Lake City, Utah 84108-1295
GRANT:

TITLE:

\section{DE-FG02-90ER-14133} in Oil-Reservoir Evolution in the Basin and Range Province

Objective: The project objective remains a thorough test of the following hypothesis: Modern and fossil geothermal systems, by various means, have been instrumental in the formation of petroleum reservoirs in the Great Basin.

Project Description: Eastem Nevada hosts numerous shallow and geothermally anomalous oil fields (for example, Blackburn and Grant Canyon) which share a surprisingly large number of essential attributes with many of the oil-bearing, Carlin-type, low-grade, disseminated gold deposits which occur in the same region, particularly those of the Alligator Ridge-Bald Mountain mining district in White Pine County. Is there a true genetic affiliation between these seemingly disparate natural resources, and are the Alligator Ridge deposits three-dimensionally exposed analogues of the concealed, still-hot oil reservoirs? In seeking answers to these questions, we are focusing on the role of moderate-temperature geothermal systems in the generation, migration, and entrapment of oil, but in so doing, we are also gaining valuable new insight into the mechanisms by which Carlin-type deposits have been formed. Our approach is multidisciplinary, involving techniques including, but not limited to: (1) detailed geologic mapping as well as logging of drill cuttings and cores, with emphasis on lithology, alteration, porosity characteristics, and vein mineralogy/paragenesis; (2) three-dimensional stratigraphic/structural analysis to allow reconstruction of fluid-flow paths used by both thermal waters and liquid hydrocarbons; (3) fluid-inclusion mi crothermometry; (4) whole-rock and vein-mineral geochemistry; (5) hydrogeochemistry of oil-field vs regional waters; (6) light-stable-isotope systematics of thermal waters and selected vein and alteration minerals.

Results: This year's work has concentrated on the oil-bearing Carlin-type deposits of the Alligator Ridge-Bald Mountain district. Earlier efforts here were confined to the Yankee deposit, where preliminary fluid-inclusion microthermometry and carbonoxygen isotopic analysis permissively indicated that oil had migrated and been entrapped in the same geothermal system responsible for precious-metal mineralization. In fact, the Yankee deposit may also have been the site of a theoretically once-producible oil reservoir with at least 300,000 barrels of oil-in place prior to the deposit's wholesale oxidation. Mining at Alligator Ridge during the last two years has exposed several new deposits and furnished new exposures for three-dimensionally mapping and characterizing the oil-transporting, causative hydrothermal system(s). All these newly revealed deposits are associated with "live" oil-confined to unoxidized pods encircling the orebodies-and with coarse brown orerelated calcite veins containing abundant oil inclusions, all of which, along with coexisting aqueous inclusions, were apparently entrapped in the temperature range $100-150^{\circ} \mathrm{C}$. These are unusually low temperatures for Carlin-type gold deposits in general (mostly greater than $150^{\circ} \mathrm{C}$ to perhaps $290^{\circ} \mathrm{C}$ ), but quite comparable to modern temperatures at the nearby and geologically similar, thermally active oil fields. The goldand oil-bearing hydrothermal fluids were introduced 
not only along faults and fractures but also along spectacular carbonate-dissolution collapse breccia bodies. Massive limestones beneath the ore- and oilbearing zones are riddled with intricate hydrothermal caverns which post-date oil and ore but which appear to represent a process (decalcification) ongoing since inception of the mineralizing geothermal system. All the new Alligator Ridge pits (seven at this writing) are being geologically mapped in detail and systematically sampled. The information provided by the mapping and analytical results will be combined with data from strategically positioned exploration boreholes for full three-dimensional characterization of the oil-bearing systems and their effects.
A serendipitous new oil discovery in western Nevada's Buena Vista Valley appears to have strengthened the conceptual oil/geothermal/gold connection. A late 1993 mineral exploration borehole drilled into a siliceous sinter at Kyle Hot Springs $\left(59^{\circ} \mathrm{C}\right)$ in this valley encountered not only elevated gold values at depth but also a totally unanticipated reservoir of paraffinic heavy crude oil. Reconnaissance examination of cuttings from this corehole suggest that the oil was transported and entrapped in the same hydrothermal system which deposited gold. 
GRANTEE:

GRANT:

TITLE:

PERSON IN CHARGE:
VIRGINIA POLYTECHNIC INSTITUTE AND

STATE UNIVERSITY

Fluids Research Laboratory

Department of Geological Sciences

Blacksburg, Virginia 24061

DE-FG05-89ER14065

PVTX Properties of Fluid Systems: $\mathrm{H}_{2} \mathrm{O}-\mathrm{CO}_{2}-\mathrm{NaCl}$

R. J. Bodnar (703-231-7455; Fax 703-231-3386;

E-mail bubbles@vt.edu)

Objectives: The objective of this project is to experimentally determine the pressure-volumetemperature-composition (PVTX) relationships of $\mathrm{H}_{2} \mathrm{O}-\mathrm{CO}_{2}-\mathrm{NaCl}$ mixtures over the complete range of PTX conditions encountered in crustal energy, resource, and waste-related environments. These data are used to develop equations of state to predict the volumetric properties of these fluids in crustal rocks.

Project Description: Volumetric (PVT) data provide the fundamental information needed to understand the physical and chemical behavior of fluids in energy, resource and waste-related environments. Further, these data represent the basis for developing empirical or theoretical equations of state to predict the thermodynamic properties of fluids over crustal PTX conditions. In this study the PVTX properties of $\mathrm{H}_{2} \mathrm{O}-\mathrm{CO}_{2}-\mathrm{NaCl}$ are being experimentally determined using the synthetic fluid inclusion technique. With this technique, fluids of known composition are trapped as inclusions by healing fractures in quartz at known temperatures and pressures. Phase relations and $\mathrm{P}-\mathrm{T}$ locations of isochores in the $\mathrm{H}_{2} \mathrm{O}-\mathrm{CO}_{2}-\mathrm{NaCl}$ system are obtained by observing the temperatures and modes of homogenization of the synthetic fluid inclusions during subsequent heating and cooling experiments in a fluid inclusion stage mounted on a petrographic microscope.

Results: The procedure followed in this investigation was to first determine the PVTX behavior of the two relevant binaries $\left(\mathrm{H}_{2} \mathrm{O}-\mathrm{CO}_{2}\right.$ and $\left.\mathrm{H}_{2} \mathrm{O}-\mathrm{NaCl}\right)$, and then to extend these data into the $\mathrm{H}_{2} \mathrm{O}-\mathrm{CO}_{2}-\mathrm{NaCl}$ ternary. Previously the PVTX properties of the $\mathrm{H}_{2} \mathrm{O}$ $\mathrm{CO}_{2}$ binary were determined to $700^{\circ} \mathrm{C}$ and $5 \mathrm{kbars}$, and these data were used to develop an equation of state to predict the behavior of $\mathrm{H}_{2} \mathrm{O}-\mathrm{CO}_{2}$ solutions at crustal $\mathrm{P}-\mathrm{T}$ conditions. During the past year all experimental studies of the $\mathrm{H}_{2} \mathrm{O}-\mathrm{NaCl}$ binary were completed. The $\mathrm{H}_{2} \mathrm{O}-\mathrm{NaCl}$ data have been used to develop an empirical equation describing the relationship between temperature, pressure and composition according to:

$\mathrm{dP} / \mathrm{dT}\left(\mathrm{bar} /{ }^{\circ} \mathrm{C}\right)=\mathrm{as}_{\mathrm{S}}+\mathrm{b}_{\mathrm{S}} * \mathrm{~T}+\mathrm{cs}_{\mathrm{S}} * \mathrm{~T}^{2}$

where $\mathrm{dP} / \mathrm{dT}$ is the slope of the isochore, $T$ is the temperature along the liquid-vapor curve in degrees Celsius, and "as," "bs," and "cs" are salinity-dependent fitting parameters. Equation (1) predicts the PVTX behavior of $\mathrm{H}_{2} \mathrm{O}-\mathrm{NaCl}$ solutions over the range $0-40 \mathrm{wt} \% \mathrm{NaCl}, 50^{\circ}-700^{\circ} \mathrm{C}$ or the critical temperature, whichever is lower, and from the vapor-saturation curve to $6 \mathrm{kbars}$. Earlier work under this project has defined the relationship between temperature, composition and vapor pressure along the vapor-saturation curve in the $\mathrm{H}_{2} \mathrm{O}-\mathrm{NaCl}$ system.

One of the goals of this project is to develop a numerical model that can be used to interpret microthermometric data obtained from fluid inclusions from crustal environments. Requirements for the model are that it (1) accurately predict of the PVTX behavior of crustal fluids approximated by the $\mathrm{H}_{2} \mathrm{O}$ $\mathrm{CO}_{2}-\mathrm{NaCl}$ ternary system and (2) use as input data 
only information that is available from conventional microthermometric analysis of inclusions. A numerical model that satisfies these requirements for the $\mathrm{H}_{2} \mathrm{O}-\mathrm{NaCl}$ binary has been developed. The model requires only temperatures of ice-melting or halite dissolution and the fluid inclusion homogenization tem perature as input. From these input data the salinity, vapor-pressure, density, and possible formation P-T conditions are calculated. 
GRANTEE:

PERSON IN CHARGE:
TITLE:

\section{GRANT:}

VIRGINIA POLYTECHNIC INSTITUTE AND

STATE UNIVERSITY

Department of Geological Sciences

Blacksburg, Virginia 24061

\section{DE-FG-05-88ER13951}

\section{Zircons and Fluids: An Experimental Investigation with Applications for Radioactive Waste Storage}

Objectives: The research objective of the VPI\&SU program is to develop a predictive correlation between the physical and chemical (including $\mathrm{U}-$ $\mathrm{Pb}$ isotopic studies) stability of $\mathrm{ZrSiO}_{4}$ and metamictization for its consideration as host for high-level radioactive waste.

Project Description: Past efforts have been focused on developing techniques for preparation of synthetic zircons (for use in hydrothermal experiments), developing analytical techniques for high sensitivity electron microprobe analyses, conducting hydrothermal experiments for studying the chemical, physical and isotopic response of zircons to fluids, and evaluating the transport mechanisms for cations in both metamict and crystalline zircons.

Results: Our current research is focused on evaluating the correlation between activation energies (for $\mathrm{Pb}$ transport) measured from experimental and field observations. Experimental data of Sinha et al. (1992) and published diffusion data yield activation energies that range from 10 to $280 \mathrm{kcal} / \mathrm{mol}$. Coupled with ongoing experiments, our research supports the contention of Tilton (1960) that the difference between the high and low temperature activation energies (higher values at higher temperatures) is the result of two separate processes. Low temperature transport is modeled by us to be the result of fast transport diffusion along self-induced dislocations associated with metamictization or vacancies formed during crystallization (Lee and Sinha, 1992), while higher activation energies are required for bulk diffusion at higher temperature.

We are conducting isotopic, SEM and electron microprobe studies of zircons from the Eldora stock, Colorado, where changes in $\mathrm{U} / \mathrm{Pb}$ ages at varying distances from the intrusive contact suggested activation energies of $\sim 200 \mathrm{kcal} / \mathrm{mol}$. Our chemical mapping of zircons shows that the discordancy in measured ages appears to be a function of core/overgrowth ratio (Solberg et al., 1992) and cannot be utilized for calculating activation energies. We are currently in the process of preparing samples for ion probe work where it is anticipated that information on discordancy on only the core regions will provide information on thermally enhanced diffusion. The correct evaluation of transport mechanisms (based partly on U/Pb isotopic analyses) must be considered one of the most fundamental issues associated with open- versus closed-system behavior of waste forms. 
GRANTEE:

GRANT:

TITLE:

PERSON IN CHARGE:
WASHINGTON STATE UNIVERSITY

Department of Geology

Pullman, Washington 99164-2812

(Cooperative study with Westinghouse Hanford Co.)

DE-FG06-91ER14172

Origin of Flood-Basalt Volcanism on the Columbia Plateau: an Integrated Approach Using Geology, Geophysics, and Petrology

S. P. Reidel (509-376-9932; Fax 509-376-7816;

E-mailw65395@fepl.rl.gov)

Objectives: The principal objectives of this project are to understand: the causes and evolution of flood-basalt volcanism on the Columbia Plateau; the relationship between flood-basalt volcanism and the tectonic history of the Pacific Northwest; and how flood-basalt volcanism has influenced the post-floodbasalt tectonic development of the Columbia Plateau and its resources.

Project Description: The study involves five areas: (1) a study of the main eruptive units of the Columbia River Basalt Group; this includes a detailed analysis of the physical and chemical aspects of the large volume flows; (2) the structural development of the Columbia Plateau prior to, during and following the eruption of the Columbia River Basalt Group; (3) the timing and rates of structural deformation on the Columbia Plateau and their relationships to the timing and rates of eruption of the Columbia River Basalt Group; (4) an assessment of the tectonic implications of paleomagnetic data from the Columbia River Basalt Group; and (5) a synthesis of results from studies of the Columbia River Basalt Group, tectonism in the Pacific Northwest, and resource potential.

Results: The study concluded during the current year. The results of the study are summarized in a series of papers and maps that have been either publised or are in various stages of publication/preparation. A Ph.D dissertation was completed as part of the study and a field trip as part of the Annual Meeting of the Geological Society of America held in Seattle during the fall of 1994 will provide field examination of some of the results. 
GRANTEE:

GRANT:

TITLE:

PERSONS IN CHARGE:
WASHINGTON UNIVERSITY

Department of Earth and Planetary Sciences

St. Louis, Missouri 63130

DE-FG02-92ER14297

Development of an Experimental Database and Theories For

Prediction of Thermodynamic Properties of Aqueous

Electrolytes and Nonelectrolytes of Geochemical Significance at Supercritical Temperatures and Pressures

Everett L. Shock (314-726-4258; Fax 314-935-7361;

E-mail shock@zonvark.wustl.edu) and R. H. Wood (302-831-2941;

Fax 302-831-6335; E-mail rwood@brahms.udel.edu)
Objectives: The objective of this research is to measure heat capacities and volumes of key compounds of importance to predictions of geochemical phenomena at high temperatures and pressures. A second objective is to use the key compounds as a database together with simulations to develop empirical and theoretical methods for predicting a wide variety of other compounds.

Project Description: Measurements of volumes and heat capacities of a wide variety of organic electrolytes and nonelectrolytes at temperatures from 25 to $325^{\circ} \mathrm{C}$ will be made. This will allow the development of group additivity schemes to predict a very wide variety of organic species containing these functional groups. Previous measurements on $\mathrm{H}_{2} \mathrm{~S}, \mathrm{CO}_{2}, \mathrm{CH}_{4}$, $\mathrm{NH}_{3}$, and $\mathrm{H}_{3} \mathrm{BO}_{3}$ are being analyzed to find correlations which can predict other species. Molecular dynamics simulations of the chemical potential of aqueous methane, ethane, and propane at temperatures from 600 to $1200^{\circ} \mathrm{C}$ and water densities from 0 to $1 \mathrm{gm} / \mathrm{cm}^{3}$ have been made. Revisions of the equations of state for aqueous ions and nonelectrolytes to allow better predictions of properties at high temperatures and pressures will be developed. A critical analysis of the various approaches used to estimate the dielectric constant of $\mathrm{H}_{2} \mathrm{O}$ at pressures $>5$ kilobars has begun, with the goal of extrapolating the range of utility of the revised-HKF equation of state for electrolytes.

Results: The volumes and heat capacities of aqueous solutions of 1-propanol, propanoic acid, pyridine, 1,4-butanediol, propylamine, adipic acid, succinic acid, propionamide, 1,6-hexanediol, 1,4-butanediamine, 1,6-hexanediamine, phenol, sodium acetate, propylamine hydrochloride, sodium propionate, and sodium benzenesulfonate have been measured at temperatures up to $250^{\circ} \mathrm{C}$. Results of the comparison of the Born model and the compressible continuum model to data on aqueous electrolytes up to $420^{\circ} \mathrm{C}$ and with simulations of the chloride ion in water at $450^{\circ} \mathrm{C}$ and $0.012 \mathrm{~g} / \mathrm{cm}^{3}$, as well as $727^{\circ} \mathrm{C}$ and $0.35 \mathrm{~g} / \mathrm{cm}^{3}$ have been published. It has been found that the equation of Harvey, Sengers and Tanger can be more accurate in the vicinity of the critical point than that of Shock et al. The latter equation provides estimates well beyond the critical region, and efforts are underway to improve its accuracy. If we know the volumes we can quite accurately estimate the heat capacities of these substances. There are also reasonable correlations of the magnitude of the critical effects, both volume and heat capacity, with critical points and Henry's law constants. 
GRANTEE:

GRANT:

TITLE:

PERSON IN CHARGE:
UNIVERSITY OF WASHINGTON

Geophysics Program

Seattle, WA 98195

DE-FG06-92ER14231

Two and Three-Dimensional Magnetotelluric Inversion

John R. Booker (206-543-0489; Fax 206-543-0489;

E-mail booker@geophys.washington.edu)
Objective: Develop efficient techniques for highresolution imaging of multi-dimensional electrical structure of the Earth's subsurface.

Project Description: Because the electromagnetic inverse problem for natural sources is generally multi dimensional, most imaging algorithms saturate available computer power before the complete data set can be addressed. We have developed an algorithm called the Rapid Relaxation Inverse (RRI) to directly invert large multi-dimensional magnetotelluric (MT) data sets. This method is orders of magnitude faster than competing methods. The key to its efficiency is that an improvement in the structure directly beneath an MT site can be calculated from a one-dimensional (1D) inverse problem if one has information about the multi-dimensional fields as function of depth beneath the site. The capability of RRI for two-dimensional (2D) structure is being enhanced and it is being extended to fully three-dimensional (3D) structure. In addition, related holographic electromagnetic imaging techniques are being investigated.

Results: In the past year, we have tested a 3D version of the code on data generated by known structure with very encouraging results. We have also applied the $2 D$ version to very large Electromagnetic Array Profiles (EMAP) collected for oil exploration. RRI can invert a 100 span EMAP with a 124 horizontal by 80 vertical node model in less than two hours on a high speed workstation. We found that we required a structure penalty that differed in two significant ways from the one we have been using for MT profiles. First, the horizontal smoothing had to be increased by a factor of 4 to 16 times and second, the depth-dependence of the horizontal smoothing had to be made it eration-dependent. This forces the algorithm to generate shallow structure before it tries to generate deep structure. 
GRANTEE:

GRANT:

TITLE:

PERSON IN CHARGE:
UNIVERSITY OF WISCONSIN

Department of Geology and Geophysics

Madison, Wisconsin 53706
DE-FG02-93ER14328

HRTEM Investigations of Interactions Between Minerals, Fluids, and Lithobiontic Communities During Natural Weathering

Jillian F. Banfield (608-262-0915; Fax 608262 0693;

E-mail jill@geology.wisc.edu)

Objectives: The objective of our research is to explore the hypothesis that reactions occurring at the mineral-lichen interface are strongly impacted by biochemical processes and thus differ in their rates and products from those reactions occurring at distance from this interface.

Project description: We are using high-resolution transmission electron microscopy (HRTEM), energy dispersive $\mathrm{x}$-ray spectroscopy, and selected area electron diffraction as well as light microscopy, $x$-ray diffraction, and scanning electron microscopy to characterize intact lichen-mineral interfaces. These techniques provide millimeter to sub-nanometer-scale morphological, chemical and structural information. Specifically, we are characterizing the contacts between crustose saxicolous lichens and K-feldspar, albite, biotite and hornblende in the Stettin amphibole syenite $(1.6 \mathrm{Ga}$ intrusive complex near Wausau, Wisconsin). We have also commenced study on a diverse lichen assemblage on amphibolites from near Eau Claire, Wisconsin. For comparison, samples from within weathering rinds, and thus not subjected to direct attack by lichen-derived compounds have been collected.

The samples are diamond sawed, mounted on petrographic microscope slides and thin sectioned. $3 \mathrm{~mm}$ areas of interest are mounted on TEM grids and $\mathrm{Ar}$ ion-milled to electron transparency. Duplicate material is re-embedded in plastic and ultrathin sectioned using diamond knife ultramicrotomy.
Results: Porpidia albocaerulescens and Rhizocarpon grande are the dominant species of crustose lichens on the syenites. Lichen substances used in identification are sequestered in the upper thallus and probably play no important role in mineral dissolution.

Biological fixation and embedment protocols have been adapted to prepare rock samples encrusted with entire lithobiontic communities. All mineral surfaces are coated in fungal and bacterial mucopolysaccharides. Dissolution does not involve pervasive leaching. The smallest mineral fragments retain their chemical and structural identity. Previous studies that employed chemical digestion of organic material reported lichens completely extract cations from some minerals, leaving only silica. No siliceous relics have been identified.

Amphibole surfaces along hyphae-filled channels are highly corroded, with surface topography defined by few-nanometer-wide serrations bounded by $[110\}$ planes. Reaction products include Fe-rich smectite and minor goethite. Mass balance considerations indicate conversion of amphibole to smectite involves a partial loss of $\mathrm{Ca}$ (and $\mathrm{K}$ ) and complete loss of $\mathrm{Na}$. The smectite is topotactically oriented (c-smectite // a-am phibole; b-smectite // b-amphibole). Biotite interpenetrated by fungal hyphae is partially converted to vermiculite. Like biologically mediated weathering, physiochemical weathering is neither isochemical nor isovolumetric. Reaction at distance from the lichenmineral interface results in nanocrystalline goethite plus minor Fe-rich smectite. 
GRANTEE:

GRANT:

TITLE:

PERSON IN CHARGE:
UNIVERSITY OF WISCONSIN

Department of Geology and Geophysics

Madison, Wisconsin 53706

DE-FG02-93ER14389

Microanalysis of Stable Isotope Ratios in Geothermal Systems: Long Valley and Skye

John W. Valley (608-263-5659; Fax 608-262-0693;

E-mail valley@geology.wisc.edu)

Objectives: This project will use new geochemical techniques to decipher the complex effects of superimposed hydrothermal events in modern and ancient geothermal systems. At the Long Valley caldera in Califormia, these results will provide insight into the nature of magma chambers at depth, the size of the modern geothermal resource, and volcanic hazards.

Project Description: This study focusses on samples from the Long Valley Exploratory Well and related rocks from the Mount Morrison roof pendant and the Isle of Skye. New techniques allow analysis of stable isotope ratios in ultra-small samples and isotope ratio can now be contoured across single crystals. This study is the first application of this technology to hydrothermally altered rocks. Mineral zonation patterns will provide new insights about the processes of water/rock interaction: mechanisms of exchange, timing, degree of equilibration, variability of fluid fluxes, and fluid sources. Enhanced understanding of these processes is essential for improving computer models of fluid flow through hot rocks. The goals of this study will be enhanced by new technological developments that are proposed for application of laser probes and ion microprobes to stable isotope microanalysis.

Results: This project was initiated in October, 1993. To date approximately 1000 oxygen isotope analyses have been made of silicate minerals by laser probe to improve capabilities of microanalysis, and to study samples from Long Valley and Skye. At Long Valley, a paleo-geothermal system has been identified by analysis of microdomains within drill core of the Bishop Tuff and ancient temperatures are shown to have been more than $150^{\circ} \mathrm{C}$ higher than at present. Beneath the Bishop Tuff, in quartz (+-calcite) veins cutting metamorphic rocks of the pre-caldera basement, low oxygen isotope ratios document the deep penetration of heated meteoric waters along complex systems of micro-fractures while carbon isotope ratios of -5 to $-7 \%$ suggest a major input of magmatic fluids. At Skye, similar sub-millimeter-scale oxygen isotope heterogeneity has been shown to be common within individual quartz phenocrysts from hydrothermally altered granites from the deeply eroded caldera complex of the Westem Red Hills. 
GRANTEE:

GRANT:

TITLE:

PERSON IN CHARGE:
UNIVERSITY OF WISCONSIN

Department of Geology and Geophysics

Madison, Wisconsin 53706

DE-FG-02-91ER14194

Poroelasticity of Rock

H. F. Wang (608-262-5932; Fax 608-262-0693;

E-mailwang@geology.wisc.edu)
Objective: The primary objective is to obtain laboratory measurements of poroelastic parameters to predict rock mass behavior under conditions from quasistatic (Darcy flow) to dynamic (seismic, borehole, and ultrasonic frequencies). The emphasis in this project year was on quasistatic characterization of Berea sandstone and Indiana limestone. A secondary objective is to develop fluid flow models for rock masses containing deformable fractures.

Project Description: The main scientific issue is to understand the fluid response of a rock mass to stress, and vice versa. The quasistatic poroelastic constants are important for characterizing such coupled phenomena as fluid extraction from reservoirs and fluid pressure response to the stress field generated by an earthquake.

Results: Complete sets of poroelastic constants have been measured for Berea sandstone and Indiana limestone. The four independent moduli were obtained by nonlinear, least squares inversion of eight measurements. Young's modulus, bulk modulus and Poisson's ratio were measured under both drained and undrained conditions. In addition, the unjacketed bulk modulus and Skempton's coefficient were measured. The specific storage coefficient for conditions of constant mean strain was approximately one-half that for conditions of constant mean stress. The specific storage coefficient used in hydrogeology (uniaxial strain and constant vertical stress) was closer to the constant mean strain value.

Poroelastic strains are produced as a result of the axial pressure variation during the transient decay of the pressure pulse used in the standard technique for obtaining permeability and specific storage of low permeability rocks. The poroelastic strains were calculated from an uncoupled model (one that assumes pressure is determined by the homogeneous diffusion equation, neglecting the term that contains the time rate of change of stress). The poroelastic effects are negligible for long, small diameter cores, but can be significant for short, large diameter samples. The lateral and axial strains at a particular distance along the sample wall are proportional to the pore pressure, and combinations of poroelastic moduli are the proportionality constants.

Results have been obtained from a model for flow to a well in a fractured, double-porosity reservoir in which the fractures are deformable. An optimum flow rate exists between large fracture drawdown driving flow from matrix to fracture and the large fracture drawdown reducing fracture permeability. The model accounts for the fracture compressibility to be a function of the effective stress on the fracture. 
GRANTEE:

GRANT:

TITLE:

PERSON IN CHARGE:
UNIVERSITY OF WISCONSIN

Department of Geology and Geophysics

1215 West Dayton St.

Madison, Wisconsin 53706

DE-FG02-94ER14439

Testing the Correlation Between Seismic Stratigraphy, Diagenesis and Physical Rock Properties: Evaluation of Fluid Flow During Early and Late Diagenesis

Jean M. Bahr (608-262-5513; Fax 608-262-0693;

E-mail jmbahr@geology.wisc.edu)

Objectives: This project, being conducted in collaboration with G. Eberli and P. Swart of the University of Miami, is designed to test the conceptual models of diagenesis developed by those researchers with numerical modeling of fluid flow through the Great Bahama Bank.

Project Description: The finite difference code HST3D is being used to simulate fluid flow, heat transport and solute transport through the Great Bahama Bank. Initial simulations are focussed on a 2-D profile for which the major hydrologic units and properties were chosen based on available seismic and core data provided by the Miami collaborators. The model is being used to assess the sensitivity of flow patterns and flow rates to variations in hydraulic, thermal and density gradients and boundary conditions. The numerical model will also be used to study the effects of sea level fluctuations and changes in permeability due to diagenesis. This will involve modification of the boundary conditions and permeability distribution to reflect conditions that are inferred to have existed during earlier diagenetic periods or as a result of sea level change.
Results: This project was initiated in April 1994. Completed simulations of fluid flow for isothermal conditions have investigated the sensitivity to variations in permeability within the bank created by five major permeability zones. These zones consist of carbonate deposited (1) in the Straits of Florida, (2) on the Bimini Bank, (3) in the Straits of Andros, (4) on the Andros Bank and (5) during Holocene time, draping the upper surface of the bank. These simulations have also assessed the sensitivity to variations in head between Andros Island, the western portion of the bank extending to the Straits of Florida, and the eastem Tongue of the Ocean. Anisotropy of permeability, which is consistent with large vertical variations of permeabilty measured in core studies, tends to promote fluid flow across the bank, while isotropic conditions lead to a divide beneath Andros Island. Large permeability contrasts between the Holocene carbonate and the underlying bank and straits permeability zones results in strong horizontal flow in the upper portion of the bank and weaker vertical flow at the boundaries between the bank and straits units. Heat transport simulations are now being initiated to examine the the potential for Kohout convection in a heterogeneous bank. 
GRANTEE:

GRANT:

TITLE:
WOODS HOLE OCEANOGRAPHIC INSTITUTION

Dept. of Marine Chemistry and Geochemistry,

Woods Hole, Massachusetts 02543

\section{DE-FG02-92ER14232}

\section{Geochemical Incorporation of Sulfur into Organic Matter: Role of Sulfur in the Formation and Diagenesis of Macromolecular Organic Matter in Sediments}

\section{PERSON IN CHARGE:}

Timothy I. Eglinton (508-457-2000 ext. 2627; Fax 508-457-2164; E-mail teglinton@whoi.edu)

Objectives: The overall goal of this study is to improve our understanding of the role of sulfur in organic matter (OM) diagenesis. Three specific objectives are outlined: (1) development and evaluation of structural models quantitatively describing organically-bound sulfur (OBS) in sediments; (2) application of these models for (a) assessment of sulfur incorporation into organic matter as a preservation (kerogen formation) mechanism and (b) elucidation of diage netic pathways for OBS.

Project Description: The experimental and theoretical approach is based on the premise that OBS can be represented as model structures that differ in sulfur linkage type (inter-molecular linkages vs intra-molecular bonds), as well as the number of linkages per molecule and the number of sulfur atoms in each linkage. These models are pertinent for accurate prediction of organic carbon burial efficiency in sediments and delineation of temperature-time requirements for petroleum generation from organic-rich sedimentary rocks. Emphasis is placed upon detailed characterization of complex macromolecules since these compounds represent the dominant fraction of sedimentary $\mathrm{OM}$ and play an integral role in petroleum generation.

A multifaceted analytical strategy is used in order obtain geochemical information on OBS: X-ray absorption spectroscopy (XANES) is used for determi nation of sulfur speciation; chemical degradation experiments are employed to selectively cleave organic molecules linked by sulfur, providing information on linkage type, the sites of sulfur attachment, the num- ber of linkages involved and the molecular structures of the sulfur-containing molecules; analytical pyrolysis is used to derive structural information and to provide estimates on organic sulfur content. These analyses were performed in addition to conventional bulk measurements (elemental analysis, TOC etc.) on a series of fractions isolated from sedimentary $\mathrm{OM}$ according to approximate molecular size and/or solubility. Peru margin and Monterey Fm sediments have been selected as the primary study areas because of their high organic carbon and organic sulfur contents, and apparent equivalence in terms of (paleo) depositional environment. A Monterey Fm. sample was the subject of a series of isothermal laboratory heating experiments designed to simulate natural geologic maturation in the subsurface. Eight temperatures from $125^{\circ} \mathrm{C}$ to $360^{\circ} \mathrm{C}$ (each $100 \mathrm{hr}$ duration) were employed under closed vessel hydrous pyrolysis conditions. Gaseous, liquid and solid products from these experiments were analyzed using the same analytical strategy described above.

Results: (1) Although OBS formation occurs primarily within the upper few meters of Peru margin sediments, sulfur "in-growth" continues at greater depths. The timing of sulfurization thus appears more diffuse than has previously been proposed.

(2) XANES data indicate the presence of organic sulfur compounds displaying a broad array of oxidation states. The presence of sulfonic acids as unexpectedly prominent constituents of total sulfur (up to $20 \%$ ) in surficial sediments may be of particular sig- 
nificance as potential diagenetic intermediates. There is a systematic increase in the relative proportion of thiophenic to sulfidic sulfur in the Peru kerogens with increasing depth, as observed by analytical pyrolysis. There is also an increase in the ratio of thiophenic to hydrocarbon pyrolysis products with depth, with the deepest samples approaching values similar to that of the Monterey kerogen. The distribution of alkylthiophenes in both the Peru and Monterey kerogens is consistent with Type II-S kerogen, both liberating high relative abundances of sulfur-containing pyrolysis products with isoprenoid and/or steroidal carbon skeletons. Geochemical evidence for these two deposits thus suggests that similarities extend down to the molecular level;

(3) No strong evidence was found between molecular size and the proportion of sulfide bridges for surficial sediments of the Peru margin. This implies that sulfur cross-linking reactions do not retard
OM degradation to a significant degree in the zone of active remineralization. Thus, if sulfur does play a role in preservation of labile molecules, a different mechanism must be operative. In contrast, there may be a causal relationship between molecular-size, solubility and sulfur cross-linking in the case of the Monterey sample. Chemolysis experiments on OM subfractions from the Monterey sample revealed systematic variation between the number of sulfur linkages and molecular size and allowed further inferences to be made on the structure and mode of at tachment of sulfur-bound macromolecules.

(4) Artificial maturation of Monterey sediment induced marked changes in the OBS composition of liquid and solid products, which varied strongly and systematically as a function of temperature. Preferential loss of sulfur-containing moieties was apparent and the proportion of thiophenic to sulfides increased with maturation temperature. 
GRANTEE:

GRANT:

TITLE:
WOODS HOLE OCEANOGRAPHIC INSTITUTION

Department of Marine Chemistry and Geochemistry

Woods Hole Oceanographic Institution

Woods Hole, Massachusetts 02543

\title{
DE-FG02-89ER13466
}

\section{Organic Geochemistry of Outer Continental Margins and Deep Water Sediments}

PERSON IN CHARGE:

\author{
J. K. Whelan (508-457-2000, ext. 2819; Fax 508-457-2164; \\ E-mail jwhelan@whoi.edu)
}

Objectives: The objective of this program is to develop a better understanding of processes of hydrocarbon generation and migration in coastal and offshore sedimentary basins as an aid in predicting favorable exploration areas for oil and gas.

Project Description: We are the principal organic geochemical arm of the Global Basin Research Network (GBRN), a distributed network of scientists working to understand the coupled physical and chem ical processes that control fluid movement in sedimentary basins. These processes, which are currently poorly understood, are fundamental to oil and gas formation and migration, metal ore deposit formation, and hydrology and associated pollutant movements around basins.

Results: Several lines of investigation have come together in the last year in our laboratory showing that gas generation and migration are key to understanding oil migration:

- Hydrous pyrolysis experiments simulating subsurface conditions in deeper hotter formations have shown that hydrogen for methane formation is coming from water as well as from kerogen and oil cracking. The reactions involved are highly dependent on the redox state of the chemical system, which in turn, may be influenced by the presence of redox sensitive inorganic minerals. If these processes also occur in nature, then gas generation can occur at much greater depths than previously thought.

- Hydrous pyrolysis experiments have shown that sufficient methane can be produced even from some relatively organic lean Type III kerogens to be able to dissolve and cause migration of indigenous oil at depths greater than about $10,000 \mathrm{ft}$.

- It has been known for some time that a single gas(methane)-oil phase forms at depths greater than about 10,000 feet. At shallower depths concomitant with pressure decrease, separate gas and oil phases form. These concepts have not been widely applied to processes of pore plugging, oil and gas migration, and appearance and disappearance of pressure cells in petroleum basins. The presence of a separate gas phase, possibly aided by separation of asphaltene/heavy oil, may cause plugging of porosity and the formation of individual "pressure compartments" in the subsurface.

- Oil cracking to gas at depth and, under some conditions, kerogen cracking to gas can cause overpressures great enough to fracture rocks resulting in upward flow of gas and oil.

- In many Gulf Coast wells that exhibit constant porosity in deeper sections, compaction cannot be the cause of either overpressuring or oil and gas expulsion.

- Organic geochemical data from the Louisiana Gulf Coast Eugene Island block 330 (EI-330) provides compelling evidence that fluid injection into EI-330 is a continuing episodic process, with the most recent injections having occurred within the last few years.

- Biomarker analyses together with oil and gas maturities provide a possible scenario for generation and migration of EI-330 oils which may also apply to 
other deeper water regions of the Gulf Coast: the EI330 oils were initially generated and trapped under salt causing retardation of their destruction by build up of gas pressure beneath evaporitic layers. More recently, oil cracking to gas has caused pressure buildup and upward migration of oil dissolved in methane through faults and through geopressure. Upward migration and release of pressure causes a fractionation with progressively lighter oil fractions filling progressively shallower reservoirs.

These collective observations lead to a very dif- ferent way of thinking about oil and gas migration processes in which the oil/gas phase changes themselves may be responsible for migration, for determining where oil will collect, for varying pressure regimes in the subsurface, and for the final compositions of gases and oils found at various depths. Discussions with other scientists suggest that similar processes may explain previously puzzling observations in basins worldwide including the Viking Graben of the North Sea, the Trinidad Basin, Niger Delta, and the Mahakam Delta. 
GRANTEE:

GRANT:

TITLE:

PERSON IN CHARGE:
WOODS HOLE OCEANOGRAPHIC INSTITUTION

Department of Marine Chemistry and Geochemistry

Woods Hole Oceanographic Institution

Woods Hole, Massachusetts 02543

DE-FG02-94ER14435

Robust, Controlled Leverage Magnetotelluric Data Analysis

A. D. Chave (508-457-2000 ext. 2833; Fax 508-457-2150;

E-mail alan@faraday.whol.edu)

Objectives: To develop an improved understanding of the causes of bias and variability in magnetotelluric response function estimates, particularly in the presence of source field problems and cultural noise, and to develop new processing methods that will eliminate these problems and apply tensor decompositions for galvanic distortion in an automatic fashion.

Project Description: Over the past decade, a collaboration with D. J. Thomson of AT\&T Bell Laboratories has resulted in major improvements to magnetotelluric data processing methodology, including robust remote reference algorithms that eliminate outliers in the electric field and extension of the jackknife to obtain nonparametric estimates of confidence limits. However, these methods do fail under some circumstances. This research will focus on further ad- vances that will be driven by analysis of diverse types of data, including those of interest in industry. The major problems to be addressed include:

1. Investigating the efficacy of multiple remote references.

2. Designing algorithms that control the influence of extreme data in the magnetic as well as the electric field (which conventional robust algorithms cannot do).

3. Tests of the hypothesis that statistically based data sorting can remove many of the confounding influences that sometimes affect magnetotelluric data.

4. Tests of the importance of magnetic field galvanic distortion in a variety of data.

Results: This project has only recently been initiated. 
GRANTEE:
GRANT:

TITLE:

PERSONS IN CHARGE:
YALE UNIVERSITY

Department of Geology and Geophysics

New Haven, Connecticut 06511

\section{DE-FG02-9OER14153}

\section{Reactive Fluid Flow and Applications to Diagenesis, Mineral Deposits, and Crustal Rocks}
A. C. Lasaga (203-432-3114; Fax 203-432-3134) and
D. M. Rye

Objectives: The objectives are to integrate new results and to develop new techniques along four directions: (a) experimental studies of water-rock reactions, (b) theoretical modeling of coupled fluid flowchemical reactions, (c) geochemical field-based studies of a lateritic bauxite deposit, and (d) stable isotopic variations on the regional scale, the vein scale, and the mineral grain scale in several geologic settings.

Project Description: The main thrust of the theoretical modeling continues to be the further development of the differences between equilibrium, steady state, and non-steady-state behavior of the chemical evolution of open fluid-rock systems. These differences have not been fully appreciated in previous models. The computer code developed in this project numerically treats multi-component, finite-rate reactions combined with advective and dispersive transport in one, two, and three dimensions and incorporates isotopic exchange and heat and mass transfer. Further development includes code that models flow along both fractures and porous media simultaneously. An important goal is to include a sophisticated algorithm that enables the code to track evolving reaction fronts efficiently without introduction of numerical dispersion.

We have developed micro-sampling techniques to be used in stable isotopic studies. The project is currently using these techniques to provide data sets that can be input into our models to determine the length and time scales relevant to fluid transport in a wide variety of geologic settings. These areas include: (1) the Wepawaug metamorphic schist, (2) the Irish base-metal ore system, (3) the Naxos metamorphic complex, (4) the Pijiguaos bauxite deposit, and (5) the Dalradian metamorphic complex in Scotland.

The numerical codes are being tested in all of the isotopic study areas as well in the Marysville contact aureole.

Extensive $a b$ initio research and surface chemistry studies on the kinetics of water-rock reactions will be integrated with the numerical codes, isotopic measurements, and field studies.

Results: The one- and two-dimensional reactive transport model has been applied to two important problems related to reactive flow in hydrothermal systems. The calculations indicate that the saturation state of the fluids in a fractured rock depends on its bulk permeability, which determines the flow velocities, and the spacing of fractures, which for a given porosity and permeability, determines the aperture of the fractures. For example, results of calculations applicable to high Rayleigh number flow in systems with variable upper boundaries indicate that significant disequilibrium with respect to silicate phases may occur in the low-temperature thermal boundary layers. We have shown that the degree of supersaturation in the boundary layer depends inversely on the fracture spacing (and thus on the fracture aperture) and inversely on the square of the upward flow velocity. For permeabilities as high as $10^{-14} \mathrm{~m}^{2}$ in systems with an impermeable upper surface, the local equilibrium approximation appears to be reasonable unless the fractures are widely spaced (for example, $>100 \mathrm{~m}$ ). The second problem investigated is the effects of reaction- 
induced porosity and permeability change on the character of the convective regime. For example, using a porosity-permeability relationship such as that observed for the Skaergaard intrusion, the calculations indicate that reaction-induced permeability change will prevent the convection cell from attaining a hydrodynamic or thermal steady state.

New code developments include the treatment of complex temporal and spatial variations in porosity and permeability. In particular, use of subgrid-scale grain models more accurately tracks the surface area to fluid volume effects upon porosity changes than what has been used in previous studies. The possibility of a large increase in the computational efficiency is being studied using a hybrid spectral transform method.

We have obtained the first reliable oxygen isotopic measurements on kyanite and staurolite. It was previously not possible to obtain reliable oxygen isotopic results on these minerals, because only about $40 \%$ of the oxygen was recovered from the minerals. By adding $\mathrm{NaBr}$ to the $\mathrm{Ni}$ reaction vessels we are now able to extract $100 \%$ of the oxygen.

In the Wepawaug Schist, the application of the experimental data to the kinetics of isotopic exchange of water with quartz, and the model results has shown that fluid flow was transient in cracks (now preserved as veins). Not only was the flow transient, the isotopic composition of the fluid oscillated between values that were isoptically lighter and heavier than the surrounding host rocks.

Oxygen isotopic zonation in garnets as well as isotopic, modal, and chemical profiles for individual minerals in wall rocks next to veins show that each fluid recorded in the veins infiltrated and reacted with the wall rocks. Garnets are isoptically zoned with the cores being isotopically lighter than the rims. Staurolite and kyanite throughout the profile appear to have formed late and are isotopically heavy. Quartz, biotite, and muscovite have intermediate isotopic compositions, and Plagioclase is isotopically light. The isotopic systematics between these minerals are now being used to put constraints on time-scales of fluid presence during transient fluid flow events.

The experimental work pioneered in our laboratories has produced several startling results on the kinetic rate laws of silicate-water reactions. The emerging results from recent experiments suggest that the variation of the rate with saturation state is much more complex than anticipated. The presence of a surface transition in the mechanism of dissolution leads to highly nonlinear variations of the rate with $\Delta G_{r}$. Such surface effects have been tentatively identified as stemming from the energetic role of dislocation defects on the surface of the minerals. A new full-rate law was proposed that explicitly incorporates the effect of $\Delta G$, as well as that of temperature and adsorption of $\mathrm{H}^{+}, \mathrm{OH}^{-}$, and other ions.

The experimental data can account quite well for many of the observations in global chemical weathering. Not only can the experimental data predict the correct stability ordering of the minerals, but also quantitatively account for the time scales of global chemical weathering. In addition, the new experimental data can explain the variation of silica in rivers worldwide as a function of runoff, without the need of recourse to an equilibrium model. Finally, the residence times for transport of debris from high altitudes may be fast compared to the time required for chemical reaction. Such feedback between physical and chemical weathering can help formulate better the models for the geochemical cycles of $\mathrm{CO}_{2}$.

Atomic force microscope studies of the surfaces of reacted kaolinite and muscovite have been successfully carried out and in situ studies are just beginning.

We have been successful in establishing a close collaboration both with BAUXIVEN, the Venezuelan aluminum company, and with the University of Caracas, for the purpose of generating a wide spectrum of geochemical data on the Pijiguaos bauxite deposit on the Guiana Shield. To test the various theoretical, experimental and isotopic methods mentioned above, data are currently obtained on: (1) Mineral abundance variation with depth on a fine scale $25 \mathrm{~m} \times 25 \mathrm{~m}$ horizontal grid. This includes depth profiles that penetrate almost to the parent Precambrian granite. (2) Chemistry and D and $O$ isotopic analysis of meteoric water collected on a weekly basis. (3) Chemistry and D and $O$ isotopic analysis of seasonal ground water samples. (4) Isotopic data on the minerals. 


\section{TOPICAL INDEX}

\section{GEOPHYSICS AND EARTH DYNAMICS}

Large-Scale Earth Dynamics 65,105

Evolution of Geologic Structures $11,30,31,65,99,104,109,116,125,147$

Properties of Earth Materials $3,7,17,18,19,21,25,26,27,46,48,50,61,66,74,75,77,80,100$, $107,108,110,119,120,123,126,130,134,136,138,144,146$

Rock Mechanics, Fracture, and Fluid Flow $.7,10,11,16,17,19,21,27,46,47,48,81,85,94,96,105$, $108,110,111,112,131,132,134,137,152,153$

Underground Imaging $8,9,11,15,20,25,27,35,46,82,94,96,97,111,112,116$, $125,128,140,141,149,158$

\section{GEOCHEMISTRY}

Thermochemical Properties of Geologic Materials. $12,22,23,36,37,38,39,43,48,69$ $70,71,73,79,84,119,144$

Rock-Fluid Interactions $3,4,5,6,13,14,16,18,24,28,29,31,36,37,38,39,40,41,43,48,49,63,64$, $70,75,78,79,80,81,85,86,90,98,99,123,126,138,144,148,150,159$

Organic Geochemistry $4,5,6,24,31,70,86,117,124,138,142,148,154,156$

Geochemical Transport $3,4,13,18,22,28,29,41,49,50,63,64,67$, $75,99,109,123,138,142,146,151,156$

\section{ENERGY RESOURCE RECOGNITION, EVALUATION, AND UTILIZATION}

Resource Definition and Utilization $5,6,8,9,15,17,26,36,37,38,39,43,94$ $111,112,124,125,128,140,147,149$

Reservoir Dynamics and Modeling $4,8,27,85,89,139,142,156$

Properties and Dynamics of Magma $28,66,69,73,77,84,100$

Continental Scientific Drilling $14,52,53,58,83,97,104,117,141$

\section{HYDROGEOLOGY AND EXOGEOCHEMISTRY}

Fluid Transport Dynamics and Modeling $7,13,27,94,98,106,114,128,131,135,159$

Thermochemical Properties of Energy Materials $24,85,138,144$

Perturbations of Fluid Flow $51,98,135$

\section{SOLAR-TERRESTRIAL INTERACTIONS}

Magnetospheric Physics $32,33,34,57$

Upper Atmosphere Chemistry and Physics 44,45

Solar Radiation and Solar Physics $34,44,45,57$ 


\section{INDEX OF TECHNICAL CONTRIBUTORS}

CONTRIBUTOR

Adler, L.

Akasofu, S.-I.

Aki, $\mathrm{K}$.

Arehart, G. B.

Arthur, M. A.

Attrep, M., Jr.

Aydin, A.

Baer, D. R.

Bahr, J. M.

Bakel, A. J.

Banfield, J. F.

Barker, C.

Becker, A.

Bell, D. R.

Benson, W. E.

Berryman, J. G.

Birn, J.

Blair, S. C.

Blencoe, J. G.

Bodnar, R. J.

Bonner, B. P.

Booker, J. R.

Boyd, F. R.

Brady, P. V.

Bredehoeft, J. D.

Brown, G. E.

Brown, S. R.

Burnham, A. K.

Carmichael, I. S. E.

Carter, N. L.

Casey, W. H.

Casey, W. H.

Chave, A. D.

Cheng, C. H. A.

Chiarello, R. P.

Clayton, R. W.

Cole, D. R.

Compton, J. S.

Cook, N. G. W.

Crossey, L. J.

Crowley, K. D.

Curtis, D. B.

INSTITUTION

PAGES

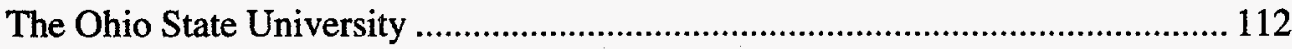

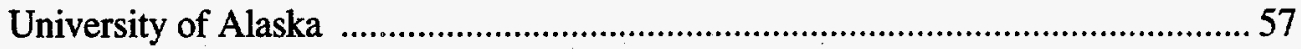

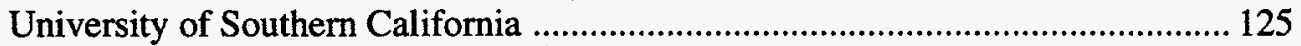

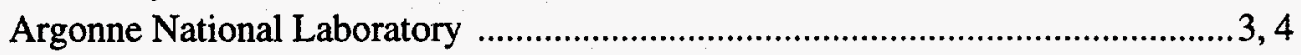

Pennsylvania State University ......................................................................117

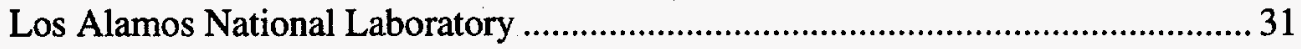

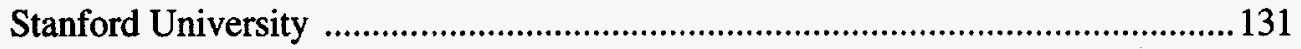

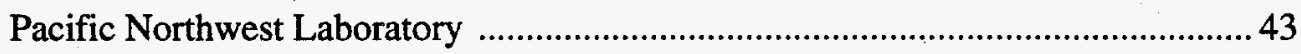

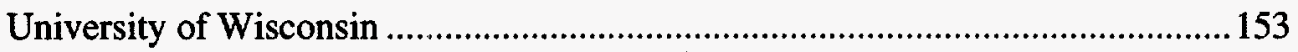

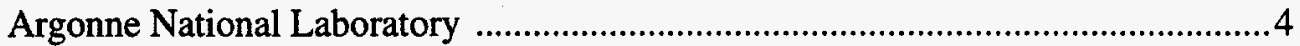

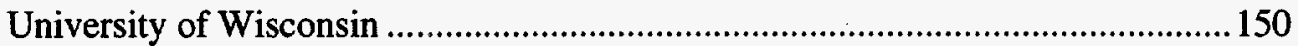

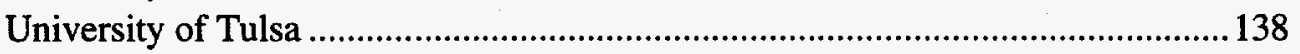

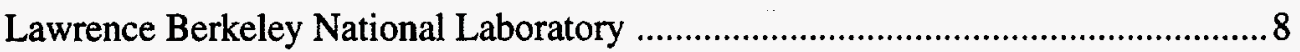

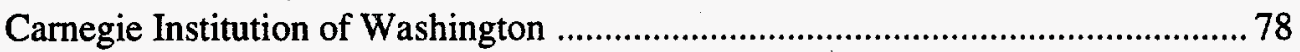

National Academy of Sciences/National Research Council ............................... 103

Lawrence Livermore National Laboratory ..................................................... 19

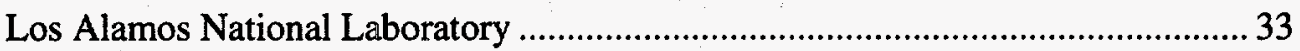

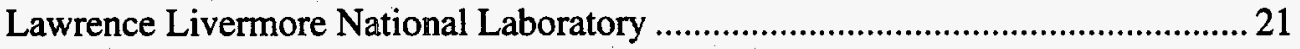

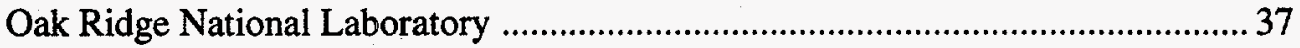

Virginia Polytechnic Institute and State University .......................................... 144

Lawrence Livermore National Laboratory ...................................... 16, 17, 20, 27

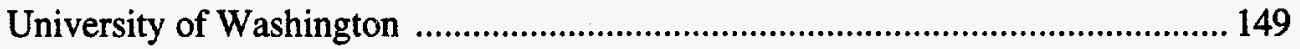

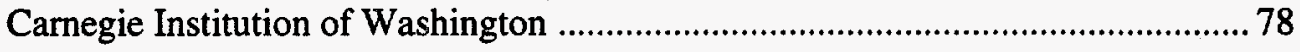

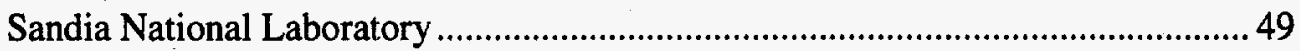

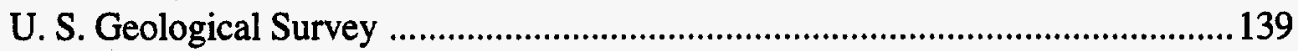

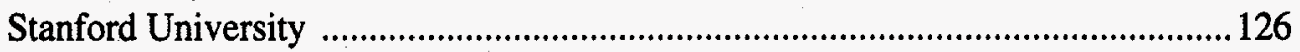

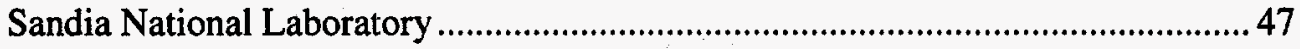

Lawrence Livermore National Laboratory ........................................................ 24

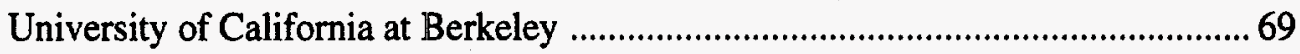

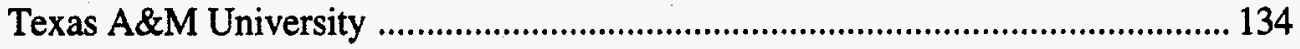

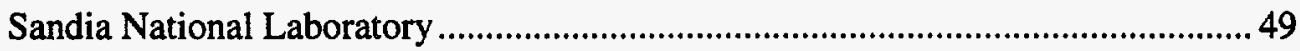

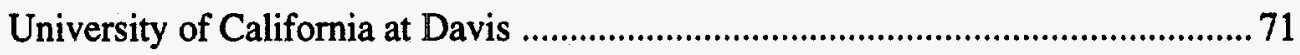

Woods Hole Oceanographic Institution ...........................................................158

Massachusetts Institute of Technology ................................................................... 94

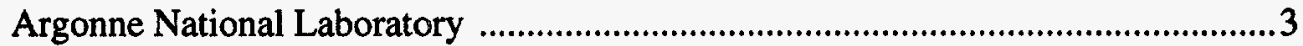

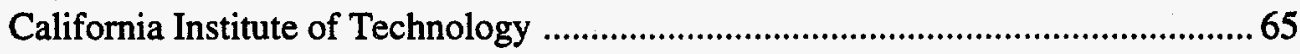

Oak Ridge National Laboratory .....................................................36, 38, 39, 40

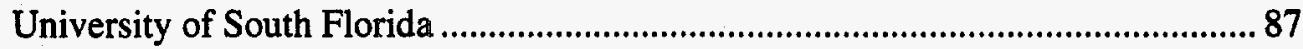

Lawrence Berkeley National Laboratory ............................................ 7, 10, 47

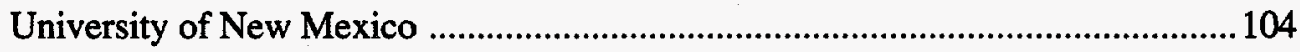

National Academy of Sciences/National Research Council ................................. 103

Los Alamos National Laboratory ......................................................................... 29 
Cygan, R. T.

Davin, E. M.

Dean, W. E.

DePaolo, D. J.

Devaney, A. J.

Dixon, P. R.

Duba, A. G.

Durham, W. B.

Eberli, G.

Egbert, G. D.

Eglinton, T. I.

Eichelberger, J. C.

Elmore, R. D.

Engel, M. H.

Epstein, S.

Fabryka-Martin, J. T.

Farver, J. R.

Fehler, M.

Flexser, S.

Foote, H. P.

Fredrich, J. T.

Fukui, L. M.

Gary, S. P.

Gisler, G. R.

Goldstein, S. J.

Hacker, B. R.

Hall, C. M.

Halliday, A. N.

Hanson, G. N.

Harrison, T. M.

Helgeson, H. C.

Hervig, R. L.

Hess, A. C.

Holcomb, D. J.

Holt, B. D.

Hones, E. W., Jr.

Horita, J.

House, L.

Hulen, J. B.

Ilton, E. S.

Jacobson, $\mathbf{R}$.

Janecky, D. R.

Johnson, A. M.

Johnson, M. C.

Johnson, P. A.

Joyce, D. B.

Kennedy, B. M.
Sandia National Laboratory 49,50

American Geological Institute 60

U. S. Geological Survey 117

Lawrence Berkeley National Laboratory .........................................................13

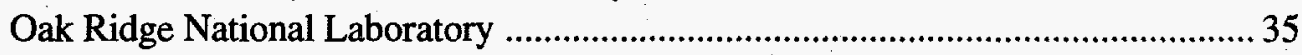

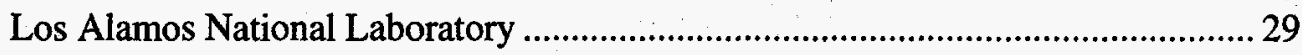

Lawrence Livermore National Laboratory .................................................17, 26

Lawrence Livermore National Laboratory ...................................................... 16

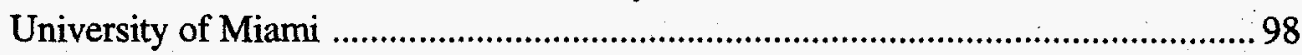

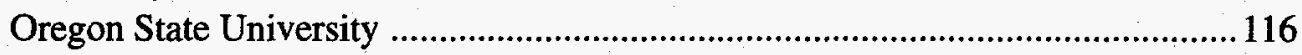

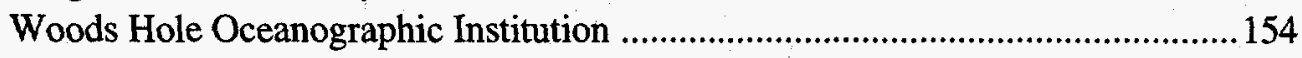

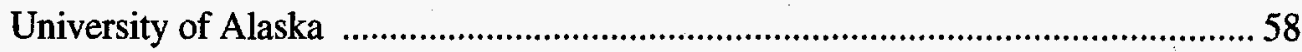

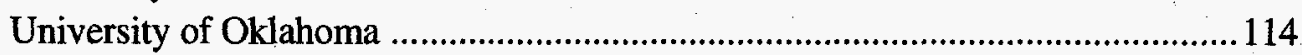

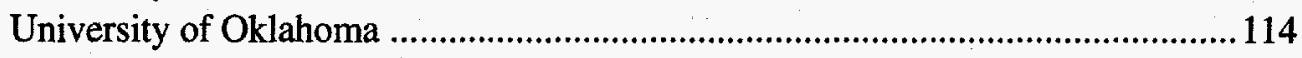

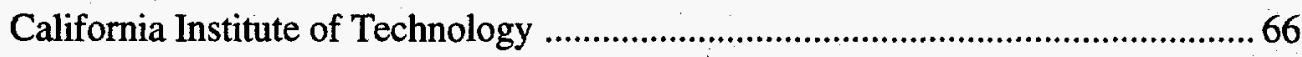

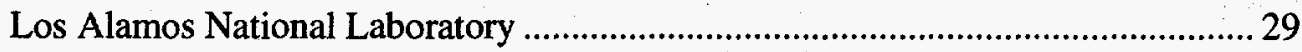

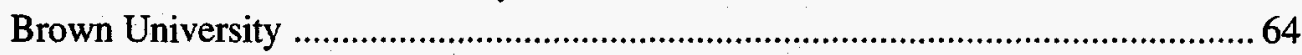

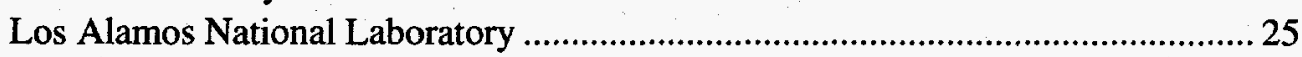

Lawrence Berkeley National Laboratory ........................................................ 14

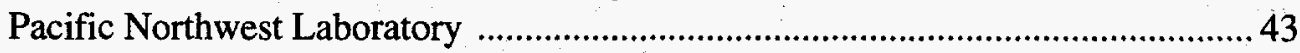

Sandia National Laboratory ................................................................46, 108

U.S. Department of Energy Core and Sample Repository ..................................8 83

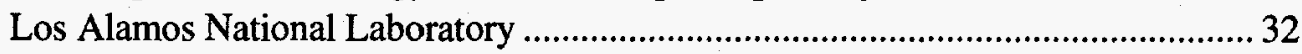

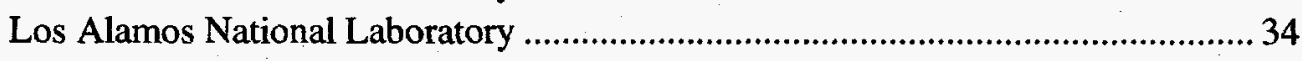

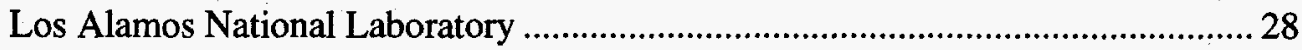

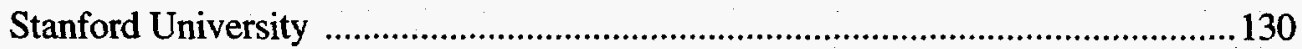

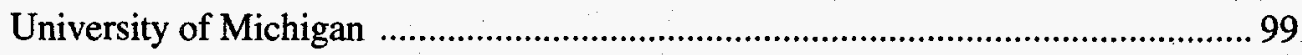

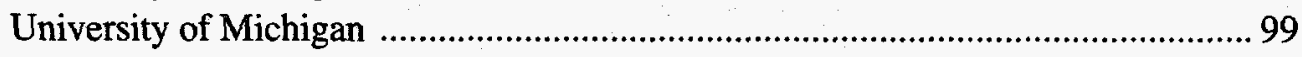

State University of New York at Stony Brook ...................................................109

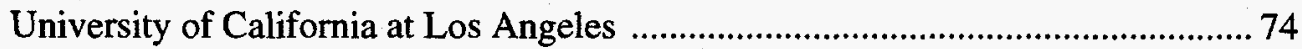

University of California at Berkeley ..................................................................... 70

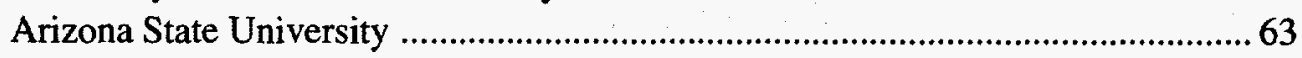

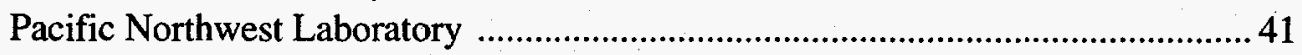

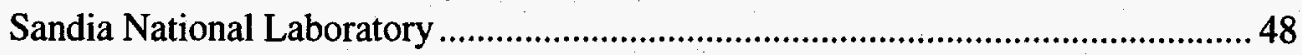

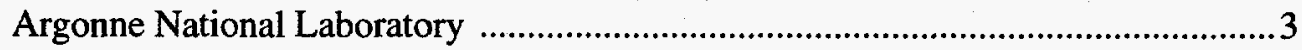

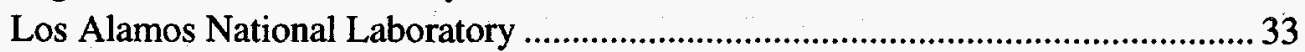

Oak Ridge National Laboratory ..................................................... 36, 38, 40

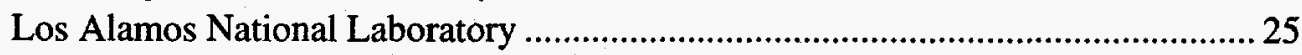

University of Utah Research Institute .......................................................142

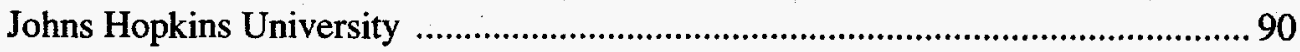

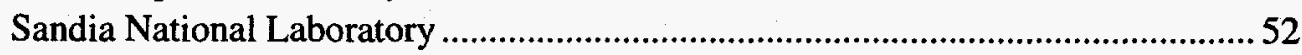

Los Alamos National Laboratory ........................................................... 27, 31

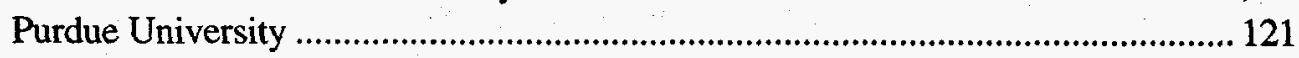

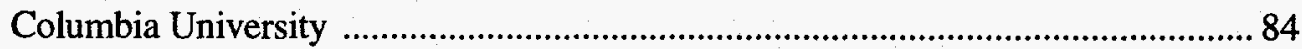

Los Alamos National Laboratory .......................................................... 20, 27

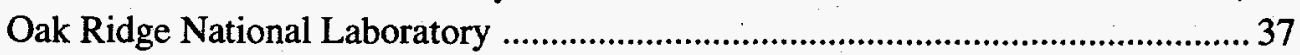

Lawrence Berkeley National Laboratory .................................................13, 14 
Klein, W.

Koplik, J.

Korneev, V. A.

Kronenberg, A. K.

LaFemina, J. P.

Lambert, S. J.

Land, L. S.

Larner, $\mathrm{K}$.

Larson, N. R.

Lasaga, A. C.

Lee, K. H.

Lee, L. C.

Lesher, C. E.

Lindquuist, W. B.

Liou, J. G.

Lysne, $\mathrm{P}$.

Mack, L. E.

Mackie, R.

Madden, T.

Majer, E. L.

Mango, F. D.

Manowitz, B.

Mathez, E. A.

McCarthy, M. I.

McEvilly, T. V.

McKeegan, K. D.

Meyers, W. J.

Miller, D. G.

Milliken, K. L.

Morrison, H. F.

Moses, C. O.

Murrell, M. T.

Myer, L. R.

Nagy, P. B.

Navrotsky, A.

Nelson, P.

Newman, G. A.

Nihei, K. T.

Nishiizumi, $\mathrm{K}$.

Noorishad, J.

Norton, $\mathrm{S}$.

Nur, A.

Olsson, W. A.

Onstott, T. C.

Ortoleva, P.

Parks, G. A.

Pickett, D. A.

Santa Fe Institute

105

The City College of the City University of New York

106

Lawrence Berkeley National Laboratory .......................................................... 9

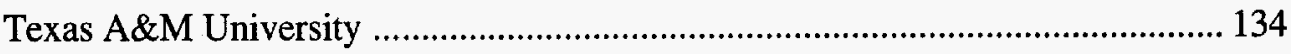

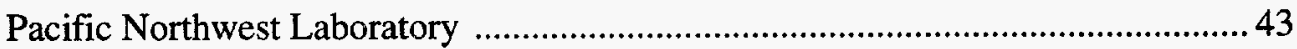

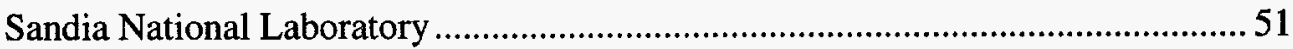

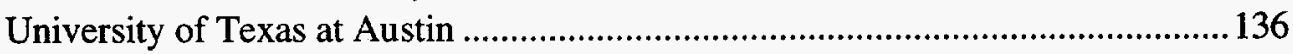

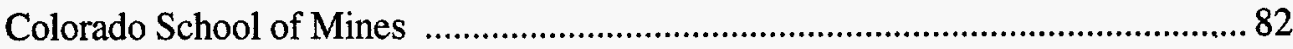

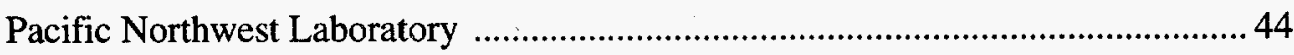

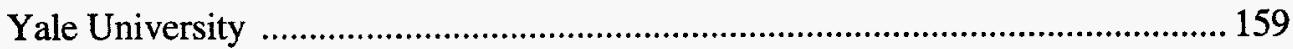

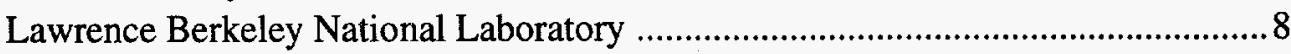

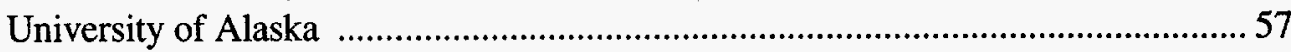

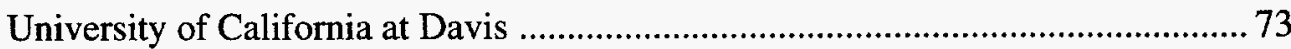

State University of New York at Stony Brook …...............................................107

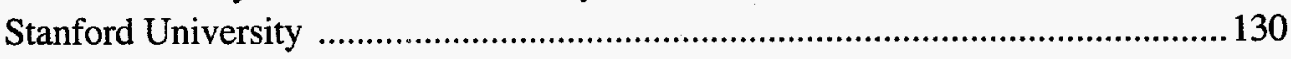

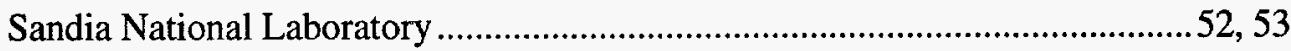

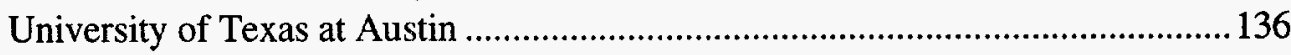

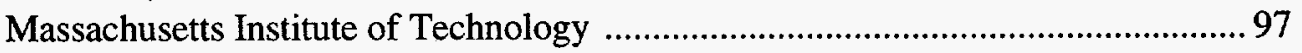

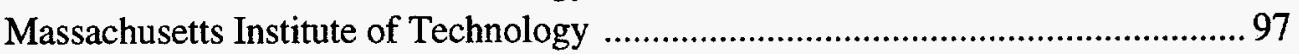

Lawrence Berkeley National Laboratory ................................................ 15

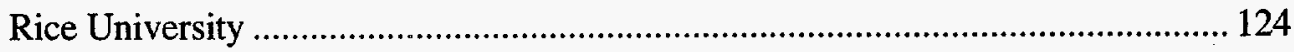

Brookhaven National Laboratory ............................................................... 5, 6

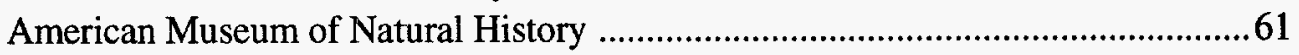

Pacific Northwest Laboratory ......................................................................... 41

Lawrence Berkeley National Laboratory .....................................9, 11, 15, 20, 27

University of California at Los Angeles .....................................................18, 75

State University of New York at Stony Brook .................................................. 109

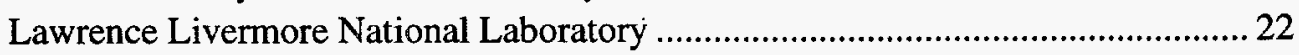

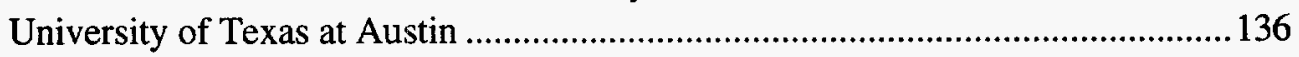

Lawrence Berkeley National Laboratory …..........................................8, 15, 116

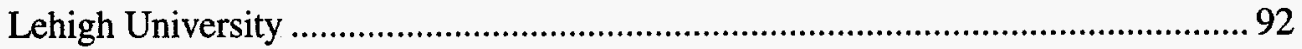

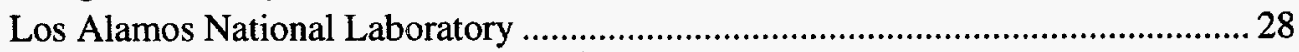

Lawrence Berkeley National Laboratory ............................ 7, 9, 10, 20, 21, 27, 47

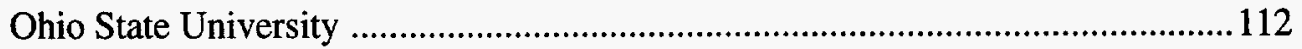

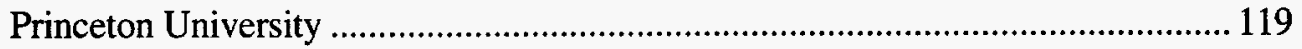

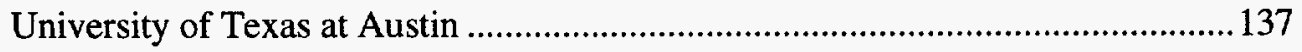

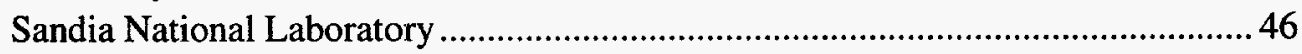

Lawrence Berkeley National Laboratory ….......................................... 7, 9, 10

Lawrence Berkeley National Laboratory ............................................................14

Lawrence Berkeley National Laboratory .............................................................11

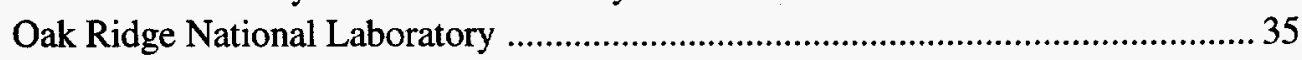

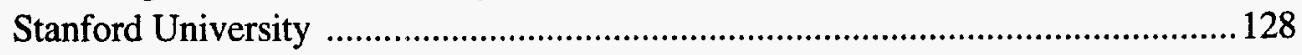

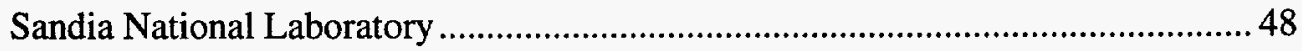

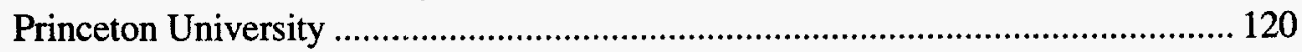

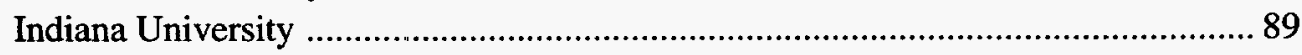

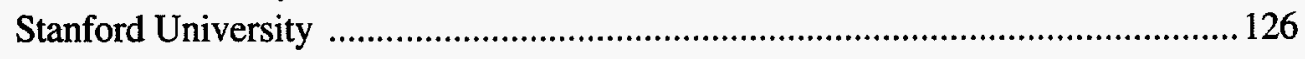

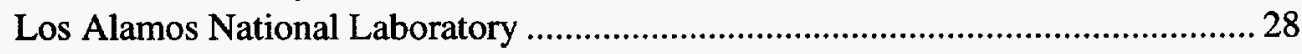


Pitzer, K. S.

Pollard, D. D.

Poths, J.

Price, J. G.

Pyrak-Nolte, L. J.

Rard, J. A.

Reeves, G. D.

Reidel, S. P.

Riciputi, L. R.

Risch, J. S.

Rock, P. A.

Rokop, D. J.

Rudnicki, J. W.

Rumble, D.

Rundle, J. B.

Russell, J. E.

Rye, D. M.

Ryerson, F. J.

Sackett, W. M.

Sattler, A.

Schwandt, C. S.

Segall, $P$.

Seitz, J. C.

Shankland, T. J.

Sharp, J. M., Jr.

Shaw, H. F.

Shock, E. L.

Sims, K. W. W.

Sinha, A. K.

Slater, D. W.

Smyth, J. R.

Spall, W. D.

Spera, F. J.

Spetzler, H.

Stockman, H. W.

Stolper, E.

Sturchio, N. C.

Sutton, S. R.

Swanson, S. E.

Tait, C. D.

Toksoz, M. N.

Torgersen, $\mathrm{T}$.

Tripp, A. C.

Tsang, C.-F.

Turcotte, D.

Vairavamurthy, A.

Valley, J. W.
Lawrence Berkeley National Laboratory ............................................................ 12

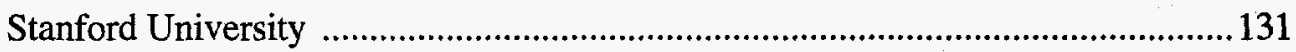

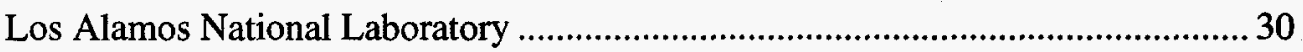

National Academy of Sciences/National Research Council ............................... 101

University of Notre Dame ........................................................................... 111

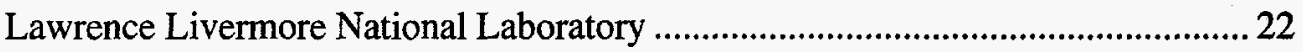

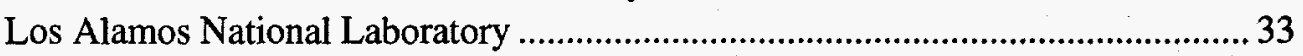

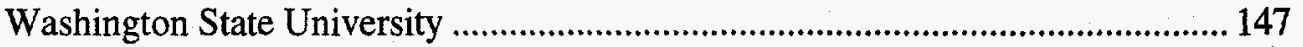

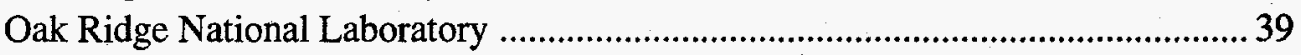

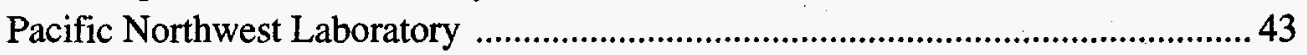

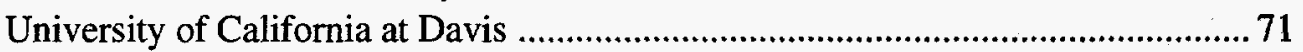

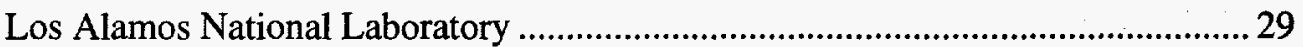

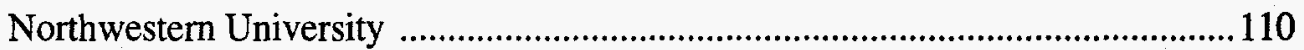

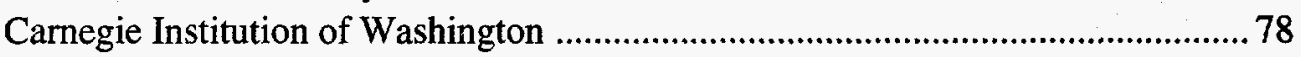

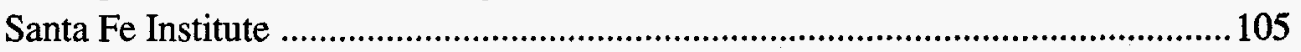

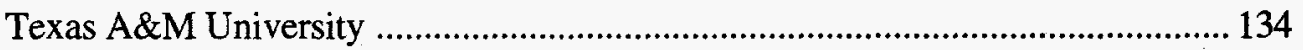

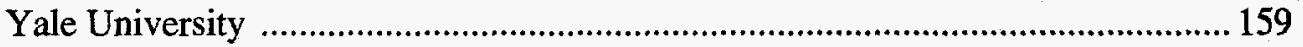

Lawrence Livermore National Laboratory …............................................18, 23

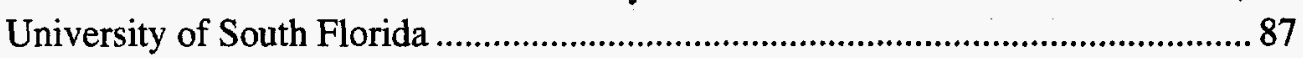

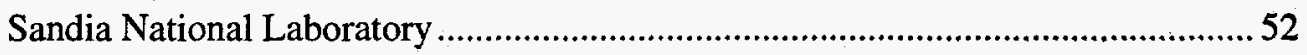

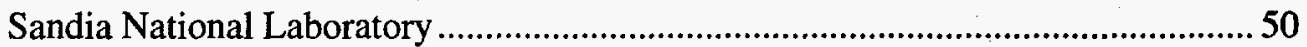

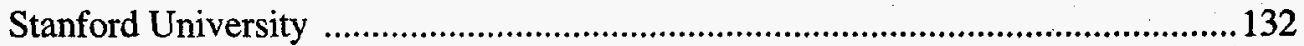

Oak Ridge National Laboratory ...........................................................36, 37

Los Alamos National Laboratory ............................................ 17, 20, 26, 27

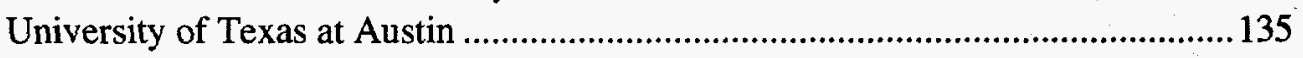

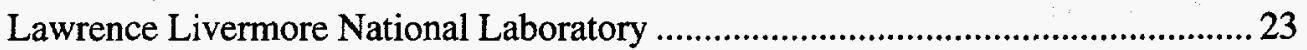

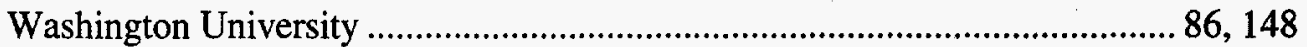

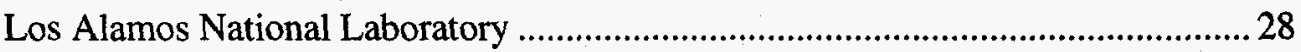

Virginia Polytechnic Institute and State University .............................................146

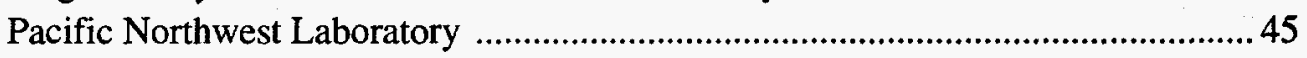

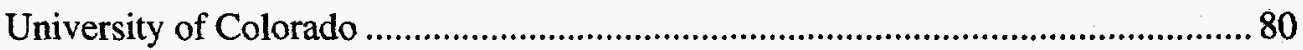

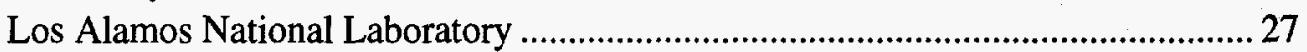

University of California at Santa Barbara ........................................................ 77

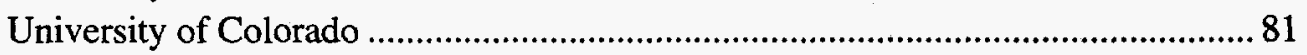

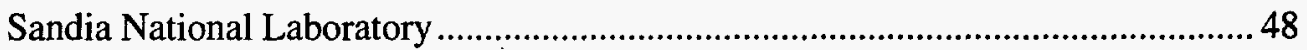

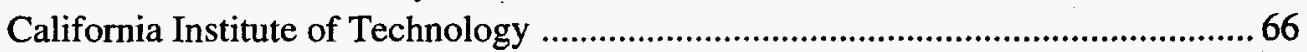

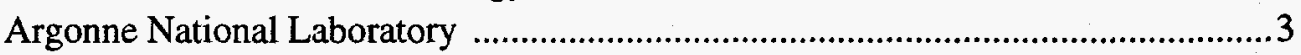

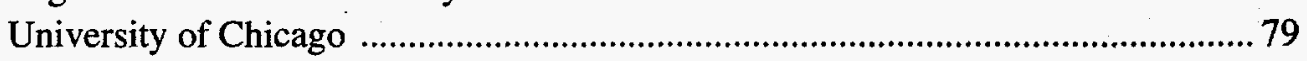

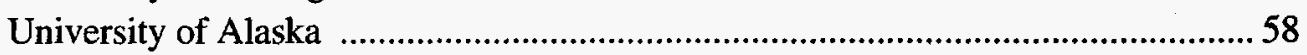

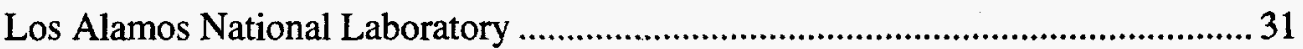

Massachusetts Institute of Technology .................................................... 94, 96

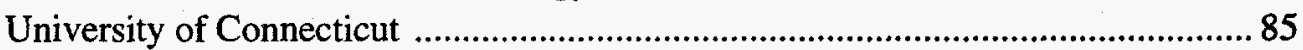

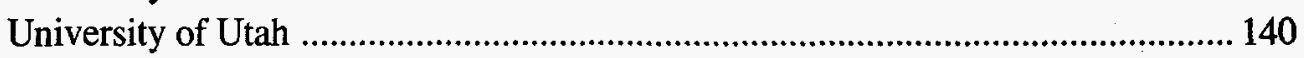

Lawrence Berkeley National Laboratory ..........................................................11

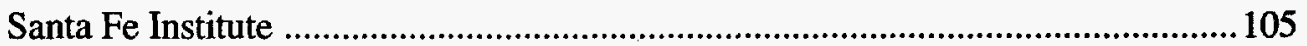

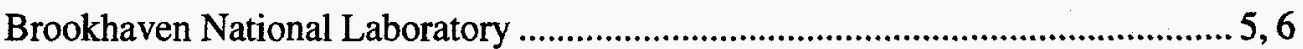

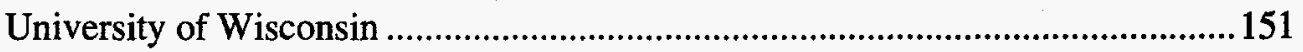


Veblen, D. R.

Walker, D.

Wang, H. F.

Wannamaker, P. E.

Wasserburg, G. J.

Watson, E. B.

Wawersik, W. R.

Wesolowski, D. J.

Westrich, H. R.

Whelan, J. K.

Williams, L.

Williams, P. L.

Witten, A. J.

Wong, T.-F.

Wood, R. H.

Wukelic, G. E.

Yang, G.

Yuen, D. A.

Yund, R. A.

Zoback, M. D.
Johns Hopkins University

Columbia University 84

University of Wisconsin

17,152

University of Utah Research Institute 141

California Institute of Technology .67

Rensselaer Polytechnic Institute 123

Sandia National Laboratory 48

Oak Ridge National Laboratory $36,38,40$

Sandia National Laboratory 49,50

Woods Hole Oceanographic Institution 156

Arizona State University 63

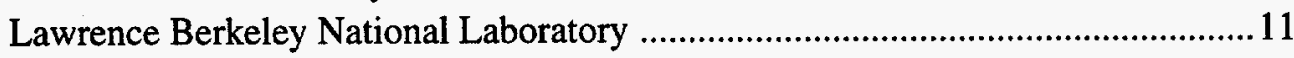

Oak Ridge National Laboratory 35

State University of New York at Stony Brook

University of Delaware 46,108

Pacific Northwest Laboratory 86,148

Lawrence Berkeley National Laboratory

University of Minnesota, Twin Cities

Brown University

7,47

Stanford University

100


GEOSCIENCES RESEARCH PROGRAM

Division of Engineering and Geosciences

Office of Basic Energy Sciences

Office of Energy Research

U.S. Department of Energy

\begin{tabular}{|c|c|c|c|c|c|}
\hline ON-SITE INSTITUTIONS & FY90 & FY91 & FY92 & FY93 & FY94 \\
\hline Argonne National Laboratory & 454 & 385 & 440 & 540 & 533 \\
\hline Brookhaven National Laboratory & 49 & - & 213 & 384 & 363 \\
\hline Idaho National Engr. Laboratory & - & & 35 & 50 & 121 \\
\hline Los Alamos National Laboratory & 2613 & 2518 & 2730 & 2622 & 1881 \\
\hline Lawrence Berkeley Laboratory & 2372 & 2109 & 2225 & 2340 & 2253 \\
\hline Lawrence Livermore National Laboratory & 2169 & 2103 & 2288 & 2025 & 1743 \\
\hline Oak Ridge National Laboratory & 1226 & 1097 & 1209 & 1041 & 1163 \\
\hline Pacific Northwest Laboratory & 819 & 735 & 780 & 975 & 664 \\
\hline Sandia National Laboratories & 1828 & 2167 & 2098 & 1987 & 1545 \\
\hline Westinghouse Hanford Laboratory & - & 44 & 46 & 45 & 0 \\
\hline Grand Junction Project Office & - & - & - & 87 & 87 \\
\hline total, on-site & 11530 & 11158 & 12064 & 12096 & 10353 \\
\hline total, off-site & 5685 & 5987 & 7114 & 7250 & 8477 \\
\hline total, operating & 17215 & 17145 & 19178 & 19346 & 18830 \\
\hline total, equipment & 1150 & 1110 & 1302 & 1270 & 1262 \\
\hline Total Geosciences & $\underline{1836.5}$ & $\underline{18255}$ & $\underline{20480}$ & 20616 & 20092 \\
\hline \multicolumn{6}{|l|}{ OFF-SITE INSTITUTIONS } \\
\hline U/Alaska (Lee) & 140 & 145 & 125 & 151 & 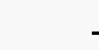 \\
\hline U/Alaska (Eichelberger)* & - & - & 149 & 120 & 112 \\
\hline Am. Geolog. Inst. (Davin) & - & - & - & - & 36 \\
\hline Am. Geophys. Union (Spilhaus) & - & - & - & - & . \\
\hline Am. Mus. NY (Mathez) & - & - & 49 & 39 & 37 \\
\hline U/Arizona (Anovitz) & 60 & 47 & - & - & . \\
\hline U/Arizona (Hill) & 120 & 126 & 130 & - & - \\
\hline Arizona St. (Hervig) & - & - & - & - & 62 \\
\hline Arizona St. (Williams) & - & 108 & - & - & . \\
\hline Brown U (Yund) & 70 & 71 & 141 & 146 & 302 \\
\hline Cal Tech (Clayton) & - & - & - & 139 & 142 \\
\hline Cal Tech (Stolper) & 85 & 87 & 90 & 150 & 153 \\
\hline Cal Tech (Wasserburg) & 250 & 300 & 345 & 370 & 388 \\
\hline Calif, Univ of-Berk (Carmichael) & - & 117 & 109 & 115 & \\
\hline Calif, Univ of-Berk (Helgeson) & 120 & 135 & 140 & 150 & 349 \\
\hline Calif, Univ of-Berk (Morrison) & - & - & 68 & - & - \\
\hline Calif, Univ of-Berk (Reynolds) & 245 & 245 & 264 & - & - \\
\hline Calif, Univ of-Davis (Lesher) & - & - & 65 & 65 & 66 \\
\hline Calif, Univ of-Davis (Rock) & - & - & 83 & 77 & 78 \\
\hline Calif, Univ of-LA (Harrison) & 54 & 54 & 57 & - & 100 \\
\hline Calif, Univ of-LA (McKeegan) & - & 64 & - & 40 & 85 \\
\hline Calif, Univ of-Riv (McKibben)* & 49 & - & - & - & - \\
\hline Calif, Univ of-SB (Spera) & 47 & 101 & - & 43 & . \\
\hline Calif, Univ of-SD (Schimmelmann) & - & - & 110 & - &. \\
\hline
\end{tabular}




\section{GEOSCIENCES RESEARCH PROGRAM \\ Division of Engineering and Geosciences \\ Office of Basic Energy Sciences \\ Office of Energy Research \\ U.S. Department of Energy}

\begin{tabular}{|c|c|c|c|c|c|}
\hline OFF-SITE INSTITUTIONS & FY90 & FY91 & FY92 & FY93 & FY94 \\
\hline Chicago, Univ of (Richter) & - & - & - & - & 247 \\
\hline Chicago, Univ of (Rivers) & - & - & - & - & 458 \\
\hline Chicago, Univ of (Smith/Sutton) & - & - & 105 & 126 & 127 \\
\hline Colo, Univ of (Smyth) & - & - & 93 & 81 & 10 \\
\hline Colo, Univ of (Spetzler) & - & 50 & 64 & 57 & 145 \\
\hline Colo Sch Mines (Larner) & 195 & 200 & - & - & 97 \\
\hline Columbia Univ (Jacob) & 203 & - & 25 & - & - \\
\hline \multirow[t]{2}{*}{ Columbia Univ (Walker) } & 127 & 127 & 77 & 110 & 103 \\
\hline & 4 & - & 110 & 31 & - \\
\hline Conn., Univ of (Torgersen) & - & - & - & - & 19 \\
\hline Delaware, Univ of (Wood) & 56 & 67 & 176 & - & 90 \\
\hline DOSECC (Friedman)* & 65 & 70 & 71 & - & - \\
\hline Florida, So. Univ of (Compton) & - & - & 122 & - & 56 \\
\hline Florida St, Univ of (SCC) & - & - & - & 99 & 214 \\
\hline Geophys. Lab, CIW (Bell) & - & - & - & 92 & 89 \\
\hline Houston, Univ of (McDonald) & 295 & 221 & - & - & - \\
\hline Headquarters Services & 5 & 2 & 5 & 5 & 1 \\
\hline Indiana, Univ of (Hayes) & 150 & - & - & - & - \\
\hline Indiana, Univ of (Ortoleva) & - & 80 & 85 & 63 & - \\
\hline Johns Hopkins Univ (Veblen) & 66 & 135 & 134 & 138 & - \\
\hline JPL, IAU Coloq (Tobiska) & - & - & - & 3 & - \\
\hline Lehigh Univ (Moses) & - & - & - & 223 & - \\
\hline Louisiana St. Univ (Ferrell) & - & 127 & - & - & - \\
\hline Maryland, Iniv of (Tossell) & - & - & - & - & 35 \\
\hline Miami, Univ of (Eberli) & - & - & 127 & 155 & 169 \\
\hline Michigan, Univ of (Halliday) & - & - & - & - & 147 \\
\hline Min. Soc. Amer (Guthrie) & - & - & - & 5 & - \\
\hline Minn., Univ of (Yuen) & 42 & 102 & - & 47 & - \\
\hline MIT (Madden) & - & - & - & - & 70 \\
\hline MIT (Toksoz) & 498 & 485 & 372 & 342 & 374 \\
\hline MT BuMines (Bartholomew) & - & 9 & - & - & - \\
\hline NASA (Blankston) & - & - & - & - & 100 \\
\hline NAS/NRC (Benson/Crowley) & - & - & - & - & 10 \\
\hline NAS/NRC (Carter) & 3 & - & - & - & - \\
\hline NAS/NRC (Hart/Long/Burke) & 105 & 200 & - & 100 & - \\
\hline NAS/NRC (Phillips) & - & - & - & - & 121 \\
\hline NAS/NRC (Price) & - & - & $\therefore$ & - & 100 \\
\hline Nevada, Univ of (Karlin) & - & - & 48 & - & - \\
\hline New Mexico, Univ of (Crossey) & - & - & 43 & 43 & - \\
\hline New Mexico, Univ of (Papike) & 200 & - & - & - & - \\
\hline NY, City Univ of-CC (Koplick) & - & - & - & 125 & 121 \\
\hline NY, City Univ of-Q (E. Schreiber) & - & - & - & - & - \\
\hline NY, City Univ of-Q (C. Schreiber) & $\mathrm{NFX}$ & 119 & 126 & 92 & \\
\hline NY, State Univ of-P (Wolosz) & 42 & - & - & - & - \\
\hline NY, State Univ of-SB (Hanson) & 119 & 124 & 128 & - & 121 \\
\hline NY, State Univ of-SB (Lindquist) & - & - & 21 & 22 & 22 \\
\hline
\end{tabular}




\section{GEOSCIENCES RESEARCH PROGRAM Division of Engineering and Geosciences \\ Office of Basic Energy Sciences \\ Office of Energy Research \\ U.S. Department of Energy}

\begin{tabular}{|c|c|c|c|c|c|}
\hline OFF-SITE INSTITUTIONS & FY90 & FY91 & FY92 & FY93 & FY94 \\
\hline NY, State Univ of-SB (Wong) & - & - & - & - & 69 \\
\hline Northeastern Univ (Devaney) & - & - & - & 145 & - \\
\hline Northwestern Univ (Rudnicki) & - & - & - & 75 & 72 \\
\hline Notre Dame Univ (Pyrak-Nolte) & - & - & - & 61 & 61 \\
\hline Ohio St. Univ (Adler) & 54 & 56 & 59 & 62 & 161 \\
\hline Ohio St. Univ (Sahagian) & - & 40 & - & - & - \\
\hline Okla, Univ of (Elmore) & - & 109 & 112 & 247 & - \\
\hline Okla, Univ of (Engel) & 106 & - & - & - & - \\
\hline Okla, Univ of (Philp) & 121 & 143 & - & - & - \\
\hline Oregon St. Univ (Egbert) & 41 & - & 111 & - & - \\
\hline Penn St. Univ (Arthur) & - & - & 129 & 134 & - \\
\hline Princeton Univ (Navrotsky) & 123 & 125 & 130 & 198 & 145 \\
\hline Princeton Univ (Onstott) & - & 103 & - & - & - \\
\hline Purdue Univ (Aydin) & 56 & - & - & - & - \\
\hline Purdue Univ (Fritz) & 71 & 44 & 47 & - & - \\
\hline Purdue Univ (Johnson) & - & - & - & 170 & - \\
\hline Rensselaer Polytech. Inst. (Watson) & - & - & - & - & 144 \\
\hline Rice Univ (Mango) & - & - & 127 & 100 & 97 \\
\hline San Diego St. Univ (Jiracek) & 5 & - & 10 & - & - \\
\hline Santa Fe Inst (Rundle) & - & - & - & - & 11 \\
\hline Calif, Univ of So. (Aki)* & 147 & 160 & 160 & 160 & 155 \\
\hline Stanford Univ (Brown) & - & - & - & 241 & 204 \\
\hline Stanford Univ (Ernst) & 100 & 101 & 158 & - & - \\
\hline Stanford Univ (Liou) & - & - & - & 160 & - \\
\hline Stanford Univ (Nur) & 328 & - & 176 & - & 173 \\
\hline Stanford Univ (Pollard)* & 30 & - & - & - & - \\
\hline Stanford Univ (Pollard) & 75 & 183 & 159 & - & 210 \\
\hline Stanford Univ (Segall) & 80 & - & 70 & 87 & 83 \\
\hline Stanford Univ (Zoback) & - & - & - & - & 72 \\
\hline Texas, Univ of-Aus (Land) & - & - & 100 & 104 & 104 \\
\hline Texas, Univ of-Aus (Nelson) & - & - & - & - & 5 \\
\hline Texas, Univ of-Aus (Sharp) & - & - & 98 & - & 48 \\
\hline Texas, Univ of-Dallas (Mitterer) & 119 & 112 & 114 & 0 & 0 \\
\hline Texas A\&M Univ (Kronenberg) & 149 & 143 & 149 & 155 & 156 \\
\hline Tulsa, Univ of (Barker) & 71 & 84 & 205 & - & - \\
\hline USGS (Bredehoeft) & - & - & - & 29 & 30 \\
\hline USGS (Dean)* & - & - & 99 & - & - \\
\hline USGS (Kharaka) & - & - & 18 & - & . \\
\hline USGS (Russ) & - & 137 & 56 & - & 126 \\
\hline Utah, Univ of (Hulen) & - & - & - & 204 & - \\
\hline Utah, Univ of (Hulen)* & 85 & 126 & - & - & - \\
\hline Utah, Univ of (Tripp) & - & - & - & 57 & 59 \\
\hline Utah, Univ of (Wannamaker) & - & - & 75 & - & - \\
\hline VPI \& SU (Bodnar) & 78 & - & 127 & 129 & 133 \\
\hline VPI \& SU (Sinha) & 87 & 74 & 63 & 28 & - \\
\hline Washington, Univ of (Booker) & 81 & - & 101 & 104 & 247 \\
\hline
\end{tabular}




\section{GEOSCIENCES RESEARCH PROGRAM}

Division of Engineering and Geosciences

Office of Basic Energy Sciences

Office of Energy Research

U.S. Department of Energy

\begin{tabular}{|c|c|c|c|c|c|}
\hline OFF-SITE INSTITUTIONS & FY90 & FY91 & FY92 & FY93 & FY94 \\
\hline Washington St. Univ-R (Reidel) & - & 45 & 48 & 49 & 5 \\
\hline Washington St. Univ-TC (Conca)* & - & 95 & - & - & \\
\hline Wash Univ, St. Louis (Shock) & - & - & 46 & - & 24 \\
\hline Wisconsin, Univ of (Bahr) & - & - & - & - & 46 \\
\hline Wisconsin, Univ of (Banfield) & - & - & - & 76 & 98 \\
\hline Wisconsin, Univ of (Haimson) & - & - & - & 10 & 10 \\
\hline Wisconsin, Univ of (Valley) & - & $\cdot$ & - & 144 & 142 \\
\hline Wisconsin, Univ of (Wang) & - & 97 & 99 & 105 & - \\
\hline WHOI (Chave) & - & - & - & - & 91 \\
\hline WHOI (Eglinton) & - & - & 99 & 82 & 275 \\
\hline WHOI (Whelan) & 208 & 197 & 199 & 180 & 180 \\
\hline Yale University (Lasaga) & 50 & 91 & 113 & 385 & - \\
\hline Other & 5 & 4 & - & 5 & 85 \\
\hline OEF-SITE TOTALS & --1-- & $\begin{array}{l}------ \\
5987\end{array}$ & ----- & 7250 & 8477 \\
\hline
\end{tabular}

